\title{
Fire Toxicity Scaling
}

Emil Braun, Barbara C. Levin, Maya Paabo, Joshua Gurman, Trudi Holt, J. Samuel Steel

\section{U.S. DEPARTMENT OF COMMERCE} National Bureau of Standards National Engineering Laboratory Center for Fire Research

Gaithersburg, MD 20899

\section{February 1987}





\section{FIRE TOXICITY SCALING}

Emil Braun, Barbara C. Levin, Maya Paabo, Joshua Gurman, Trudi Holt, J. Samuel Steel

U.S. DEPARTMENT OF COMMERCE National Bureau of Standards National Engineering Laboratory

Center for Fire Research

Gaithersburg, MD 20899

February 1987

Supported in part by:

U.S. Consumer Product Safety Commission

Bethesda, Maryland

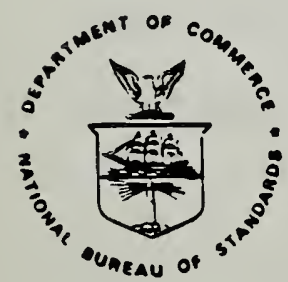

U.S. DEPARTMENT OF COMMERCE, Malcolm Baldrige, Secretary NATIONAL BUREAU OF STANDARDS, Ernest Ambler, Director 



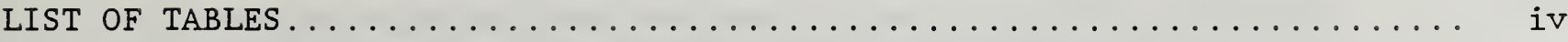

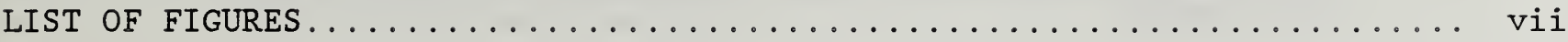

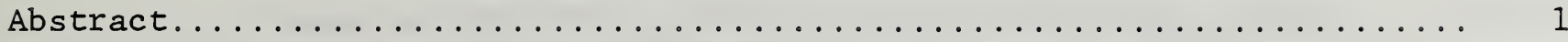

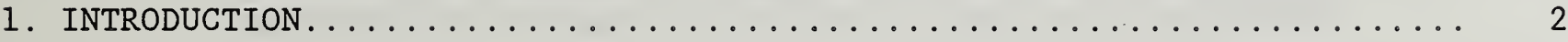

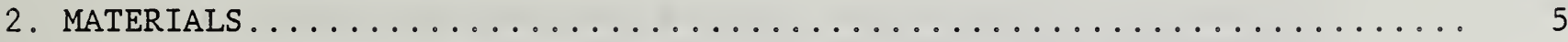

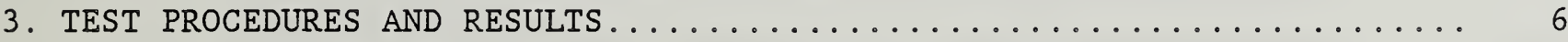

3.1 Small-scale Tests............................. 8

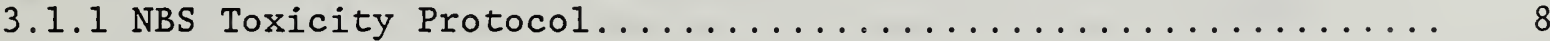

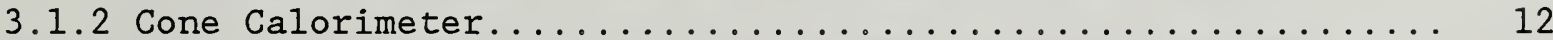

3.2 Mock-up Chair Tests--Furniture Calorimeter............... 15

3.2.1 Flaming Furniture Calorimeter Tests................. 17

3.2.2 Cigarette Ignition Furniture Calorimeter Tests........... 18

3.3 Large-scale Three Compartment Experiments................... 22

3.3.1 Room-Corridor-Room Configuration................ 23

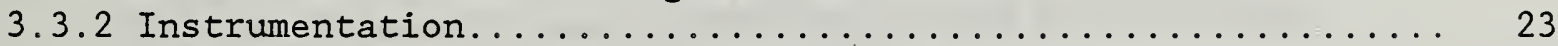

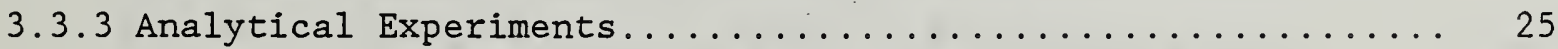

3.3.3.1 Flaming Analytical Experiments............. 25

3.3.3.2 Smoldering to Flaming Transition, Analytical Experiments................. 29

3.3.4 Three Compartment Animal Exposure Experiments........... 33

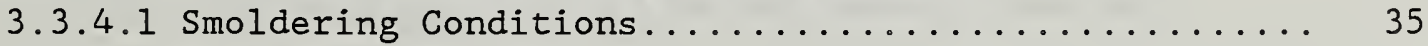

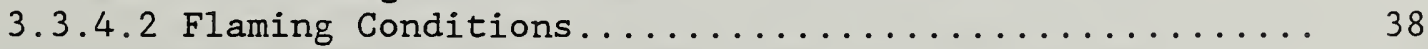

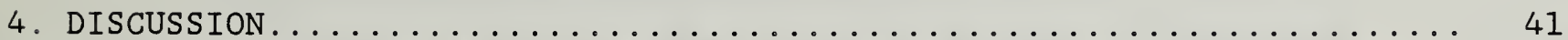

4.1 Polyurethane Foam, Non-fire Retarded.................... 41

4.2 Polyurethane Foam, Fire Retarded......................... 44

4.3 Three Gas Model.................................. 46

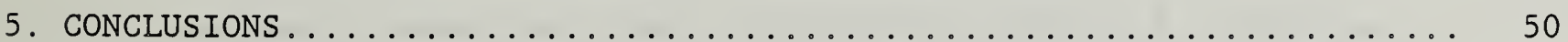

6. RECOMMENDATIONS ................................ 56

7. ACKNOWLEDGMENTS .............................. 57

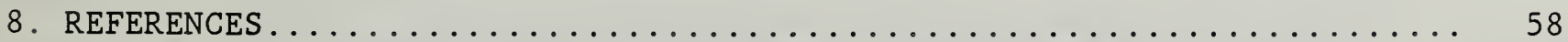


Table 1. Chemical and Toxicological Results from Flexible Polyurethane Foam \#32 (non-fire retarded) Decomposed Via the NBS Toxicity

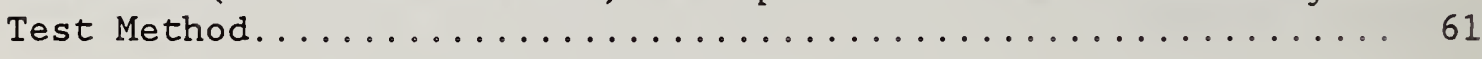

Table 2. Chemical and Toxicological Results from Fire-Retarded Flexible Polyurethane Foam \#32X Decomposed Via the NBS Toxicity Test

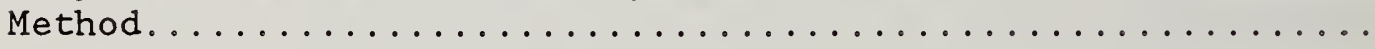

Table 3. Chemical and Toxicological Results from Haitian Cotton Fabric

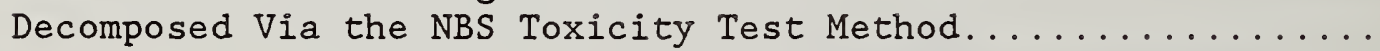

Table 4. Concentration of $\mathrm{CO}, \mathrm{CO}_{2}$, and $\mathrm{HCN}$ at the Calculated $\mathrm{LC}_{50}$ for Treated, 32X, and Non-treated, 32, Polyurethane Foam and Cotton

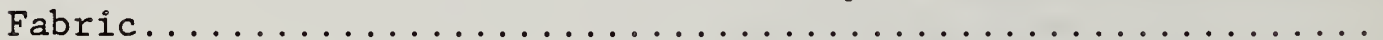

Table 5. Average Values at the Maximum Rate of Heat Release from Cone Calorimeter Tests Conducted at $25 \mathrm{~kW} / \mathrm{m}^{2}$ for a Horizontally

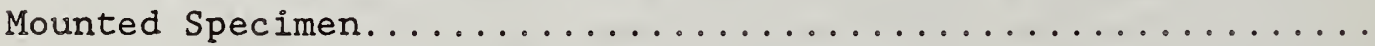

Table 6. Average Yields of $\mathrm{CO}$ and $\mathrm{CO}_{2}$ for Treated and Non-treated Foams Tested in the Cone Calorimeter.....................66

Table 7. Flaming Ignition Furniture Calorimeter Tests.............

Table 8. HCN Yields for Flaming Ignition of Treated, 32X, and NonTreated, 32, Polyurethane Foam and Cotton Fabric Mock-up Upholstery Chairs Tested in the Furniture Calorimeter........68

Table 9. Cigarette Initiated Transition Furniture Calorimeter Tests....

Table 10. HCN Yields for the Smoldering-to-Flaming Tests of Treated, 32X, and Non-treated, 32, Polyurethane Foam and Cotton Fabric Mockup Upholstery Chairs in the Furniture Calorimeter...........

Table 11. Summary of Furniture Calorimeter Tests on Treated, 32X, and Non-Treated, 32, Polyurethane Foam and Cotton Fabric Mock-up

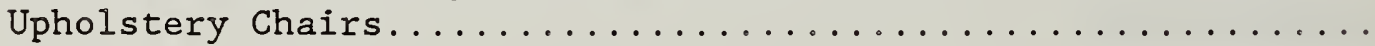

Table 12. Dimensions of Corridor and Adjoining Rooms for the Large-Scale

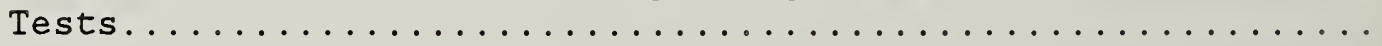

Table 13. Construction Materials of Large-Scale Fire Facility......... 73

Table 14. Location of Instrumentation......................... 74 
Table 15. Summary of Results from the Flaming Ignition of Foams 32 and $32 \mathrm{X}$ - Gas and Temperature Data in the Burn Room and the Target

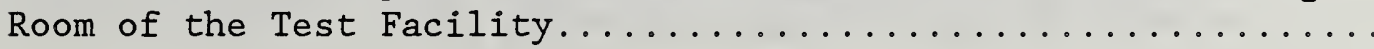

Table 16. Comparison of Gas and Temperature Data Between Animal Exposure Chambers and Respective Sampling Rooms for Flaming Ignition Experiments of Foams 32 and $32 \mathrm{X}$ - Large-Scale Results.........

Table 17. Tabulation of Gas and Temperature Data for Smoldering Combustion Prior to Initiation of Flaming Combustion -

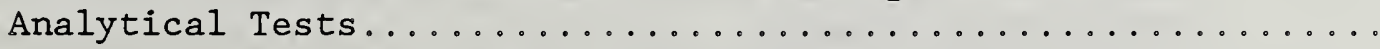

Table 18. Tabulation of Gas and Temperature Data for Flaming Combustion Conditions at Time of Maximum CO Concentration - Analytical

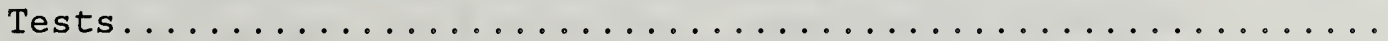

Table 19. Summary of Gas, Temperature, and Mass Loss Data for Smoldering Phase of Animal Exposure Experiments Prior to Flaming of Each

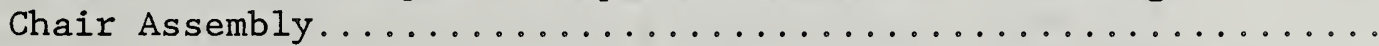

Table 20. Exposure Chamber Atmosphere During Animal Exposures for Smoldering Decomposition of Foams 32 and $32 \mathrm{x} \ldots \ldots \ldots \ldots \ldots \ldots$

Table 21. Summary of Gas, Temperature, and Mass Loss Data for PostIgnition Phase of Animal Exposure Experiments Using Foams 32 and $32 \mathrm{X}$ at the time of Maximum $\mathrm{CO}$ Concentration............

Table 22. Exposure Chamber Atmosphere During Animal Exposures Occurring

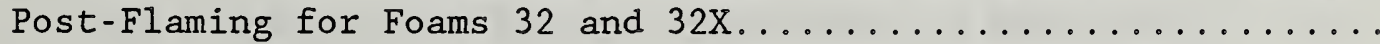

Table 23. Comparison of $\mathrm{CO}$ and $\mathrm{CO}_{2}$ Yields for Small-Scale Tests, Furniture Calorimeter and Large-Scale Compartment Tests of Non-Fire Retarded Polyurethane Foam $32 \ldots \ldots \ldots \ldots \ldots \ldots \ldots$

Table 24. Comparison of Peak Measured HCN Concentrations and Estimated Yields for NBS Toxicity Protocol Tests, Furniture Calorimeter, and Large-Scale Compartment Mock-up Upholstery Chair Tests of

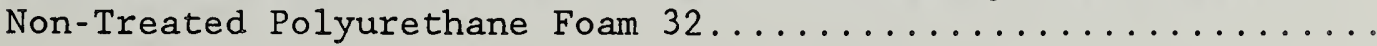

Table 25. Comparison of Yield Ratios of $\mathrm{CO}_{2} / \mathrm{CO}$ for the Small-Scale Tests, Furniture Calorimeter, and Large-Scale Compartment Tests of Non-Fire Retarded Polyurethane Foam $32 \ldots \ldots \ldots \ldots \ldots$

Table 26. Comparison of Yield Ratios of HCN/CO for the NBS Toxicity Test, Furniture Calorimeter, and Large-Scale Compartment Tests for Non-Treated Polyurethane Foam $32 \ldots \ldots \ldots \ldots \ldots \ldots$ 
Table 27. Comparison of $\mathrm{CO}$ and $\mathrm{CO}_{2}$ Yields for Small-Scale Tests, Furniture Calorimeter, and Large-Scale Compartment Tests of Fire Retarded Polyurethane Foam $32 \mathrm{x} \ldots \ldots \ldots \ldots \ldots \ldots . \ldots$

Table 28. Comparison of Peak Measured HCN Concentrations and Estimated Yields for NBS Toxicity Protocol Tests, Furniture Calorimeter, and Large-Scale Mock-up Upholstery Chair Tests of Fire Retarded

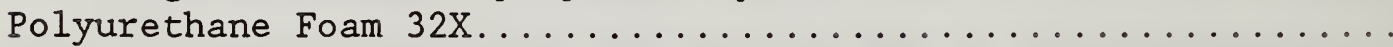

Table 29. Comparison of Yield Ratios of $\mathrm{CO}_{2} / \mathrm{CO}$ for Small-Scale Tests, Furniture Calorimeter, and Large-Scale Compartment Tests of

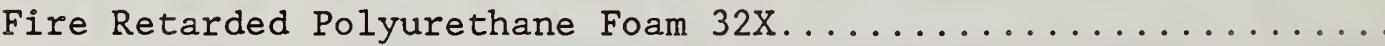

Table 30. Comparison Yield Ratios of HCN/CO for the NBS Toxicity Test, Furniture Calorimeter, and Large-Scale Compartment Tests of Fire Retarded Polyurethane Foam $32 \mathrm{X} \ldots \ldots \ldots \ldots \ldots \ldots \ldots \ldots$

Table 31. Comparison of Animal Deaths in the NBS Toxicity Test Method to 3-Gas Model Calculations for Non-Fire Retarded Polyurethane

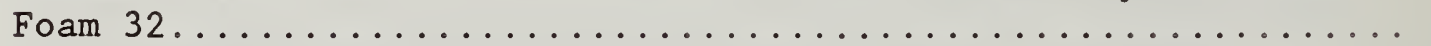

Table 32. Comparison of Animal Deaths in the NBS Toxicity Test Method to 3-Gas Model Calculations for Fire Retarded Polyurethane

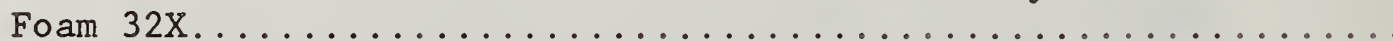

Table 33. Comparison of Animal Deaths in the Large-Scale Post-Flaming

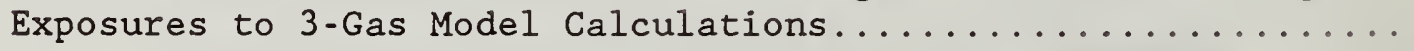

Table 34. Comparison of 3-Gas Model Results to Measured Animal Response from Non-Fire Retarded Polyurethane Foam and Cotton Upholstery

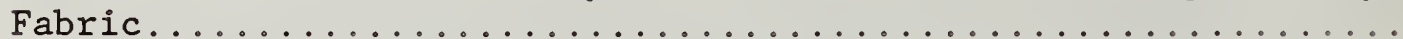

Table 35. Comparison of 3-Gas Model Results to Measured Animal Response from Fire Retarded Polyurethane Foam and Cotton Upholstery Fabric. 
Figure 1. $\quad \mathrm{HCN}$ Generation During Ramped Heating $\left(375^{\circ} \mathrm{C}\right.$ to $800^{\circ} \mathrm{C}$ ) of Foams 32 and $32 \mathrm{X}$ After Preheating at $375^{\circ} \mathrm{C}$ for 30 Minutes in the NBS Toxicity Apparatus...................... 99

Figure 2. Schematic of the Cone Calorimeter................... 100

Figure 3. Comparison of Heat Release Rate for Foam 32 Flaming and Nonflaming Exposures Without a Cover Fabric and Flaming Exposure With a Cover Fabric.......................... 101

Figure 4. Comparison of Mass Loss Rate for Foam 32 Flaming and Nonflaming exposures Without a Cover Fabric and Flaming Exposures With a Cover Fabric............................ 102

Figure 5. Comparison of Carbon Dioxide Yield for Foam 32 Flaming and Nonflaming Exposures Without a Cover Fabric and Flaming Exposure

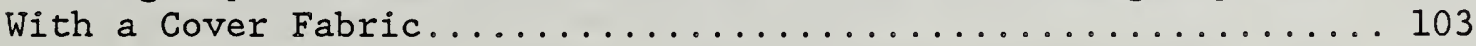

Figure 6. Comparison of Carbon Monoxide Yield for Foam 32 Flaming and Nonflaming Exposures Without a Cover Fabric and Flaming Exposure With a Cover Fabric............................ 104,

Figure 7. Comparison of Water Yield for Foam 32 Flaming and Non-flaming Exposures Without a Cover Fabric and Flaming Exposure With a

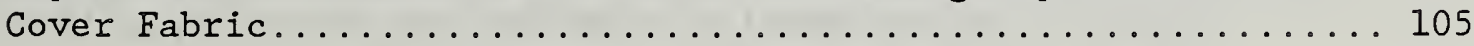

Figure 8. Comparison of Unburned Hydrocarbons for Foam 32 Flaming and Nonflaming Exposures Without a Cover Fabric and Flaming Exposure With a Cover Fabric......................... 106

Figure 9. Comparison of Smoke Extinction Area for Foam 32 Flaming and Nonflaming Exposures Without a Cover Fabric and Flaming Exposure With a Cover Fabric.......................... 107

Figure 10. Comparison of Heat Release Rate for Foam $32 \mathrm{X}$ Flaming and Nonflaming Exposures Without a Cover Fabric and Flaming Exposure With a Cover Fabric......................... 108

Figure 11. Comparison of Mass Loss Rate for Foam 32X Flaming and Nonflaming Exposures Without a Cover Fabric and Flaming Exposure With a Cover Fabric........................... 109

Figure 12. Comparison of Carbon Dioxide Yield for Foam 32X Flaming and Non-flaming Exposures Without a Cover Fabric and Flaming Exposures With a Cover Fabric.................... 110 
Figure 13. Comparison of Carbon Monoxide Yield for Foam 32X Flaming and Non-flaming Exposures Without a Cover Fabric and Flaming Exposure With a Cover Fabric.

Figure 14. Comparison of Water Yield for Foam $32 \mathrm{X}$ Flaming and Non-flaming Exposures Without a Cover Fabric and Flaming Exposure With a Cover Fabric................................ 112

Figure 15. Comparison of Unburned Hydrocarbon Yield for Foam 32X Flaming and Non-flaming Exposures Without a Cover Fabric and Flaming Exposure with a Cover Fabric..................... 113

Figure 16. Comparison of Smoke Extinction Area for Foam 32X Flaming and Non-flaming Exposures Without a Cover Fabric and Flaming Exposure with a Cover Fabric..................... 114

Figure 17. Schematic of Furniture Calorimeter................. 115

Figure 18. Four Cushion Mock-up Chair Assembly and Steel Frame......... 116

Figure 19. Furniture Calorimeter Data for the Concentration of Carbon Dioxide, Carbon Monoxide, HCN, and Oxygen for the Flaming Ignition of Mock-up Chairs made with Foam $32 \ldots \ldots \ldots \ldots \ldots \ldots$

Figure 20. Furniture Calorimeter Data for the Concentration of Carbon Dioxide, Carbon Monoxide, $\mathrm{HCN}$, and Oxygen for Flaming Ignition of Mock-up Chairs made with Foam 32x...................... 118

Figure 21. Furniture Calorimeter Data Comparing the Rate of Heat Release from the Flaming Ignition of Mock-up Chairs Made from Either

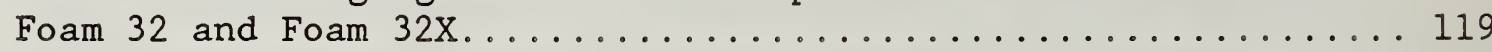

Figure 22. Furniture Calorimeter Data Comparing the Heat Flux Received by a Target Material from the Flaming Ignition of Mock-up Upholstery Chairs made from Foam 32 and Foam $32 \mathrm{x} \ldots \ldots \ldots \ldots \ldots 120$

Figure 23. Comparison of Sample Weight Loss During Flaming Ignition of Foams 32 and $32 \mathrm{X}$ in the Furniture Calorimeter............ 121

Figure 24. Comparison of the Effective Heat of Combustion from the Flaming Ignition of Foams 32 and $32 \mathrm{X}$ Mock-up Upholstery Chairs Tested in the Furniture Calorimeter...............................

Figure 25. Comparison of Carbon Dioxide Yield for the Flaming Ignition of Foams 32 and $32 \mathrm{X}$ Mock-up Upholstery Chairs Tested in the

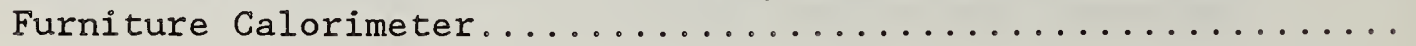


Figure 26. Comparison of Carbon Monoxide Yield for the Flaming Ignition of Foams 32 and $32 \mathrm{X}$ Mock-up Chairs Tested in the Furniture Calorimeter................................. 124

Figure 27. Comparison of the Yield of Water from the Flaming Ignition of Foams 32 and $32 \mathrm{X}$ During the Burning of Mock-up Upholstery Chairs in the Furniture Calorimeter.................. 125

Figure 28. Comparison of the Smoke Extinction Coefficient for the Flaming Ignition of Mock-up Foams 32 and 32X Upholstery Chairs Tested in the Furniture Calorimeter.................... 126

Figure 29. Upholstery Chair Mock-up with Two Smoldering Cigarettes as Tested in the Furniture Calorimeter...................

Figure 30. Comparison of Sample Weight Loss During Smoldering-to-Flaming Ignition of Mock-up Upholstery Chairs Made from Foams 32 and $32 \mathrm{X}$ Tested in the Furniture Calorimeter................. 12

Figure 31. Concentration of $\mathrm{CO}_{2}, \mathrm{CO}, \mathrm{HCN}$, and Oxygen during the Smoldering-to-Flaming Ignition of Foam 32 Mock-up Upholstery Chairs Tested in the Furniture Calorimeter............... 129

Figure 32. Concentration of $\mathrm{CO}_{2}, \mathrm{CO}, \mathrm{HCN}$, and Oxygen During the Smoldering-to-Flaming Ignition of Foam 32X Mock-up Upholstery Chairs Tested in the Furniture Calorimeter............... 130

Figure 33. Comparison of Carbon Dioxide Yields for Smoldering-to-Flaming Ignitions of Foams 32 and $32 \mathrm{X}$ Mock-up Upholstery Chairs Tested in the Furniture Calorimeter........................ 131

Figure 34. Comparison of Carbon Monoxide Yields for Smoldering-to-Flaming Ignitions of Foams 32 and 32X Upholstery Chair Mock-ups Tested in the Furniture Calorimeter (excluding early smoldering

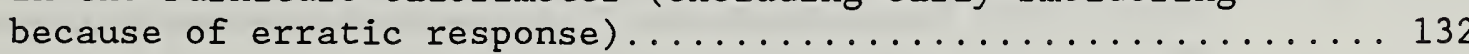

Figure 35. Comparison of the Yield of Water from Smoldering-to-Flaming Ignitions of Foams 32 and 32X Upholstery Chair Mock-ups Tested in the Furniture Calorimeter (excluding early smoldering because of erratic response $\ldots \ldots \ldots \ldots \ldots \ldots \ldots \ldots \ldots \ldots \ldots \ldots$

Figure 36. Comparison of The Heat of Combustion from the Smoldering-toFlaming Ignitions of Foams 32 and $32 \mathrm{X}$ Upholstery Chair Mock-ups Tested in the Furniture Calorimeter (excluding early smoldering because of erratic response)............... 134 
Figure 37. Comparison of the Smoke Extinction Coefficient for the Smoldering-to-Flaming Ignitions of Foams 32 and $32 \mathrm{X}$ Upholstery Chair Mock-ups Tested in the Furniture Calorimeter (excluding early smoldering because of erratic response)............ 135

Figure 38. Comparison of the Rate of Heat Release for the Smoldering-toFlaming Ignitions of Foams 32 and $32 \mathrm{X}$ Upholstery Chair Mock-ups Tested in the Furniture Calorimeter (excluding early smoldering because of erratic response) $\ldots \ldots \ldots \ldots \ldots \ldots \ldots$

Figure 39. Comparison of the Heat Flux Received by a Target Material from the Smoldering-to-Flaming Ignitions of Foams 32 and $32 \mathrm{X}$

Upholstery Chair Mock-ups Tested in the Furniture Calorimeter.. 137

Figure 40. Schematic Floor Plan of The Large-Scale Three Compartment Test

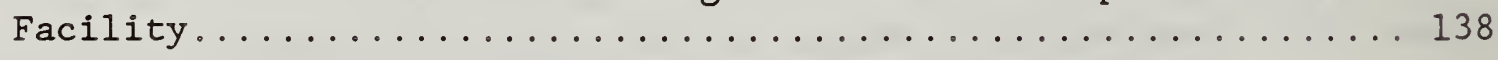

Figure 41. Comparison of Sample Weight loss for Flaming Ignition of Mock-up Upholstery Chairs made from foams 32 and $32 \mathrm{X}$ in the Large-Scale Three Compartment Tests.................... 139

Figure 42. Carbon Monoxide Concentration in Each Compartment of the Large-Scale Facility During Flaming Ignition Test of Foam 32 Mock-up Upholstery Chair Assembly..................... 140

Figure 43. Carbon Monoxide Concentration in Each Compartment of the Large-Scale Facility During Flaming Ignition Test of Foam 32X Mock-up Upholstery Chair Assembly.................... 141

Figure 44. Carbon Dioxide Concentration in Each Compartment of The Large-Scale Facility During Flaming Ignition Test of Foam 32 Mock-up Upholstery Chair Assembly...................... 142

Figure 45. Carbon Dioxide Concentration in Each Compartment of the Large-Scale Facility During Flaming Ignition Test of Foam 32X Mock-up Upholstery Chair Assembly.................... 143

Figure 46. Upper Layer Gas Temperatures in Each Compartment of the Large-Scale Facility During Flaming Ignition test of Foam 32 Mock-up Upholstery Chair Assembly..................... 144

Figure 47. Upper Layer Gas Temperatures in Each Compartment of the Large-Scale Facility During Flaming Ignition test of Foam 32 Mock-up Upholstery Chair Assembly.................... 145 
Figure 48. Comparison of Carbon Dioxide Concentration in the Burn Room and the Animal Exposure Chamber for Flaming Ignition of Foam 32 Mock-up Upholstery Chair Assembly................... 146

Figure 49. Upper Layer Gas Temperatures in Each Compartment of the Large-Scale Facility During Flaming Ignition Test of Foam 32 Mock-up Upholstery Chair Assembly...................... 147

Figure 50. Upper Layer Gas Temperatures in Each Compartment of the Large-Scale Facility During Flaming Ignition Test of Foam 32X Mock-up Upholstery Chair Assembly..................... 148

Figure 51. Comparison of Weight Loss for Preliminary Smoldering-to-Flaming Experiments of Foams 32 and 32X Mock-up Upholstery Chair

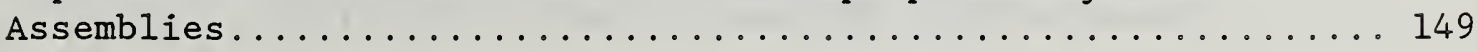

Figure 52. Comparison of Carbon Monoxide Concentrations in Each Compartment of the Large-Scale Test Facility for the One Cigarette Test of Foam 32 Mock-up Upholstery Chair Assembly.... 150

Figure 53. Comparison of Carbon Dioxide Concentrations in Each Compartment of the Large-Scale Test Facility for the One Cigarette Test of Foam 32 Mock-up Upholstery Chair Assembly............... 151

Figure 54. Comparison of Oxygen Concentrations in Each Compartment of the Large-Scale Test Facility for the One-Cigarette Test of Foam 32 Mock-up Upholstery Chair Assembly................... 152

Figure 55. Comparison of Upper Compartment Gas Temperature in Each Compartment of the Large-Scale Test Facility for the OneCigarette Test of Foam 32 Mock-up Upholstery Chair Assembly.... 153

Figure 56. Comparison of Carbon Monoxide Concentrations in Each Compartment of the Large-Scale Test Facility for the Two-Cigarette Test of Foam 32 Mock-up Upholstery Chair Assembly................. 154

Figure 57. Comparison of Carbon Dioxide Concentration in Each Compartment of the Large-Scale Test Facility for the Two-Cigarette Test of Foam 32 Mock-up Upholstery Chair Assembly................ 155

Figure 58. Comparison of Oxygen Concentrations in Each Compartment of the Large-Scale Test Facility for the Two-Cigarette Test of Foam 32 Mock-up Upholstery Chair Assembly................... 156

Figure 59. Comparison of Upper Compartment Gas Temperatures in Each Compartment of the Large-Scale Test Facility for the TwoCigarette Test of Foam 32 Mock-up Upholstery Chair Assembly.... 157 


\section{LIST OF FIGURES (continued)}

Page

Figure 60. Comparison of Carbon Monoxide Concentrations in Each

Compartment of the Large-Scale Test Facility for the Two-

Cigarette Test of Foam 32X Mock-up Upholstery Chair Assembly... 158

Figure 61. Comparison of Carbon Dioxide Concentrations in Each

Compartment of the Large-Scale Test Facility for the Two-

Cigarette Test of Foam 32X Mock-up Upholstery Chair Assembly... 159

Figure 62. Comparison of Oxygen Concentrations in Each Compartment of the Large-Scale Test Facility for the Two-Cigarette Test of Foam 32X Mock-up Upholstery Chair Assembly............... 160

Figure 63. Comparison of the Upper Compartment Gas Temperatures in Each Compartment of the Large-Scale Test Facility for the Two-

Cigarette Test of Foam 32X Mock-up Upholstery Chair Assembly... 161

Figure 64. Large-Scale Three Compartment Animal Exposure System - Three

Animal Exposure Chambers....................... 162

Figure 65. Mass Loss of Upholstery Chair Assembly Made from Foam 32 and Exposed to Two-Cigarettes in the Large-Scale Test Facility With the Animal Exposure Chambers Connected to the Burn Room....... 163

Figure 66. Comparison of Carbon Monoxide Concentrations in Each Compartment of the Large-Scale Test Facility for the Two-Cigarette Test of Foam 32 Mock-up Upholstery Chair Assembly With the Animal

Exposure Chambers Connected to the Burn Room.................. 164

Figure 67. Comparison of Carbon Dioxide Concentrations in Each Compartment of the Large-Scale Test Facility for the Two-Cigarette Test of Foam 32 Mock-up Upholstery Chair Assembly With the Animal

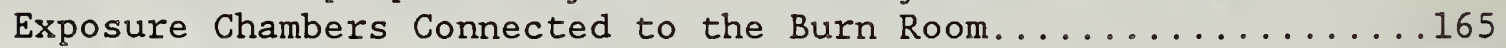

Figure 68. Comparison of Oxygen Concentrations in Each Compartment of the Large-Scale Test Facility for the Two-Cigarette Test of Foam 32 Mock-up Upholstery Chair Assembly With the Animal Exposure Chambers Connected to the Burn Room..................66

Figure 69. Comparison of the Upper Compartment Gas Temperature in Each Compartment of the Large-Scale Test Facility for the Two Cigarette Test of Foam 32 Mock-up Upholstery Chair Assembly With the Animal Exposure Chambers Connected to the Burn Room.......167

Figure 70. Mass Loss of Upholstery Chair Assembly Made from Foam 32 and Exposed to Two-Cigarettes in the Large-Scale Test Facility With the Animal Exposure Chambers Connected to the Target Room..168 


\section{LIST OF FIGURES (continued)}

Figure 71. Comparison of Carbon Monoxide Concentrations in Each

Compartment of the Large-Scale Test Facility for the Two-Cigarette Test of Foam 32 Mock-up Upholstery Chair Assembly With the Animal Exposure Chamber Connected to the Target Room

Figure 72. Comparison of Carbon Dioxide Concentration in Each Compartment of the Large-Scale Test Facility for the Two-Cigarette Test of Foam 32 Mock-up Upholstery Chair Assembly With the Animal Exposure Chamber Connected to the Target Room............... 170

Figure 73. Comparison of Oxygen Concentration in Each Compartment of the Large-Scale Test Facility for the Two-Cigarette Test of Foam 32 Mock-up Upholstery Chair Assembly With the Animal

Exposure Chamber Connected to the Target Room...............171

Figure 74. Comparison of the Upper Compartment Gas Temperatures in Each Compartment of the Large-Scale Test Facility for the TwoCigarette Test of Foam 32 Mock-up Upholstery Chair Assembly With the Animal Exposure Chamber Connected to the Target

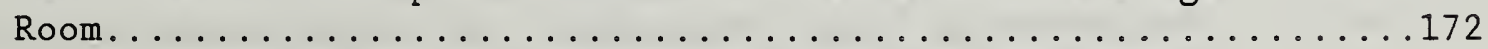

Figure 75. Mass Loss of Upholstery Chair Assembly Made from Foam 32X and Exposed to Two-Cigarettes in the Large-Scale Test Facility With the Animal Exposure Chambers Connected to the Burn Room.......173

Figure 76. Comparison of Carbon Monoxide Concentrations in Each Compartment of the Large-Scale Test Facility for the Two-Cigarette Test of Foam 32X Mock-up Upholstery Chair Assembly With the Animal

Exposure Chambers Connected to the Burn Room................174

Figure 77. Comparison of Carbon Dioxide Concentrations in Each Compartment of the Large-Scale Test Facility for the Two-Cigarette Test of Foam 32X Mock-up Upholstery Chair Assembly With the Animal Exposure Chambers Connected to the Burn Room..................

Figure 78. Comparison of Oxygen Concentrations in Each Compartment of the Large-Scale Test Facility for the Two-Cigarette Test of Foam 32X Mock-up Upholstery Chair Assembly With the Animal Exposure Chambers Connected to the Burn Room...............176

Figure 79. Comparison of Upper Compartment Gas Temperatures in Each Compartment of the Large-Scale Test Facility for the Two Cigarette Test of Foam 32X Mock-up Upholstery Chair Assembly With the Animal Exposure Chambers Connected to the Burn

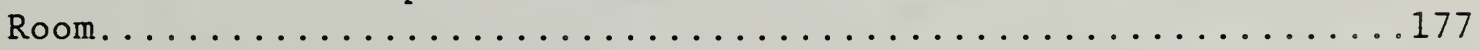


Figure 80. Mass Loss of Upholstery Chair Assembly Made from Foam 32X and Exposed to Two-Cigarettes in the Large-Scale Test Facility With the Animal Exposure Chambers Connected to the Target Room......178

Figure 81. Comparison of Carbon Monoxide Concentrations in Each Compartment of the Large-Scale Test Facility for the Two-Cigarette Test of Foam 32X Mock-up Upholstery Chair Assembly With the Animal Exposure Chambers Connected to the Target Room..............179

Figure 82. Comparison of Carbon Dioxide Concentrations in Each Compartment of the Large-Scale Test Facility for the Two-Cigarette Test of Foam 32X Mock-up Upholstery Chair Assembly With the Animal Exposure Chambers Connected to the Target Room..............180

Figure 83. Comparison of Oxygen Concentrations in Each Compartment of the Large-Scale Test Facility for the Two-Cigarette Test of Foam 32X Mock-up Upholstery Chair Assembly With the Animal Exposure Chambers Connected to the Target Room...............181

Figure 84. Comparison of Upper Compartment Gas Temperatures in Each Compartment of the Large-Scale Test Facility for the TwoCigarette Test of Foam 32X Mock-up Upholstery Chair Assembly With the Animal Exposure Chambers Connected to the Target

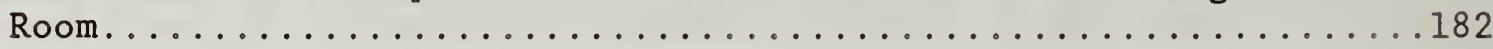


Emil Braun, Barbara C. Levin, Maya Paabo, Joshua Gurman, Trudi Holt, J. Samuel Steel

\section{Abstract}

The toxicity of the thermal decomposition products from two flexible polyurethane foams (with and without a fire retardant) and a cotton upholstery fabric was evaluated by a series of small-scale (using the NBS Toxicity Test Method) and large-scale tests (in which sets of Fischer 344 rats were exposed sequentially to either the smoldering or flaming decomposition products from single mock-up upholstery chairs in a multiroom facility). Small-scale and large-scale experiments were also conducted in the NBS Cone Calorimeter and the NBS Furniture Calorimeter, respectively, to provide other fire property data such as rates of heat release, effective heats of combustion, specific gas species yields, and smoke obscuration. The results of these tests were compared on the bases of: the predictability of the N-Gas Model; the nature of the animal deaths; and the relative contributions of $\mathrm{CO}, \mathrm{CO}_{2}$, and $\mathrm{HCN}$ to animal lethality. The degree of toxicity observed during and following the flaming tests (both large-scale room burns and the NBS Toxicity Test) could be explained by an N-Gas Model which presently includes the combined toxicological effects of $\mathrm{CO}, \mathrm{CO}_{2}$, and $\mathrm{HCN}$. Essentially no animal deaths were noted during the thirty minute exposures to the non-flaming or smoldering combustion products produced in the NBS Toxicity Test Method or the largescale room test. In both sets of experiments, the respective concentrations of $\mathrm{CO}, \mathrm{CO}_{2}$, and $\mathrm{HCN}$ were comparable. Post-exposure deaths, however, occurred 
following the small-scale non-flaming foam or cotton tests, but not following exposures to the smoldering phase of the large-scale tests. The ratio of yields of $\mathrm{CO}_{2}$ to $\mathrm{CO}$ were mostly comparable in all four sets of experiments. In the large-scale room tests, little toxicological difference was noted between decomposition products from the burn room and a second room 12 meters away.

Keywords: Cotton; fire tests; large scale fire tests; polyurethane; small scale fire tests; toxicity; upholstery.

\subsection{Introduction}

Upholstered furniture and mattresses play a major part in residential fire losses [1,2]. It has been estimated that in 1984 cigarette/soft furnishings fire incidents accounted for 49,000 residential structural fires. These fires resulted in 1,530 deaths, 3950 injuries, and $\$ 320,000,000$ in damages. While cigarette-initiated fires accounted for only 7.9 percent of all residential fires, about 65 percent of upholstered furniture fires were caused by cigarettes; 36 percent of all residential fire deaths and 19 percent of the injuries were attributed to cigarette-initiated fires. In a more general study, Lingenfelter [3] reported that, during the period 1980 to 1983 , upholstered furniture accounted for 25 percent of the first items ignited in fatal residential fires. During this same period, 63 percent of the upholstered furniture ignitions were caused by smoldering ignition sources such as cigarettes and heating equipment. Smoldering upholstered furniture 
accounted for 81 percent of the deaths and 69 percent of the injuries attributed to upholstered furniture fires. A third study reports that 80 percent of the fire victims die from smoke inhalation rather than burns [4].

Because of the large number of possible combinations of upholstery fabric and padding material coupled with variations in furniture design, large-scale flammability testing of each combination is prohibitively expensive and time consuming. Efforts have been underway for several years to develop relatively inexpensive small-scale tests for both fire growth and smoke toxicity. For these to be useful, however, methods need to be developed to translate the small-scale test results into meaningful predictions of real scale fire hazards. Recently, using a very limited set of materials, a correlation between small-scale rate of heat release data on composite assemblies and free air burning measurements of full-scale assemblies of upholstered furniture has been developed [5]. Similar research is needed to correlate other fire properties data such as smoke yield and toxic potency.

Few large-scale fire evaluations in which animals have been exposed to the products of combustion have been reported in the literature. Even fewer studies have directly compared toxicity data from small-scale and large-scale tests. Fitzgerald [6] reports on fire tests of an upholstered chair conducted in a multicompartment facility. Animal exposure stations were located in several rooms other than the room of fire origin. The upholstered chair was exposed to a flaming ignition source and the mean time to death of each group of animals was reported. These results were compared to analytical results obtained from the Monsanto Cube, an $8 \mathrm{ft.x} 8 \mathrm{ft} . \mathrm{x} 8 \mathrm{ft}$. calorimeter. Grand 
et al. [7] exposed animals located in a target room to gaseous decomposition products from a fully furnished burn room connected to the target room by a corridor which was open at one end. Alarie et al.[8] compared toxicity results obtained with the University of Pittsburgh combustion product toxicity apparatus to room corner tests of fiberglass reinforced polyester exposed to a flaming ignition source. A similar approach was followed by Alarie et al.[9] and Braun et al.[10] in evaluating the toxicity of combustion products produced by smoldering upholstery chairs in a closed room. A covered cigarette was used as the ignition source.

The objective of this work was to investigate the correlation between the burning behavior of furniture components in small-scale laboratory test methods and in large-scale experiments. The collected fire property data would also be used to guide the development of and/or establish the validity of computer fire models. Therefore, not all of the data shown in tables and graphs in this report are fully discussed in the text. Combustion characterization of the individual components was performed with the Cone Calorimeter, and the toxicological evaluation was performed using the National Bureau of Standards (NBS) toxicity protocol. Mock-up upholstered chairs of the same materials were evaluated using the NBS furniture calorimeter and in large-scale tests performed in a three compartment configuration consisting of a burn room, a corridor, and a second room (i.e., a target room).

Because cigarette-initiated fires are much more frequent than fires caused by small flame ignition sources, the large-scale tests were designed to simulate cigarette ignition and long term smoldering of an upholstered chair followed 
by flaming of the remaining combustible materials. This smoldering-flaming transitional scenario is a real and frequent occurrence in residential fires. Fire growth and smoke toxicity were measured during both stages of fire development. Since the transition from smoldering-to-flaming combustion is not well understood and appears as a random uncontrolled process, flaming combustion was forced by applying a burner to the surface of the mock-up upholstered chair. Animals were exposed to the decomposition products generated during each type of combustion. Small-scale tests were performed on the individual components as well as cone calorimeter tests on the fabric and foam combination. Animal lethality and yields of gaseous combustion products were used to compare results between the non-flaming decomposition in the small-scale tests and the smoldering decomposition in the large-scale experiments. Similar comparisons were made between the atmospheres developed during flaming combustion in small- and large-scale tests.

Since the properties of the resilient material dominate the flammability of a chair assembly, two polyurethane foams with different burning behavior were used. These and the other materials are described next. Section 3 of this report describes each individual test method and procedure along with a presentation of the test results. Section 4 is a comparison of test results among the different test methods or procedures.

\subsection{Materials}

The materials used in these experiments are commonly found in upholstered furniture, namely, flexible polyurethane foam and cotton upholstery fabric. 
In a real furniture product, foams of varying density and different fabric construction and type are used in the seat, sides, and back assemblies. In order to simplify the experimental design, each chair mock-up consisted exclusively of one of two foams covered with a fabric on a steel frame.

The two foams were based on similar formulations. However, one contained a chlorinated phosphate compound that allowed it to meet the State of California's requirements for cigarette ignition resistance and flame resistance of resilient cellular material used in upholstered furniture [11]. Both the treated (32X) and non-treated (32) foam had a density of $22.3 \mathrm{~kg} / \mathrm{m}^{3}$.

The cotton upholstery fabric was selected to ensure that the entire assembly would smolder when exposed to a burning cigarette. It was a Haitian cotton weighing $0.7 \mathrm{~kg} / \mathrm{m}^{2}$.

The chairs were ignited using the standard cigarette prescribed by the State of California [11] and the Upholstered Furniture Action Council [12]. They were $85 \mathrm{~mm}$ long and had a circumference of $25 \mathrm{~mm}$. The cigarettes were without filters and were made from natural tobacco with a density of $0.27 \pm 0.02 \mathrm{~g} / \mathrm{cc}$ and a total weight of $1.1 \pm 0.1 \mathrm{~g}$.

\subsection{Test Procedures and Results}

The test procedures were divided into three catagories; small-scale tests, full-size free burn, and large-scale compartment tests. The small-scale tests were used to measure the fire properties of the experimental materials under 
well-defined exposure conditions. Toxic potencies of the individual components were determined following the NBS toxicity protocol, while energy release and mass loss rates were measured for the individual foams and the foam/fabric assemblies using the Cone Calorimeter. These provide the basic data necessary for comparison to the large-scale tests. The furniture calorimeter tests were conducted to determine the maximum realizable free-burn mass loss rates and gas concentrations and yields. An assessment of the effect of the closed compartment on fire behavior could be determined from the large-scale compartment fire tests. Each material or material combination was tested according to the plan summarized below. The numbers in the table indicate the number of tests performed under each combustion condition for either foam 32 or foam $32 \mathrm{X}$. Since the fabric was tested alone only in the NBS Toxicity Test, the numbers in the table, with the exception of the fabric only tests, need to be doubled when considering the total number of tests performed.

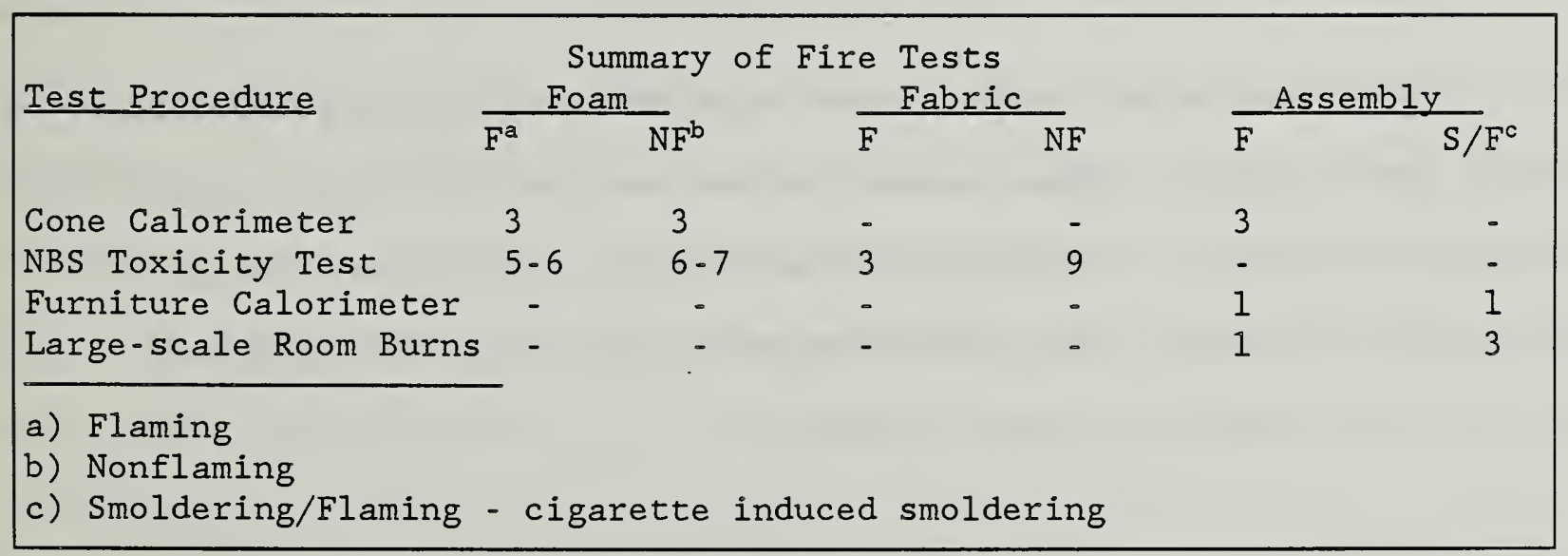

In the remainder of this section, the procedures and results for each individual test are described. Section 4.0 presents a comparison of results between the various test procedures. 


\subsection{Small-scale Tests}

\subsubsection{NBS Toxicity Protocol}

The NBS toxicity protocol has been described in detail by Levin et al. [13]. This test method uses lethality as a characteristic endpoint to measure the toxicological potency of smoke generated from the thermal decomposition of combustible materials. This toxic potency is reported as an $\mathrm{LC}_{50}$, that is, the amount of material which when thermally decomposed, either in flaming or in non-flaming modes, in a small furnace produces enough combustion products to kill 50 percent of the exposed animals either during a pre-defined exposure period or a 14 day post-exposure observation period. In this report, combined within- and post-exposure $\mathrm{LC}_{50}$ values are reported. The average animal exposure chamber concentrations of $\mathrm{CO}, \mathrm{CO}_{2}$, and $\mathrm{O}_{2}$, as well as $\mathrm{HCN}$ where appropriate, are reported.

Carbon dioxide and carbon monoxide were measured continuously by nondispersive infrared spectroscopy. Oxygen concentrations were measured continuously by a paramagnetic analyzer. The HCN generated from the polyurethane foams was sampled with a gas-tight syringe and analyzed using a gas chromatograph equipped with a thermionic detector [14].

Test samples were evaluated at $25^{\circ} \mathrm{C}$ above and below their autoignition temperatures. The autoignition temperatures for the two polyurethane foams and the cotton cover fabric were determined to be: 


\begin{tabular}{|lc|}
\hline Material & Autoignition Temperature $\left({ }^{\circ} \mathrm{C}\right)$ \\
Foam 32 & $400-425$ \\
Foam 32X (fire-retarded) & 400 \\
Haitian Cotton & 525 \\
\hline
\end{tabular}

Foam 32 exhibited inconsistent autoignition during animal exposure experiments. In order to ensure that the animals were only exposed to either flaming or non-flaming decomposition conditions, non-flaming experiments were performed at $375^{\circ} \mathrm{C}$ and $400^{\circ} \mathrm{C}$, while flaming animal experiments were conducted at $400^{\circ} \mathrm{C}$ and $450^{\circ} \mathrm{C}$ (one flaming analytical experiment was conducted at $400^{\circ} \mathrm{C}$ ).

Six animals, Fischer 344 male rats weighing 200 to $300 \mathrm{~g}$, were exposed in the head-only mode in each experiment designated by an "R" in tables 1,2 , and 3 . Exposures were for 30 minutes, at which time the animals were withdrawn and the survivors held for observation for a minimum of 14 days. The number of animals that died at each mass loading of material was plotted to produce a concentration-response curve from which an $\mathrm{LC}_{50}$ value was statistically calculated [15]. Animals that were still losing weight on day 14 were kept until they died or recovered as indicated by three days of successive weight gain. All deaths, even those occurring after the normal 14 day observation period, were included in the $\mathrm{LC}_{50}$ calculation.

During some of the experiments, one or two animals were surgically prepared with a femoral arterial cannula 24 hours before experiments [16] so that blood carboxyhemoglobin ( $\mathrm{COHb}$ ) could be measured. Surviving cannulated animals were sacrificed following the 30 minute exposure and only counted in the 
determination of the $\mathrm{LC}_{50}$ if they died during the exposure. If no deaths occurred at the highest smoke concentration tested, the $\mathrm{LC}_{50}$ is 1 isted as greater than that concentration.

The chemical and toxicological data obtained from the non-treated polyurethane foam, 32, thermally decomposed under non-flaming and flaming conditions, are presented in table 1. Similar to other non-treated polyurethane foams tested in this laboratory, no animal deaths occurred during the 30 minute exposures to smoke concentrations up to $40 \mathrm{mg} / \ell$ regardless of the mode of decomposition $[13,17,18]$. Post-exposure deaths only occurred following the non-flaming experiments. The $\mathrm{LC}_{50}$ value for the non-flaming mode was estimated to be $39 \pm$ $2 \mathrm{mg} / \ell$. The $\mathrm{LC}_{50}$ value for the flaming mode was greater than $40 \mathrm{mg} / \ell$, i.e., no animal deaths were noted from any of the concentrations tested up to 40 $\mathrm{mg} / \ell$.

The chemical and toxicological data obtained from the treated polyurethane foam, 32X, thermally decomposed under non-flaming and flaming conditions are presented in table 2. Within-exposure animal deaths were observed in these experiments in addition to post-exposure deaths. The $\mathrm{LC}_{50}$ value for the nonflaming mode was $28 \mathrm{mg} / \ell$ with 95 o confidence limits of 24 to $32 \mathrm{mg} / \mathrm{l}$, while the flaming mode had an $\mathrm{LC}_{50}$ value of $27 \mathrm{mg} / \ell$ with $95 \%$ confidence limits of 22 to $34 \mathrm{mg} / \mathrm{l}$.

All the chemical and toxicological data collected from the thermal degradation of the Haitian cotton upholstery fabric are shown in table 3 . In the nonflaming mode at $500^{\circ} \mathrm{C}$, the $\mathrm{LC}_{50}$ value of the cotton was $28 \mathrm{mg} / \mathrm{l}$ with $95 \%$ 
confidence limits of 25 to $31 \mathrm{mg} / \ell$. No animal deaths occurred within the exposure period and all post-exposure deaths occurred within four days. In the flaming mode at $525^{\circ} \mathrm{C}$, it was determined that the $\mathrm{LC}_{50}$ value for cotton was greater than $50 \mathrm{mg} / \ell$. No deaths were observed in any flaming tests.

Table 4 is a tabulation of the concentrations of $\mathrm{CO}, \mathrm{CO}_{2}$, and $\mathrm{HCN}$ at the calculated $\mathrm{LC}_{50}$ values for the two polyurethane foams, 32 and $32 \mathrm{X}$, and the Haitian cotton upholstery fabric. These values were used as target values for the introduction of animals into the combustion products from the large-scale experiments.

Previous work [19] has shown that the amount of HCN generated by the thermal decomposition of flexible polyurethane foam depends on the amount of char residue present prior to the initiation of flaming combustion. When a flexible polyurethane foam was heated under non-flaming oxidative conditions in the NBS toxicity test method, a char was produced. Subsequent heating of this char to temperatures normally inducing flaming combustion increased the amount of HCN produced, compared to direct flaming of the virgin flexible polyurethane foam. (These ramped heating experiments did not result in flaming combustion.) Similar experiments were conducted with foams 32 and 32X. Figure 1 shows the results of exposing approximately 3.9 gm of foam, which is an equivalent material loading of $20 \mathrm{mg} / \ell$, to a temperature of $375^{\circ} \mathrm{C}$ for 30 minutes. Ramping the temperature up to $800^{\circ} \mathrm{C}$ increased the $\mathrm{HCN}$ concentration in the exposure chamber from $<5 \mathrm{ppm}$ to a maximum of $170 \mathrm{ppm}$ for the non-treated foam and $220 \mathrm{ppm}$ for the fire retarded treated foam. This was nearly 3 times the average $\mathrm{HCN}$ concentration for the non-treated foam and 
nearly 2 times the average HCN concentration for the treated foam measured under flaming conditions.

\subsubsection{Cone Calorimeter}

A bench-scale rate of heat release calorimeter has been developed based on the oxygen consumption principle (figure 2) [20]. Huggett [21] showed that a constant value of energy is released per unit mass of oxygen consumed for a wide range of organic fuels. Thus the energy release rate is computed from the measurements of mass flow rate and oxygen concentration through the exhaust stack. The effective heat of combustion can readily be determined from the heat release rate and the corresponding measured mass loss rate of the sample. Specific gas species yields can be computed in the same manner. In these experiments, the gas species measured were $\mathrm{CO}_{2}, \mathrm{CO}, \mathrm{H}_{2} \mathrm{O}$, and total organic vapors. Smoke obscuration was characterized by the attenuation of a laser beam and reported as the extinction area per unit mass of material consumed. The soot yield was determined by passing a fraction of the effluent gas stream through a filter throughout the test exposure. The weight increase of the filter per total weight loss of the sample was reported.

The two polyurethane foam samples were tested individually and with the cotton fabric in the horizontal, face-up orientation in both a piloted and nonpiloted exposure with an external incident flux of $25 \mathrm{~kW} / \mathrm{m}^{2}$. To simulate preflashover conditions in a compartment, it has been customary to conduct Cone Calorimeter tests at this irradiance. The sample size was $100 \times 100 \mathrm{~mm}$ with a 
thickness of $50 \mathrm{~mm}$. Piloted tests employed a spark ignitor near the sample surface to induce flaming. The non-piloted tests did not flame. When the foam was covered with the cotton upholstery fabric, the tests were conducted using the spark ignitor. Three replicates of each type of test were conducted on each polyurethane foam -.. piloted and non-piloted tests of the foam materials alone and piloted tests of the fabric/foam assemblies.

Figures 3-9 show the data for the non-treated foam exposed with and without the cover fabric to an external incident energy of $25 \mathrm{~kW} / \mathrm{m}^{2}$. Figures $10-16$ show the data for the treated foam for the same exposure conditions. In order to better resolve the data from these tests, the time axis for the non-treated foam was 0 to 900 seconds, while the time axis for the treated foam was 0 to 600 seconds. Table 5 summarizes the average values of three replicates at each test condition at the time of the maximum heat release rate. In addition, the average ignition delay times and overall soot yields are tabulated. For each foam, at the maximum rate of heat release, non-flaming exposures produced more $\mathrm{CO}$, total unburned hydrocarbons and a greater concentration of particulates, with a higher total soot yield, than flaming exposures. The non-treated foam also produced more $\mathrm{CO}_{2}$ and $\mathrm{H}_{2} \mathrm{O}$ in the nonflaming exposure than in the flaming exposure.

Comparing the flaming foam tests with and without a cover fabric, both the treated and the non-treated foams had similar peaks for the maximum rate of heat release occurring at about the same time. The soot yields without a cover fabric are larger for the treated foam $(0.06 \mathrm{~kg}$ of soot per $\mathrm{kg}$ of 
material burned) than for the non-treated foam $(0.04 \mathrm{~kg}$ of soot per $\mathrm{kg}$ of material burned). The presence of the cover fabric reduced the yield of soot of both foams to $0.02 \mathrm{~kg} / \mathrm{kg}$. During the non-flaming experiments, the treated foam had a lower mass burning rate and produced a greater quantity of $C O$, unburned hydrocarbons and particulates. The non-treated foam produced more $\mathrm{CO}_{2}$ and $\mathrm{H}_{2} \mathrm{O}$ per mass of material burned.

Table 6 is a summary of the average overall yield values for $\mathrm{CO}$ and $\mathrm{CO}_{2}$. for the two foams with and without the cotton fabric cover. Under flaming conditions, the flame retardant treated foam without a cover fabric produced $1.13 \mathrm{~kg}$ of $\mathrm{CO}_{2}$ per $\mathrm{kg}$ of material burned. This was less than that produced by the non-treated foam, $2.34 \mathrm{~kg}$ of $\mathrm{CO}_{2}$ per $\mathrm{kg}$ of material burned, under flaming conditions. The non-treated foam produced significantly less $\mathrm{CO}, 0.013 \mathrm{~kg} / \mathrm{kg}$, than the treated foam, $0.045 \mathrm{~kg} / \mathrm{kg}$, whereas under non-flaming conditions the Co yields were similar.

Referring to figure 3 , the fabric-covered foam samples showed two burning peaks. The initial peak can be attributed to the burning of the fabric cover, while the second peak represents the burning foam. The second peak is smaller and broader than the flaming (bare) foam results because of the presence of charred fabric, which probably shields and inhibits active involvement of the foam. The second peak rate of heat release, mass loss rate, co production, $\mathrm{CO}_{2}$ production and $\mathrm{H}_{2} \mathrm{O}$ production for the assembly appear to be between the piloted and non-piloted results of the foam-only tests but generally closer to the flaming foam data. 
The presence of the cotton cover fabric during flaming tests decreased the production of $\mathrm{CO}$ from $0.045 \mathrm{~kg} / \mathrm{kg}$ to $0.026 \mathrm{~kg} / \mathrm{kg}$ for the treated foam but increased the production of CO from $0.013 \mathrm{~kg} / \mathrm{kg}$ to $0.033 \mathrm{~kg} / \mathrm{kg}$ for the nontreated foam. The cotton cover fabric also reduced the average yield of $\mathrm{CO}_{2}$ for both foams. However, the cotton fabric in conjunction with the treated foam had an average $\mathrm{CO}_{2}$ yield of $0.74 \mathrm{~kg} / \mathrm{kg}$, which was less than that measured in the non-flaming treated foam tests of $1.62 \mathrm{~kg} / \mathrm{kg}$.

\subsection{Mock-up Chair Tests--Furniture Calorimeter}

The furniture calorimeter [22] was designed to measure the heat release and mass loss rates of a piece of furniture burning in the open air. Figure 17 is a schematic representation of the apparatus. The basic principle of the apparatus, oxygen consumption calorimetry, is the same as that of the cone calorimeter previously described. The similarity to the cone calorimeter suggests direct comparability of the data from the two devices. Such correlations have been pursued for peak rate of heat release [5] and are now underway for gaseous combustion product yields.

In this study, during the burning of mock-up upholstered chairs, continuous measurements were made of gas velocity through the duct, oxygen concentration, gas temperature and mass loss so that the rate of heat release and mass loss rate could be computed. The concentrations of carbon monoxide and carbon dioxide were also continuously monitored. Evacuated bulbs were used to sample the effluent gases for $\mathrm{HCN}$ at critical times. Grab samples were taken from two locations in the exhaust stack of the calorimeter. The first sampling port 
was located in the vertical riser directly above the burning sample approximately $2 \mathrm{~m}$ from the exhaust intake. The second sampling port was at the same location as the other sampling instruments, about $10 \mathrm{~m}$ from the exhaust intake. These samples were analyzed for HCN on a gas chromatograph [14].

The mock-up chair assembly consisted of a steel framework with sides, back, and bottom designed to hold square cushions measuring $0.61 \mathrm{~m}$ on a side by 0.1 m thick (figure 18). Four cushions were used per chair. Each cushion was made by wrapping the Haitian cotton upholstery fabric around a correctly sized foam slab. The fabric was stapled closed along each seam. The cushions were installed into the steel frame and the entire assembly, resting on a load platform, was placed under the calorimeter hood. (A similar chair assembly and load platform was used in the large-scale tests.)

Two types of tests were conducted with each foam. The first type involved the flaming ignition of the mock-up assembly initiated with a small hand held butane torch set to produce a diffusion flame approximately $25 \mathrm{~cm}$ long. The torch was applied to the center of the back cushion. This flame produced sufficient energy to ignite the back cushion, while not being significantly detectable by the calorimeter instrumentation. In the second type, smoldering was initiated with a pair of burning cigarettes placed on the bottom cushion near each side crevice. The same torch was used to cause a transition from smoldering to flaming combustion. One chair mock-up of each foam type was burned. 


\subsubsection{Flaming Furniture Calorimeter Tests}

Table 7 summarizes the observations made during the testing of the two chair assemblies in the flaming ignition mode. For the mock-up chair containing the non-treated foam, the butane flame was applied for 30 seconds to the center of the back cushion. The initial flames appeared to extinguish themselves in about two minutes. The torch was reapplied to the charred cavity for about two seconds. This produced a stable flame within the cavity that continued to grow. The treated foam chair was exposed to the butane torch for two minutes. In this case, the flames also decreased but did not self-extinguish. Approximately two minutes and 50 seconds into the test, the flames began to increase in intensity.

Figures 19 and 20 show the gas concentrations for the measured gases $\left(\mathrm{CO}_{2}, \mathrm{CO}\right.$, $\mathrm{HCN}$, and $\mathrm{O}_{2}$ ) produced by foams 32 and $32 \mathrm{X}$, respectively. The peak HCN data presented in these figures are samples analyzed from both sampling ports. The time lag between the two sampling points was less than the ten second sampling interval of the other gas analyzers and the data are shown with no compensation for this difference between sampling points. The HCN concentration was $22 \mathrm{ppm}$ for the treated foam and $7 \mathrm{ppm}$ for the non-treated foam. While it is not clear from the non-treated foam data, the treated foam data appear to indicate that the production of $\mathrm{HCN}$ follows a similar form to the production of $\mathrm{CO}_{2}$.

The rates of heat release for these two assemblies are shown in figure 21. The non-treated foam, 32, reached its maximum heat release rate of $0.52 \mathrm{MW}$ in 
7.5 minutes. This was more rapid than the treated foam, $32 \mathrm{X}$, which had a maximum heat release rate of $0.50 \mathrm{MW} 9$ minutes from the start of the test. The rate of heat release of the treated foam appears to have two peaks. However, this is an artifact of the test caused by the collapse of one of the side cushions onto the bottom cushion partially quenching the flames.

As a measure of the impact a burning furniture item would have on other items in close proximity, a heat flux sensor was mounted $0.5 \mathrm{~m}$ from the leading edge of the assembly, level with the top of the seat cushion. Figure 22 shows the response of this sensor. During the maximum heat release rate the target sensor indicated that another material would have been exposed to a heat flux of 11 and $10 \mathrm{~kW} / \mathrm{m}^{2}$ for foams 32 and $32 \mathrm{x}$, respectively. These would be sufficient to ignite an "especially easily ignitable" target fuel [23]. Figure 23 shows the weight loss from chair assemblies made with foams 32 and 32X. During the short period of steady-state burning the average weight loss rate was found to be $16 \mathrm{~g} / \mathrm{s}$ and $14 \mathrm{~g} / \mathrm{s}$ for foams 32 and $32 \mathrm{X}$, respectively. Figures 24 to 27 show the effective heats of combustion and the gas yield data for $\mathrm{CO}_{2}, \mathrm{CO}$, and $\mathrm{H}_{2} \mathrm{O}$. The $\mathrm{HCN}$ yields are tabulated in table 8 . Figure 28 shows the generation of smoke particulates in terms of the extinction coefficient during the growth and decay of the fire.

\subsubsection{Cigarette Ignition Furniture Calorimeter Tests}

In each of the smoldering to flaming transition tests, two cigarettes, one along each side crevice, were placed approximately $15 \mathrm{~cm}$ from the front edge of the chair assembly, with the non-smoldering end of each cigarette in 
contact with the vertical side wall (figure 29). The rationale for using two cigarettes is the same as that in the large-scale tests (see section 4). The instrumentation and geometry were identical to the flaming furniture calorimeter tests described in section 3.2.1.

Table 9 summarizes the observations made during these two tests. The test involving the non-treated foam chair flamed spontaneously 59 minutes and 54 seconds into the test. With the foam $32 \mathrm{X}$ chair, one hour into the test, the butane torch was applied to the mid-point of the back cushion for 2 minutes and 50 seconds.

Figure 30 shows the sample weight loss for the chairs with foams 32 and $32 \mathrm{X}$. For the foam $32 \mathrm{X}$ chair, no appreciable weight loss occurs for the first 30 minutes of the test; while, for the non-treated foam chair, 32, the first sign of steady weight loss occurs 24 minutes into the test. The foam 32 chair had a measurable average weight loss rate during smoldering of $0.66 \mathrm{~g} / \mathrm{s}$, while the comparable value for the foam $32 \mathrm{X}$ chair was $0.20 \mathrm{~g} / \mathrm{s}$. During the flaming phase of these tests, the weight loss rates were $37 \mathrm{~g} / \mathrm{s}$ and $25 \mathrm{~g} / \mathrm{s}$ for foams 32 and $32 x$, respectively. The flaming weight loss rate values following a period of smoldering are much greater than those previously measured in the flaming initiated tests.

The corresponding data for $\mathrm{CO}_{2}, \mathrm{CO}, \mathrm{O}_{2}$, and $\mathrm{HCN}$ are shown in figure 31 for foam 32 chair and figure 32 for foam $32 \mathrm{x}$ chair. While the data show that both foams produce small amounts of $\mathrm{HCN}$ ( 1 to $2 \mathrm{ppm}$ ) during the smoldering portion of the burn, the transition to flaming resulted in a marked increase in the 
concentration of $\mathrm{HCN}$. Table 10 shows the HCN yield values for these two tests. The peak HCN concentration was $88 \mathrm{ppm}$ for the treated foam chair and $16 \mathrm{ppm}$ for the non-treated foam chair. For both types of foam, smoldering of the chair assembly prior to flaming generated more HCN than direct flaming of the chair assembly ( $7 \mathrm{ppm}$ and $16 \mathrm{ppm}$ for the non-treated foam chair and $22 \mathrm{ppm}$ and $88 \mathrm{ppm}$ for the treated foam chair). Similar to the flaming-initiated tests, the peak in $\mathrm{HCN}$ production seems to coincide with the peak in generation of $\mathrm{CO}_{2}$. Carbon monoxide production seems to be higher for the foam $32 \mathrm{X}$ chair than for the foam 32 chair.

The gaseous yield data for $\mathrm{CO}_{2}, \mathrm{CO}, \mathrm{H}_{2} \mathrm{O}$, and the effective heat of combustion, figures 33 to 36 , display large fluctuations due to the fluctuations in weight loss during the early part of the smoldering phase. (These erratic fluctuations have been removed from the graphs for the sake of clarity.) However, once a detectable and steady weight loss is achieved, the data, with the exception of $\mathrm{CO}_{2}$, tend to approach a quasi-steady state value. The values for these parameters can be separated into smoldering and flaming regions. The $\mathrm{CO}_{2}$ (figure 33) and $\mathrm{CO}$ (figure 34) data show, at best, modest differences between the treated and non-treated foam assemblies. The water yields and effective heats of combustion during smoldering and flaming combustion, from the two chair assemblies shown in figures 35 and 36 , respectively, are also similar.

Figure 37 shows the smoke extinction coefficient for both foams. The data show that two maximum values for each material assembly exist and that significant smoke development is caused by small amounts of decomposed 
material. The first maximum for both chair assemblies is coincident with a weight loss of approximately $0.21 \mathrm{~kg}$ of material. This is only a weight loss of 3 to 48 of the total combustible mass of the chair assemblies. The second occurs just after the transition to flaming combustion.

The rates of heat release are shown in figure 38. There is no significant heat released prior to the transition to flaming combustion. Following the initiation of flaming, the peak rate of heat released by the foam 32 chair was 1.12 MW and 0.63 MW for the foam $32 \mathrm{X}$ chair. Both of these tests had higher maximum heat release rates than the previous flaming-initiated tests ( $0.52 \mathrm{MW}$ for foam 32 and $0.50 \mathrm{MW}$ for foam $32 \mathrm{x}$ ). The heat flux received by a target material is also negligible $\left(<0.5 \mathrm{~kW} / \mathrm{m}^{2}\right)$ prior to the transition to flaming combustion (figure 39). The time of maximum target irradiance corresponds to the time of the maximum heat release rate for each material. The maximum target irradiance for the foam 32 chair was $21 \mathrm{~kW} / \mathrm{m}^{2}$. Based on previous work [23], this means that a second item, having a "normal" ignitability level, located adjacent to this mock-up upholstery chair might have been expected to ignite. With a target irradiance of $15 \mathrm{~kW} / \mathrm{m}^{2}$, chairs made from foam $32 \mathrm{X}$ and Haitian cotton would not have been expected to ignite the same type of secondary items under comparable exposure times.

Table 11 is a summary of the burning characteristics of the polyurethane foam mock-up chair assemblies tested in the furniture calorimeter. In general, smoldering the upholstery assembly prior to inducing flaming, resulted in a higher peak rate of mass loss which, in turn, caused an increase in the heat release rate, target irradiance, and extinction coefficient. The maximum 
effective heat of combustion was not affected by the increased weight loss rate nor were the yield values for $\mathrm{CO}_{2}, \mathrm{CO}$, and $\mathrm{H}_{2} \mathrm{O}$ greatly altered. The $\mathrm{HCN}$ yield, during flaming, increased as a result of the initial smoldering decomposition of the chair assemblies. It was approximately $75 \%$ greater for the foam 32 chair and 4 times greater for the foam $32 \mathrm{X}$ chair. Since HCN is not sampled continuously, the maximum $\mathrm{HCN}$ values reported for all tests may not be true maximums. Comparing work on commercially-constructed upholstery items [22] with results from these assemblies shows that measured target irradiances and maximum heat release rates were about $30 \%$ lower for the current tests, while the effective heats of combustion were about the same.

\subsection{Large-scale Three Compartment Tests}

A total of nine building-scale tests were conducted to evaluate the toxic potency of the atmosphere in the test facility during various phases of fire development. Mock-up upholstery chairs, with an initial mass of approximately $5.7 \mathrm{~kg}$, identical to those used in the furniture calorimeter experiments were placed on a load platform in a burn room and ignited with a burner flame or allowed to smolder for about 60 minutes and then forced into flaming with a burner flame. Four of these tests involved the use of animals. In all of the tests analytical data on gas temperatures, smoke obscuration, mass loss, flow between compartments, and concentrations of oxygen, carbon monoxide, carbon dioxide, and HCN were recorded. 


\subsubsection{Room-Corridor-Room Configuration}

The experimental arrangement is shown in figure 40 and consisted of two rooms, a burn room and a second room (i.e. target room), connected to a long corridor. The dimensions of the corridor and adjoining rooms and door sizes are described in table 12 and the construction materials are described in table 13. With the exception of an undercut of approximately $10 \mathrm{~mm}$ at the door at the end of the corridor and leaks through construction cracks, these tests were all conducted with the burn facility closed to the rest of the building.

\subsubsection{Instrumentation}

The locations of all instrumentation (the thermocouples, smoke meters, gas analyzers, pressure transducers, and a load platform) that were used in the double-room/corridor configuration are summarized in table 14 and most are shown in figure 40. Data were recorded with an automatic data logging system at a rate of 24 channels per second with a repeat cycle time of 10 seconds. (For a discussion of the mathematical calculations used to derive engineering values from instrumental measurements, see Peacock et al. [24].)

Two NBS toxicity protocol animal exposure chambers (without animals and with the animal ports sealed) were used during the analytical experiments. One was connected to the burn room via a $55 \mathrm{~mm}$ diameter pyrex sampling line, with the exhaust gases returned to the bottom of the burn room. The other animal exposure chamber was similarly connected to the target room. Each animal 
exposure chamber had its own $\mathrm{CO}, \mathrm{CO}_{2}$, and $\mathrm{O}_{2}$ analyzers, as well as a thermocouple and a port connection to take bulb samples for HCN analysis. A continuous flow of gas was maintained through each chamber for the duration of the analytical tests.

For the animal exposure experiments, three such animal exposure chambers (each equipped with gas analyzers for $\mathrm{CO}, \mathrm{CO}_{2}$, and $\mathrm{O}_{2}$ as well as a thermocouple and an individual sampling port for $\mathrm{HCN}$ ) were connected either to the burn room animal sampling line or to the target room animal sampling line. These experiments were designed to expose sets of six rats for 30 minutes to different time segments of the decomposition products from the burning mock-up upholstered chairs from either the burn room or the target room. During the smoldering phase of burning, gases from either the burn room or the target room were circulated through all three exposure chambers with no animals present. A continuous flow of gas was maintained through the animal exposure chambers from their respective rooms from the beginning of the test until the time the atmosphere in the exposure chamber reached pre-selected conditions. At the desired time of exposure, the sampling and return lines to an individual chamber, now filled with smoke, were closed and the animals introduced such that their heads were exposed to the static chamber atmosphere. With the exception of the effect the animals and the analyzers had on the atmosphere in each chamber, chamber gases were not altered during each 30 minute exposure. Three sets of rats were exposed to different time fractions of gases generated from the smoldering decomposition. Similarly, two sets of animals were exposed to the smoke from the flaming phase of the fixe. 


\subsubsection{Analytical Experiments}

A total of five exploratory analytical experiments were performed to provide baseline data prior to the animal exposure experiments and for ultimate comparison to computer-calculated hazard assessment results. Two experiments were strictly flaming tests initiated by a small burner impinging on the inside surface of the back cushion. The other three experiments were smoldering to flaming transition tests initiated by lit cigarettes placed on the side crevices of the mock-up assembly and later forced into a flaming fire as previously described with the furniture calorimeter tests in section 3.2.2.

\subsubsection{Flaming Analytical Experiments}

The first two tests were initiated by a natural gas burner located such that the burner flame impinged on the back cushion approximately $20 \mathrm{~cm}$ from the left side cushion and $15 \mathrm{~cm}$ above the bottom cushion. The burner was equipped with a remotely controlled automatic igniter and thermocouple sensor. With the gas flow set to produce approximately a $12 \mathrm{~cm}$ flame, the electric ignitor was used to start each flaming test. The data acquisition system was started with the visible appearance of the burner flame.

In both flaming experiments, surface charring was visible almost immediately after the ignition of the burner. However, a stable flame on the back cushion was not established for four minutes on the chair containing foam 32 , and 5.5 minutes on the chair with treated foam $32 \mathrm{X}$. Steady-state burning, as measured 
by sample weight loss, did not develop for the first six minutes of the experiment for the foam 32 chair and eight minutes for the foam $32 \mathrm{X}$ chair. Figure 41 shows the weight loss as a function of time for these two experiments. During steady-state burning, the average rate of weight loss for the foam $32 \mathrm{X}$ chair was $16 \mathrm{~g} / \mathrm{s}$, while the foam 32 chair burned at the rate of $25 \mathrm{~g} / \mathrm{s}$. At the conclusion of each test, less than $10 \%$ of the original mass of combustible material remained in the burn room; no material was observed to have fallen off of the load platform.

Figures 42 and 43 show the co data for foam 32 chair and foam $32 \mathrm{X}$ chair, respectively, during flaming combustion. Figures 44 and 45 show the $\mathrm{CO}_{2}$ data and figures 46 and 47 show the upper layer gas temperatures for each foam chair test.

By the end of each of the tests, the various compartments were completely filled with smoke. It was no longer possible to assume that there existed an upper layer filled with smoke and a lower layer clear of combustion products. Ignoring losses from minor openings in the test facility, the lower limit for the mass concentration of decomposition products was approximately $56 \mathrm{mg} / \ell$. This was determined by dividing the total mass of material consumed by the volume of the three compartment test facility. The peak $\mathrm{CO}, \mathrm{CO}_{2}$, and $\mathrm{HCN}$ values produced in the burn room and target room of the test facility are tabulated in table 15. Also listed in this table are the maximum average upper layer and average lower layer temperatures and minimum oxygen concentrations in the burn room and target room. These data indicate that the atmospheric conditions in the burn room were much more severe than in the 
target room. Table 16 compares the gas and temperature results from the test facility with the exposure chambers. No gas samples for HCN analysis were taken from the exposure chamber connected to the target room. During these experiments the flow rate through the animal exposure chambers were maintained at

\begin{tabular}{|lcc|}
\hline & \multicolumn{2}{c|}{ Flow Rate from } \\
\cline { 2 - 3 } Chair with & $\begin{array}{c}\text { Burn Room } \\
(\ell / \text { min })\end{array}$ & $\begin{array}{c}\text { Target Room } \\
(\ell / \text { min })\end{array}$ \\
\cline { 2 - 3 } Foam 32 & 200 & 210 \\
Foam 32X & 155 & 150 \\
\hline
\end{tabular}

Figure 48 shows a comparison of $\mathrm{CO}_{2}$ concentrations between the burn room and the animal exposure chamber connected to the burn room during a flaming ignition test for the foam 32 chair. At the above flow rates, the animal exposure chambers require approximately three to four minutes for a $90 \%$ change in the chamber atmosphere. This means that changes in the exposure chamber atmosphere lag behind the changes in the burn room atmosphere. In this test, the burn room atmosphere and the animal exposure chamber achieved near equilibrium after the end of active burning. Furthermore, since the later tests never achieved steady-state gas concentrations during the filling of the first four animal exposure chambers in either the burn room or the target room, the maximum in the animal exposure chamber was always less than the maximum in the burn facility. This smoothing effect is also evident in figure 48. Because of a failure in the sampling line for the gas analyzers in the burn room, similar burn room data for the chair containing the treated foam was not obtained. However, similar results were observed in the gas data associated with the burn room in other tests of the treated foam. 
The times to achieve maximum co concentration in the burn room and its animal exposure chamber, the target room and its animal exposure chamber are listed below.

\begin{tabular}{|lcccc|}
\hline & \multicolumn{4}{c|}{ Time of Maximum CO (s) } \\
\cline { 2 - 5 } Chair with & Burn Room & Exp. Chamber & Target Room & Exp. Chamber \\
\cline { 2 - 5 } Foam 32 & 480 & 740 & 700 & 1010 \\
Foam 32X & 720 & 1500 & 910 & 1220 \\
\hline
\end{tabular}

Comparison of the target room data with the burn room data showed that the time difference of the peak Co concentration between the burn room and the target room were about the same for foam 32 (220 seconds) and foam $32 \mathrm{X}$ (190 seconds). Differences of time to maximum CO concentration between either the burn room or the target room and its associated exposure chamber were within 50 seconds of each other. For foam 32, the time between peaks was marginally less for the burn room (260 seconds) than for the target room (310 seconds). The time to peak CO for the burn room exposure chamber, foam $32 \mathrm{X}$, is unusually high because the intake gate valve had been inadvertently left closed prior to the start of the test. This was corrected about 600 seconds from the start of the test and the observed delay was due, in part, to the initial filling of the exposure chamber.

Figures 49 and 50 show the upper compartment temperatures for these flaming experiments for foam assemblies 32 and $32 \mathrm{X}$, respectively. Based on a criterion of $600^{\circ} \mathrm{C}[25,26]$ in the upper half of the burn room compartment, the non-treated foam chair test would have resulted in flashover, while the treated foam chair test would not have caused flashover. If $500^{\circ} \mathrm{C}$ [27] were 
used as the criterion for flashover, both tests would have resulted in flashover conditions in the burn room. In either case, in the burn room, upper compartment temperatures decayed rapidly following peak values. Maximum upper compartment temperatures in the target room were well below either flashover criterion. Heat losses in the sampling lines to the animal exposure chambers resulted in chamber temperatures between $25^{\circ} \mathrm{C}$ and $30^{\circ} \mathrm{C}$, as indicated in table 16. These are well within the maximum average temperatures recommended for the animal toxicity exposures [28].

\subsubsection{Smoldering to Flaming Transition, Analytical Experiments}

Three exploratory experiments were conducted using cigarettes as the ignition source. These experiments were designed to provide an extended period of smoldering combustion followed by a forced transition to flaming combustion. The first preliminary smoldering experiment used one cigarette placed on the center front edge of the bottom cushion, while all other smoldering to flaming experiments used two cigarettes placed in opposite side crevices. (As shall be shown, the addition of a second cigarette merely accelerated the development of what would be considered to be a toxic atmosphere in the burn facility without appreciably affecting the smoldering process.) The animal exposure chambers were connected to the burn room and target room as described for the flaming experiments. The flow rates through the chambers varied because of differences in blower motors. 


\begin{tabular}{|c|c|c|c|}
\hline \multirow[b]{2}{*}{ Chair with } & \multirow[b]{2}{*}{ Ignition Source } & \multicolumn{2}{|c|}{ Flow Rate from } \\
\hline & & $\begin{array}{c}\text { Burn Room } \\
(\ell / \mathrm{min})\end{array}$ & $\begin{array}{c}\text { Target Room } \\
(\ell / \mathrm{min})\end{array}$ \\
\hline Foam 32 & one cigarette & 250 & 625 \\
\hline Foam 32 & two cigarettes & 250 & 625 \\
\hline Foam $32 \mathrm{X}$ & two cigarettes & 190 & 185 \\
\hline
\end{tabular}

The one-cigarette experiment took the longest time to develop. Approximately 21 minutes elapsed before smoke could be seen in the corridor for the onecigarette experiment as compared to 12 minutes for the two-cigarette foam 32 chair experiment. The foam $32 \mathrm{x}$ chair experiment took 18.5 minutes to begin filling the corridor with visible smoke. (After approximately 60 minutes from the start of each experiment, flaming combustion was initiated by igniting the back cushion with the same gas burner used in the strictly flaming large-scale experiments.) For the one-cigarette experiment, the burner impinged on the left side cushion. All other experiments had the burner impinging on the back cushion.

The mass loss for each mock-up upholstery chair in the smoldering to flaming transition experiments is shown in figure 51. (Because of an instrumental failure of the load cell in the two-cigarette foam 32 chair experiment, the data presented for this experiment in figure 51 are composites of the two subsequent animal exposure experiments normalized to the turn-on time of the ignition burner.) Two mass loss rates can be distinguished in these experiments. The first is associated with the smoldering of the mock-up assembly, while the second represents flaming combustion. For the foam 32 chair experiment, the average smoldering mass $10 s$ ș was $0.10 \mathrm{~g} / \mathrm{s}$ for the single-cigarette experiment and $0.26 \mathrm{~g} / \mathrm{s}$ for the two-cigarette case. For the treated foam chair, the mass loss rate was $0.33 \mathrm{~g} / \mathrm{s}$ for the two-cigarette 
case. A brief induction period followed the ignition of the gas burner. The average mass loss rate did not change appreciably during the transition to full flame involvement. During the flaming portion of the experiment, these mass loss rates increased to $21 \mathrm{~g} / \mathrm{s}$ for the one-cigarette and $18 \mathrm{~g} / \mathrm{s}$ for the two-cigarette foam 32 chair experiments, while for the two-cigarette foam $32 \mathrm{X}$ chair experiment the mass loss rate increased to $30 \mathrm{~g} / \mathrm{s}$.

Table 17 summarizes the gas and temperature data for these experiments just prior to the ignition of the burner. It can be seen that for the foam 32 twocigarette experiment produced approximately three times as much $\mathrm{CO}$ in the animal chamber in sixty minutes as the one-cigarette experiment produced in seventy minutes. The other parameters were only marginally different from ambient conditions, with the exception of the $\mathrm{CO}_{2}$ concentration in the burn room. The $\mathrm{CO}_{2}$ concentration for this experiment seems to have built up more rapidly than in any other experiment. Virtually all of the data for the foam 32 and foam $32 \mathrm{X}$ two-cigarette chair experiments appear to be comparable just prior to the ignition of the burner flame. Differences in the animal exposure chamber gas concentrations were probably due to differences in sampling flow rates. Marginal amounts of $\mathrm{HCN}$ (1-6 ppm) were detected in the burn room atmosphere for all pre-flaming test conditions. Animal exposure chamber temperatures never exceeded $31^{\circ} \mathrm{C}$.

Table 18 summarizes the gas and temperature data for the burn room, target room, and animal exposure chambers at the time of maximum CO concentration. In all cases this occurred after the transition to flaming combustion. The time of the ignition of the burner as well as the time of maximum CO 
concentration are also tabulated. The difference between these times varies from 12.7 minutes for the one-cigarette foam 32 chair experiment to four minutes for the two-cigarette foam 32 chair experiment. The two-cigarette foam $32 \mathrm{X}$ chair experiment had a delay time of 7.3 minutes from ignition of the burner to maximum $\mathrm{CO}$ concentration. Since $\mathrm{HCN}$ analysis was performed on grab samples that were not necessarily taken at the time of maximum $C O$ concentration, the time of the measured maximum $\mathrm{HCN}$ concentration is also listed.

All three experiments exceeded the upper gas temperature criterion used to define flashover. The HCN concentration in the burn room during the foam $32 \mathrm{X}$ chair experiment was three times larger than for any location of the two foam 32 chair experiments. This, however, was more a result of the sampling technique for HCN than any differences between the two foams. Apparently, in spite of the fact that the stainless steel sampling line from the burn room was heated, its long length allowed for the removal of $\mathrm{HCN}$ from the gas stream filling the evacuated glass bulbs. During the flaming portion of these experiments, the $\mathrm{HCN}$ concentration in the animal exposure chamber connected to the burn room exceeded the $\mathrm{LC}_{50}$ for this gas. Also, the chamber temperature was above the recommended limits but may not have been at lethal limits, which have not been determined. The presence of higher concentrations of HCN in the animal exposure chamber than in the burn room were also due to losses in the heated stainless steel HCN sampling line. This was corrected in later experiments by sampling from the animal exposure chamber intake manifold close to the burn room wall rather than using a separate heated stainless sampling line. The larger diameter glass pipe had a lower loss coefficient for HCN 
than the stainless steel tubing. In the two-cigarette foam $32 \mathrm{X}$ experiment the target room animal exposure chamber contained a combined lethal concentration of $\mathrm{CO}$ and $\mathrm{HCN}$, but the one cigarette foam 32 experiment appears to have had sublethal concentrations of $\mathrm{CO}$ and $\mathrm{HCN}$ even in combination with $\mathrm{CO}_{2}$.

Figures 52 to 55 show the burn facility data for $\mathrm{CO}, \mathrm{CO}_{2}$, and temperature for the foam 32 one-cigarette chair experiment, while figures 56 to 59 show the foam 32 two-cigarette chair data for these same parameters. Figures 60 to 63 show the results for the foam $32 \mathrm{X}$ chair.

\subsubsection{Three Compartment Animal Exposure Experiments}

Four large-scale experiments were conducted wherein animals were exposed to the combustion products generated during the smoldering and flaming phases of decomposition. Two experiments were conducted using chairs of each

polyurethane foam. All four experiments employed the two-cigarette ignition method used in the preliminary experiments to initiate smoldering in the mockup assembly. Each of these experiments involved the exposure of five sets of animals (six animals per set) in a head-only mode in an exposure chamber similar to that used in the NBS toxicity protocol. The animals used were of the same type as those described in section 3.1.1. In each of these experiments, three animal exposure chambers were connected in parallel to either the burn room or the target room and animals were exposed to the combustion products from only one of the rooms. Figure 64 shows the three animal exposure chambers as they were used in these experiments. Initially, 
gases from the selected room were pumped through all three exposure chambers. At predetermined times, each chamber was individually isolated from the burn facility by closing the connecting intake and exhaust valves to the rooms. Six rats were simultaneously exposed to the combustion atmospheres in the closed exposure chambers. After 30 minutes, the animals were withdrawn, the animal ports re-plugged and the valves to the burn room or target room opened, thereby reconnecting the animal exposure chamber to its source of smoke. This procedure allowed for three sets of animals to be exposed sequentially to preflaming combustion conditions and two sets of animals to be exposed to the gases from the flaming period of the experiment.

In the non-flaming small-scale toxicity tests (table 4 ) 50 percent of the animals died post-exposure following exposures to combustion atmospheres in which the $C O$ concentration of the non-flaming gases in the animal exposure chamber reached approximately $1000 \mathrm{ppm}$ for foam 32 and $700 \mathrm{ppm}$ for foam $32 \mathrm{X}$. Pure CO gas experiments at NBS have shown that $1000 \mathrm{ppm}$ of $\mathrm{CO}$ is not lethal and that $C O$ does not cause post-exposure deaths [29]. The toxic contribution of the cotton fabric was discounted, because it was felt that the bulk of the pre-flaming smoke in the large-scale tests was a result of the decomposition of the polyurethane foam and not the cotton fabric. The earlier two-cigarette experiments, section 3.3 .3 .2 , indicated that smoldering would have to be maintained for at least 60 minutes before the co concentration in the burn room would reach 1000 ppm. Earlier large-scale NBS unpublished room fire tests of polyurethane foam slabs indicated that there were no post-exposure deaths when the animals were only exposed to smoke generated later in the experiments and containing higher concentrations of CO. Therefore, in order 
to investigate the presence of additional toxicants causing post-exposure deaths, animals were exposed to smoke generated earlier in the experiment to suppress the effects of high CO concentrations. The subsequent two sets of pre-flaming animal exposures followed 10 to 20 minutes apart. The procedure was adjusted during each experiment to prevent the possibility of having to remove one set of animals at the same time that another set was being inserted.

Throughout these experiments there was a concern that the mock-up assembly might self-ignite before all three groups of pre-flaming animals were exposed and at least one chamber flushed with the smoke from the flaming atmospheres for post-flaming exposures. This did occur during the first animal exposure experiment using a foam 32 chair. However, all three pre-flaming exposures were initiated prior to flaming. The gases in both post-flaming chambers represented smoke from the burn room after the fire had self-extinguished.

\subsubsection{Smoldering Conditions}

The mass loss, $\mathrm{CO}, \mathrm{CO}_{2}, \mathrm{O}_{2}$, and upper compartment gas temperature for the twocigarette smoldering initiated foam 32 upholstery chair assembly tests are shown in figures 65 to 69 (for test with animal exposure chambers connected to the burn room) and figures 70 to 74 (for test with animal exposure chambers connected to the target room). Figures 75 to 79 and 80 to 84 are the comparable data for the two-cigarette smoldering initiated foam $32 \mathrm{X}$ upholstery assemblies. Table 19 summarizes the data from the burn room and the target room for these four experiments ( 2 mock-up chairs with foam 32 and 2 mock-up 
chairs with foam 32X) during smoldering combustion, while table 20 summarizes the animal exposure chamber data for each set of animals. From an analytical point of view, these experiments represent two replicates for each material combination and the data within each pair are indicative of the degree of reproducibility of this kind of test.

In the first experiment on the foam 32 chair (table 19), the mock-up assembly self-ignited in 57.8 minutes. While in the second experiment with this foam, the mock-up assembly was forced into ignition at 70.6 minutes. The decomposition rate of the first experiment was a little higher than in the second experiment. The reason for this is unclear and may be due to tensioning of the fabric around the foam during construction of the cushions or fit of the cushions in the chair frame.

During smoldering combustion of the foam 32 chair, $\mathrm{CO}_{2}$ and $\mathrm{HCN}$ production were very small and the oxygen concentration did not differ substantially from ambient conditions. However, the Co concentration increased to approximately $1500 \mathrm{ppm}$ in 34.8 minutes and the smoke level dropped to the floor of the corridor reducing visibility across the corridor to zero in 45 minutes.

Because of the lower decomposition rate of the foam $32 \mathrm{X}$ chair, it took longer to exceed the $1000 \mathrm{ppm} \mathrm{CO}$ level. Again, the $\mathrm{CO}_{2}$ and $\mathrm{HCN}$ concentrations were low and the oxygen concentrations were near the initial values. However, the CO concentration ultimately reached $1200 \mathrm{ppm}$ in the first foam $32 \mathrm{X}$ chair experiment and is estimated, based on the $\mathrm{CO}$ burn room to $\mathrm{CO}$ target room ratio from previous tests, to have been over $2200 \mathrm{ppm}$ in the second experiment. 
Zero visibility across the corridor was achieved in 45.8 minutes and 49.0 minutes for the two experiments.

The total flow of combustion products from the burn facility to the animal exposure chambers was maintained at an average of

\begin{tabular}{|c|c|c|}
\hline \multirow[b]{2}{*}{ Chair with } & \multicolumn{2}{|c|}{ Flow Rate from } \\
\hline & $\begin{array}{l}\text { Burn Room } \\
(l / \mathrm{min})\end{array}$ & $\begin{array}{c}\text { Target Room } \\
(\mathrm{l} / \mathrm{min})\end{array}$ \\
\hline Foam 32 & 320 & 330 \\
\hline Foam $32 \mathrm{X}$ & 190 & 320 \\
\hline
\end{tabular}

Approximately a third of this flow was diverted to each exposure chamber. Three air changes in the exposure chamber required about six minutes for all the experiments except for the foam $32 \mathrm{X}$ chair burn room sampling which, because of the low flow rate, required ten minutes for three air changes. An estimate of the total smoke mass loading for each animal exposure chamber was determined by first distributing the amount of material consumed among the three compartments according to the fractional concentration of $C O$ in each compartment. The pyrolysate concentration in each compartment was calculated by dividing the material distribution in each compartment by the smoke layer volume in that compartment. The concentration of pyrolysate in the animal exposure chamber was calculated as the average ratio of co concentration in the room to the $C O$ concentration in the animal exposure chamber times the average pyrolysate concentration in the room. During the latter part of the filling process for the third animal exposure chamber, the total compartment volume was used because the smoke layer had reached the floor of the largescale facility. Since the smoke in each compartment was not uniformly 
distributed throughout the compartment volume, this calculation represents a lower limit on the concentration of the pyrolysate.

The pyrolysate concentration values (i.e. material loading) are tabulated in table 20 for either the burn room or the target room and the third animal exposure chamber. While initial animal exposures were conducted under low CO concentrations, those just prior to the transition to flaming combustion were near or above the CO conditions previously determined from the LC $_{50}$ data of the NBS toxicity protocol. Out of 72 animals exposed to the decomposition products from smoldering foams 32 and $32 \mathrm{X}$ chair assemblies, only one animal was observed to have died. This animal died during the 30 minute exposure to the target room combustion products resulting from the decomposition of the foam 32 chair.

\subsubsection{Flaming Conditions}

With the exception of the first animal exposure test of the foam 32 chair which spontaneously burst into flames, the remaining three experiments were forced into flaming combustion as noted in table 21. This table also summarizes the burn facility data at the time of maximum $C O$ concentration. The first foam 32 chair experiment self-ignited at 57.8 minutes into the experiment. The time delay from when the burner was turned on (or the selfignition time) to the maximum $C O$ concentration in the burn room varied from 2.3 minutes for the first foam 32 chair experiment to 17 minutes for the second foam $32 \mathrm{X}$ chair experiment. The other two experiments had about five minute delays. The reason for this variation is unclear, since this does not 
correlate with variations in mass loss rate. There was an additional delay of up to one minute for the maximum Co concentration to be detected in the target room. The mass loss rates for these experiments were all about $26 \mathrm{~g} / \mathrm{s}$. They resulted in upper compartment temperatures in excess of $600^{\circ} \mathrm{C}$. (For the second foam 32 chair experiment, this is estimated from lower compartment temperatures in the other experiments.)

All flaming combustion gas data (table 21) were dramatically different from those of smoldering combustion (table 19). Oxygen concentrations in the burn room dropped below 3 percent, while co concentrations exceeded 10,000 ppm (the instrument limit) and $\mathrm{CO}_{2}$ values were varied from $14 \%$ to $16.7 \%$. These values persisted for less than five minutes. The gas and temperature data appear to indicate that, once flaming combustion has been initiated, the resulting atmospheres that develop from the two foams do not greatly differ. The exception, at first glance, is that $\mathrm{HCN}$ production, as measured in the burn room, is greater for the non-treated foam. This could be misleading because the HCN concentration is a function of when the sample is taken. The maximum HCN concentration (1320 ppm) was detected in the second foam 32 chair experiment. This sample was taken almost at the same time that the Co concentration was reaching its peak value. Because the first foam 32 mock-up assembly self-ignited, the gas sample with the maximum $H C N$ value was taken almost 15 minutes after flaming was initiated. Similarly, the foam $32 \mathrm{X}$ chair samples, which were taken before the maximum CO concentration was achieved, may have been taken too early to detect the true maximum HCN concentration. The importance of sample timing can be seen by comparing the maximum HCN concentration for the analytical tests (table 18) of the foam 32 chair (1360 
ppm) to the animal exposure tests (table 21) of the foam $32 \mathrm{X}$ chair ( $460 \mathrm{ppm}$ ). This suggests that the foam 32 chair produced more $\mathrm{HCN}$ than the foam $32 \mathrm{X}$ chair. More experiments with more frequent sampling for $\mathrm{HCN}$ are needed to determine if these two foams produced different yields of HCN. A continuous or integrating technique for $\mathrm{HCN}$ measurement needs to be developed to be absolutely sure that peak concentrations are not missed.

The target room data (table 21), damped by gas transport between compartments, appear to be stable for a longer period of time. Therefore, they should provide a more sound basis for comparison of HCN concentration. The target room data indicate that there is little difference between gas data for the two types of foam. The minimum oxygen concentrations were about the same for all four experiments - $12 \%$. Higher peak concentrations of $C O$ were measured in the foam $32 \mathrm{X}$ chair experiments, but the $\mathrm{CO}_{2}$ values were lower in these experiments compared to the foam 32 chair experiments.

Conditions in the animal exposure chambers for the flaming phase of the experiments are compiled in table 22. While extremely high temperatures were always recorded in the burn room $\left(680^{\circ} \mathrm{C}\right)$, the animal exposure chambers connected to the burn room had temperatures in the range of 23 to $41^{\circ} \mathrm{C}$. In general, the CO concentration varied from 750 to $2900 \mathrm{ppm}$ and the HCN concentration range was 20 to $145 \mathrm{ppm}$. Only one flaming exposure resulted in no deaths ... the foam 32 chair experiment, sampling from the target room. During this exposure, the $\mathrm{CO}(750 \mathrm{ppm}$ ) and $\mathrm{HCN}$ (38 ppm) concentrations were very low. This may have been due to insufficient sampling time (nine minutes) for the first post-flaming exposure. While, in all cases, the first animal 
exposure chamber following flaming contained a mixture of smoldering smoke and post-flaming smoke, this particular chamber probably contained more smoldering smoke because of the short refilling time which was further aggravated by the propagation delay of the smoke from the burn room to the target room. Most animals exposed to flaming decomposition products died within-exposure. However, two experiments, both foam 32 experiments, had post-exposure deaths and, in one case, two animals survived the 14 day post-exposure period. In these experiments, the CO concentrations were 2050 and 2200 ppm, with HCN concentrations of about $20 \mathrm{ppm}$ both and $\mathrm{CO}_{2}$ concentrations of about 5 percent.

\subsection{Discussion}

\subsection{Polyurethane Foam, Non-Fire Retarded}

In comparing test results from the various experimental conditions used in this program, much thought was directed towards the effect of different thermal exposures on the overall yields of $\mathrm{CO}, \mathrm{CO}_{2}$, and $\mathrm{HCN}$. Table 23 presents a comparison of the yield values for $\mathrm{CO}$ and $\mathrm{CO}_{2}$ from all four sets of conditions under which the non-treated polyurethane foam was tested. Table 24 presents the overall HCN yields for those test conditions where HCN was measured for the same polyurethane foam.

Since the absolute yields for these three gases may well be a function of a number of external parameters (i.e., sample size, sample heating rate, sample configuration, sample assembly, etc.), relative gaseous yields are more 
meaningful. The $\mathrm{CO}_{2}$ to $\mathrm{CO}$ ratio for the four tests under flaming and nonflaming or smoldering conditions are listed in table 25. Under flaminginitiated conditions, the $\mathrm{CO}_{2} / \mathrm{CO}$ ratio was relatively constant (50 to 80 ) for all tests, with or without a cover fabric, except for the Cone Calorimeter foam-only test which had a $\mathrm{CO}_{2} / \mathrm{CO}$ ratio of approximately 200 . This indicates that while all of the flaming tests are well ventilated, the Cone Calorimeter was more efficient in burning the foam alone than with a cover fabric. The non-flaming Cone Calorimeter tests of the foam alone resulted in a combustion efficiency comparable to the flaming tests under other test conditions. Smoldering yield ratios were not consistent among the four test procedures.

Pre-smoldering of the foam chair assemblies in the furniture calorimeter and the three compartment experiments, resulted in a smoldering yield ratio of 40 for the furniture calorimeter and 7 for the large-scale tests. After the transition to flaming, the yield ratio of $\mathrm{CO}_{2} / \mathrm{CO}$ was 30 for both chair assembly tests. These differences cannot be explained at present.

Table 26 lists the HCN to CO yield ratios for those tests where both $\mathrm{HCN}$ and CO were measured. In general, the data shows that fewer than 10 parts of $\mathrm{HCN}$ are produced for 100 parts of CO. The NBS toxicity test under flaming conditions is a more efficient $\mathrm{HCN}$ generator ( $\mathrm{HCN} / \mathrm{CO}$ is 0.09 ) than any of the other three tests (The HCN/CO range is $<0.01$ to 0.04 .) The yield ratio of $\mathrm{HCN}$ to $\mathrm{CO}$ allows one to estimate the concentration of $\mathrm{HCN}$ in a specified volume can be determined, for this foam under similar combustion conditions from $\mathrm{CO}$ measurements. The lethality of $\mathrm{CO}, \mathrm{CO}_{2}$, and $\mathrm{HCN}$ in combination is discussed in section 4.3 
The small-scale toxicity results indicate that during the non-flaming decomposition of foam 32 essentially no within-exposure deaths were observed. This was also the case during smoldering exposures in the large-scale tests (table 20). Post-exposure deaths were seen in the small-scale toxicity tests as a result of non-flaming exposures from the polyurethane foam 32 (table 1 ) and the cotton upholstery fabric (table 3 ). The $\mathrm{LC}_{50}$ values were $39 \mathrm{mg} / \ell$ and $28 \mathrm{mg} / \ell$, respectively, based on mass loading. In the large-scale tests, no post-exposure deaths were observed following any smoldering exposure. Based on mass consumed, the comparable small-scale data were approximately $35 \mathrm{mg} / \ell$ for the polyurethane foam 32 and $26 \mathrm{mg} / \ell$ for the Haitian cotton. The minimum concentration for which deaths were observed was $32.9 \mathrm{mg} / \ell$ and $23.6 \mathrm{mg} / \ell$ (on a mass consumed basis) for the polyurethane foam 32 and cotton, respectively. Assuming a well mixed atmosphere in the large-scale burn facility, the lower limit loading for the smoldering phase of the large-scale experiments was calculated to be $33 \mathrm{mg} / \ell$ in the animal exposure chamber. If less than the total burn facility volume was filled with smoke then the concentration of smoke at the sampling point would be higher. Therefore, the concentrations of smoke based on mass consumed in the small-scale and large-scale tests were comparable and do not explain the differences in post-exposure deaths.

In the small-scale toxicity tests, no within- or post-exposure deaths resulted from 30 minute exposures to the flaming decomposition products produced either by the polyurethane foam 32 or by the cotton upholstery fabric. The $\mathrm{LC}_{50}$ values for these two materials were in excess of $40 \mathrm{mg} / \ell$ for the polyurethane foam 32 and $50 \mathrm{mg} / \ell$ for the cotton fabric. On the other hand, in 
the large-scale flaming tests 10 of the 12 animals exposed to the burn room atmosphere died. Six died within exposure to the gases produced during postflaming of the mock-up upholstery assembly. Three died within-exposure and one died post-exposure from the second set of animals exposed to the postflaming atmosphere. The material loading in the atmosphere based on mass consumed for the first set and second set of animals was $51 \mathrm{mg} / \ell$ and $52 \mathrm{mg} / \ell$, respectively. These values were thus significantly higher than the exposures in the NBS small-scale toxicity test method and probably account for the deaths seen in the large-scale tests and not observed in the small-scale toxicity tests. Target room exposures showed that lethal conditions were also developed in a compartment at some distances from the room of fire origin. The lower limit material loading in the animal exposure chamber based on mass consumed was $21 \mathrm{mg} / \ell$ for animal set one (no deaths occurred) and $40 \mathrm{mg} / \ell$ for animal set two ( 5 animals died within exposure and one died post-exposure. Again, if the mixing of the combustion products was not complete throughout the large-scale burn facility, these concentrations may be lower than the actual concentrations and may explain the deaths observed.

\subsection{Polyurethane Foam, Fire Retarded}

Table 27 lists the $\mathrm{CO}$ and $\mathrm{CO}_{2}$ yields for the fire retarded polyurethane foam tested by the four procedures described in this report under flaming and nonflaming or smoldering decomposition. Table 28 presents the HCN yield data for the three tests (NBS toxicity test, furniture calorimeter, and large-scale compartment tests) where HCN was measured. 
A comparison of the $\mathrm{CO}_{2}$ to $\mathrm{CO}$ ratio (table 29) shows that all of the tests resulted in a narrow ratio range of 15 to 40 under flaming conditions and inconsistent results, ranging from 5 to 60 , during non-flaming or smoldering combustion.

Table 30 compares the $\mathrm{HCN}$ to $\mathrm{CO}$ yield ratio for the fire retarded polyurethane foam. As was noted previously (section 4.1), 10 parts or less of HCN are produced for every 100 parts of CO. The NBS toxicity test is twice as efficient in generating $\mathrm{HCN}$ ( $\mathrm{HCN} / \mathrm{CO}$ is 0.1 ) as any of the other three test procedures ( $\mathrm{HCN} / \mathrm{CO}$ is $<0.001$ to 0.05$)$. Lethality of the combination of $\mathrm{CO}$, $\mathrm{CO}_{2}$, and $\mathrm{HCN}$ is discussed in the next section.

The small-scale toxicity results for the fire retarded polyurethane foam (table 2) indicated that the smoke generated during non-flaming decomposition had an $\mathrm{LC}_{50}$ of $28 \mathrm{mg} / \ell$ compared to a flaming decomposition $\mathrm{LC}_{50}$ of $27 \mathrm{mg} / \ell$, based on mass loading. Based on mass consumed, the LC $_{50}$ for the non-flaming condition was approximately $23 \mathrm{mg} / \ell$ and $26 \mathrm{mg} / \ell$ for the flaming condition. The minimum concentrations at which deaths were observed with this material were $19.4 \mathrm{mg} / \ell$ and $23.9 \mathrm{mg} / \ell$ (based on mass consumed) for the non-flaming and flaming conditions, respectively. The lower limit material concentration based on mass consumed (which includes both the polyurethane foam $32 \mathrm{X}$ and cotton upholstery fabric) calculated in the animal exposure chambers for the smoldering phase of the large-scale experiments was $38 \mathrm{mg} / \mathrm{l}$ (table 20). No animals were observed to die from this material concentration. For the largescale flaming chair experiments, the concentration of consumed material (table 
22) was approximately $68 \mathrm{mg} / \mathrm{l}$ and $64 \mathrm{mg} / \ell$ for the first and second sets of post-flaming animals exposed to the combustion products from the burn room. Under these conditions, all animals were observed to die when exposed for 30 minutes. Target room exposures showed similar lethal conditions. In all cases, deaths occurred at mass consumed concentrations in excess of those used in the small-scale toxicity test method. Therefore, it is necessary, in future experiments, to include dilution of the smoke from the flaming largescale tests in order to be better able to compare with the small-scale. experimental results. The presence of excessive amounts of $\mathrm{CO}, \mathrm{CO}_{2}$, and $\mathrm{HCN}$ may have masked the effects of other toxicants.

A comparison of non-flaming small-scale toxicity results with smoldering large-scale results showed that animal deaths were generally observed to occur post-exposure in the small-scale toxicity tests and no animals died in the large-scale tests within- or post-exposure. Even in the small-scale toxicity tests, under flaming conditions, some of the deaths from the fire retarded foam occurred post-exposure. Since all the animals in the large-scale fire retarded foam experiments died during the 30 minute exposure period of the flaming tests, it is not clear as to whether post-exposure deaths would have occurred at lower smoke concentrations.

\subsection{Three Gas Model}

Recent results [30] on the toxicity of $\mathrm{CO}, \mathrm{CO}_{2}$ and $\mathrm{HCN}$ alone and in various combinations using rats have shown that the 30 minute $\mathrm{LC}_{50}$ values for these individual gases in air are: 


\begin{tabular}{|lr|}
\hline $\mathrm{GaS}$ & $\mathrm{LC}_{50} \frac{(\mathrm{ppm})}{4600}$ \\
$\mathrm{CO}$ & $>180000$ \\
$\mathrm{CO}$ & 160 \\
\hline
\end{tabular}

In general, no animals were observed to die from a 30 minute co exposure below 4100 ppm and no post-exposure deaths occurred at any concentration. However, when $\mathrm{CO}$ and $\mathrm{CO}_{2}$ were combined, the presence of $5 \% \mathrm{CO}_{2}$ increased the toxicity of CO such that animals died from 30 minute exposures of $2500 \mathrm{ppm}$ of $\mathrm{CO}$. Some of these deaths occurred within 24 hours of the experiment. The combination of $\mathrm{CO}$ and $\mathrm{HCN}$ showed an additive interaction. It was empirically determined that this effect could be modelled by:

$$
\frac{[\mathrm{CO}]}{\mathrm{LC}_{50}(\mathrm{CO})}+\frac{[\mathrm{HCN}]}{\mathrm{LC}_{50}(\mathrm{HCN})} \geq 1
$$

Values below 1 are indicative of no expected animal deaths, while a value equal to or more than 1 indicates that animals would be expected to die from the exposure. This model has recently been modified by Levin et al. [29] to include the effect of $\mathrm{CO}_{2}$ on the likelihood of observing deaths from a combination of $\mathrm{CO}, \mathrm{CO}_{2}$, and $\mathrm{HCN}$. The modified model is:

$$
\frac{\mathrm{m}[\mathrm{CO}]}{\left[\mathrm{CO}_{2}\right]-\mathrm{b}}+\frac{[\mathrm{HCN}]}{\mathrm{LC}_{50}(\mathrm{HCN})} \geq 1
$$

where $[\mathrm{CO}],\left[\mathrm{CO}_{2}\right]$, and $[\mathrm{HCN}]$ are the average atmospheric test concentrations during a 30 minute exposure period and $\mathrm{LC}_{50}(\mathrm{HCN})$ is the (lethal) concentration of HCN that will kill $50 \%$ of the exposed animals. The terms $m$ and $b$ are equal to -28 and 117000 , respectively, if the atmospheric concentration of $\mathrm{CO}_{2}$ is $\leq 5 \%$, and equal to 150 and -313000 , respectively, for $\mathrm{CO}_{2}$ concentrations $>5 \%$. 
An empirical estimate of the error in distinguishing between agreement and disagreement in equation $B$ can be made based on a review of previous results [30]. The data indicates that variations in the left hand side of equation $B$ of the order of $\pm 20 \%$ is a reasonable estimate. This estimate takes into account the uncertainties inherent in deriving equation $B$ as well as measurement uncertainties associated with $\mathrm{CO}, \mathrm{CO}_{2}$, and $\mathrm{HCN}$ in a fire environment.

Using the gas concentrations generated from the NBS toxicity test method for the current polyurethane foams (tables 1 and 2), the pure gas model, equation $B$, showed that lethal amounts of these gases were not produced in any of the non-treated foam tests (table 31 ) or the non-flaming treated foam tests (table 32). The treated foam, in the flaming mode had all but one test exceed the model criterion and one test that was within $95 \%$ of the criterion. For these experiments, post-exposure deaths occurred within 24 hours after exposure. For the remaining tests that did not approach or exceed the model criterion, post-exposure deaths were observed from the second day onward. This is indicative of the presence of additional toxicants or other factors not included in the 3 -gas model which impact on the model.

For the Haitian cotton upholstery fabric, the CO concentration was less than $70 \%$ of the $\mathrm{LC}_{50}$ of pure $\mathrm{CO}$. Since no $\mathrm{HCN}$ was produced and the $\mathrm{CO}_{2}$ concentration never approached 5\%, the synergistic interaction between $\mathrm{CO}$ and $\mathrm{CO}_{2}$ can not be assumed. Therefore, in these experiments, other toxic combustion products or factors contributed to the deaths. The deaths which occurred from all experiments not meeting the model criterion were probably 
due to the presence of other toxic combustion products or to undetermined factors.

The data from table 22 were used in the 3-gas model to calculate whether the test animals would die from the $\mathrm{CO}, \mathrm{CO}_{2}$, and $\mathrm{HCN}$ concentrations measured in the animal exposure chambers after the initiation of flaming. The results are listed in table 33 for the treated and non-treated polyurethane foam chair assemblies. Based on this model, there was sufficient $\mathrm{CO}, \mathrm{CO}_{2}$, and $\mathrm{HCN}$ to account for the observed deaths. The calculations and animal mortality in table 33 indicate that in those tests where the values calculated according to equation (B) are equal to or greater than 1 , all of the animals died withinexposure. In one case the calculated value from the model was 0.4 and the experimental results indicated no animal deaths. This shows that a calculated value between 0.9 and 1 coincides with less than the maximum number of animal deaths.

Table 34 shows that the deaths in the small-scale experiments for non-treated polyurethane foam and cotton fabric at or near the $L_{50}$ concentration could not be attributed solely to the presence of $\mathrm{CO}, \mathrm{CO}_{2}$, and $\mathrm{HCN}$. This implies that additional toxicants were present in the decomposition products generated. These products need to be identified and incorporated into an expanded toxicity gas model. The application of this 3 -gas model to the large-scale chair experiments indicates that the responses of animals exposed to the smoldering atmosphere and the post-flaming atmosphere were consistent with the measured concentrations of the three gases. It also correctly predicts the lack of deaths from animals exposed to the flaming conditions in 
the small-scale test method. Although other gaseous toxicants may have been present, no additional toxicants are necessary to account for animal responses.

Again, applying the 3-gas model, as was done previously, table 35 shows that for the polyurethane foam $32 \mathrm{X}$ tested in the small-scale toxicity test at or near the $\mathrm{LC}_{50}$ concentration under flaming conditions, $\mathrm{CO}, \mathrm{CO}_{2}$, and $\mathrm{HCN}$ can reasonably account for the within-exposure deaths. For the post-flaming period of the large-scale tests, there was more than enough of these gases to kill the animals, so the presence of other possible toxicants cannot be assessed. For the large-scale smoldering tests and for the remaining smallscale tests, the model predicts no animal deaths. However, some animals died during the post-exposure observation period in the small-scale toxicity tests under non-flaming conditions for both the foam and the fabric. This indicates the presence of other toxic species. As stated previously, the unknown gases need to be identified and the 3 -gas model expanded to incorporate additional toxicants.

\section{0 Conclusions}

The bases for a detailed comparison between the toxicity of smoke from smalland large-scale burns of these materials are best made by determining:

- The predictability of test animal deaths using the $\mathrm{N}$-gas model with $\mathrm{N}=3\left(\mathrm{CO}_{2}, \mathrm{CO}\right.$, and $\left.\mathrm{HCN}\right)$; 
- The nature of those deaths, whether within-exposure or postexposure; and

- The relative contributions to lethality (relative yields) of $\mathrm{CO}_{2}$, $\mathrm{CO}$, and $\mathrm{HCN}$.

The toxicity of the thermal decomposition products from two flexible polyurethane foams (with and without a fire retardant) and a cotton upholstery fabric was evaluated by using the NBS Toxicity Test Method. These results were compared to the toxicological results obtained from large-scale three compartment fire tests of mock-up chair assemblies composed of the same flexible polyurethane foam and cotton upholstery fabric held in a steel frame. The NBS Cone Calorimeter and the NBS Furniture Calorimeter were used to measure other fire property data such as heat release, effective heat of combustion, specific gas species yields, and smoke obscuration. These latter two tests provided baseline fire property data under well-ventilated conditions which were used to determine the effect of combustion differences between the NBS Toxicity Test and the large-scale room burns. In addition, the data is necessary for subsequent evaluation of the predictive capabilities of computer fire models.

In general, the Cone Calorimeter and the Furniture Calorimeter showed that the NBS Toxicity Test and the large-scale burns were performed under comparable ventilation conditions, as defined by the $\mathrm{CO}_{2} / \mathrm{CO}$ ratio. While the large-scale burns and the Furniture Calorimeter tests resulted in comparable HCN/CO ratios during flaming combustion, the NBS Toxicity Test had an HCN/CO ratio that was approximately twice as large. 
With regard to the degree of toxicity observed in the NBS Toxicity Test and the large-scale burns, two types of combustion conditions were investigated.

- During non-flaming or smoldering combustion, essentially no animal deaths were noted during the thirty minute exposures. In both sets of experiments, the respective concentrations of $\mathrm{CO}$, $\mathrm{CO}_{2}$, and $\mathrm{HCN}$ were comparable. Post-exposure deaths were observed following the NBS Toxicity Test of both foams and cotton fabric, but not following exposures to the smoldering phase of the largescale burns.

- During flaming combustion, neither foam 32 nor cotton fabric produced with-in or post-exposure deaths up to the maximum material concentration obtainable in the NBS Toxicity Test. Within and post-exposure deaths were observed for foam $32 \mathrm{x}$. At somewhat higher material concentrations, with-in and post-exposure deaths were observed in the large-scale room burns for both foam chair assemblies.

N-gas model calculations were preformed on the gas data from both test procedures. The calculations showed that the $\mathrm{N}$-gas model which presently includes the combined toxicological effects of $\mathrm{CO}, \mathrm{CO}_{2}$, and $\mathrm{HCN}$ can explain the toxicity of the flaming tests. However, for the non-flaming tests, it is necessary to include additional terms into the $\mathrm{N}$-gas model in order to explain the observed animal responses.

The following paragraphs present a more detailed set of conclusions according to the three points of comparison between small-and large-scale toxicity 
tests previously enumerated. It is implicit that all of the conclusions are limited to the few materials involved in this study.

1. Prediction of Mortality

Under flaming conditions in the small-scale test, these materials (except foam 32X) did not generate a toxic atmosphere at the highest concentration tested. For the one flaming case (foam $32 \mathrm{X}$ ) in which an $\mathrm{LC}_{50}$ could be determined using the NBS toxicity test method, the 3-gas model correctly predicted that some animals should die. To explain the primarily post-exposure deaths from the non-flaming combustion products from all three materials, additional toxic species need to be added.

In all of the large-scale room fires, the 3-gas model correctly predicted the within-exposure survival or death of the animals. In most of these cases, the concentrations of the three gases were so high or so low that the importance of other possible (unknown) toxic species could not be assessed. However, in the two cases where the model predicted that some but not all of the animals would die, that was indeed observed. All of these were for exposures to atmospheres after the transition to flaming combustion.

The post-exposure deaths observed in the small-scale, non-flaming experiments were not observed following the smoldering large-scale experiments, although in some cases comparable concentrations of $\mathrm{CO}, \mathrm{CO}_{2}$, and $\mathrm{HCN}$ were generated and the material mass consumed was similar. Since the 3 -gas model does not explain post-exposure deaths beyond 24 hours, there are probably additional 
toxic species that need to be measured in the small-scale tests. The possibility exists that some of these condensible toxic components of the smoke may have been lost in the sampling lines that transport the smoke from the large-scale rooms to the animals exposure chambers.

Therefore, for flaming combustion, we feel guarded optimism about the use of the NBS toxicity test method to replicate full-scale performance and the predictive sufficiency of the 3-gas model. For non-flaming combustion,. the relationship between the two experimental scales awaits the extension of the model, the analytical measurements, and the smoke sampling technology.

\section{Comparison of Time of Mortality}

In the one flaming combustion case (foam $32 \mathrm{X}$ ) where test animals died in the NBS test method, many died post-exposure. In most of the sets of animals exposed to smoke from the flaming part of the large-scale experiments the smoke concentration was well beyond that needed to cause within-exposure deaths. However, in the two cases where the atmosphere was near the threshold of lethality, post-exposure deaths were observed. Again, there are grounds for guarded optimism that the NBS toxicity test is predictive.

The non-flaming, small-scale experiments and smoldering large-scale experiments agreed in that there were no within-exposure deaths. However, in the non-flaming, small-scale experiments, many animals died (post-exposure), whereas, in the smoldering, large-scale tests, no animals died. Thus, there is no basis for assessing the predictivity of the NBS toxicity test method. 
3. Relative Contributions to Lethality

The $\mathrm{CO}_{2} / \mathrm{CO}$ yield ratio is a good indicator of the degree of ventilation in the combustion. For flaming combustion, there is a remarkable level of agreement between the values of this ratio for all four types of tests in this study. In the various non-flaming modes, the furniture calorimeter, large-scale compartment tests and the NBS toxicity test method show remarkable agreement. In spite of the fact that the Cone Calorimeter is distinctly more ventilated than the other three test procedures, only the flaming non-treated polyurethane foam test exhibited an unusually high ventilation factor. With the exception, then, of this last case, one would expect some degree of predictivity of the relative contributions of $\mathrm{CO}$ and $\mathrm{CO}_{2}$ to the animal mortality from the small-scale data.

In the three methods (NBS toxicity test method, furniture calorimeter, and large-scale compartment experiments) where HCN was measured, the non-flaming or smoldering phases produced low concentrations of $\mathrm{HCN}$; flaming combustion produced higher concentrations. Under the ramped temperature conditions of the small-scale test, $\mathrm{HCN}$ concentrations were above the 30 minute $\mathrm{LC}_{50}$ value determined for pure HCN. HCN was an important toxicological factor in the chair burns once flaming had occurred. Its importance during the smoldering phase cannot be assessed since no animals died. Under conditions of the NBS toxicity test method, HCN was a factor in the toxicity of smoke only from flaming foams 32 and foam $32 \mathrm{X}$. While there was a near total lack of correlation between the various combustion methods for HCN yields, the HCN/CO 
ratio was, with one exception (NBS toxicity test - flaming mode), in reasonable agreement. More research is needed to determine the proper way to mirror the importance of HCN (and perhaps other trace toxicants) in smallscale combustion devices.

\subsection{Recommendations}

Further research is necessary to resolve the uncertainties revealed by this series of experiments. The following recommendations focus on the tests needed to clarify the reasons for the current lack of correlation.

1. Large-scale smoldering or non-flaming combustion tests should be conducted in a compartment of reduced volume in order to increase the gas concentrations.

2. Some smoldering combustion tests should involve in-place, 30 minute animal exposures rather than transferring the smoke to the animal exposure chambers or should otherwise try to minimize species losses that may have occurred in the sampling lines between the burn facility and the animal exposure chamber.

3. The varying relative importance of $\mathrm{HCN}$ and the unknown toxicant(s) raises the issue of comparability between oxidative pyrolysis and smoldering decomposition. True smoldering combustion should be studied 
in the NBS toxicity protocol. This can be accomplished with the cotton fabric and foam assemblies studied in this report.

4. Large-scale, flaming tests should be run in which the test animals are exposed to the combustion products at various dilutions. This will enable a more accurate determination of a full-scale $\mathrm{LC}_{50}$ and thus an assessment of whether other important toxicants may be present.

\subsection{Acknowledgments}

The authors gratefully acknowledge the assistance of Richard Zile, Tom Maher, Mel Womble, and Roy McLane in conducting the medium- and large-scale tests. The work of Gerald King and William Twilley on the cone calorimeter is greatly appreciated. Dr. Richard Gann provided important assistance in the interpretation of the results. Because of the limited amount of information available on large-scale animal testing procedures, we would especially like to thank the Consumer Product Safety Commission, Dr. Rita Orzel, project officer under contract no. 753-2388 (CPSC Task Order No. 85-4), for supporting in part a unique and much needed experimental program of this type. 


\subsection{References}

1. Karter, M. J., Fire Loss in the United States During 1984, Fire Journal, 49 (Sept. 1985).

2. Harwood, B., Consumer Product Safety Commission Internal Memorandum, (July 1986).

3. Lingenfelter, G. E., Progress in Fire Safety Technology: Furnishings and Contents - NFPA Activity, Presented at Joint Conference of the Fire Retardant Chemicals Association and the Society of the Plastic Industry (March 1986).

4. Loftus, J. J., Back-Up Report for the Proposed Standard for the Flammability (Cigarette Ignition) of Upholstered Furniture, U. S. Nat. Bur. Stand. NBSIR 78-1438 (1978).

5. Babrauskas, V. and Krasny, J. F., Prediction of Upholstered Chair Heat Release Rates from Bench-Scale Measurements, Fire Safety: Science and Engineering, ASTM STP 882, T. Z. Harmathy, Ed., American Society for Testing and Materials, Philadelphia (1985).

6. Fitzgerald, W. E., Combustion Product Generation for Toxicity Testing, Fire Retardant Chemicals Association, Fourth Annual Meeting, Washington, D. C. (March 1977).

7. Grand, A. F., Kaplan, H.L., Beitel, J. J. III, Switzer, W. G., and Hartze11, G. E., An Evaluation of Toxic Hazards from Full-Scale Furnished Room Fire Studies, Special Technical Publication 882, American Society for Testing and Materials (1986).

8. Alarie, Y., Anderson, R. C., Stock, M. F., Dombroske, R. L., Keller, L. W., Hayduk, L. W., and Park, R. E., Toxicity of Thermal Decomposition Products: An Attempt to Correlate Results Obtained in Small Scale with Large Scale Tests, J. Comb. Tox. 8:58-68 (1981).

9. Alarie, Y., Stock, M. F., Matijak-Schaper, M., and Birky, M. M., Toxicity of Smoke During Chair Smoldering Tests and Small Scale Tests Using the Same Materials, Fund. Appl. Tox. 3:619-626 (1983).

10. Braun, E., Krasny, J.F., Peacock, R.D., Paabo, M., Smith, G. F., and Stolte, A., Cigarette Ignition of Upholstered Chairs, J. Consumer Product Flamm., 9:167-183 (1982).

11. Flammability Information Package, State of California, Department of Consumer Affairs, Bureau of Home Furnishings, North Highlands, CA (1983). 
12. Important Consumer Information from UFAC, Upholstered Furniture Action Council, High Point, NC (1984).

13. Levin, B. C., Fowe11, A. J., Birky, M. M., Paabo, M., Stolte, A., and Malek, D., Further Development of a Test Method for the Assessment of the Acute Inhalation Toxicity of Combustion Products, U. S. Nat. Bur. Stand. NBSIR 82-2532, Gaithersburg, MD (1982).

14. Paabo, M., Birky, M. M., and Womble, S. E., Analysis of Hydrogen Cyanide in Fire Environments, J. Comb. Tox. 6:99-108 (1979).

15. Litchfield, J. T., Jr., and Wilcoxon, F., A Simplified Method of Evaluating Dose-effect Experiments, J. Pharmacol. and Exp. Therapeut. $96: 99-113(1949)$.

16. Packham, S. C., Frens, D. B., McCandless, J. B., Patajan, J. H., and Birky, M. M., A Chronic Intra-arterial Cannula and Rapid Technique for Carboxyhemoglobin Determination, J. Comb. Tox. 3:471-478 (1976).

17. Levin, B. C., Paabo. M., Bailey, C. S., and Harris, S.E., Toxicity of the Combustion Products from a flexible polyurethane foam and a Polyester Fabric Evaluated Separately and together by the NBS Toxicity Test Method, Fire Safety Science-Proceeding of the First International Symposium, Gaithersburg, MD, Hemisphere Publishing Corp., Washington, DC, pp 1111-1122 (1986).

18. Levin, B. C., Paabo, M., Fultz, M. L., Bailey, C., Yin, W., and Harris, S. E., An Acute Inhalation Toxicological Evaluation of Combustion Products from Fire Retarded And Non-Fire Retarded Flexible Polyurethane Foam and Polyester, Nat. Bur. Stand. (U.S.) Gaithersburg, MD, NBSIR 832791 (1983).

19. Levin, B. C., Paabo, M., Fultz, M. L., and Bailey, C. S., Generation of Hydrogen Cyanide from Flexible Polyurethane Foam Decomposed under Different Combustion Conditions, Fire and Materials, 9:3,125-133 (1985).

20. Babrauskas, V., Development of the Cone Calorimeter - - A Bench-Scale Heat Release Rate Apparatus Based on Oxygen Consumption, U. S. Nat. Bur. Stand. NBSIR 82-2611 (1982).

21. Huggett, C., Estimation of the Rate of Heat Release by Means of Oxygen Consumption Measurements, Fire and Materials, 4:61-5 (1980).

22. Babrauskas, V., Lawson, J. R., Walton, W. D., Twilley, W. H., Uphoistered Furniture Heat Release Rates Measured with a Furniture Calorimeter, U. S. Nat. Bur. Stand. NBSIR 82-2604 (1982).

23. Babrauskas, V., Will the Second Item Ignite?, Fire Safety J. 4:287-292 (1982).

24. Peacock, R. D., Davis, S., and Lee, B. T., Experimental Data for Model Validation, U. S. Nat. Bur. Stand. NBSIR (in preparation). 
25. McCaffrey, B. J., Quintiere, J. Q., and Harkleroad, M. F., Estimating Room Temperatures and the Likelihood of Flashover Using Fire Test Data Correlations, Fire Technology, 17:2, 98-119 (1981).

26. Babrauskas, V., Combustion of Mattresses Exposed to Flaming Ignition Sources Part I. Full-Scale Tests and Hazard Analysis, U. S. Nat. Bur. Stand. NBSIR 77-1290 (1977).

27. Lawson, J. R. and Quintiere, J. G., Slide-Rule Estimates of Fire Growth, U. S. Nat. Bur. Stand. NBSIR 85-3196 (1985).

28. Birky, M. M., Paabo, M., Levin, B. C., Womble, S. E., and Malek, D., Development of Recommended Test Method for Toxicological Assessment of Inhaled Combustion Products, U. S. Nat. Bur. Stand. NBSIR 80-2077. (1980).

29. Levin, B. C., Paabo, M., Gurman, J. L., and Harris, S. E., Effects of Exposure to Single or Multiple Combinations of the Predominant Toxic Gases and Low Oxygen Atmospheres Produced in Fires, (submitted to Fundamental \& Applied Toxicology).

30. Levin, B. C., Paabo, M., Gurman, J. L., and Harris, S. E., Exposure to Single or Multiple Combinations of the Predominant Toxic Gases and Low Oxygen Atmospheres Produced in Fires, Fund. Appl Toxicology (accepted for publication, 1986). 


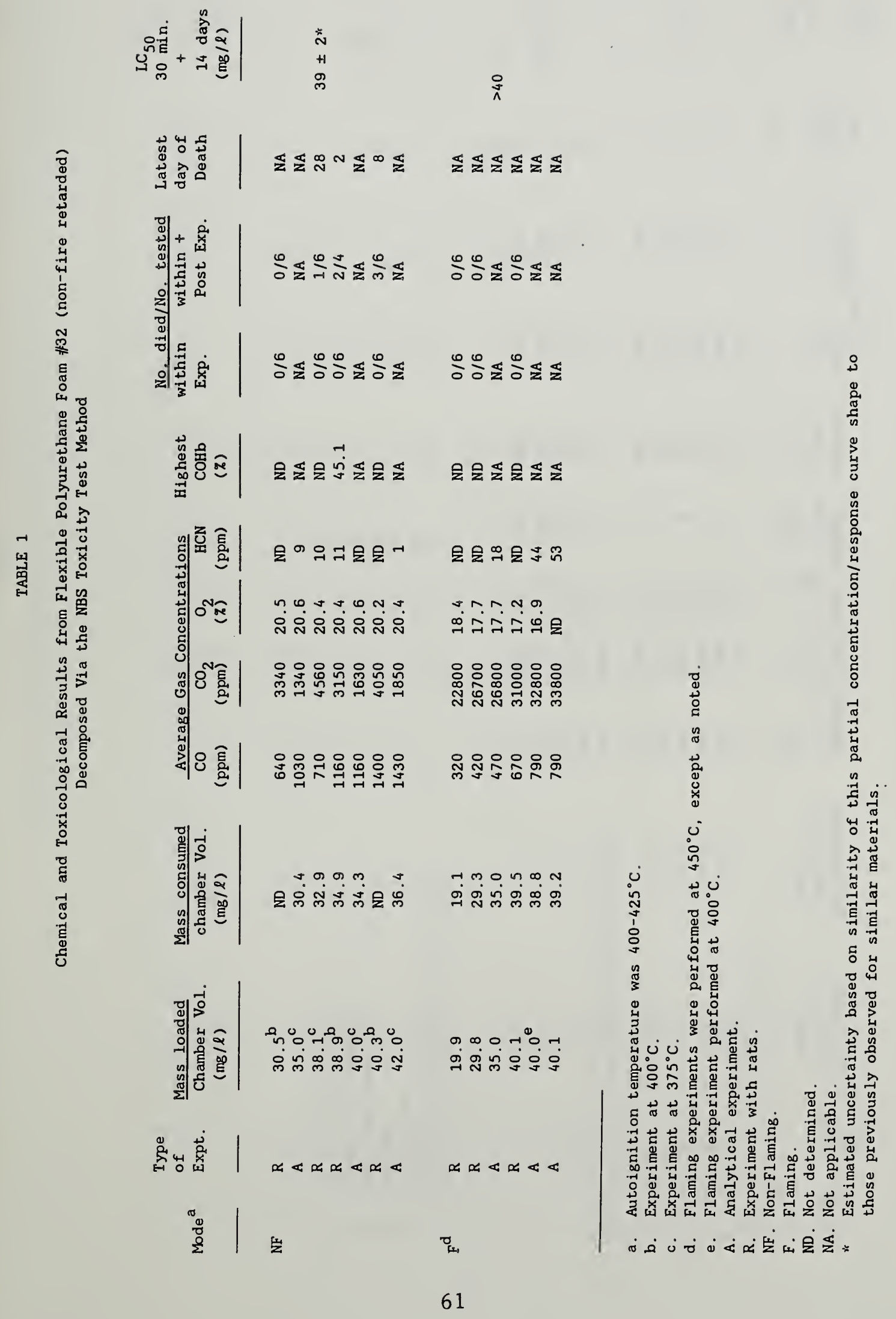




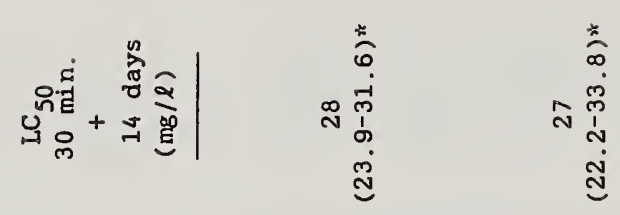

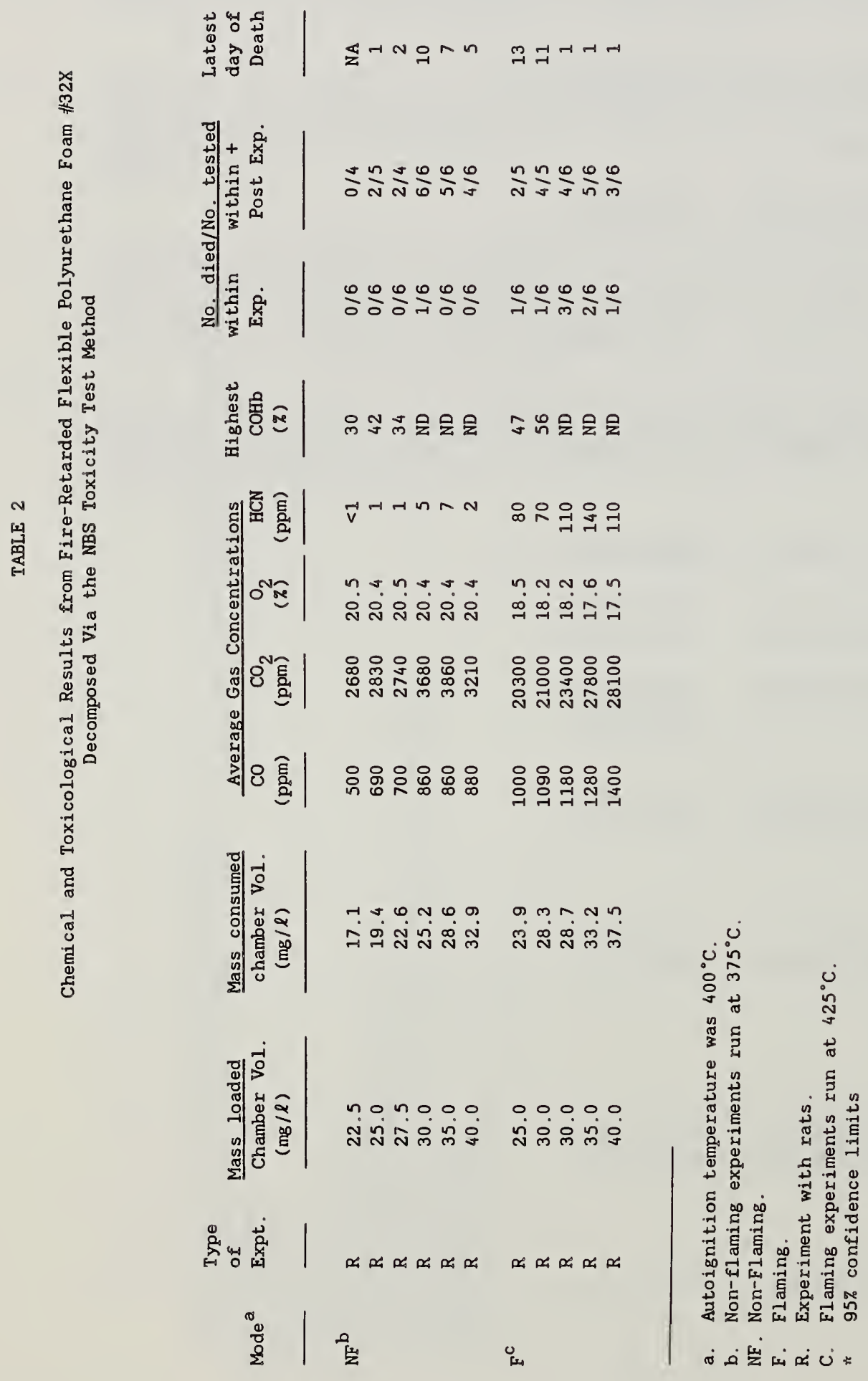




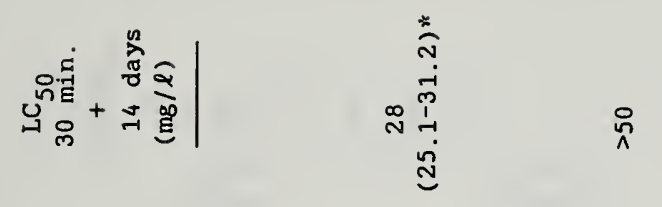

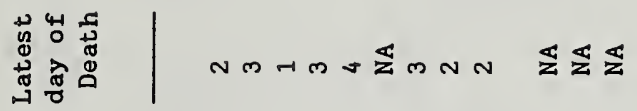

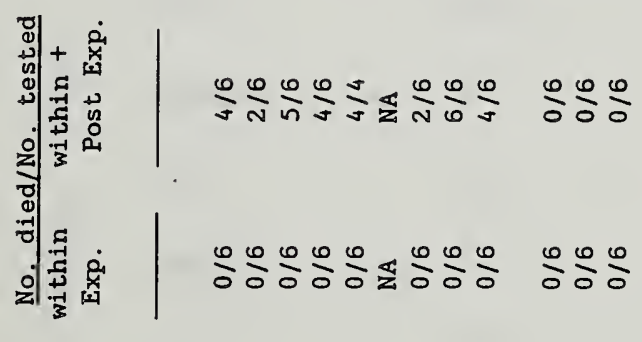

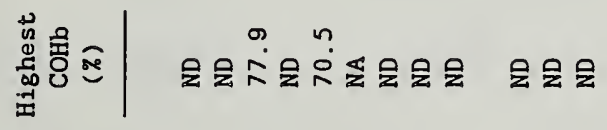

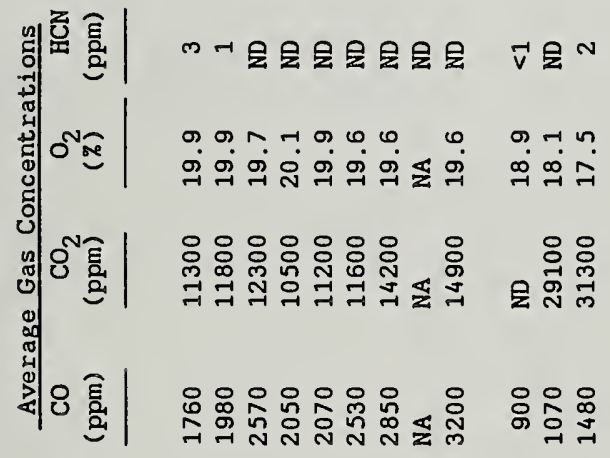

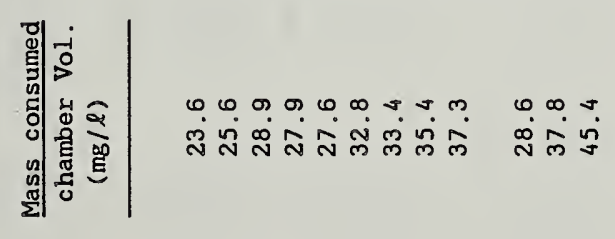

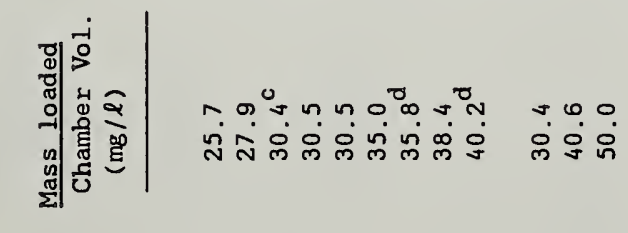

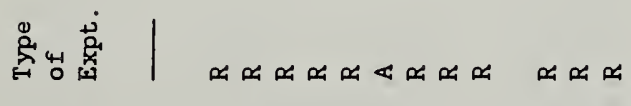
\begin{tabular}{l|l}
$\pi$ & \\
$\frac{0}{8}$ & $\frac{0}{2}$
\end{tabular}

$\stackrel{0}{i}$

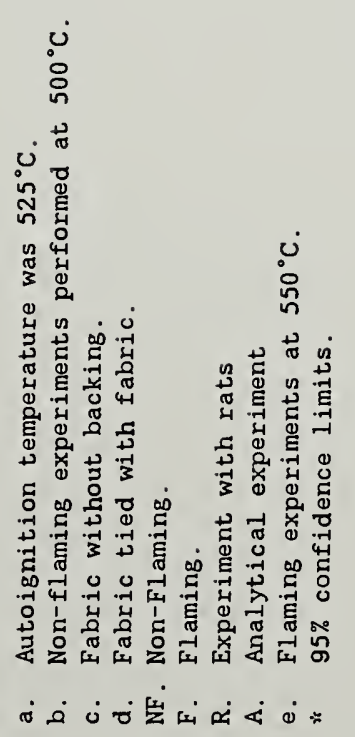




\section{TABLE 4}

Concentration of $\mathrm{CO}, \mathrm{CO}_{2}$, and $\mathrm{HCN}$ at the Calculated $\mathrm{LC}_{50}$ for Treated, $32 \mathrm{X}$, and Non-Treated, 32, Polyurethane Foam and Cotton Fabric

Material

$\longrightarrow$

Foam 32

Foam $32 \mathrm{X}$

Cotton

Cotton

Decomposition

Mode

\begin{tabular}{c}
$\mathrm{CO}$ \\
$(\mathrm{ppm})$ \\
\hline
\end{tabular}

$\mathrm{CO}_{2}$

(ppm)

HCN

$1 \mathrm{ppm})$

NF

F

NF

F

NF

F
1150
$>\quad 680$

680

1010

2090

$>1420$
7

$>33300$

$>40$

2850

3

85

10900

$>33100$

$\mathrm{NF}=$ Non-flaming

$F=$ Flaming 


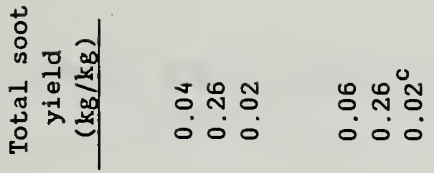

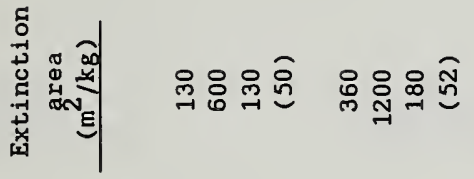

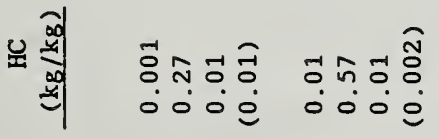

액ำ

๑青

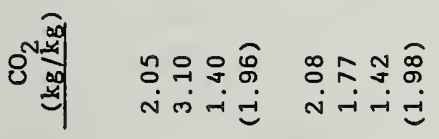

.

器器

के

峦

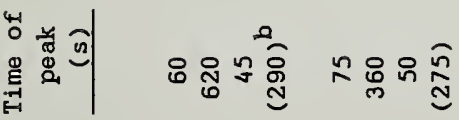

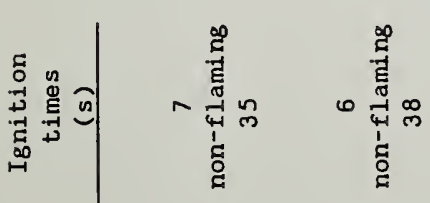

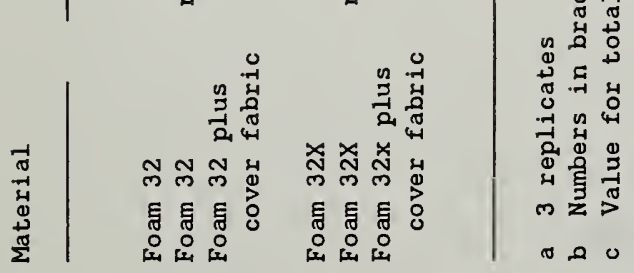


Average Yields of $\mathrm{CO}$ and $\mathrm{CO}_{2}$ for Treated and Non-Treated Foam Tested in the Cone Calorimeter

\begin{tabular}{|c|c|c|c|c|}
\hline Material & $\begin{array}{l}\text { Cotton } \\
\text { cover } \\
\end{array}$ & Mode & $\begin{array}{c}\mathrm{CO} \\
(\mathrm{kg} / \mathrm{kg})\end{array}$ & $\begin{array}{c}\mathrm{CO}_{2} \\
(\mathrm{~kg} / \mathrm{kg})\end{array}$ \\
\hline 32 & - & Flaming & $0.013 \pm 0.001$ & $2.34 \pm 0.13$ \\
\hline 32 & - & Non-Flaming & $0.040 \pm 0.002$ & $1.71 \pm 0.31$ \\
\hline 32 & + & Flaming & $0.033 \pm 0.004$ & $1.94 \pm 0.05$ \\
\hline $32 x$ & - & Flaming & $0.045 \pm 0.003$ & $1.13 \pm 0.91$ \\
\hline $32 \mathrm{X}$ & - & Non-Flaming & $0.039 \pm 0.002$ & $0.74 \pm 0.17$ \\
\hline $32 x$ & + & Flaming & $0.026 \pm 0.003$ & $1.62 \pm 0.26$ \\
\hline
\end{tabular}




\section{TABLE 7}

Flaming Ignition Furniture Calorimeter Tests

Observation

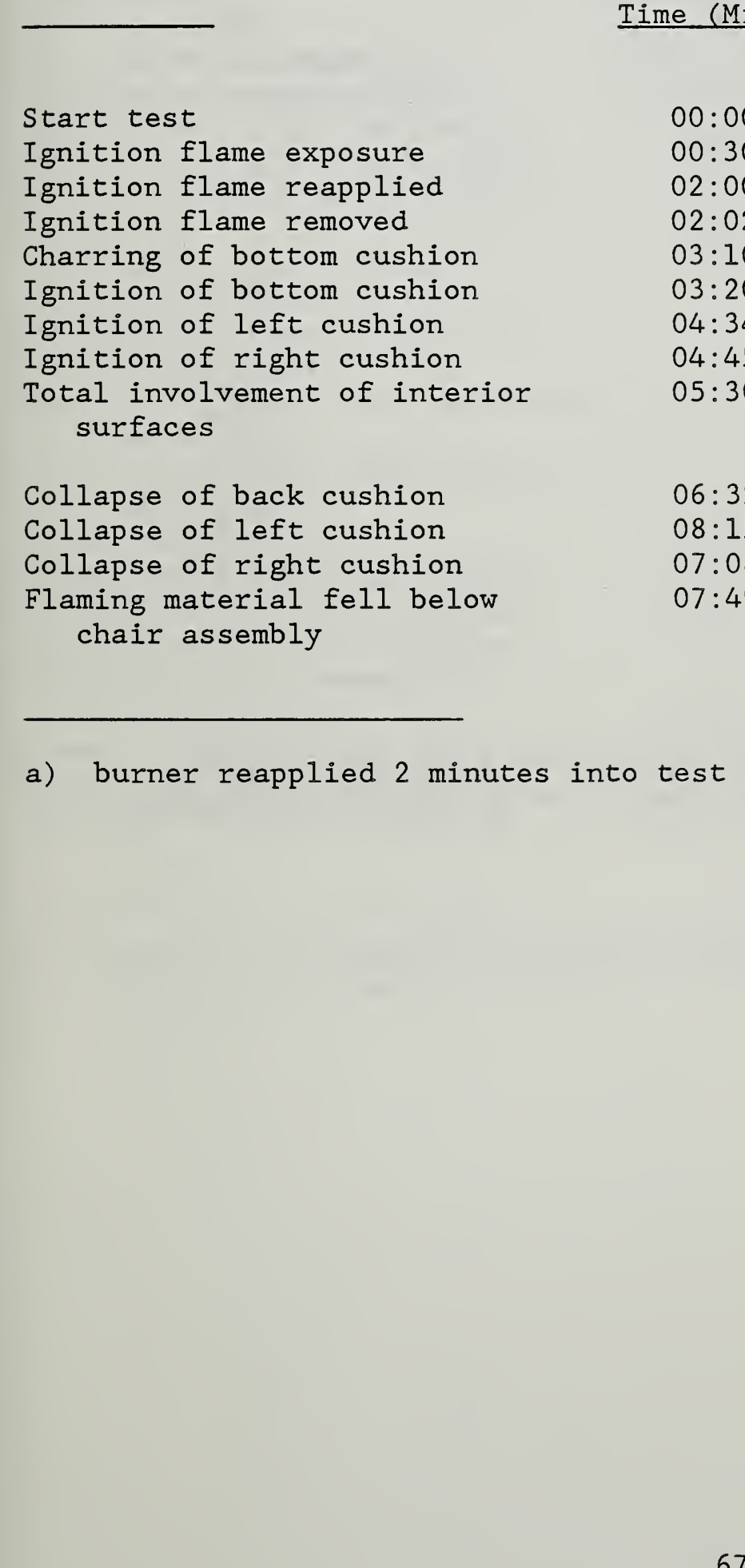




\section{TABLE 8}

HCN Yields for the Flaming Ignition of Treated, 32X, and Non-Treated, 32 , Polyurethane Foam and Cotton Fabric Mockup Upholstery Chairs Tested in the Furniture Calorimeter

HCN Yield

Time

(s)

330

360

390

420

540

540

570

600

630

660

750

780

900
32

$\frac{(\mathrm{kg} / \mathrm{kg} \times 1}{32}$

$32 \mathrm{X}$

$\left(\mathrm{kg} / \mathrm{kg} \times 10^{-3}\right)$

$8.7^{a, b}$

$1.3^{a}$

1.0

$1.5^{a}$

1.8

$2.0^{\mathrm{a}}$

3.7

$0.4^{\mathrm{a}}$

1.5

1.2

a) Designates sample taken from sampling port nearer the test sample

b) Based on HCN concentration at lower resolution of detection technique $(1.5 \mathrm{ppm})$. 
TABLE 9

Cigarette Initiated Transition Furniture Calorimeter Tests

Observation

Two cigarettes on mockup

Charring on bottom cushion

Charring on right side cushion

Charring on left side cushion

Discoloration of outer vertical surfaces

Charring on front surface of right side panel

Charring on front surface of left side panel

Charring on left front surface of bottom cushion

Charring on right front surface of bottom cushion

Burner application

Flames contact bottom cushion

Flaming on right side cushion

Flaming on left side cushion

Total flame involvement of interior surfaces

Flames dropping to platform

Right side cushion collapsing

Left side cushion collapsing
Foam 32

Time (min:sec)

$00: 00$

$04: 50$

$15: 30$

$16: 15$

$32: 50$

$33: 11$

$43: 00$

$35: 00$

$35: 00$

$59: 54^{a}$

$60: 04$

$60: 05$

$59: 54$

$60: 15$

$60: 20$

$60: 37$

$61: 06$
Foam 32X

Time (min:sec)

$00: 00$

$06: 15$

$16: 10$

$17: 45$

$51: 00$

$51: 30$

$46: 00$

$35: 00$

$60: 02^{\mathrm{b}}$

$65: 58$

$66: 25$

$66: 38$

$66: 59$

$67: 00$

$67: 22$

$67: 40$

a) assembly self-flamed on left side cushion

b) butane flame removed at 62:50 
HCN Yields for the Smoldering to Flaming Tests of Treated, 32X, and NonTreated, 32, Polyurethane Foam and Cotton Fabric Mockup Upholstery Chairs in the Furniture Calorimeter

HCN Yield

\begin{tabular}{l}
$\begin{array}{l}\text { Time } \\
(\mathrm{s})\end{array}$ \\
\hline 1800 \\
2400 \\
2405 \\
3000 \\
3600 \\
3615 \\
3660 \\
3705 \\
3720 \\
3840 \\
3900 \\
3960 \\
3960 \\
4020 \\
4050 \\
4080 \\
4140
\end{tabular}

$$
\begin{gathered}
\frac{\left(\mathrm{kg} / \mathrm{kg} \times 10^{-3}\right)}{0.5^{\mathrm{b}}} \\
1.4^{\mathrm{a}, \mathrm{b}} \\
0.2^{\mathrm{a}} \\
1.1^{\mathrm{a}, \mathrm{b}} \\
0.1^{\mathrm{a}} \times \\
0.2^{\mathrm{b}}
\end{gathered}
$$$$
\left(\mathrm{kg} / \mathrm{kg} \times 10^{-3}\right)
$$

$$
0
$$$$
0^{a}
$$$$
0
$$$$
0
$$$$
0.5^{\mathrm{b}}
$$

\section{0}

0

$5^{\mathrm{b}}$

${ }^{0}$
$0.3^{b}$
$1.8^{a}$
$1.5^{a}$
7.1
$6.3^{a}$
1.3
$<0.1$

a) Designates sample taken from sampling point nearer the test sample

b) Based on HCN concentration at lower resolution of detection technique (1-5 ppm). 


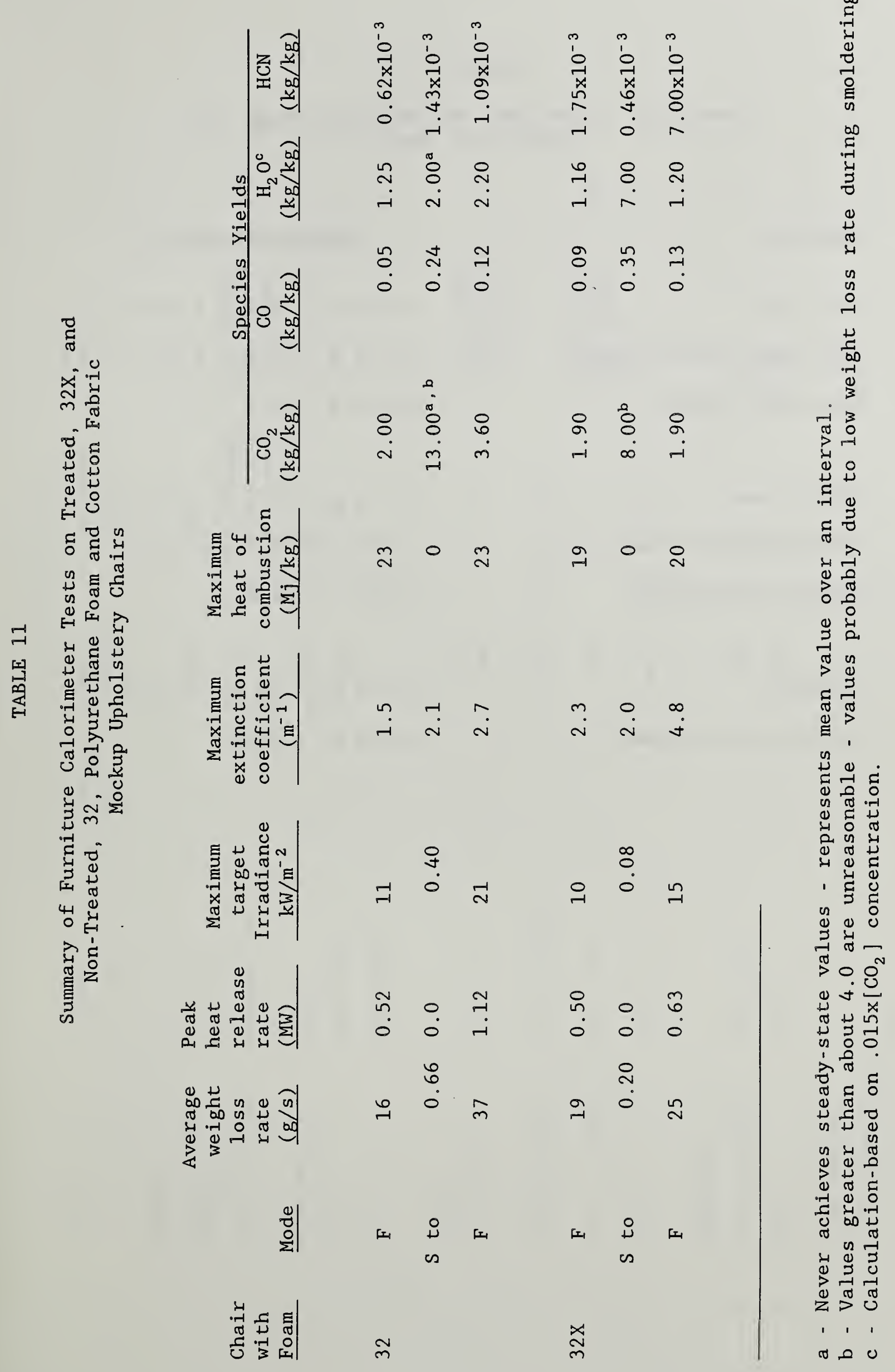




\section{TABLE 12 .}

\section{Dimensions of Corridor and Adjoining Rooms for Large-Scale Tests}

Location

Burn room

Burn room stub corridor

Burn room doorway

Target room

Target room stub corridor

Target room doorway

Corridor

Corridor exit doorway
Dimensions (m)

$2.34 \mathrm{~W} \times 2.34 \mathrm{~L} \times 2.16 \mathrm{H}$

$1.02 \mathrm{~W} \times 1.03 \mathrm{~L} \times 2.00 \mathrm{H}$

$0.81 \mathrm{~W} \times 1.60 \mathrm{H}$

$2.24 \mathrm{~W} \times 2.22 \mathrm{~L} \times 2.43 \mathrm{H}$

$0.79 \mathrm{~W} \times 0.94 \mathrm{~L} \times 2.04 \mathrm{H}$

$0.79 \mathrm{~W} \times 2.04 \mathrm{H}$

$2.44 \mathrm{~W} \times 12.19 \mathrm{~L} \times 2.44 \mathrm{H}$

$1.02 \mathrm{WX} 2.03 \mathrm{H}$ 


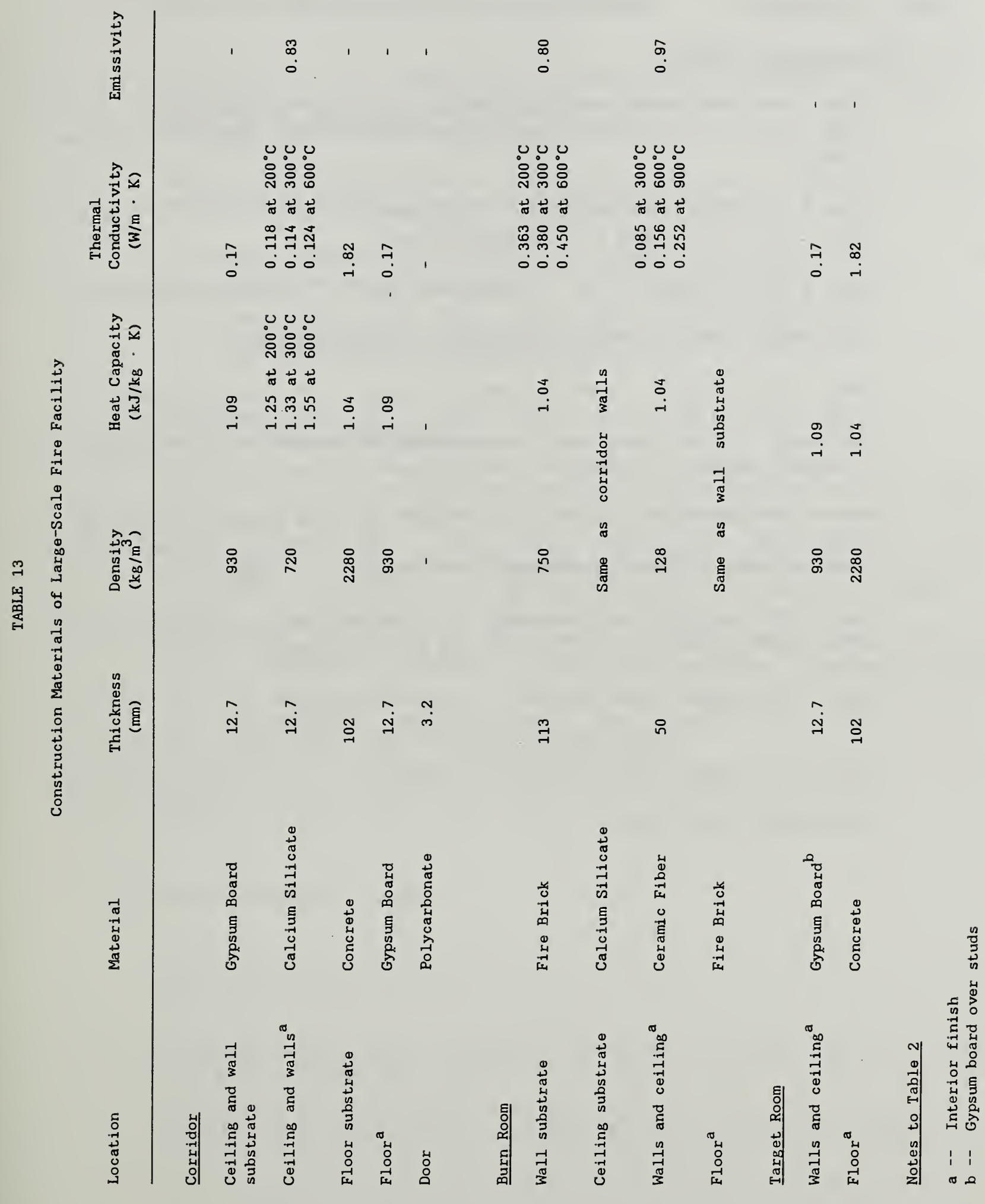


I. Room -. Corridor

\section{A. Thermocouple Trees}

Tree 1 in burn room, Northwest quadrant - 10 thermocouples at 0.15 , $0.66,0.97,1.12,1.27,1.42,1.57,1.88,2.03$, and $2.15 \mathrm{~m}$ from floor.

Tree 2 in burn room doorway -7 thermocouples at $0.15,0.61,0.91$, $1.07,1.22,1.37$ and $1.52 \mathrm{~m}$ from floor.

Tree 3 in corridor, $1.37 \mathrm{~m}$ from East end - 10 thermocouples at $0.15,0.61,0.91,1.22,1.52,1.83,2.13,2.29$, and $2.44 \mathrm{~m}$ (ceiling) from floor and unexposed ceiling surface.

Tree 4 in corridor, $5.49 \mathrm{~m}$ from East end - 10 thermocouples at $0.15,0.61,0.91,1.22,1.52,1.83,2.13,2.29$, and $2.44 \mathrm{~m}$ (ceiling) from floor and 1 thermocouple embedded in ceiling at 6.4 $\mathrm{mm}$ above exposed surface and unexposed ceiling surface.

Tree 5 in corridor, $11.73 \mathrm{~m}$ from East end -10 thermocouples at $0.15,0.61,0.91,1.07,1.22,1.52,1.83,2.13,2.29$, and $2.44 \mathrm{~m}$ (ceiling) from floor and unexposed ceiling surface.

Tree 6 in corridor exit doorway - 8 thermocouples at $0.15,0.61$, $0.91,1.07,1.22,1.52,1.83,2.13 \mathrm{~m}$ from floor.

Tree 7 in target room doorway - 8 thermocouples at $0.15,0.61$, $0.91,1.07,1.22,1.52,1.83$ and $1.93 \mathrm{~m}$ from floor.

Tree 8 in target room, Northeast quadrant - 10 thermocouples at $0.15,0.61,0.91,1.07,1.22,1.52,1.83,2.13,2.29$ and $2.43 \mathrm{~m}$ (ceiling) from floor. 
B. Burn room ceiling and wall thermocouples

South wall, $1.64 \mathrm{~m}$ high - 4 thermocouples at surface, 6.4 , and 12.7 $\mathrm{mm}$ below surface of ceramic fiber insulation and at interface between insulation and brick substrate.

South wall, $0.55 \mathrm{~m}$ high - 3 thermocouples at surface, 6.4 , and 12.7 $\mathrm{mm}$ below surface of ceramic fiber insulation.

Ceiling, Southeast quadrant - 3 thermocouples on surface, 6.4 , and $12.7 \mathrm{~mm}$ below surface of ceramic fiber insulation.

Floor, Southeast quadrant - 3 thermocouples on surface, 6.4 and $12.7 \mathrm{~mm}$ below surface of fire brick.

\section{Corridor wall thermocouples}

North wall, $1.37 \mathrm{~m}$ from East end -6 thermocouples at 0.61 and $1.83 \mathrm{~m}$ heights on surface, $6.4 \mathrm{~mm}$ below surface, unexposed surface.

North wall, $5.79 \mathrm{~m}$ from East end - 6 thermocouples at 0.61 and 1.83 $\mathrm{m}$ heights on surface, $6.4 \mathrm{~mm}$ below surface, unexposed surface.

North wall, $10.67 \mathrm{~m}$ from East end -6 thermocouples at 0.61 and $1.83 \mathrm{~m}$ heights on surface, $6.4 \mathrm{~mm}$ below surface, unexposed surface.

\section{Target room wall and ceiling thermocouples}

None

\section{E. Static pressure probes}

Burn room, North wall - 5 probes at $25 \mathrm{~mm}, 0.30 \mathrm{~m}, 0.61 \mathrm{~m}, 1.22 \mathrm{~m}$, and $1.52 \mathrm{~m}$ from the floor.

Corridor, West wall - 5 probes at $76 \mathrm{~mm}, 0.61 \mathrm{~m}, 1.22 \mathrm{~m}, 1.52 \mathrm{~m}$, and $1.83 \mathrm{~m}$ from the floor.

Target room, North wall - 1 probe at $0.08 \mathrm{~m}$ from the floor. 
F. Flux meters

Corridor ceiling, center - 1 flux meter on surface.

\section{G. Smoke indicators}

Corridor, $5.49 \mathrm{~m}$ from East end - 6 horizontal smoke meters at 0.61 , $0.91,1.22,1.52,1.83$, and $2.29 \mathrm{~m}$ from floor.

Corridor, $5.03 \mathrm{~m}$ from East end - 1 vertical smoke meter.

Corridor, $10.36 \mathrm{~m}$ from East end - 2 horizontal smoke meters at 1.98 and $2.29 \mathrm{~m}$ from floor.

Corridor, $11.13 \mathrm{~m}$ from East end - 1 vertical smoke meter on corridor centerline.

Corridor exit - side of doorway marked every $0.30 \mathrm{~m}$ from floor.

Target room, $0.65 \mathrm{~m}$ from South wall - 3 horizontal smoke meters at $0.61,1.22$, and $1.83 \mathrm{~m}$ from floor.

H. Gas Probes

Burn room

Probe for carbon monoxide and carbon dioxide at $100 \mathrm{~mm}$ below ceiling. Oxygen probe at $100 \mathrm{~mm}$ above floor. HCN taken from animal sampling line.

Corridor, midway Probe for carbon monoxide and carbon dioxide at $100 \mathrm{~mm}$ below ceiling. Oxygen probe at $100 \mathrm{~mm}$ above floor.

Target room

Probe for carbon monoxide and carbon dioxide at $100 \mathrm{~mm}$ below ceiling. Oxygen probe at $100 \mathrm{~mm}$ above floor. HCN port adjacent to animal sampling line.

Animal Exposure Probe for $\mathrm{CO}, \mathrm{CO}_{2}$, and $\mathrm{O}_{2}$, port for $\mathrm{HCN}$. Chamber 
(TABLE 14 Continued)

II. Miscellaneous

Burn room, over burner 1 thermocouple $0.91 \mathrm{~m}$ above burner, $0.15 \mathrm{~m}$ from back wall. I thermocouple $0.20 \mathrm{~m}$ above burner, $0.15 \mathrm{~m}$ from back wall.

Burn room ceiling

$1.17 \mathrm{~m}$ from East wall - 2 thermocouples on surface at $1.17 \mathrm{~m}$ and $0.61 \mathrm{~m}$ from North wall.

Burn room

Load platform - cables for platform suspension system through ceiling.

Burn room

Animal sampling - $80 \mathrm{~mm}$ diameter glass sampling line - centered in room $1.88 \mathrm{~m}$ from floor return $0.1 \mathrm{~m}$ from floor - west wall on east wall $1 \mathrm{~m}$ from $\mathrm{SE}$ corner.

Burn room

$1.17 \mathrm{~m}$ from East wall - 3 thermocouples on North wall surface at $0,0.71$, and $1.45 \mathrm{~m}$ below ceiling.

Corridor

$0.38 \mathrm{~m}$ from East wall - 2 thermocouples on ceiling surface at 0.61 and $1.22 \mathrm{~m}$ from North wall. 3 thermocouples on North wall surface at $0,0.81$, and $1.63 \mathrm{~m}$ below ceiling.

Target room

Animal sampling - $80 \mathrm{~mm}$ diameter glass sampling line - $0.1 \mathrm{~m}$ from wall - $2.24 \mathrm{~m}$ from floor return $0.1 \mathrm{~m}$ from floor. 
Summary of Results from the Flaming Ignition of Foams 32 and $32 \mathrm{X}$ Gas and Temperature Data in the Burn Room and the Target Room of the Large-Scale Test Facility

Foam 32

Burn room Target Room

Foam $32 x$

Burn Room Target Room

\begin{abstract}
Time Max CO (s)
Max. CO (ppm)

$\operatorname{Max} . \mathrm{CO}_{2}(8)$

Max. HCN (ppm)
\end{abstract}

Min. $\mathrm{O}_{2} \quad\left(\frac{8}{8}\right)$

6.5

11

110

60

$720^{\mathrm{a}}$

910

4000

12

78

24

Max. upper compartment $\left({ }^{\circ} \mathrm{C}\right) 680$

Max. lower compartment $\left({ }^{\circ} \mathrm{C}\right) 320$
500

114

64

8.6

$-b$

6

13

145

60

a - Time of maximum temperature because of sampling line failure

b - Failure in sampling line 

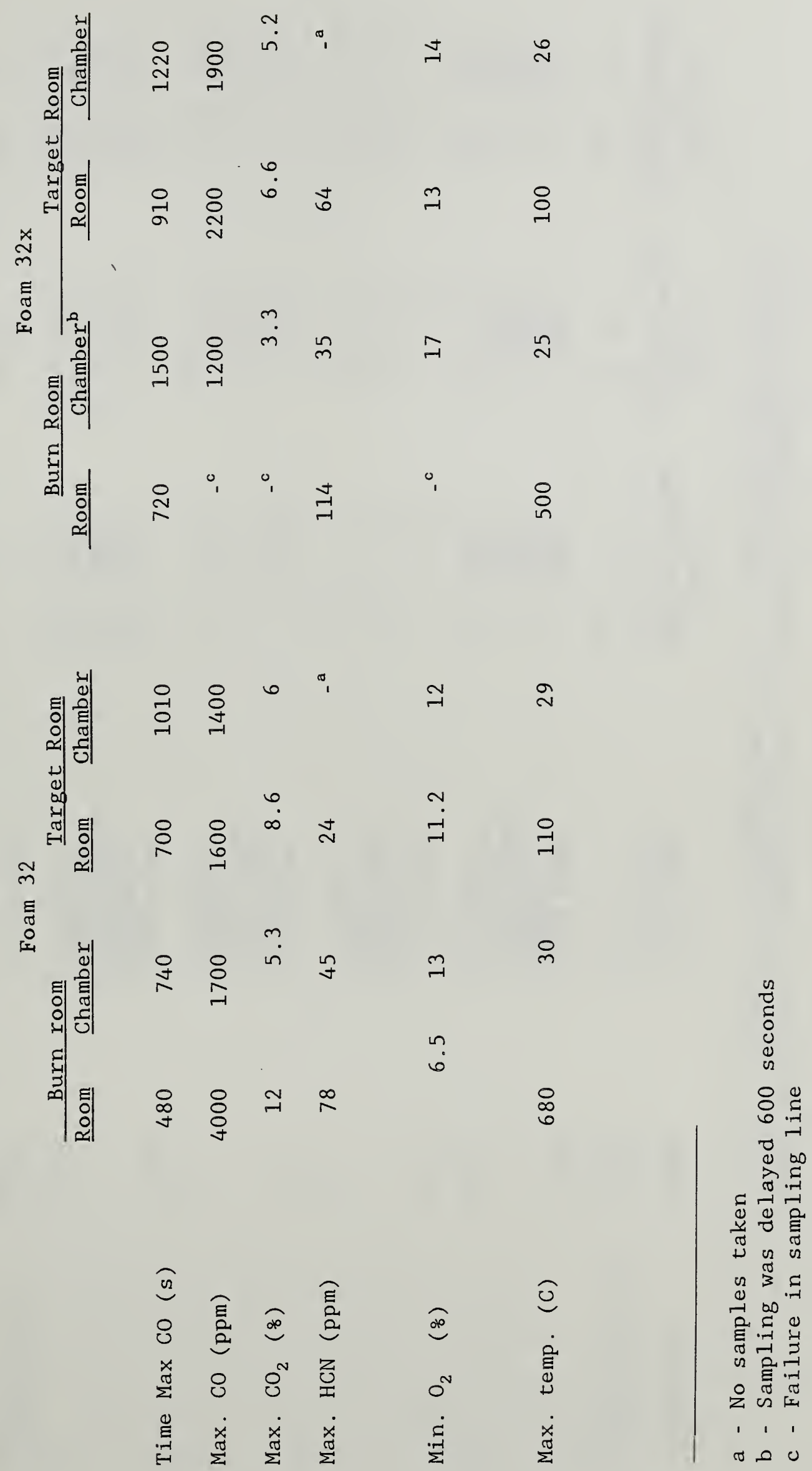

4 ज

듀융

車

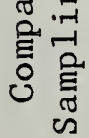

0
$\stackrel{1}{0}$
0
0
0
0
0
0
$\simeq$

ن̀ 


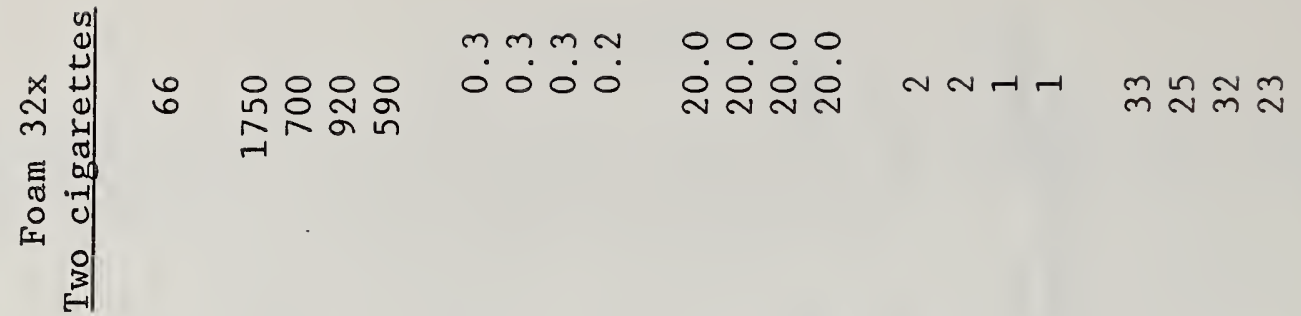

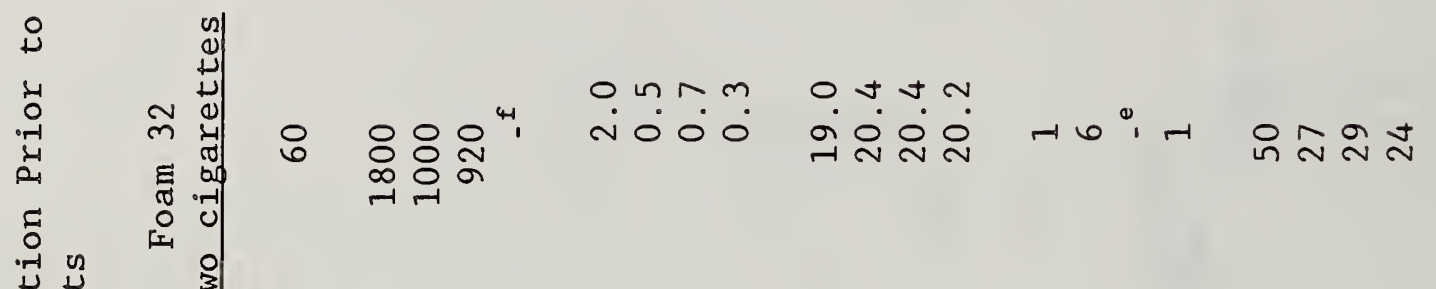

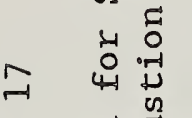

$$
\begin{aligned}
& \text { 过 } \\
& \text { 我 } \\
& \text { 萬 } \\
& \text { 离 } \\
& \text { 离 } 4 \\
& \text { चี हี }
\end{aligned}
$$

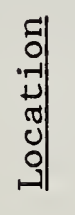

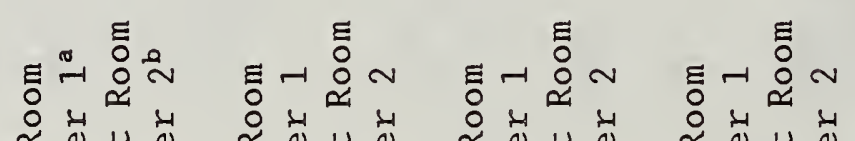

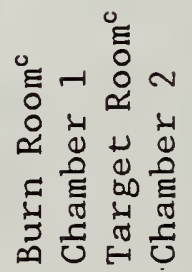

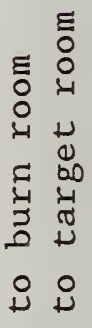

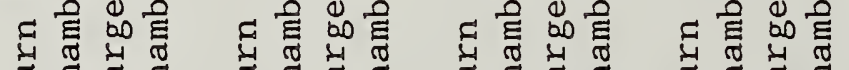

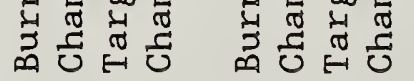

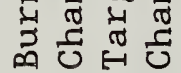

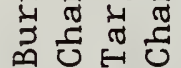

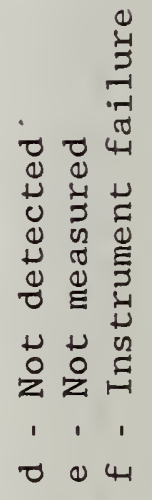

$$
\begin{aligned}
& \text { o } \pi \\
& \text { ठำ } \\
& \text { फ्. 댕 } \\
& \text { }
\end{aligned}
$$

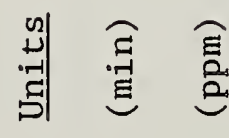

$$
\begin{aligned}
& \widehat{\text { ab }} \\
& \text { હิ } \\
& \text { త }
\end{aligned}
$$

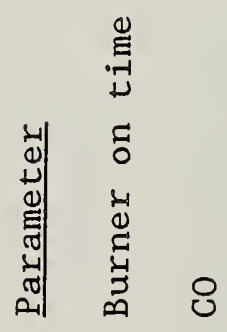

$$
\begin{aligned}
& \text { O } \\
& 0^{2}
\end{aligned}
$$
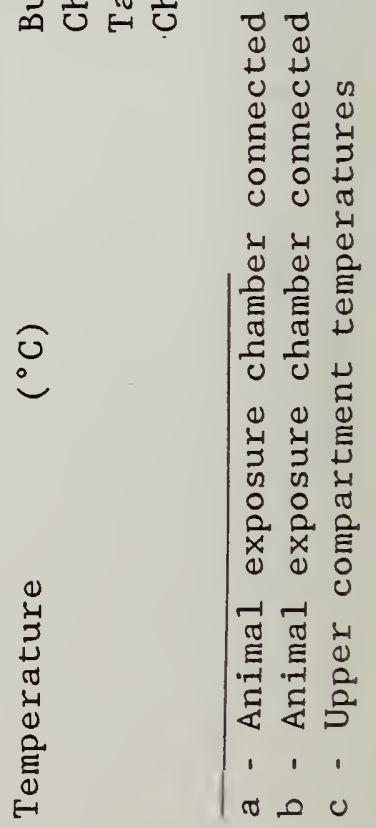


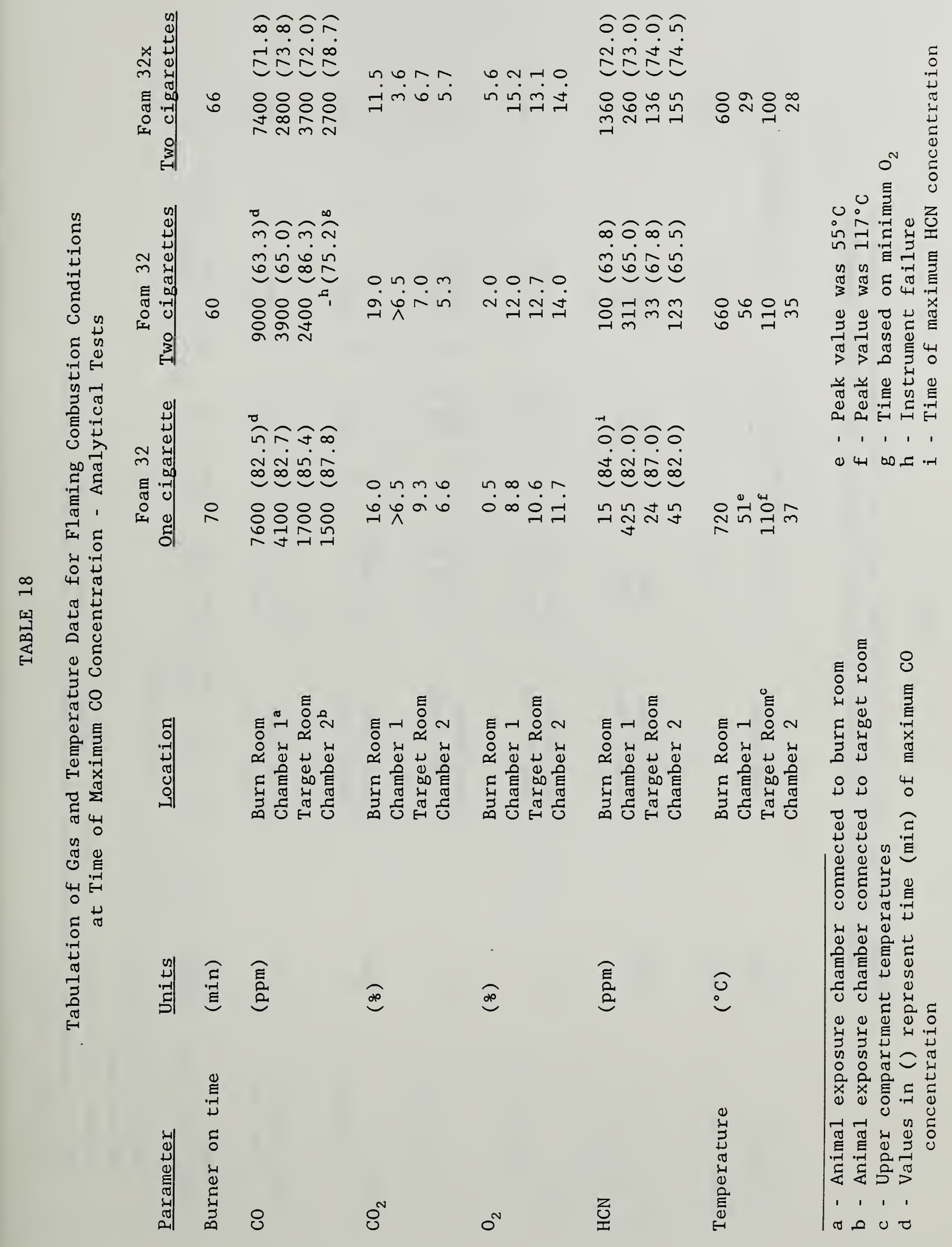




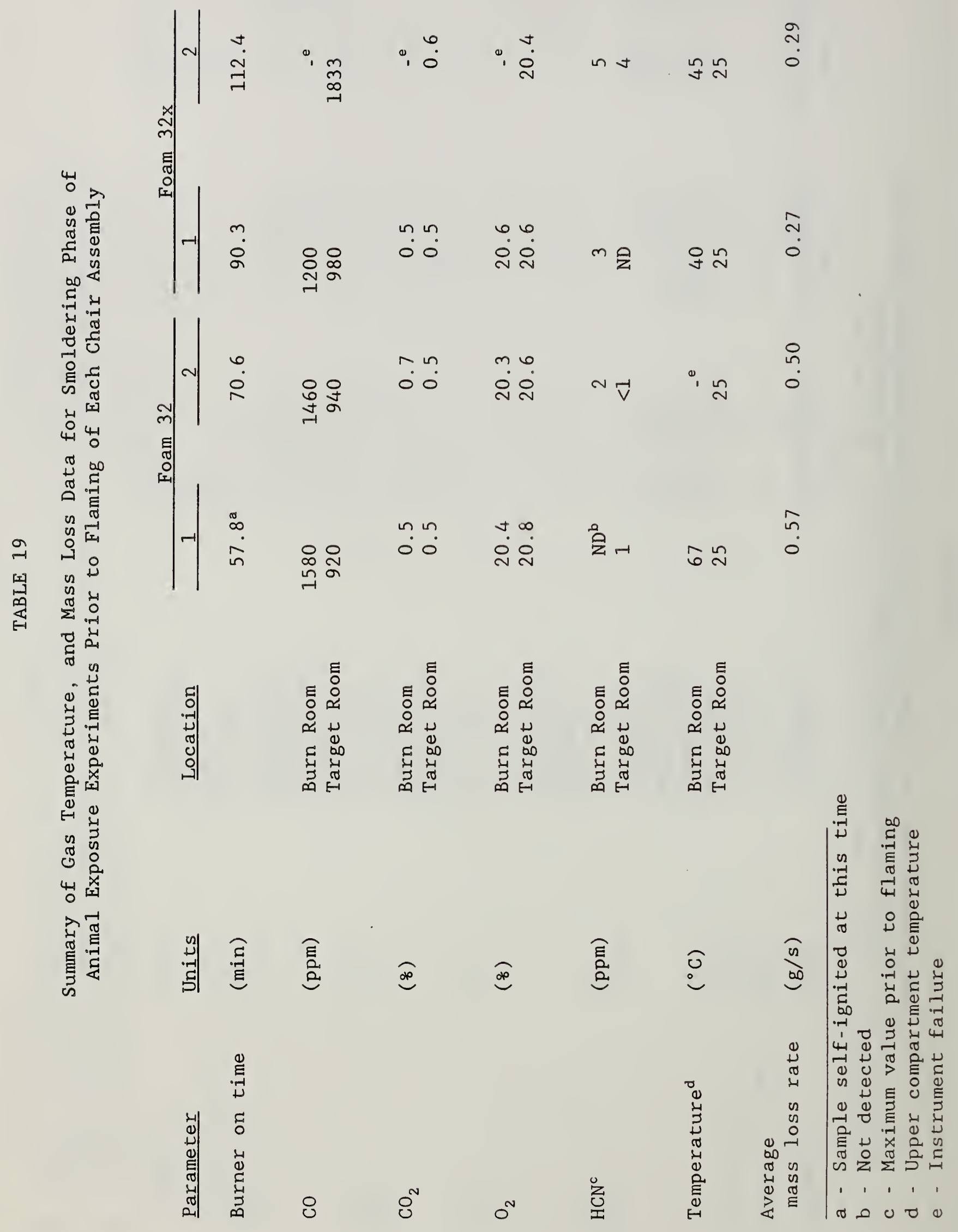




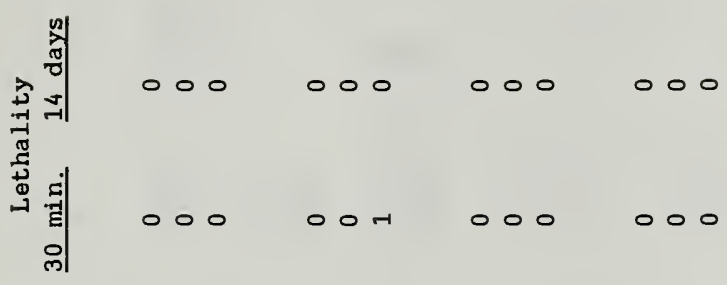

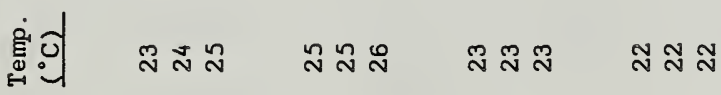
กำ

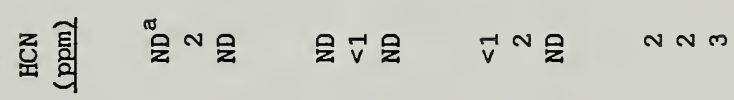

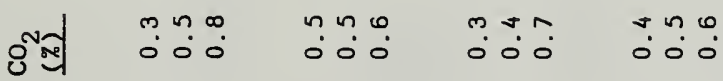

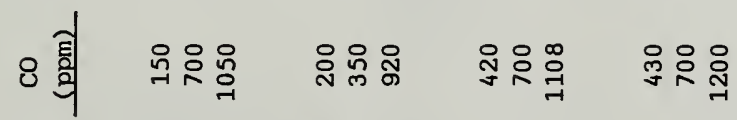

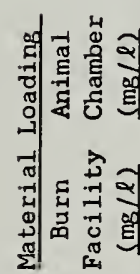

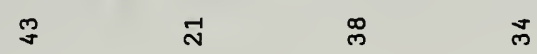
$\frac{4}{2} \quad \frac{1}{2}$

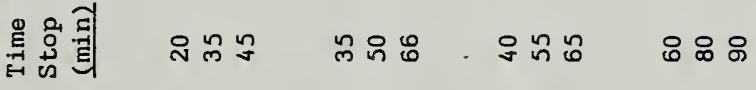

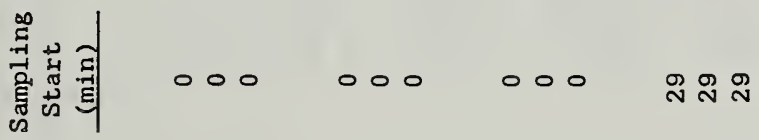

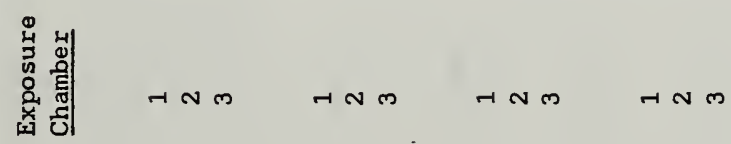

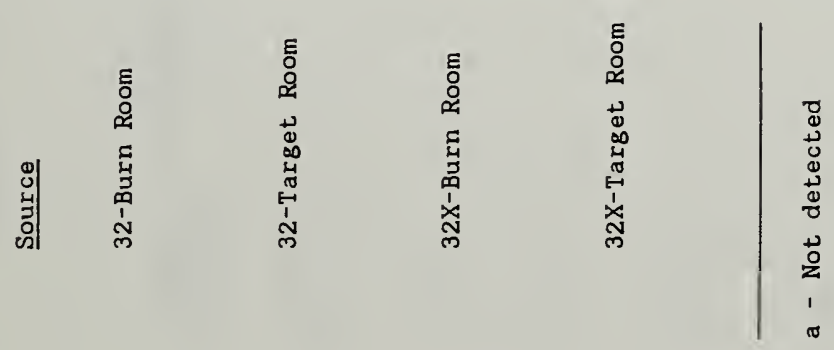




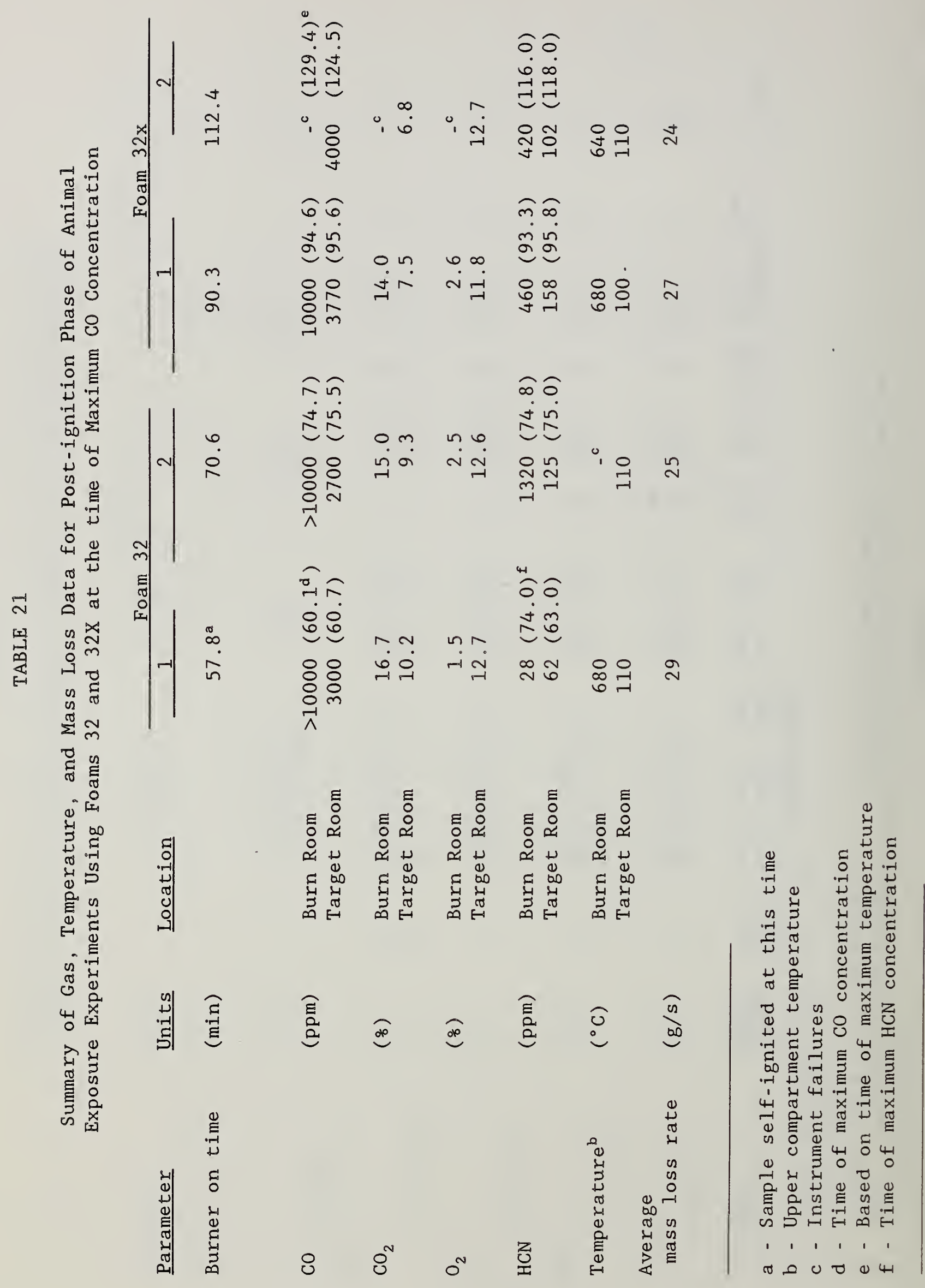




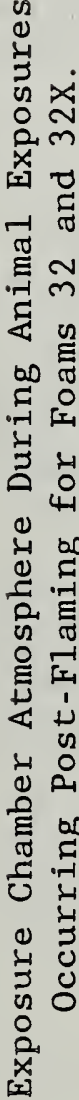

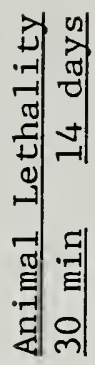

on 0 in 606

E⿹

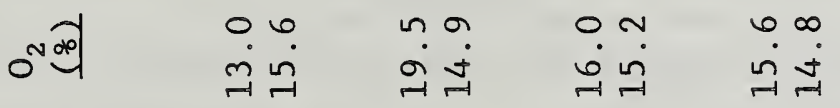

褐

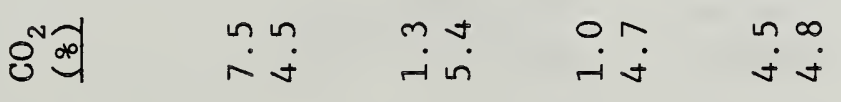

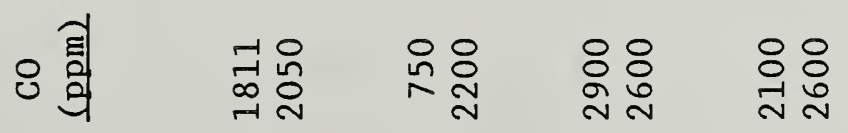

ำ จุ

近

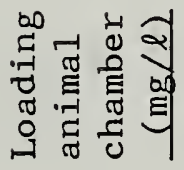

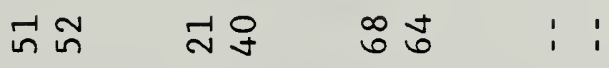

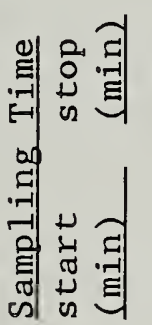

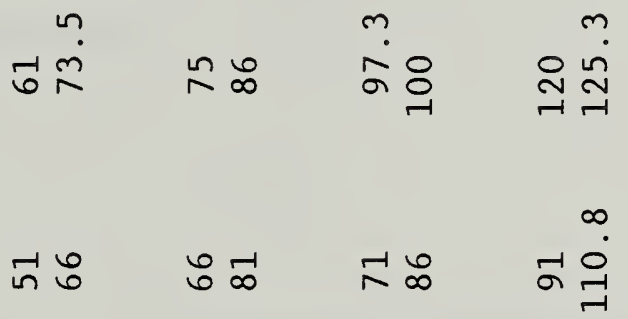

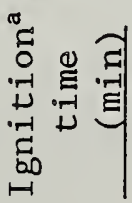

\begin{tabular}{llll}
$\infty$ & 0 & $m$ & \multirow{2}{*}{} \\
in & 0 & 0 & ก
\end{tabular}

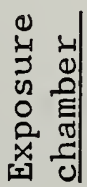

$\pi N \pi \mathrm{n}$ HN

$\stackrel{0}{1}$



ธั

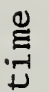

ธ

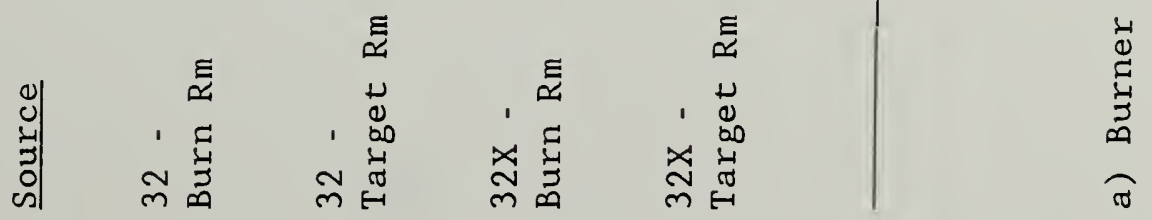


TABLE 23

Comparison of $\mathrm{CO}$ and $\mathrm{CO}_{2}$ Yields for Small-Scale Tests, Furniture Calorimeter and Large-Scale Compartment Tests of Non-Fire Retarded Polyurethane Foam 32

\begin{tabular}{|c|c|c|c|c|}
\hline Cotton & \multicolumn{2}{|c|}{$\mathrm{CO}(\mathrm{kg} / \mathrm{kg})$} & \multicolumn{2}{|c|}{$\mathrm{CO}_{2}(\mathrm{~kg} / \mathrm{kg})$} \\
\hline cover & $\mathrm{F}^{\mathrm{a}}$ & $\mathrm{NF}^{\mathrm{b}}$ & F & $\mathrm{NF}$ \\
\hline- & 0.02 & 0.03 & 1.6 & 0.2 \\
\hline- & 0.01 & 0.03 & 2.3 & 1.7 \\
\hline+ & 0.03 & & 2.0 & \\
\hline+ & 0.04 & $0.24^{c}(0.12)^{d}$ & 1.9 & $9.0^{c}(3.6)^{d}$ \\
\hline+ & 0.04 & $0.15^{c}(0.09)^{d}$ & 2.9 & $1.0^{c}(2.8)^{d}$ \\
\hline
\end{tabular}

\footnotetext{
a - Flaming

b - Nonflaming

c - Smoldering

d - After smoldering-to-flaming transition
} 
TABLE 24

Comparison of Peak Measured HCN Concentrations and Estimated Yields for NBS Toxicity Protocol Tests, Furniture Calorimeter and Large-Scale Mock-Up Upholstery Chair Tests of Non-treated Polyurethane Foam 32

HCN Peak

(ppm)
NBS Toxicity Protocol
Non-flaming
Flaming
Ramped

Furniture Calorimeter

Smoldering - to-

Flaming

Flaming

Large-Scale Tests

Smoldering - to -

Flaming

Flaming
11

53

173

$<1^{a}$

16

7

2

1315

78
HCN Yield

$\underline{\left(\mathrm{kg} / \mathrm{kg} \times 10^{-3}\right)}$

a - Lower detection limit of GC calibration 
Comparison of Yield Ratios of $\mathrm{CO}_{2} / \mathrm{CO}$ for the Small-Scale Tests, Furniture Calorimeter and Large-Scale Compartment Tests of Non-Fire Retarded Polyurethane Foam 32

Cotton

cover

NBS Toxicity Test

Cone Calorimeter

Cone Calorimeter

Furniture Calorimeter

Furniture Calorimeter

Large-Scale Tests

Large-Scale Tests

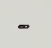

$-$

$+$

$+$

$+$

$+$

$+$
Yield ratio of $\mathrm{CO}_{2} \angle \mathrm{CO}$ Flaming

Non-flaming

80

200

65

50

$30^{\mathrm{a}}$

$40^{\mathrm{b}}$

70

$30^{a}$
6

55

(1)

a After smoldering to flaming transition

b Smoldering 
TABLE 26
Comparison of Yield Ratios of HCN/CO for the NBS Toxicity Test, Furniture Calorimeter, and Large-Scale Compartment Tests for Non-treated Polyurethane Foam 32

$\underline{\mathrm{HCN} / \mathrm{CO}}$

$\begin{array}{lr}\text { NBS Toxicity Test } & \\ \text { Non-flaming } & .01 \\ \text { Flaming } & .09 \\ \text { Ramped } & \text { ND }^{\mathrm{a}} \\ \text { Furniture Calorimeter } & \\ \text { Smoldering-to- } & <.01 \\ \text { Flaming } & .01 \\ \text { Flaming } & .02 \\ & \\ \text { Large-Scale Tests } & <.01 \\ \text { Smoldering-to- } & .04 \\ \text { Flaming } & .01 \\ \text { Flaming } & \end{array}$

a - Not determined 
Comparison of $\mathrm{CO}$ and $\mathrm{CO}_{2}$ Yields for Small-Scale Tests, Furniture Calorimeter, and Large-Scale Compartment Tests of Fire Retarded Polyurethane Foam $32 \mathrm{X}$

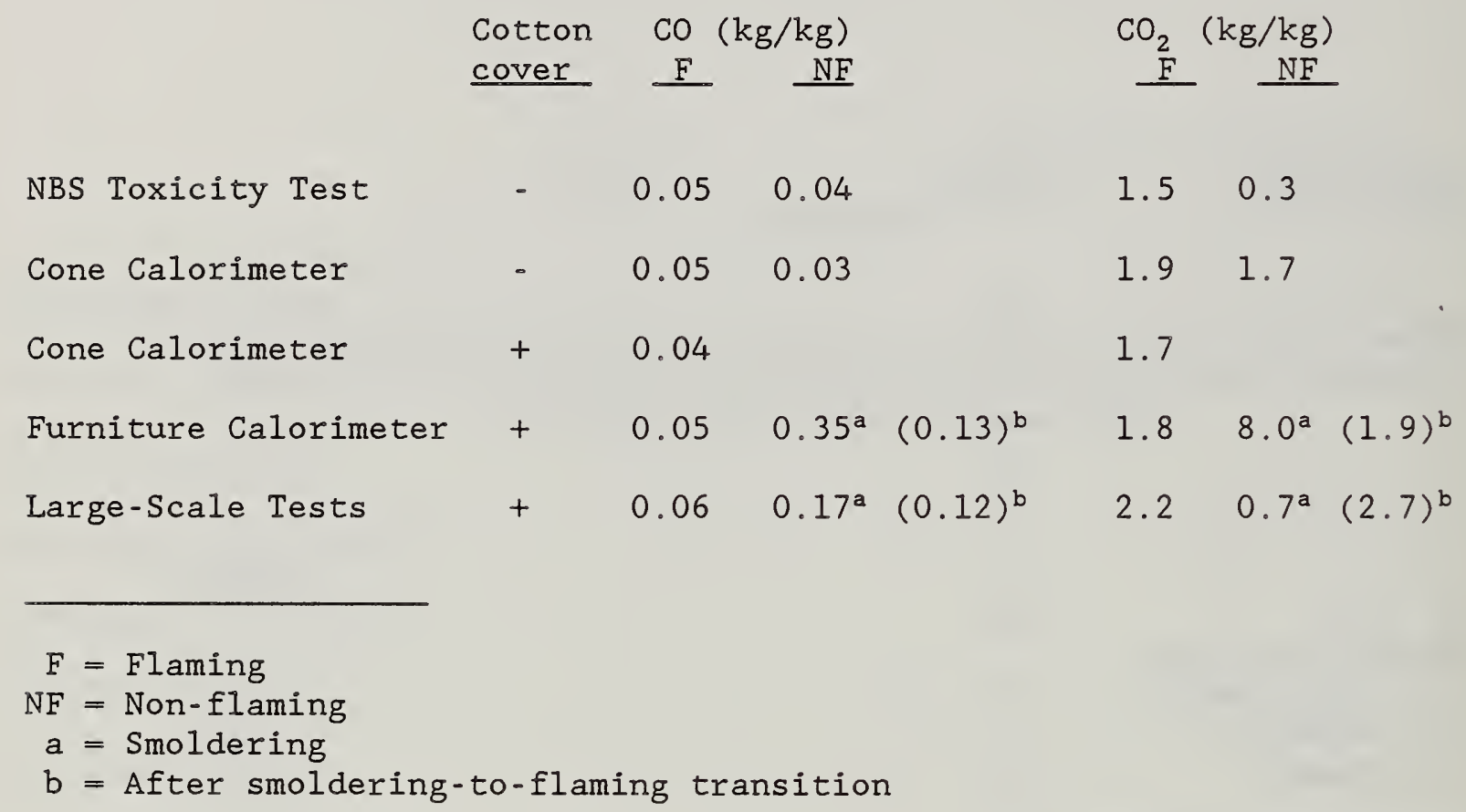


TABLE 28

Comparison of Peak Measured HCN Concentrations and Estimated Yields for NBS Toxicity Protocol Tests, Furniture Calorimeter, and Large-Scale Mock-up Upholstered Chair Tests of Fire Retarded Polyurethane Foam 32X

HCN Peak (ppm)

NBS Toxicity Protocol Non-flaming

Flaming

Ramped

Furniture Calorimeter

Smoldering - to -

Flaming

Flaming

Large-Scale Tests

Smoldering - to -

Flaming

Flaming
HCN Yield

$\underline{\left(\mathrm{kg} / \mathrm{kg} \times 10^{3}\right)}$

\section{a - Within lower detection limit of GC calibration}


TABLE 29

Comparison of Yield Ratios of $\mathrm{CO}_{2} / \mathrm{CO}$ for Small-Scale Tests, Furniture Calorimeter and Large-Scale Compartment Tests of

Fire Retarded Polyurethane Foam 32X

\begin{tabular}{|c|c|c|c|}
\hline & $\begin{array}{l}\text { Cotton } \\
\text { cover } \\
\end{array}$ & Flaming & Non-flaming \\
\hline NBS Toxicity Test & - & 30 & 8 \\
\hline Cone Calorimeter & - & 40 & 60 \\
\hline Cone Calorimeter & + & 40 & \\
\hline Furniture Calorimeter & + & 40 & \\
\hline Furniture Calorimeter & + & $15^{a}$ & $20^{b}$ \\
\hline Large-Scale Tests & + & 40 & \\
\hline Large-Scale Tests & + & $20^{a}$ & $5^{b}$ \\
\hline
\end{tabular}


TABLE 30

Comparison of Yield Ratios of HCN/CO for the NBS Toxicity Test, Furniture Calorimeter, and Large-Scale Compartment Tests for Fire Retarded Polyurethane Foam 32X

$\underline{\mathrm{HCN} / \mathrm{CO}}$

NBS Toxicity Test

Non-flaming

Flaming

.01

Ramped

10

ND

Furniture Calorimeter

Smoldering-to-

Flaming

.001

Flaming

Large-Scale Tests

Smoldering-to-

$<.001$

Flaming

.03

Flaming

a - Not determined 
Comparison of Animal Deaths in the NBS Toxicity Test Method

for 3-Gas Model Calculations for Non-fire Retarded Polyurethane Foam 32

\begin{tabular}{|c|c|c|c|c|}
\hline \multirow[b]{2}{*}{ Mode } & \multirow{2}{*}{$\begin{array}{l}\text { Mass Loaded } \\
\text { Chamber Vol } \\
\quad(\mathrm{mg} / \mathrm{l})\end{array}$} & \multicolumn{2}{|c|}{ No. Died/No. Tested } & \multirow[b]{2}{*}{$\begin{array}{l}\text { 3-Gas } \\
\text { Mode1 } \\
\end{array}$} \\
\hline & & $\begin{array}{l}\text { Within } \\
\text { Exposure }\end{array}$ & $\begin{array}{c}\text { Within }+ \\
\text { Post-exposure }\end{array}$ & \\
\hline$N F^{a}$ & $\begin{array}{l}30.5 \\
38.1 \\
38.9 \\
40.3\end{array}$ & $\begin{array}{l}0 / 6 \\
0 / 6 \\
0 / 6 \\
0 / 6\end{array}$ & $\begin{array}{l}0 / 6 \\
1 / 6 \\
2 / 4 \\
3 / 6\end{array}$ & $\begin{array}{l}0.24 \\
0.27 \\
0.39 \\
0.44\end{array}$ \\
\hline$F^{b}$ & $\begin{array}{l}19.9 \\
29.8 \\
40.1\end{array}$ & $\begin{array}{l}0 / 6 \\
0 / 6 \\
0 / 6\end{array}$ & $\begin{array}{l}0 / 6 \\
0 / 6 \\
0 / 6\end{array}$ & $\begin{array}{l}0.26 \\
0.29 \\
0.62\end{array}$ \\
\hline
\end{tabular}

a - Non-flaming

b - Flaming 
Comparison of Animal Deaths in the NBS Toxicity Test Method to 3-Gas Model Calculations for Fire Retarded Polyurethane Foam 32X

\begin{tabular}{|c|c|c|c|c|}
\hline \multirow[b]{2}{*}{ Mode } & \multirow{2}{*}{$\begin{array}{l}\text { Mass Loaded } \\
\text { Chamber Vol. } \\
\text { (mg/l) }\end{array}$} & \multicolumn{2}{|c|}{ No. Died/No. Tested } & \multirow[b]{2}{*}{$\begin{array}{l}\text { 3-Gas } \\
\text { Mode1 }\end{array}$} \\
\hline & & $\begin{array}{l}\text { Within } \\
\text { Exposure }\end{array}$ & $\begin{array}{c}\text { Within }+ \\
\text { Post-exposure }\end{array}$ & \\
\hline $\mathrm{NF}^{\mathrm{a}}$ & $\begin{array}{l}22.5 \\
25.0 \\
27.5 \\
30.0 \\
35.0 \\
40.0\end{array}$ & $\begin{array}{l}0 / 6 \\
0 / 6 \\
0 / 6 \\
1 / 6 \\
0 / 6 \\
0 / 6\end{array}$ & $\begin{array}{l}0 / 4 \\
2 / 5 \\
2 / 4 \\
6 / 6 \\
5 / 6 \\
4 / 6\end{array}$ & $\begin{array}{l}0.13 \\
0.18 \\
0.18 \\
0.26 \\
0.28 \\
0.23\end{array}$ \\
\hline$F^{b}$ & $\begin{array}{l}25.0 \\
30.0 \\
30.0 \\
35.0 \\
40.0\end{array}$ & $\begin{array}{l}1 / 6 \\
1 / 6 \\
3 / 6 \\
2 / 6 \\
1 / 6\end{array}$ & $\begin{array}{l}2 / 5 \\
4 / 5 \\
4 / 6 \\
5 / 6 \\
3 / 6\end{array}$ & $\begin{array}{l}1.02 \\
0.95 \\
1.35 \\
1.67 \\
1.44\end{array}$ \\
\hline
\end{tabular}

a - Non-flaming

b - Flaming 
TABLE 33

\section{Comparison of Animal Deaths in the Large-Scale Post-Flaming Exposures with 3-Gas Model Calculations}

\begin{tabular}{|c|c|c|c|c|c|}
\hline \multirow{2}{*}{\multicolumn{2}{|c|}{ Source }} & \multirow{2}{*}{$\begin{array}{l}\text { Exposure } \\
\text { chamber }\end{array}$} & \multicolumn{2}{|c|}{ Animal lethality } & \multirow{2}{*}{$\begin{array}{l}\text { 3-Gas } \\
\text { Model }\end{array}$} \\
\hline & & & $30 \mathrm{~min}$ & 14 days & \\
\hline \multirow[t]{2}{*}{32} & Burn & 1 & 6 & - & 1.5 \\
\hline & & 2 & 3 & 1 & 0.9 \\
\hline \multirow[t]{2}{*}{32} & Target & 1 & 0 & 0 & 0.4 \\
\hline & & 2 & 5 & 1 & 1.0 \\
\hline \multirow{2}{*}{\multicolumn{2}{|c|}{$32 x-$ Burn }} & 1 & 6 & 0 & 2.1 \\
\hline & & 2 & 6 & - & 1.8 \\
\hline \multirow{2}{*}{\multicolumn{2}{|c|}{$32 \mathrm{X}$ - Target }} & 1 & 6 & - & 1.3 \\
\hline & & 2 & 6 & - & 1.4 \\
\hline
\end{tabular}




\section{TABLE 34}

Comparison of Three Gas Model Results with Measured Animal Response from Non-Fire Retarded Polyurethane Foam and Cotton Upholstery Fabric

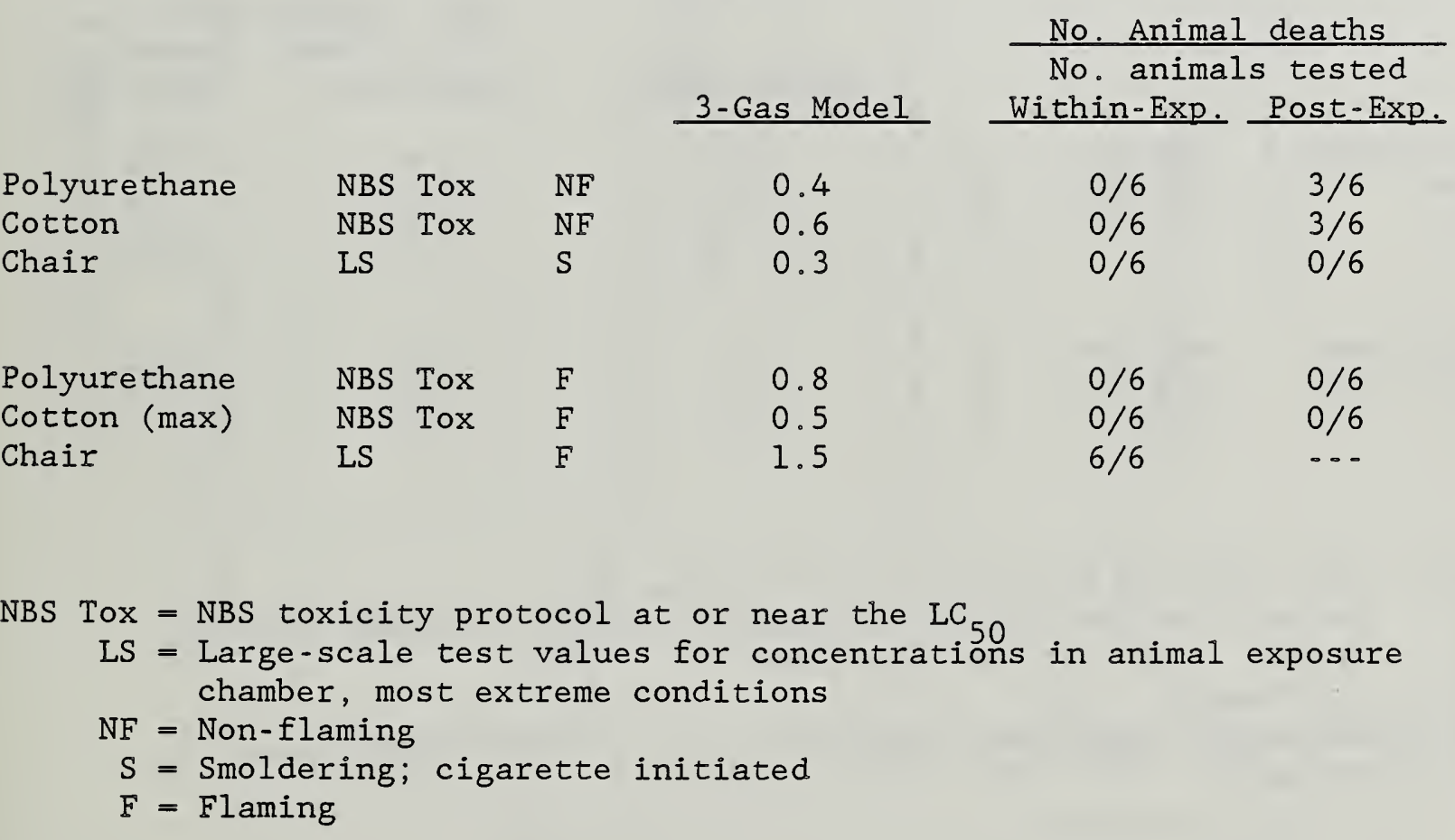


TABLE 35

Comparison of Three Gas Model Results with Measured Animal Response far Fire Retarded Polyurethane foam and Cotton Upholstery Fabric.

3-Gas Mode1

Polyurethane Cotton

Chair

Polyurethane Cotton (max)

Chair

$\begin{array}{lll}\text { NBS } & \text { Tox } & \text { NF } \\ \text { NBS } & \text { Tox } & \text { NF } \\ \text { LS } & & \text { S }\end{array}$

0.2

0.6

0.3

1.0

0.5

1.5
No. animal deaths

No. animals tested. Within Exp. Post-Exp.

$0 / 6$

$2 / 4$

$0 / 6$

$3 / 6$

$0 / 6$

$0 / 6$

NBS Tox $=$ NBS toxicity protocol at or near the LC $_{50}$

LS = Large-scale test values for concentrations in animal exposure chamber, most extreme conditions

$\mathrm{NF}=$ Non-flaming

$\mathrm{S}=$ Smoldering; cigarette initiated

$\mathrm{F}=$ Flaming 


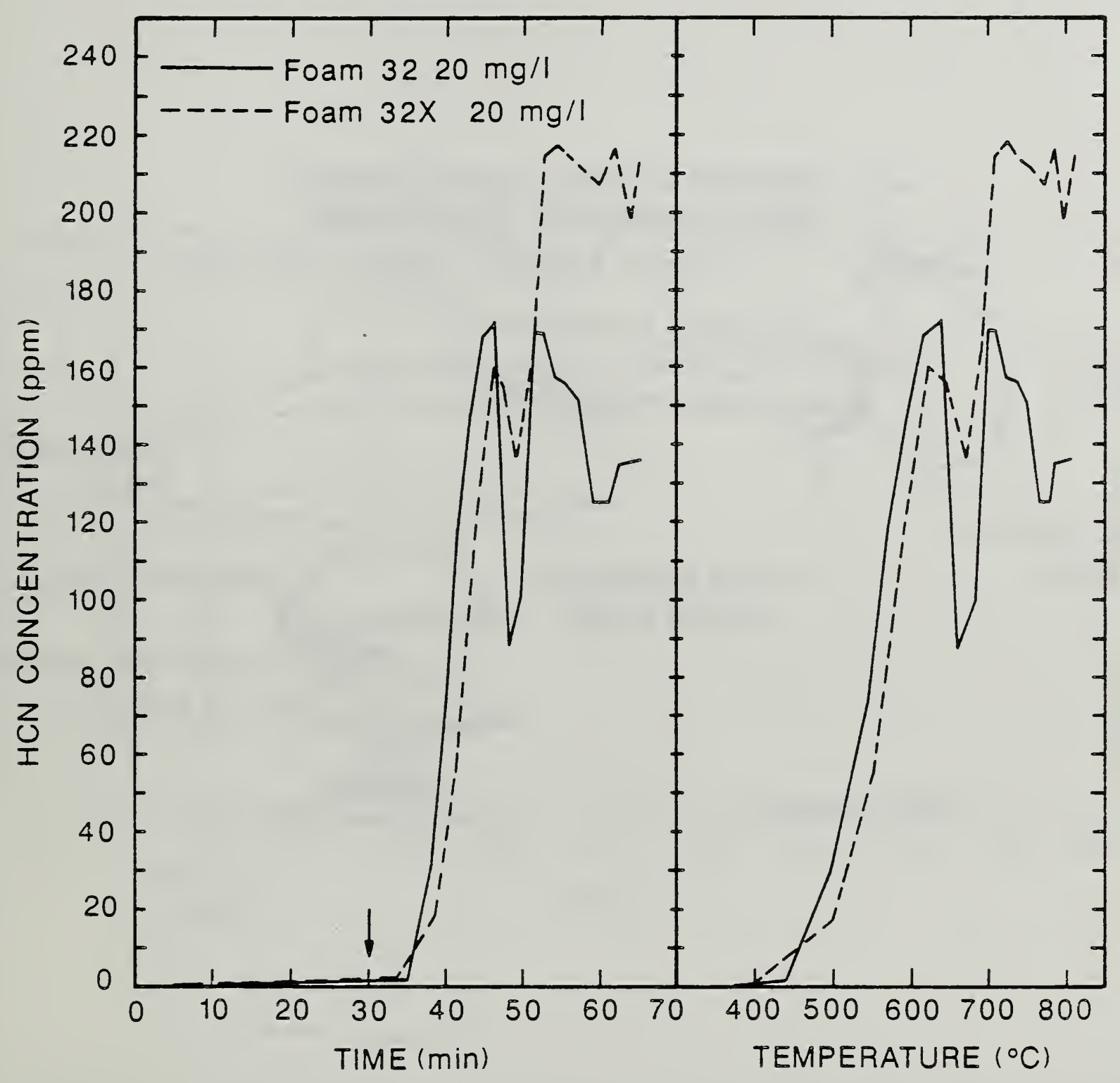

Figure 1. HCN Generation During Ramped Heating $\left(375^{\circ} \mathrm{C}\right.$ to $\left.800^{\circ} \mathrm{C}\right)$ of Foams 32 and $32 \mathrm{X}$ After Preheating at $375^{\circ} \mathrm{C}$ for 30 Minutes in the NBS Toxicity Apparatus. 


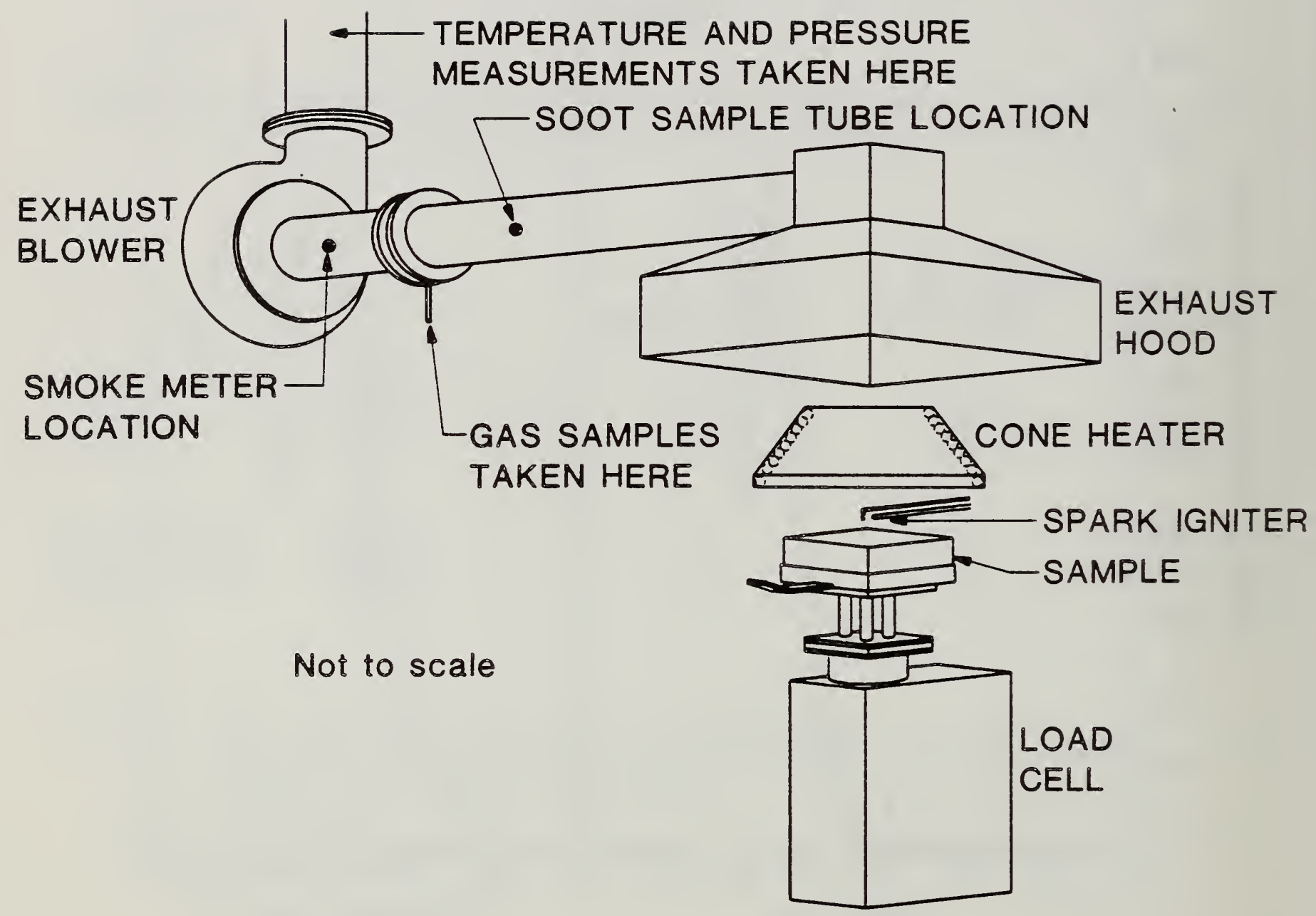

Figure 2. Schematic of the Cone Calorimeter. 


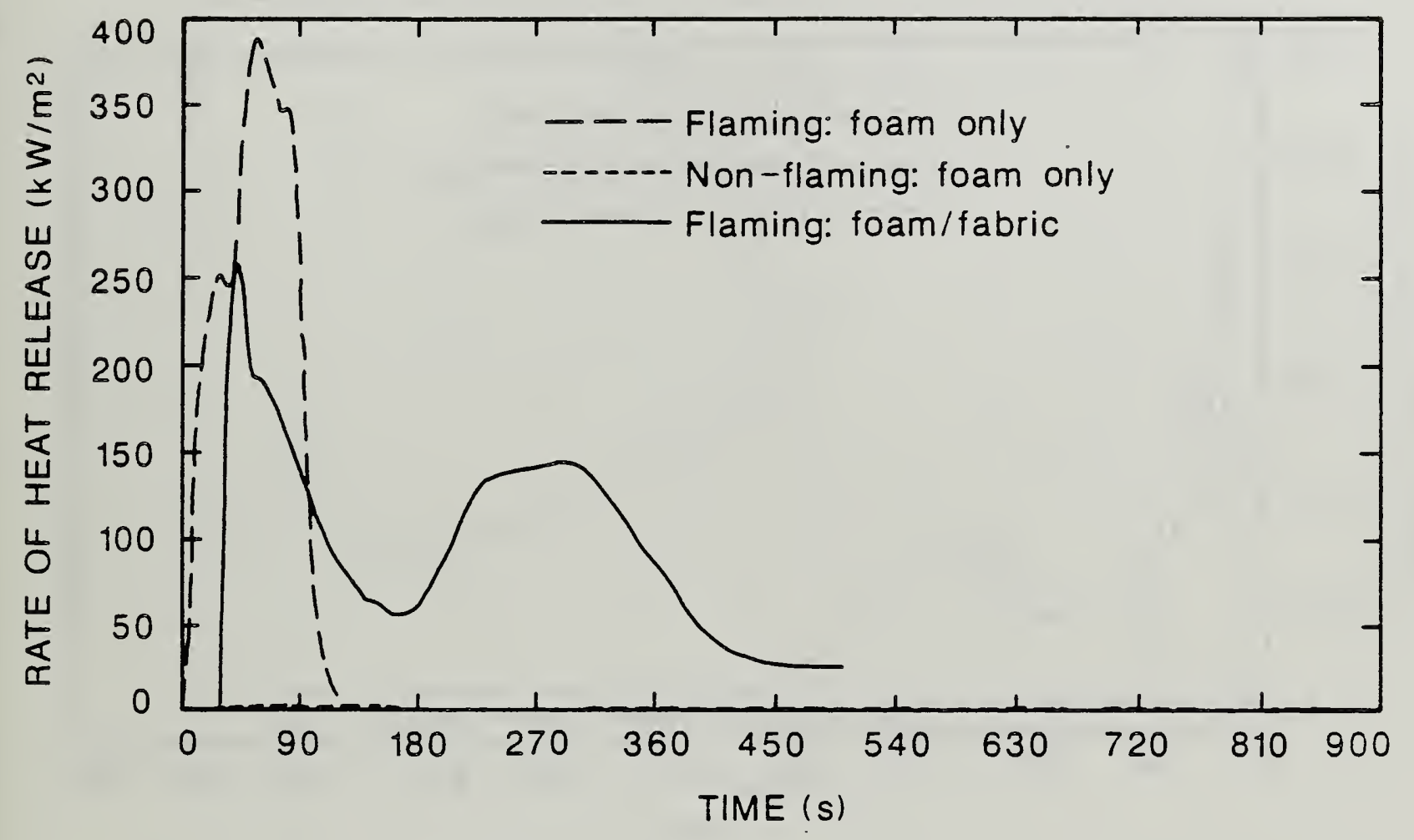

Figure 3. Comparison of Heat Release Rate for Foam 32 Flaming and Nonflaming Exposures Without a Cover Fabric and Flaming Exposure With a Cover Fabric.' 


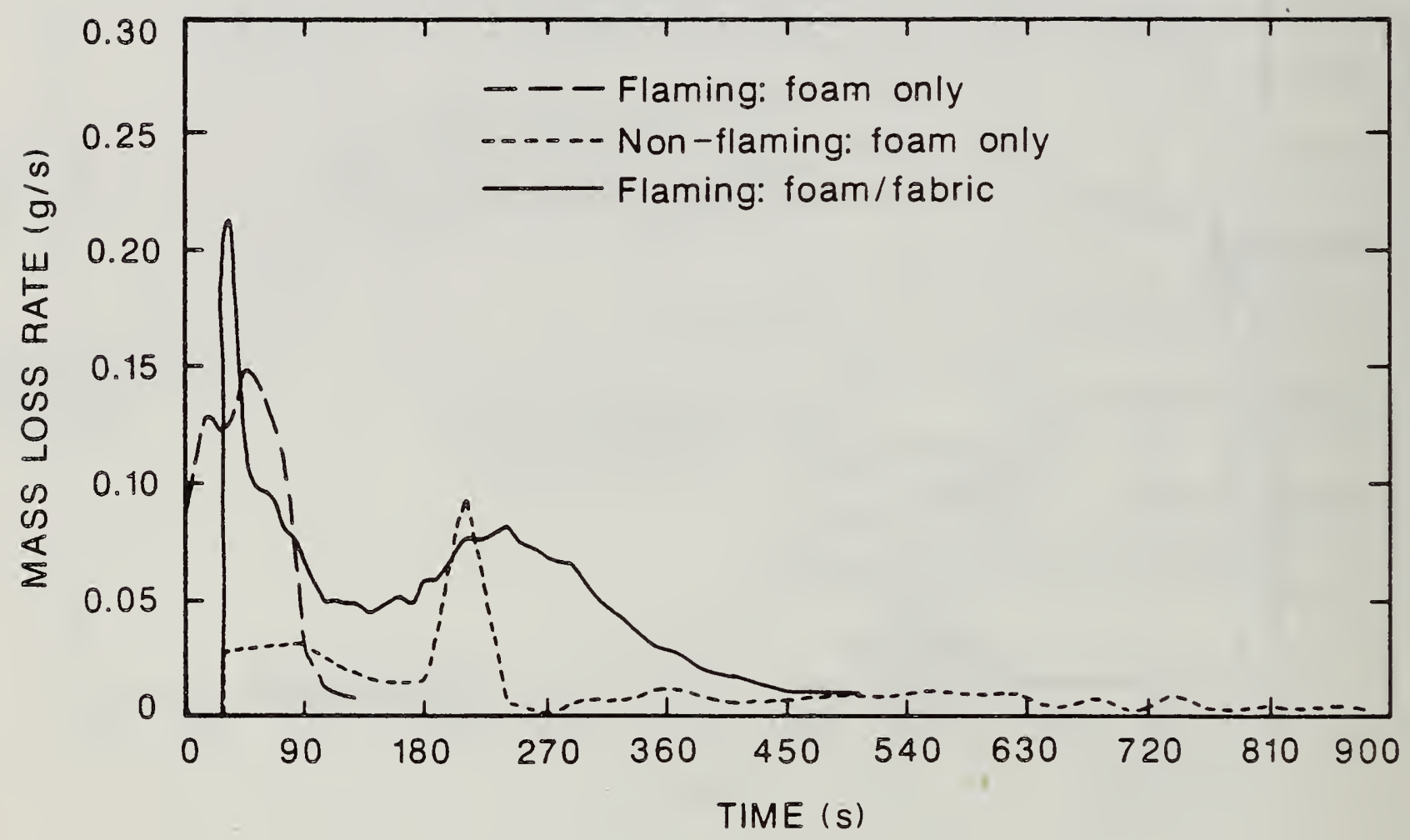

Figure 4. Comparison of Mass Loss Rate for Foam 32 Flaming and Nonflaming exposures Without a Cover Fabric and Flaming Exposures With a Cover Fabric. 


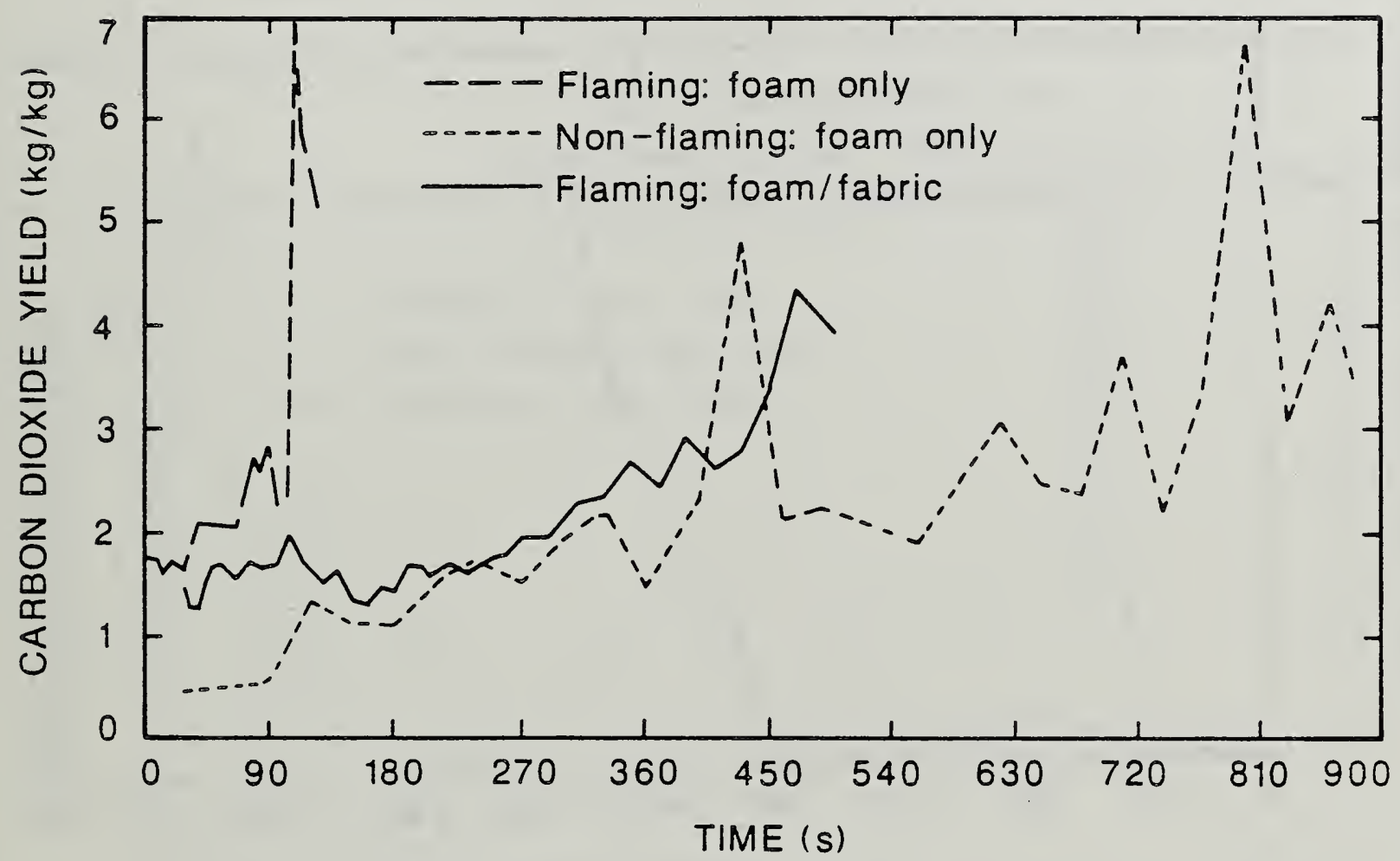

Figure 5. Comparison of Carbon Dioxide Yield for Foam 32 Flaming and Nonflaming Exposures Without a Cover Fabric and Flaming Exposure With a Cover Fabric. 


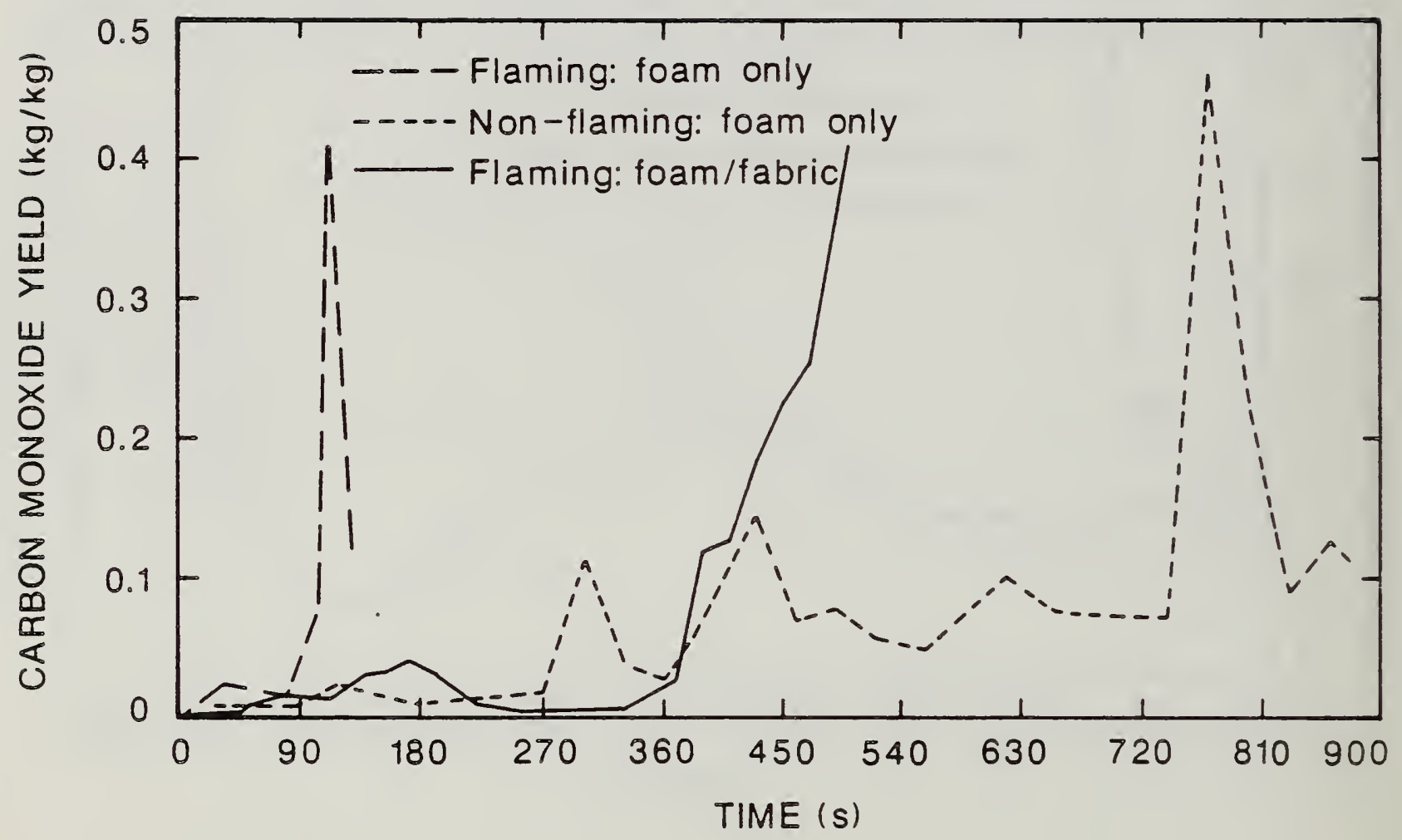

Figure 6. Comparison of Carbon Monoxide Yield for Foam 32 Flaming and Nonflaming Exposures Without a Cover Fabric and Flaming Exposure Hith a Cover Fabric. 


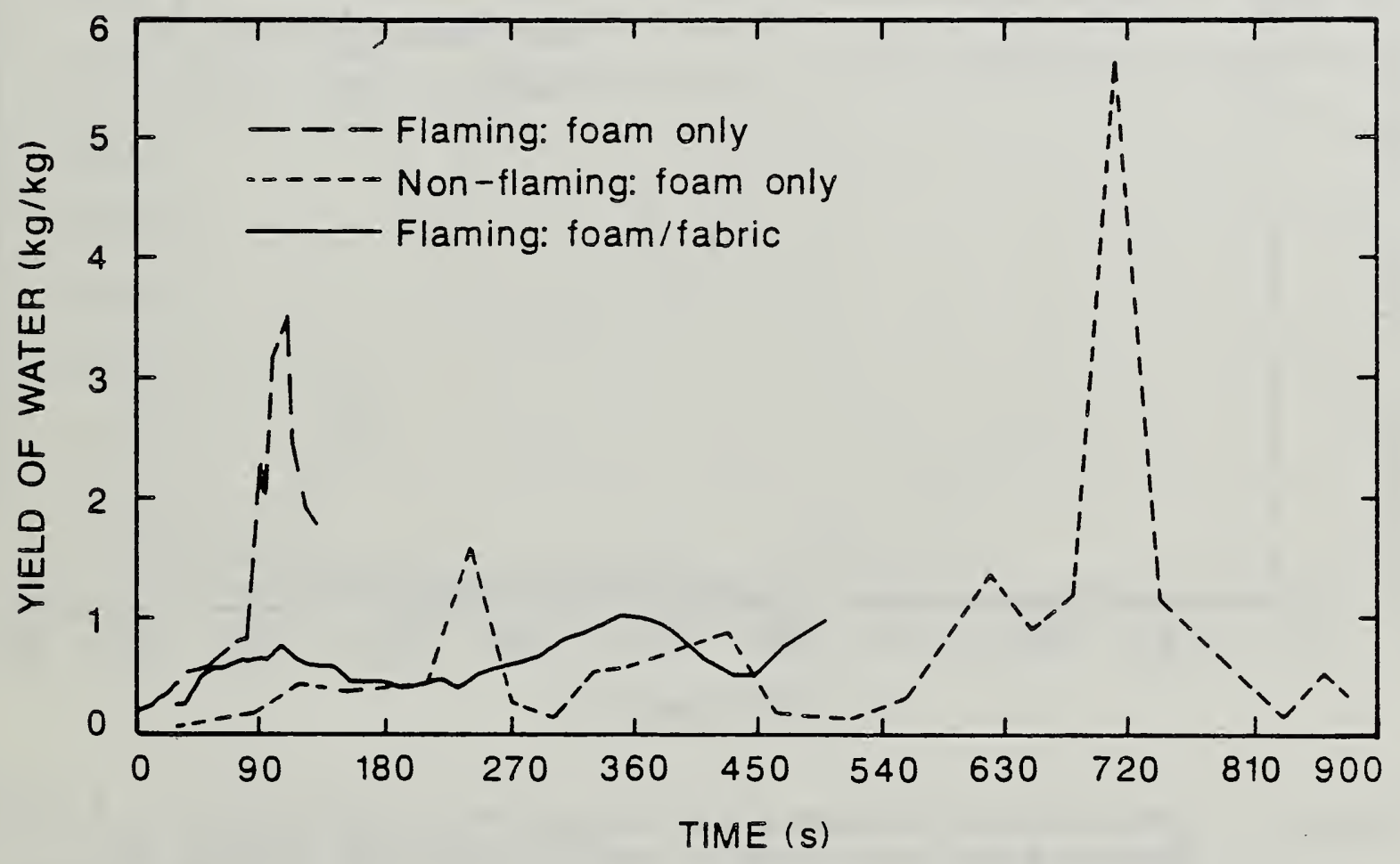

Figure 7. Comparison of Water Yield for Foam 32 Flaming and Non-flaming Exposures Without a Cover Fabric and Flaming Exposure with a Cover Fabric. 


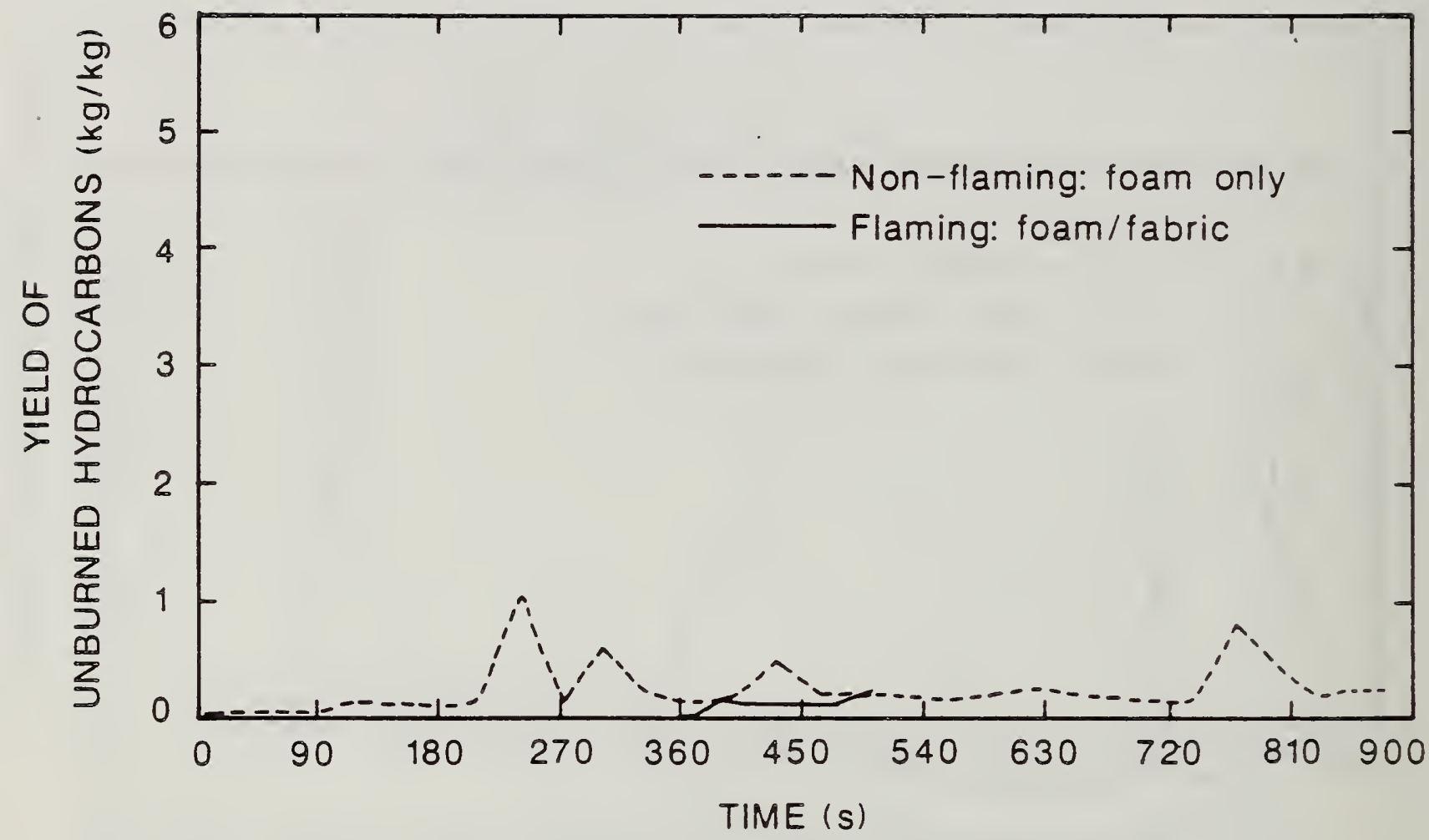

Figure 8. Comparison of Unburned Hydrocarbons for Foam 32 Flaming and Nonflaming Exposures without a Cover Fabric and Flaming Exposure With a Cover Fabric. 


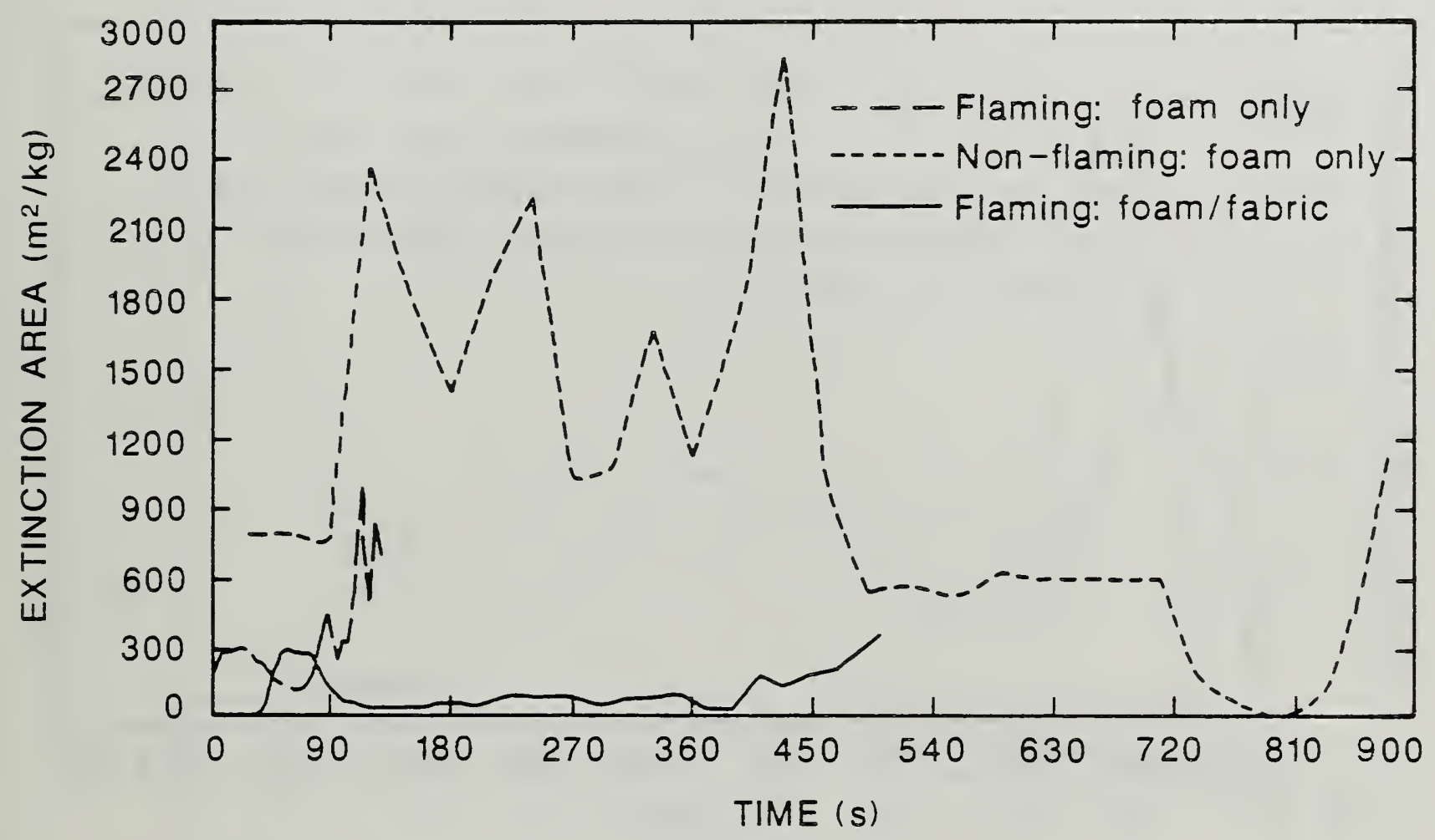

Figure 9. Comparison of Smoke Extinction Area for Foam 32 Flaming and Nonflaming Exposures hithout a Cover Fabric and Flaming Exposure With a Cover Fabric.. 


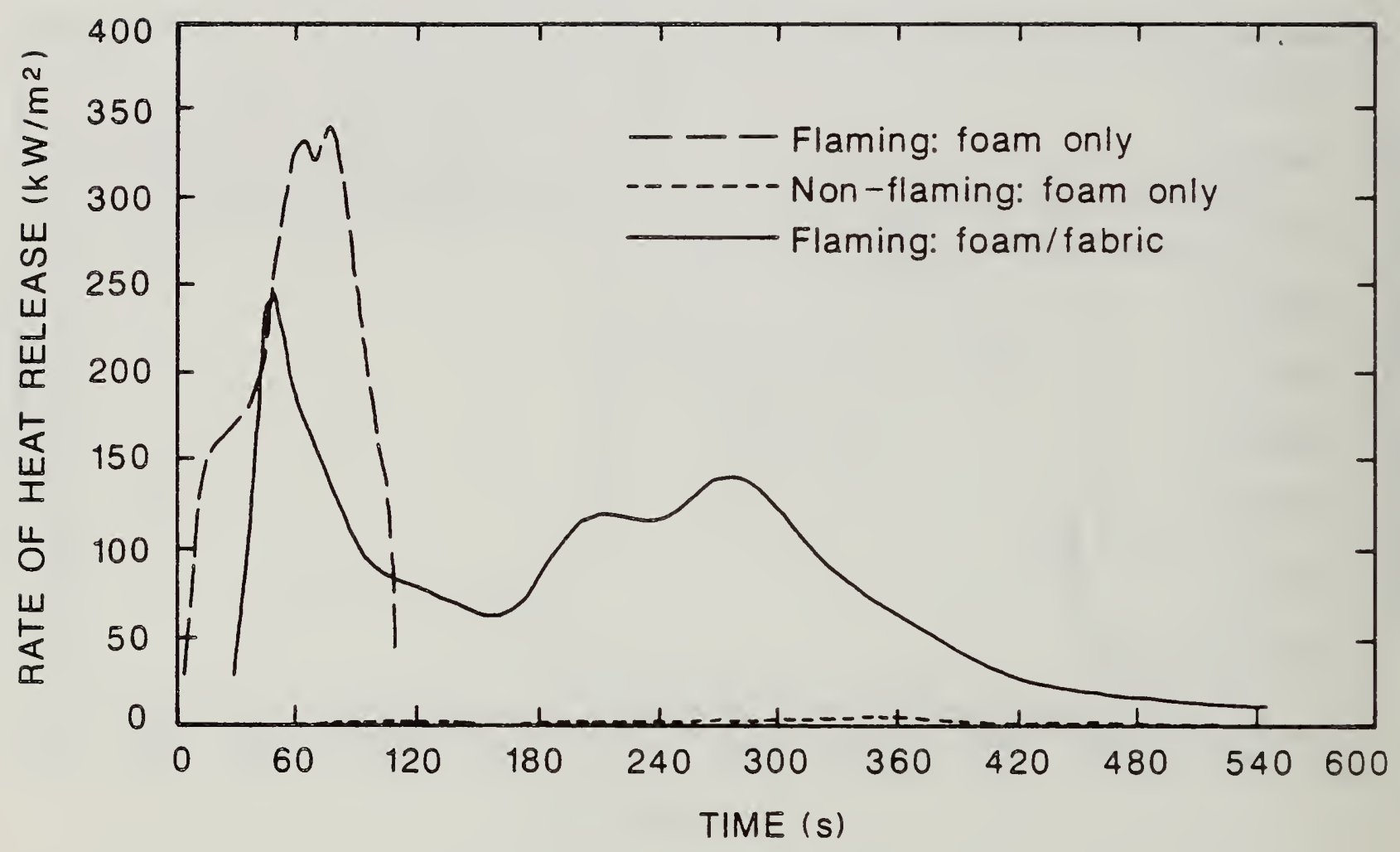

Figure 10. Comparison of Heat Release Rate for Foam $32 \mathrm{X}$ Flaming and Nonflaming Exposures Without a Cover Fabric and Flaming Exposure With a Cover Fabric. 


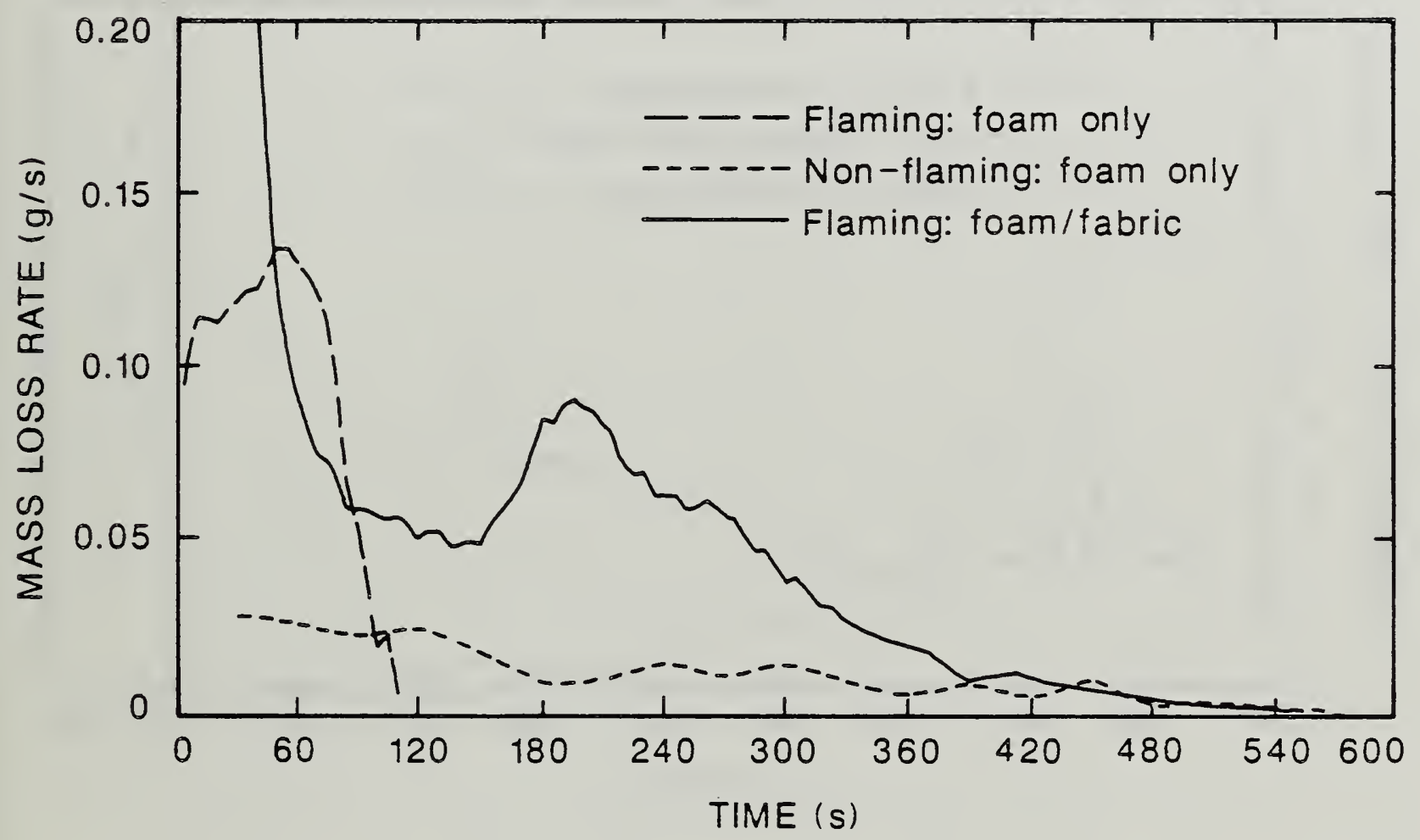

Figure 11. Comparison of Mass Loss Rate for Foam $32 \mathrm{X} \mathrm{Flaming} \mathrm{and} \mathrm{Non-}$ flaming Exposures Without a Cover Fabric and Flaming Exposure With a Cover Fabric.: 


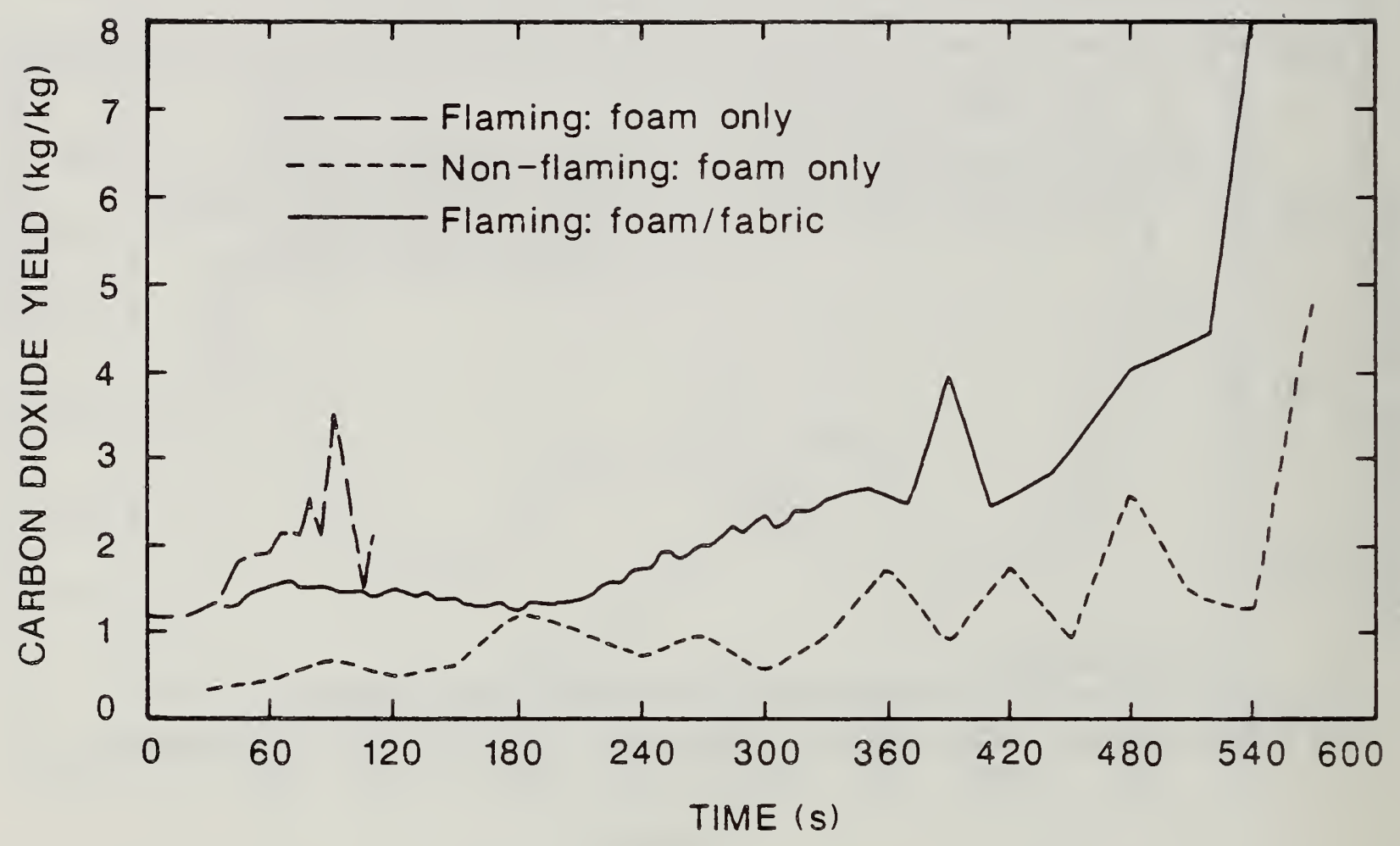

Figure 12. Comparison of Carbon Dioxide Yield for Foam $32 \mathrm{X}$ Flaming and Non-flaming Exposures Without a Cover Fabric and Flaming Exposures with a Cover Fabric. 


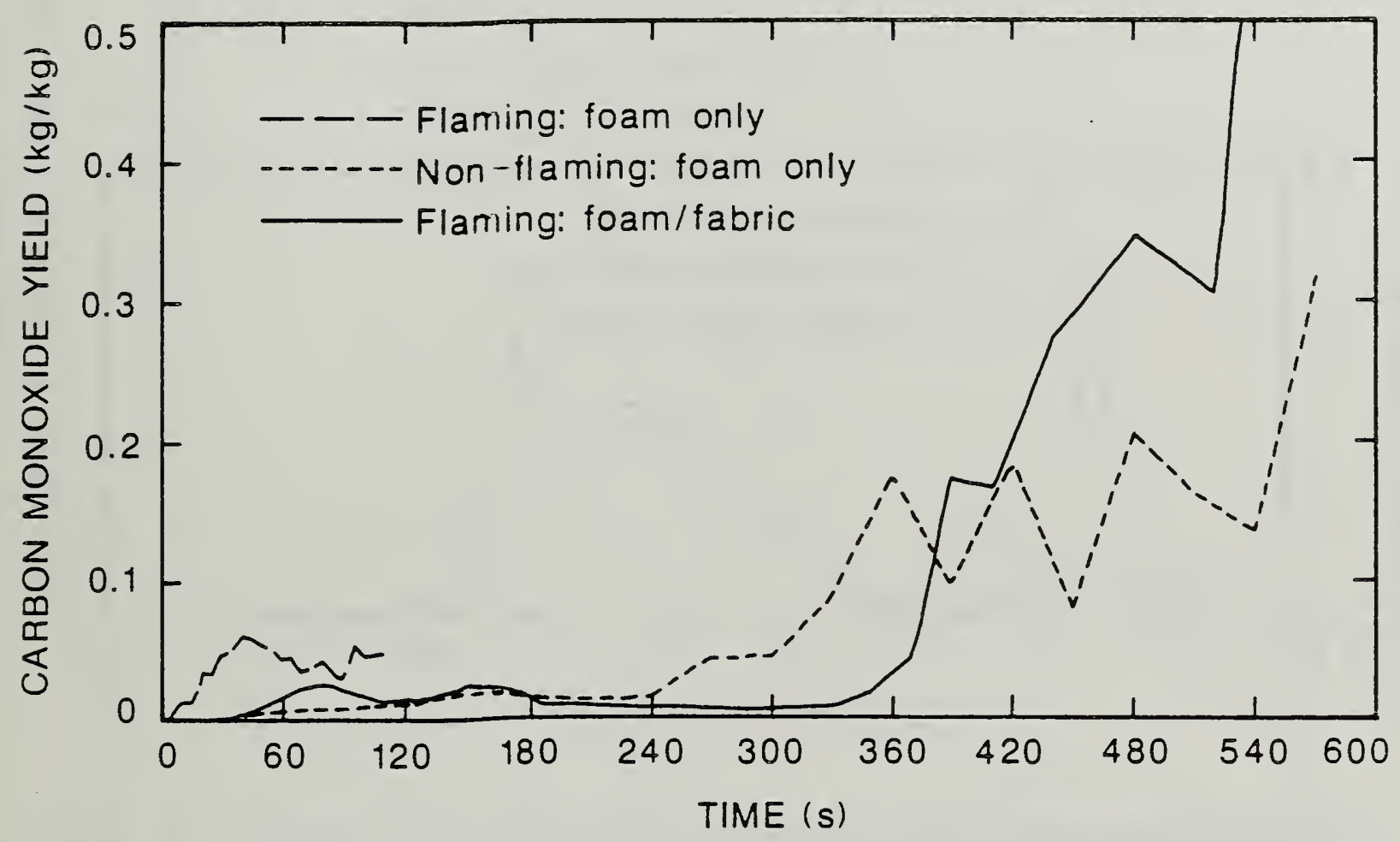

Figure 13. Comparison of Carbon Monoxide Yield for Foam $32 \mathrm{X}$ Flaming and Non-flaming Exposures Without a Cover Fabric and Flaming Exposure With a Cover Fabric. 


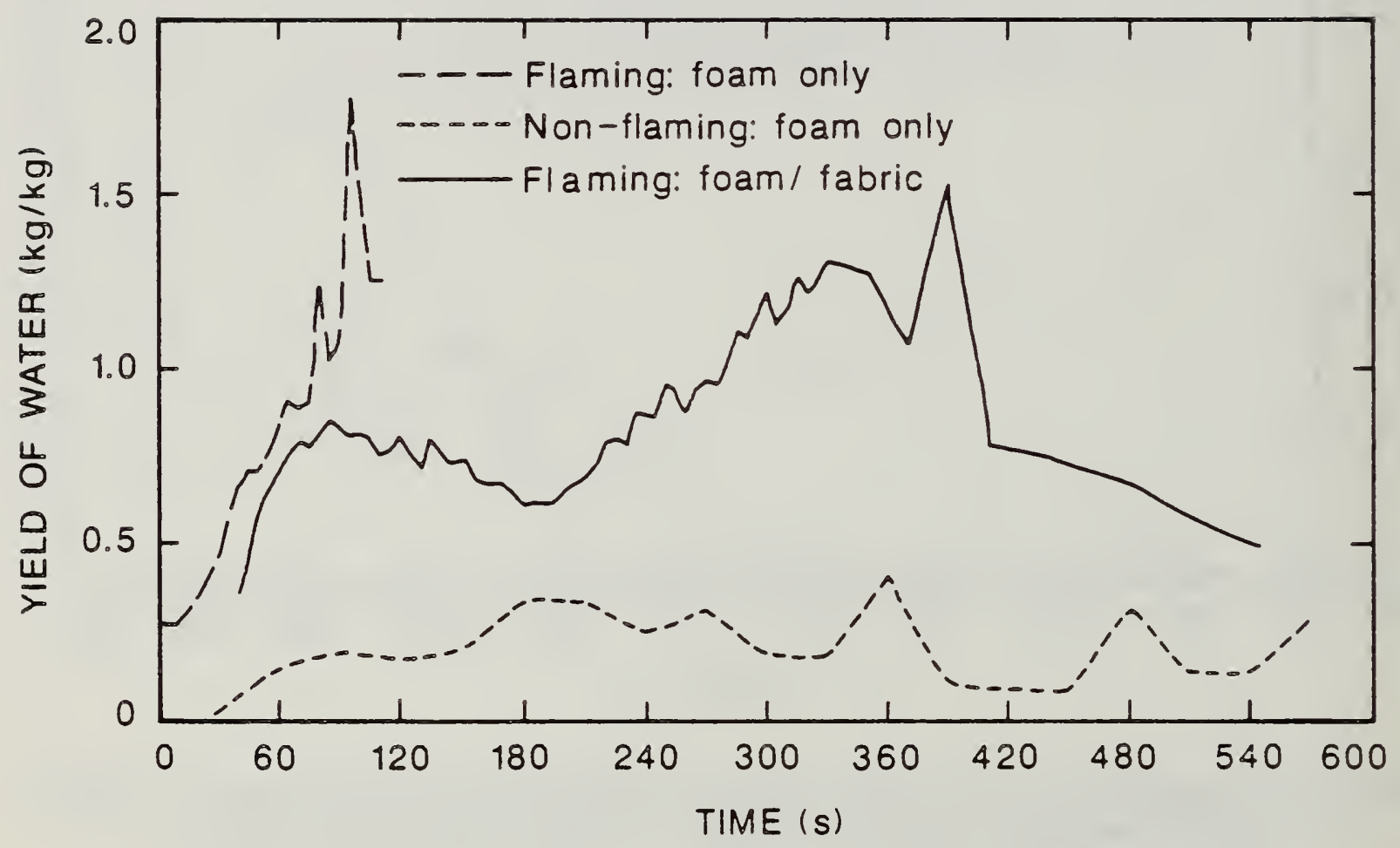

Figure 14. Comparison of Water Yield for Foam $32 \mathrm{X}$ Flaming and Non-flaming Exposures Without a Cover Fabric and Flaming Exposure With a Cover Fabric. 


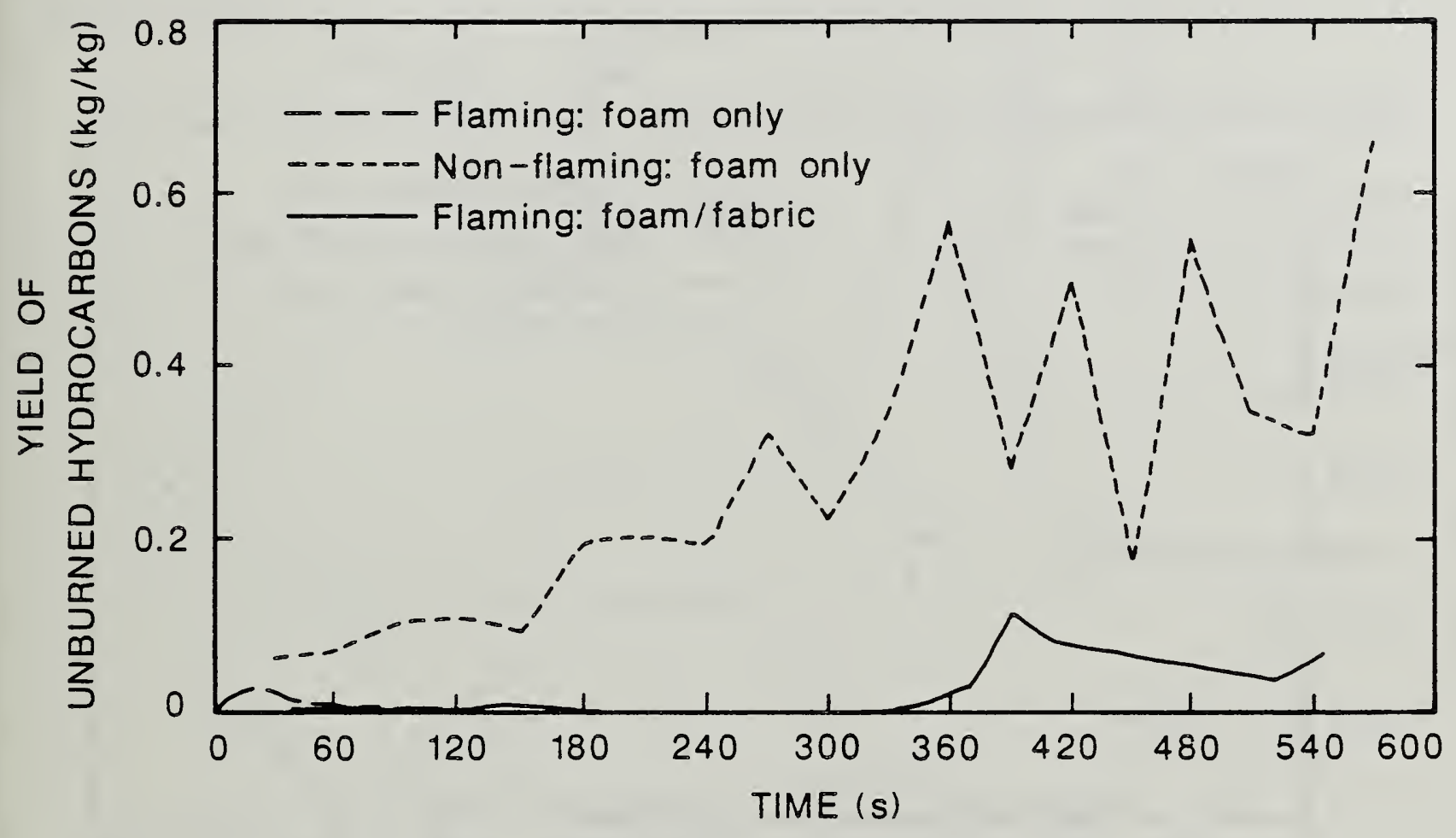

Figure 15. Comparison of Unburned Hydrocarbon Yield for Foam $32 \mathrm{X}$ Flaming and Non-flaming Exposures Without a Cover Fabric and Flaming Exposure With a Cover Fabric. 


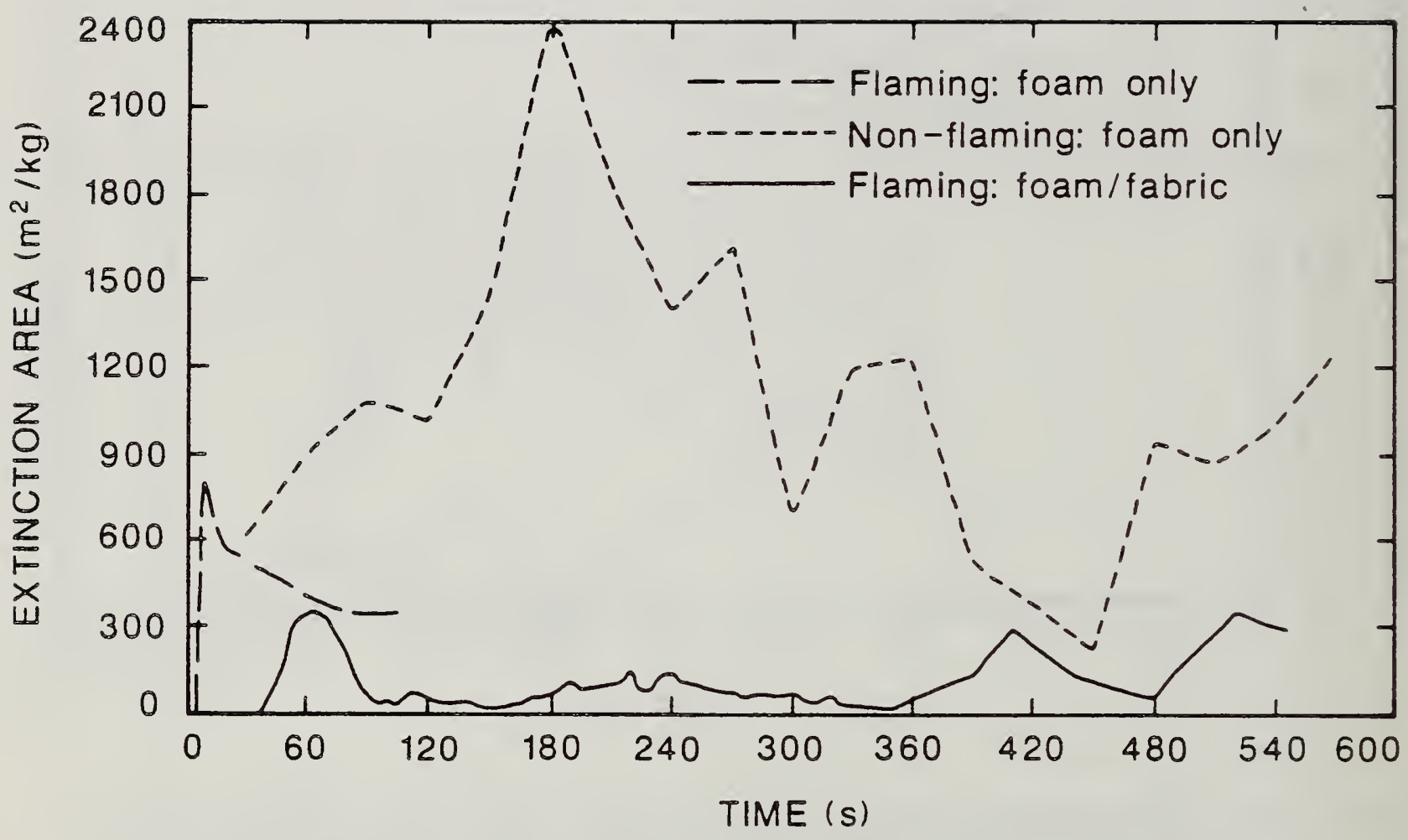

Figure 16. Comparison of Smoke Extinction Area for Foam 32X Flaming and Non-flaming Exposures Without a Cover Fabric and Flaming Exposure with a Cover Fabric. 

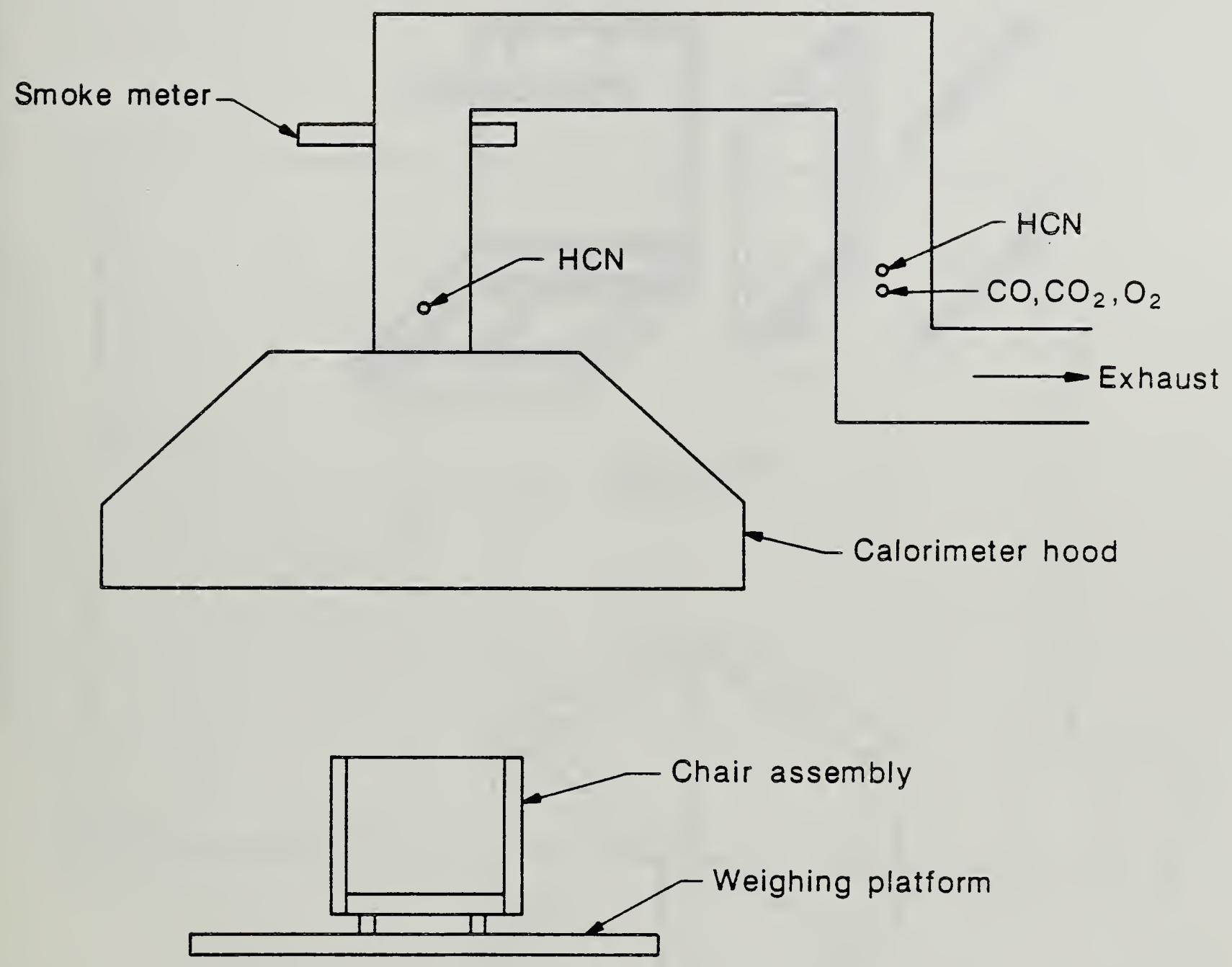

Figure 17. Schematic of Furniture Calorimeter. 
Left hand arm and cushion supports not shown
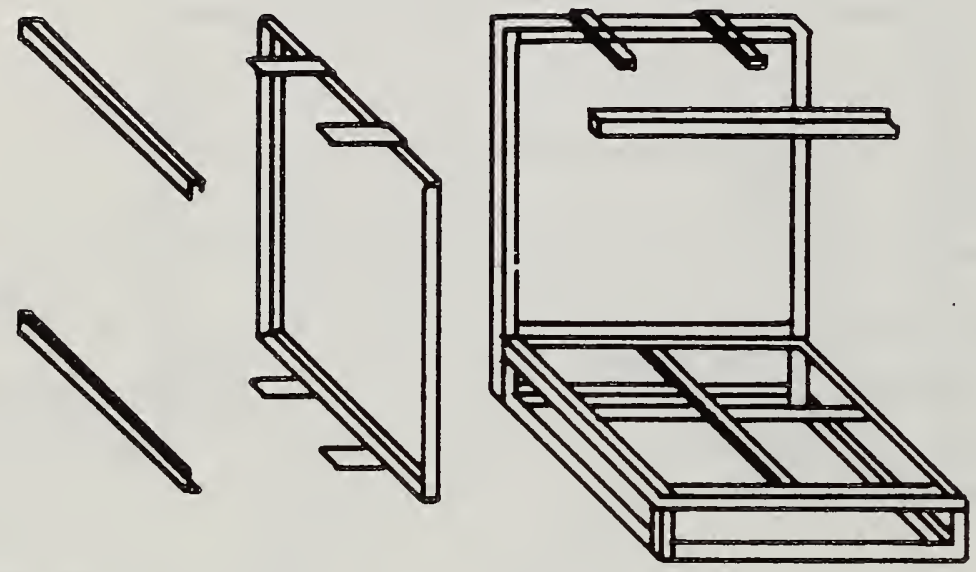

Frame

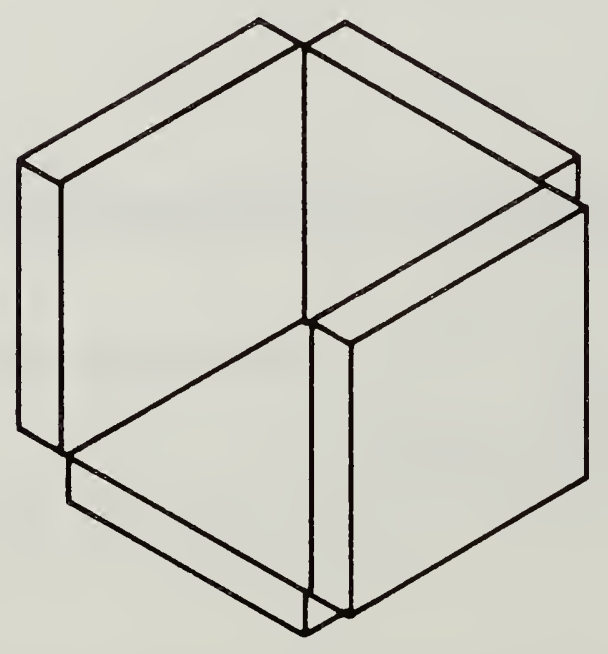

4 cushions

Figure 18. Four Cushion Mock-up Chair Assembly and Steel Frame. 


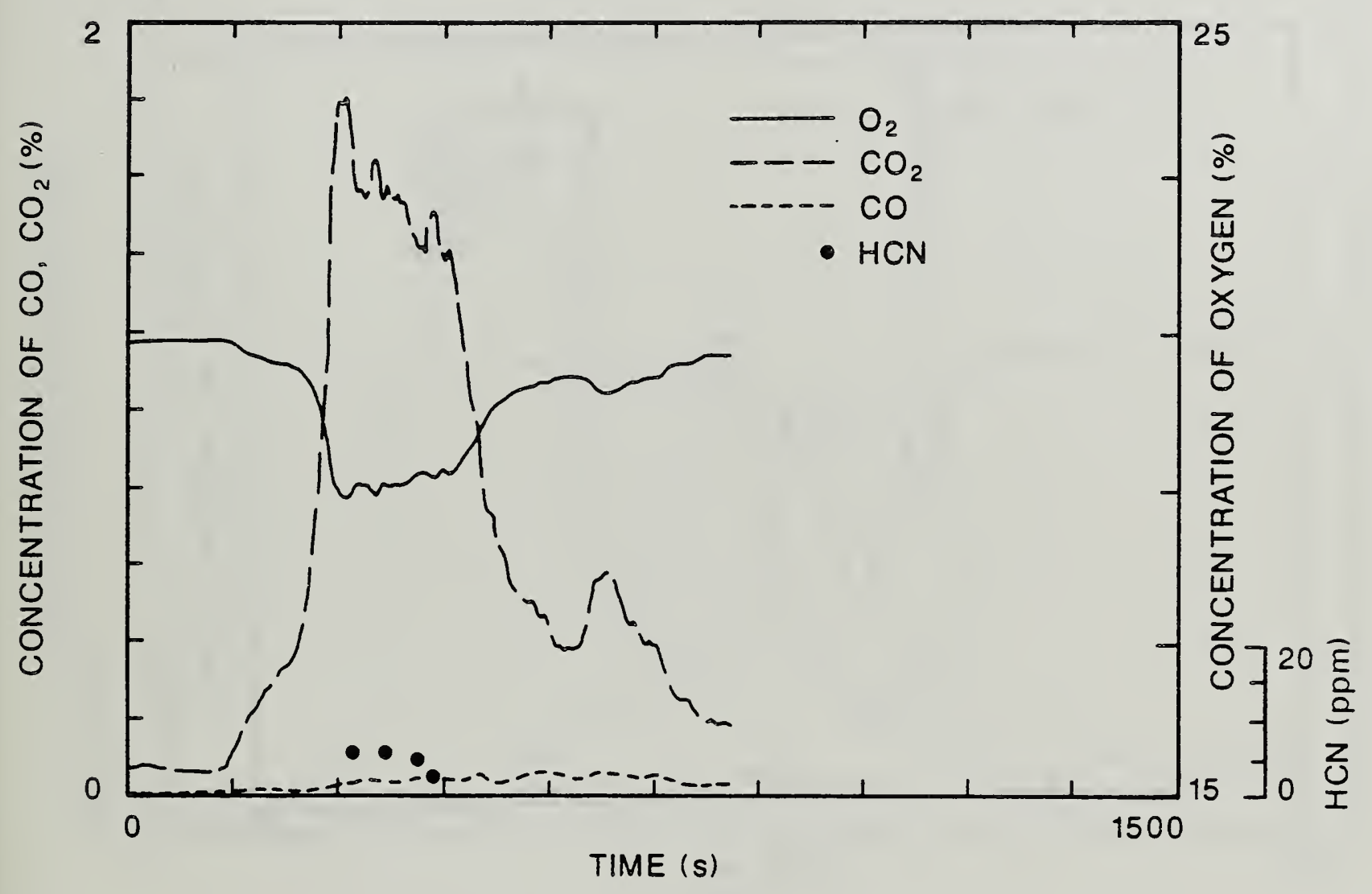

Figure 19. Furniture Calorimeter Data for the Concentration of Carbon Dioxide, Carbon Monoxide, HCN, and Oxygen for the Flaming Ignition of Mock-up Chairs made with Foam 32. 


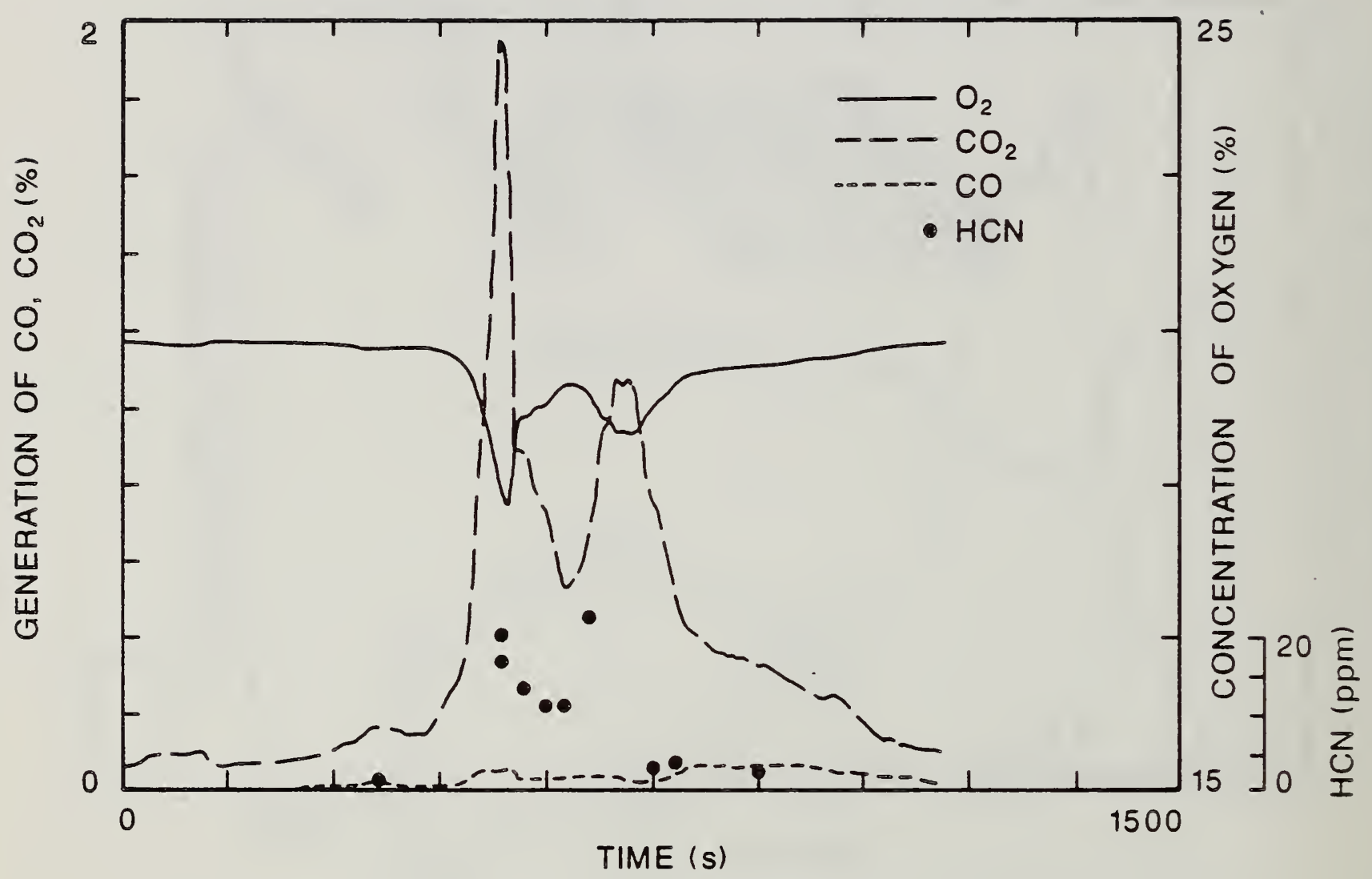

Figure 20. Furniture Calorimeter Data for the Concentration of Carbon Dioxide, Carbon Monoxide, HCN, and Oxygen for Flaming Ignition of Mock-up Chairs made with Foam $32 \mathrm{X}$. 


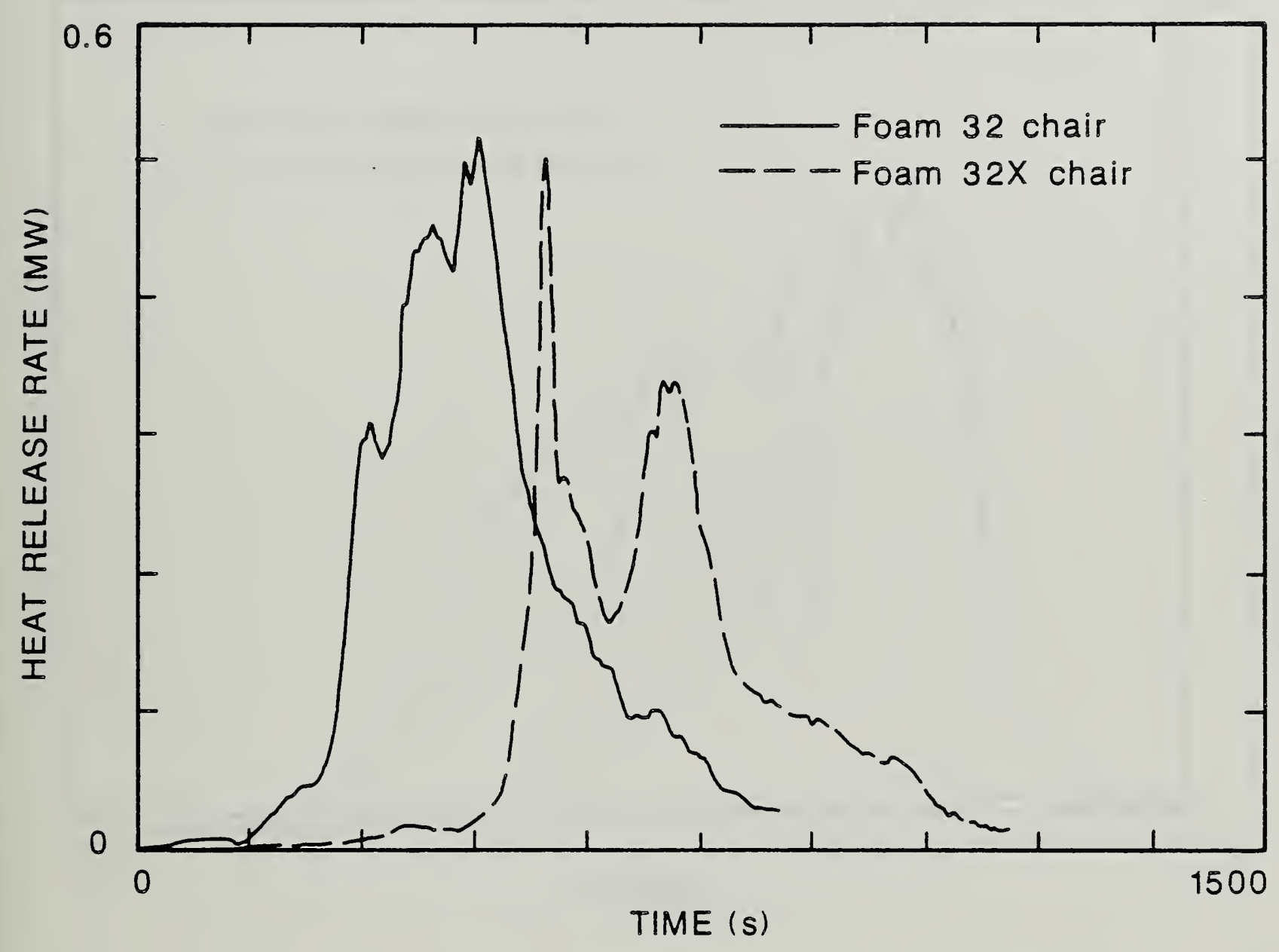

Figure 21. Furniture Calorimeter Data Comparing the Rate of Heat Release from the Flaming Ignition of Mock-up Chairs Made from Either Foam 32 and Foam $32 \mathrm{X}$. 


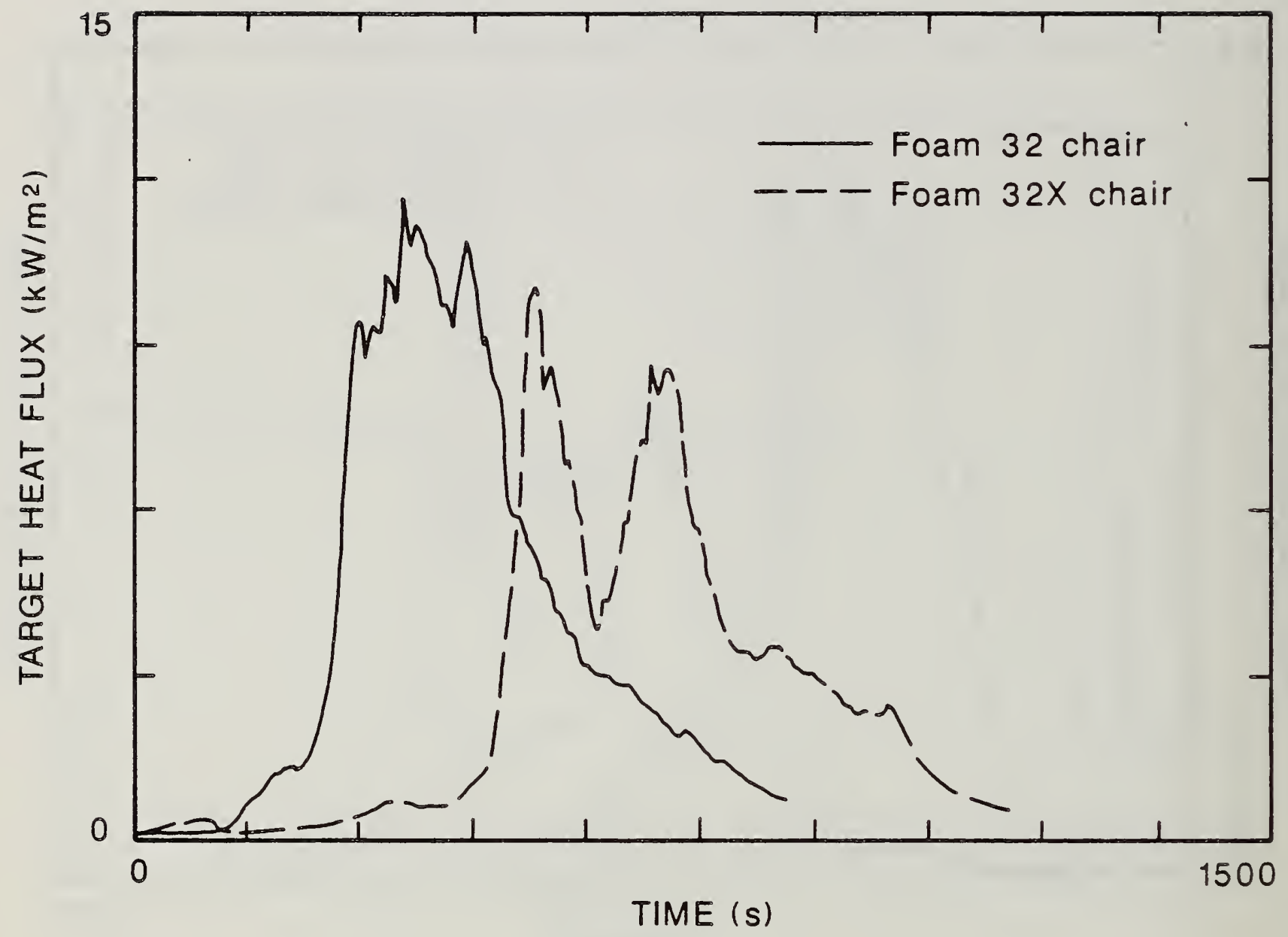

Figure 22. Furniture Calorimeter Data Comparing the Heat Flux Received by a Target Material from the Flaming Ignition of Mock-up Upholstery Chairs made from Foam 32 and Foam $32 \mathrm{X}$. 


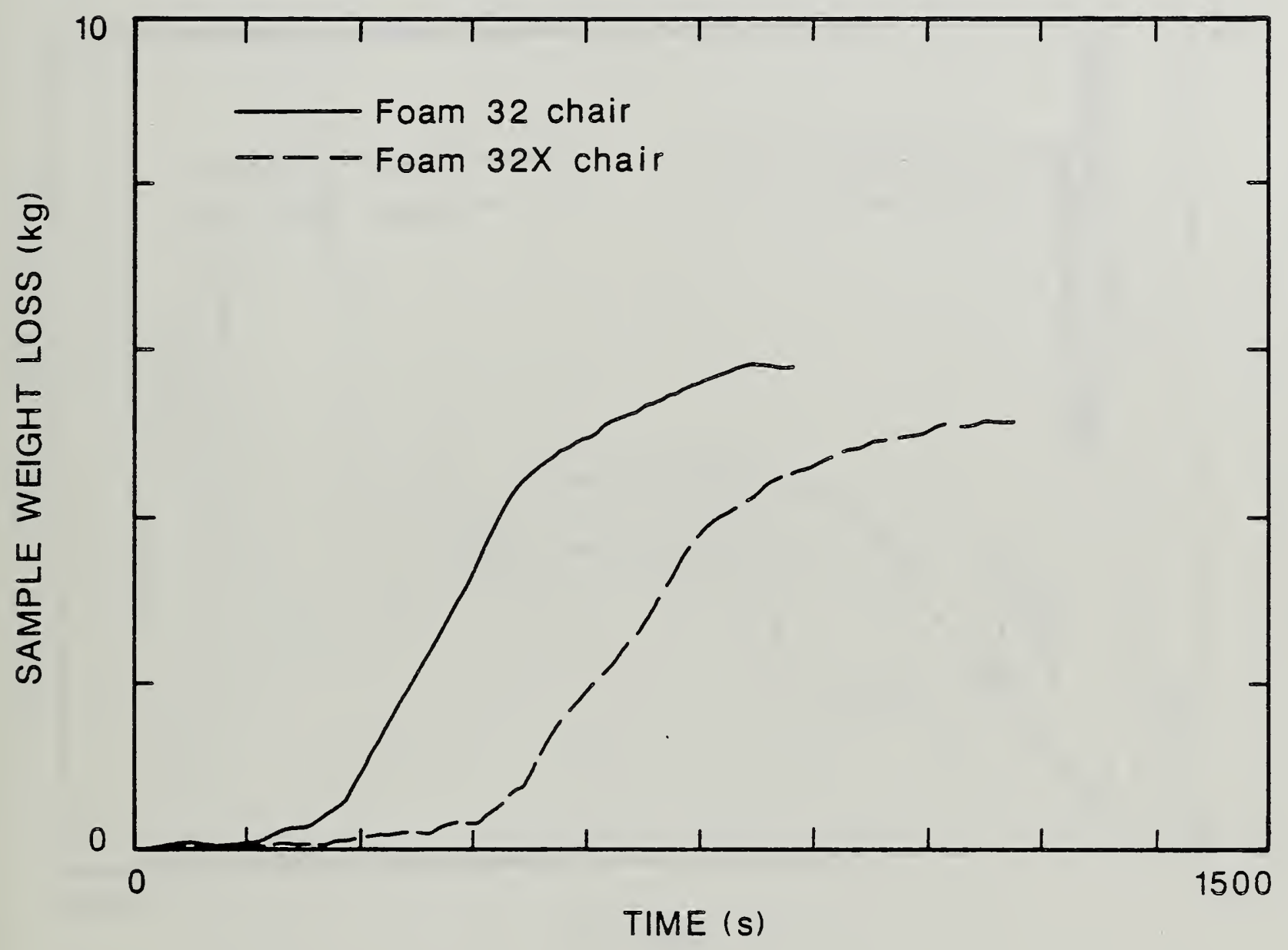

Figure 23. Comparison of Sample Weight Loss During Flaming Ignition of Foams 32 and $32 \mathrm{X}$ in the Furniture Calorimeter. 


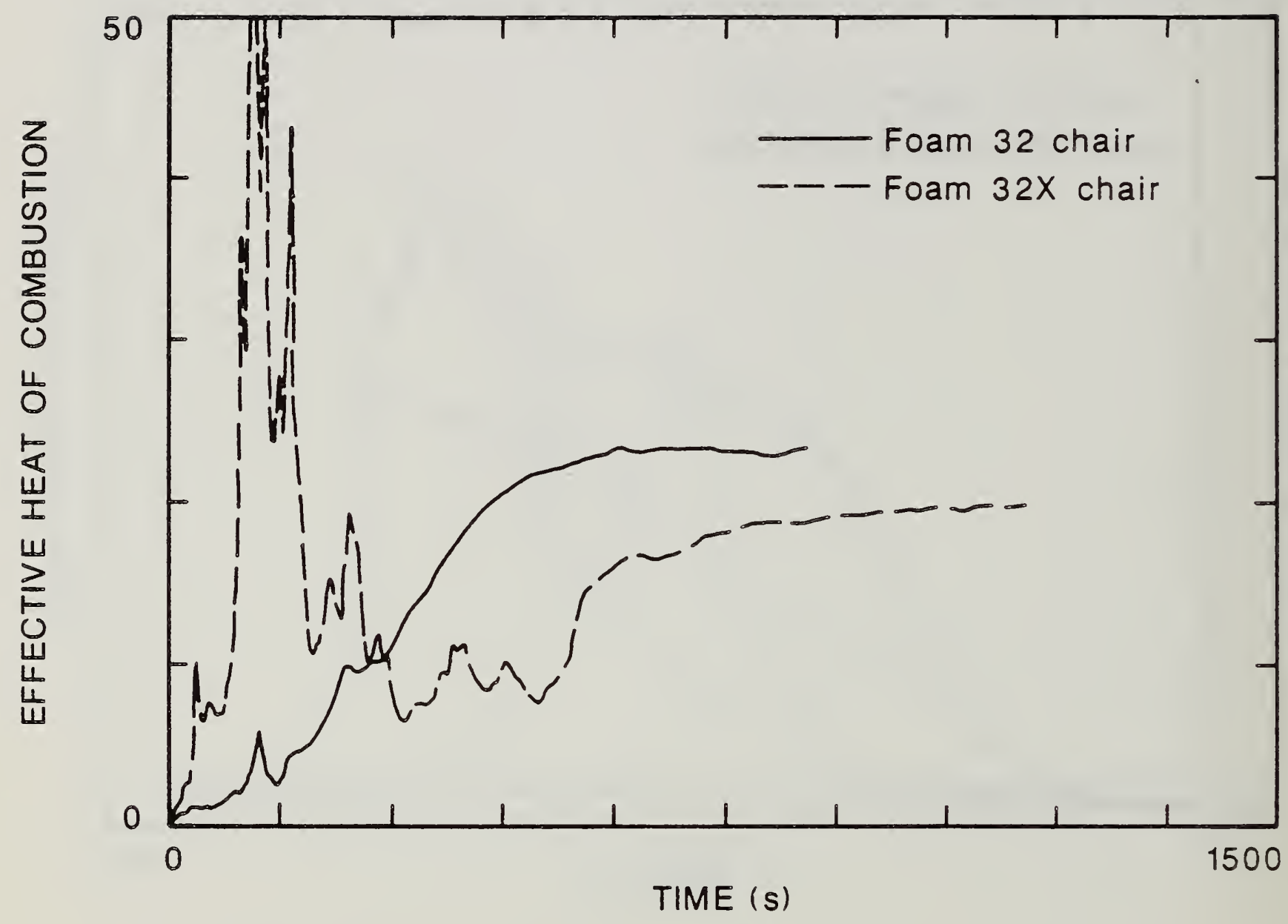

Figure 24. Comparison of the Effective Heat of Combustion from the Flaming Ignition of Foams 32 and $32 \mathrm{X}$ Mock-up Upholstery Chairs Tested in the Furniture Calorimeter. 


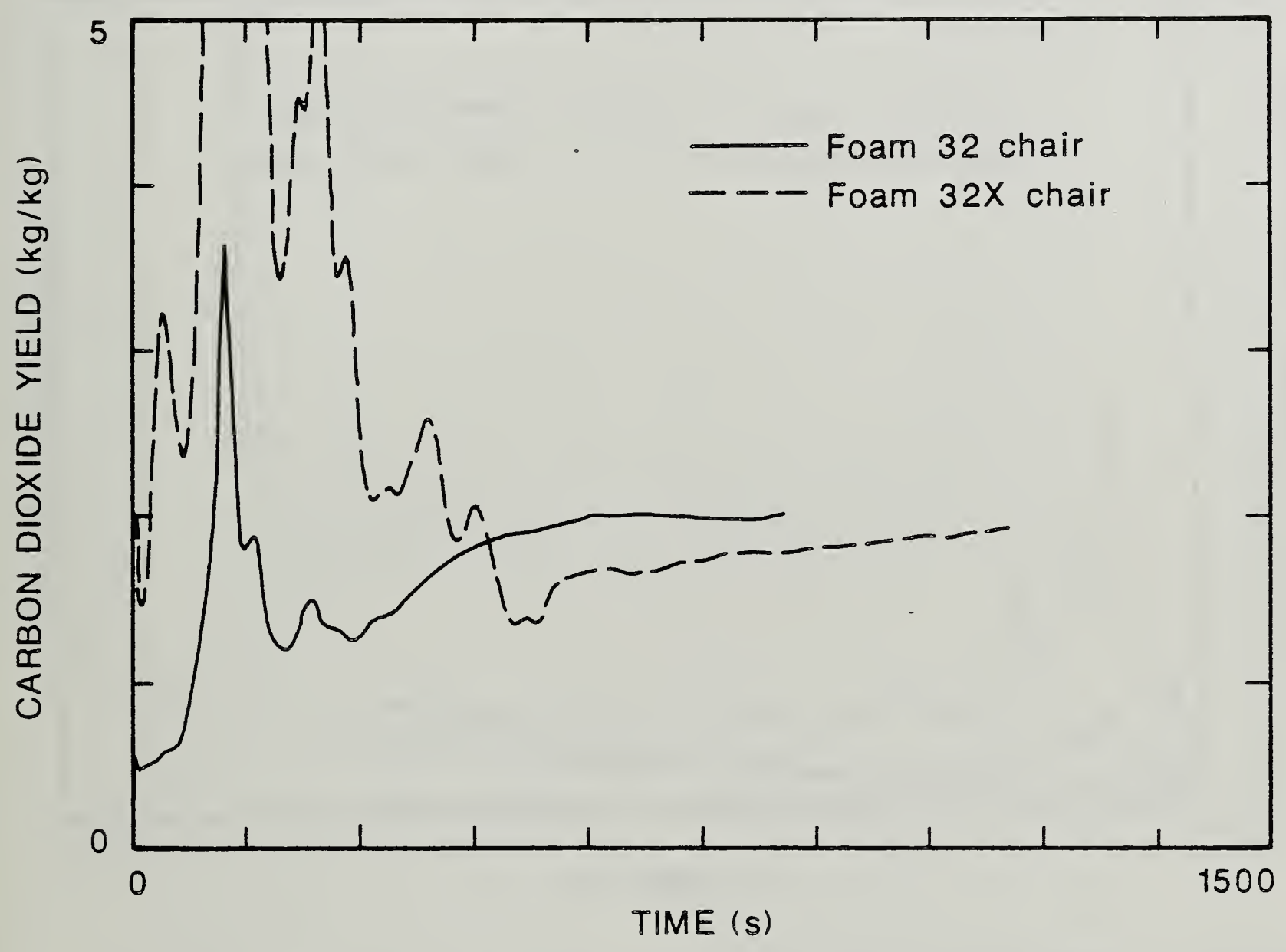

Figure 25. Comparison of Carbon Dioxide Yield for the Flaming Ignition of Foams 32 and $32 \mathrm{X}$ Mock-up Upholstery Chairs Tested in the Furniture Calorimeter. 


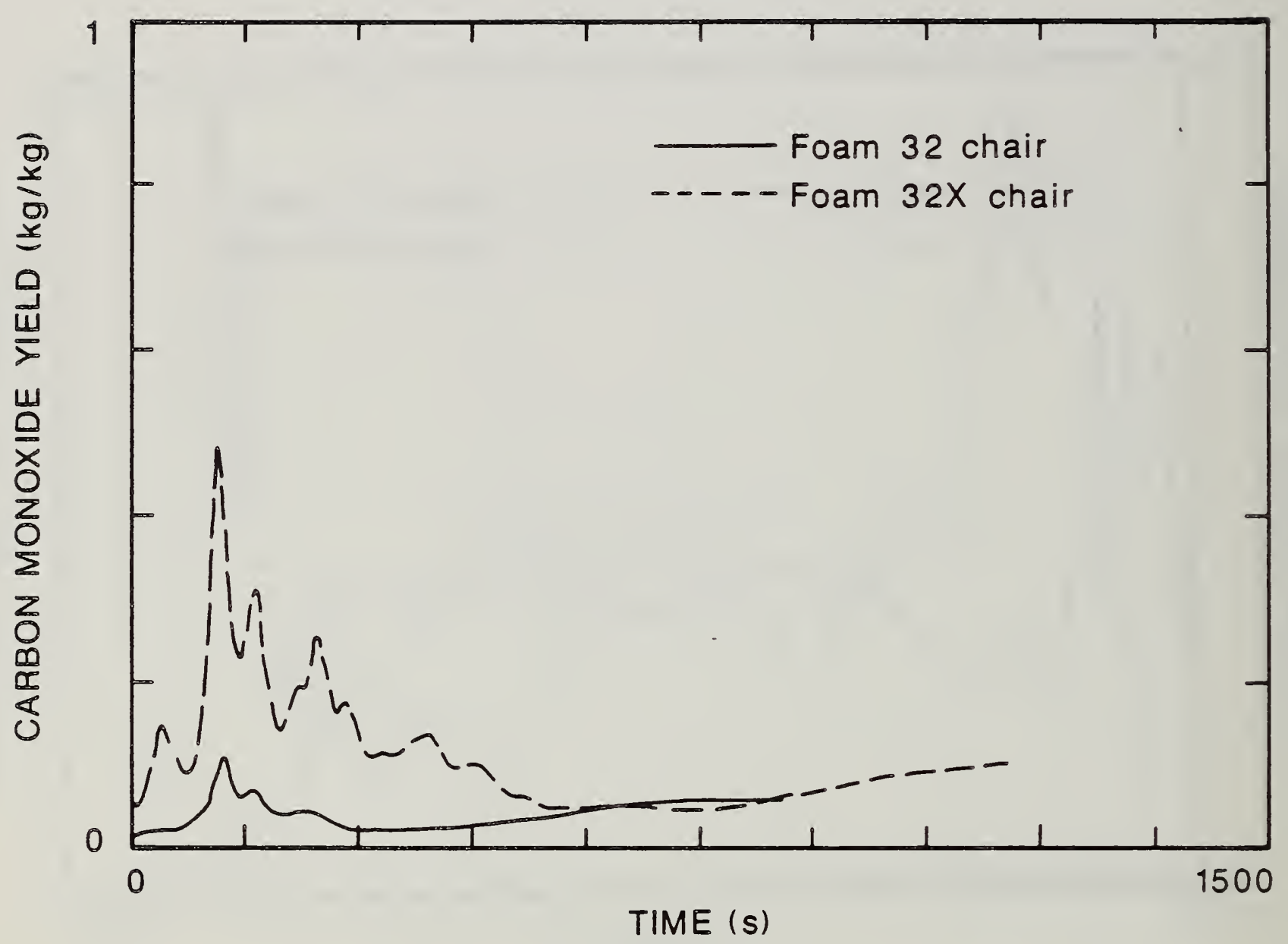

Figure 26. Comparison of Carbon Monoxide Yield for the Flaming Ignition of Foams 32 and $32 \mathrm{X}$ Mock-up Chairs Tested in the Furniture Calorimeter. 


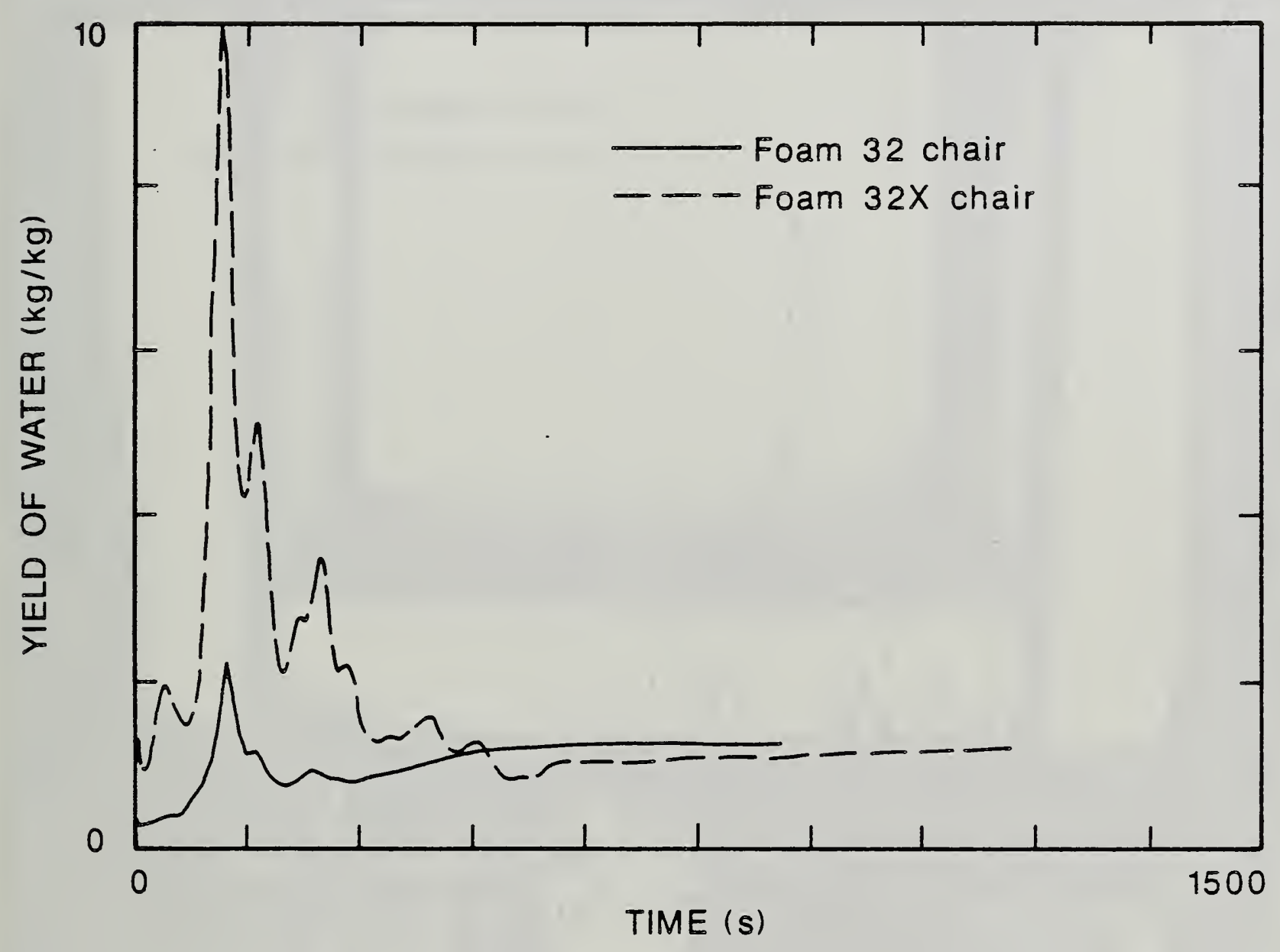

Figure 27. Comparison of the Yield of Water from the Flaming Ignition of Foams 32 and $32 \mathrm{X}$ During the Burning of Mock-up Upholstery Chairs in the Furniture Calorimeter. 


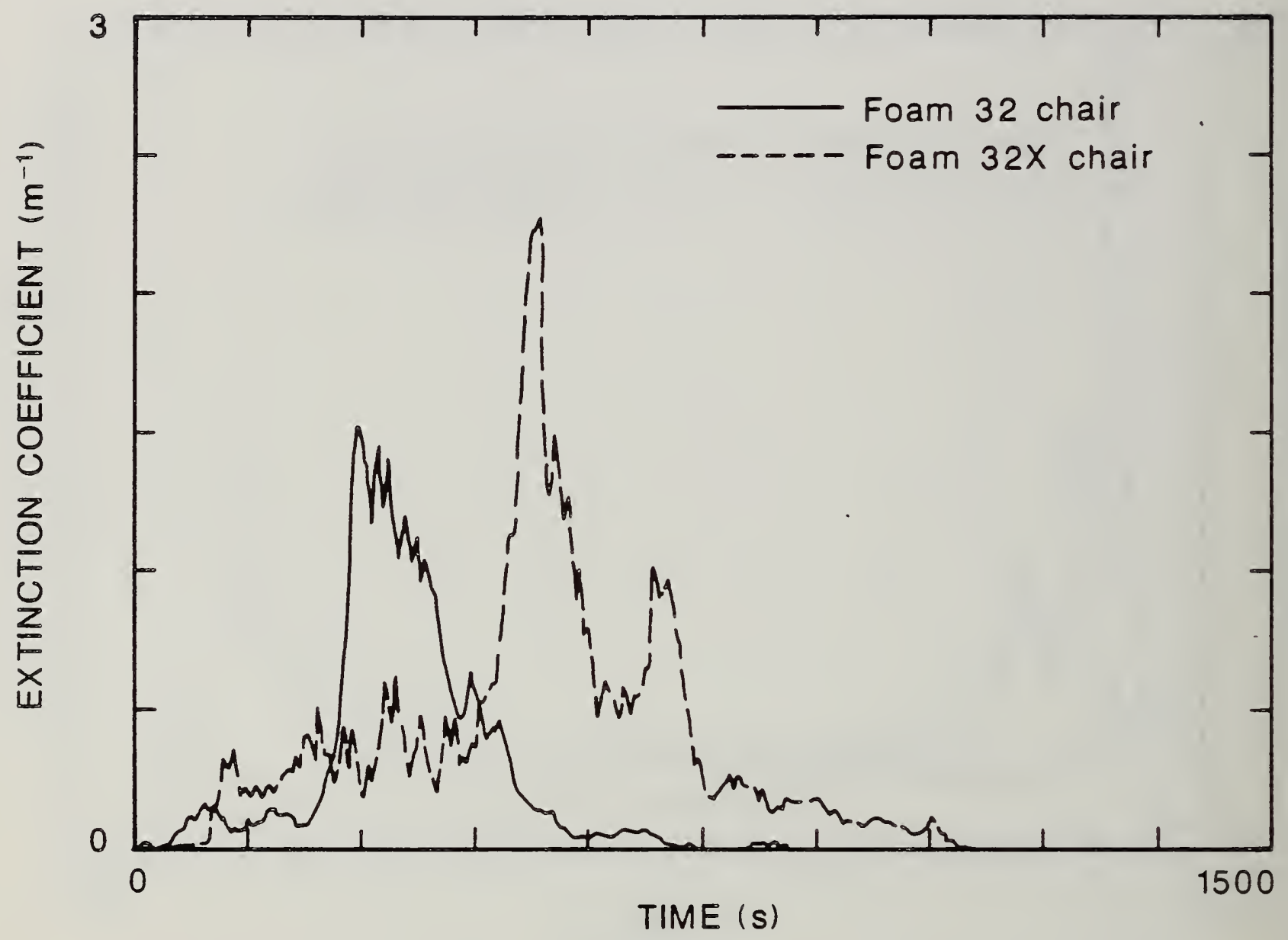

Figure 28. Comparison of the Smoke Extinction Coefficient for the Flaming Ignition of Mock-up Foams 32 and $32 x$ Upholstery Chairs Tested in the Furniture Calorimeter. 


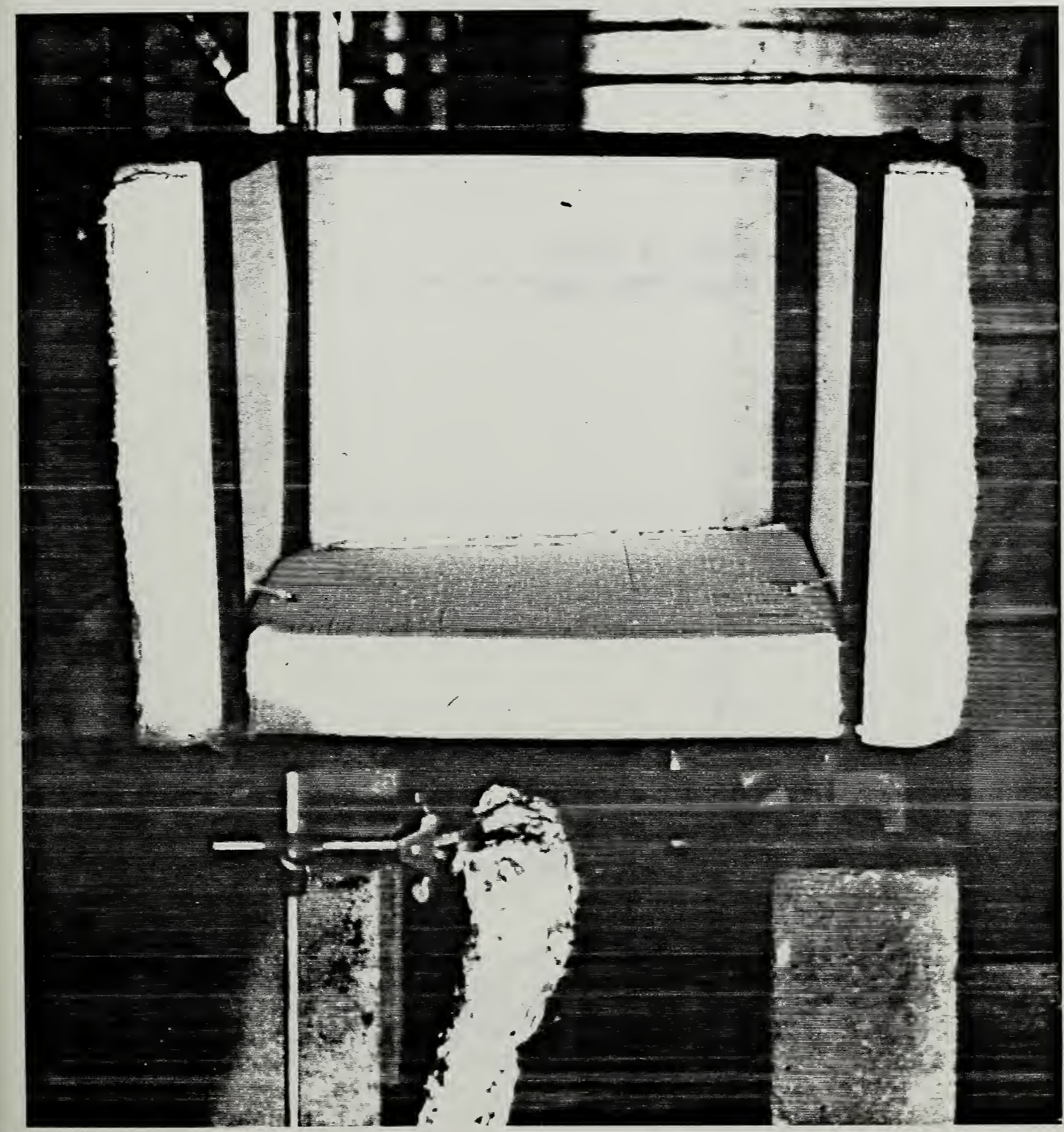

Figure 29. Upholstery Chair Mock-up with Two Smoldering Cigarettes as Tested in the Furniture Calorimeter. 


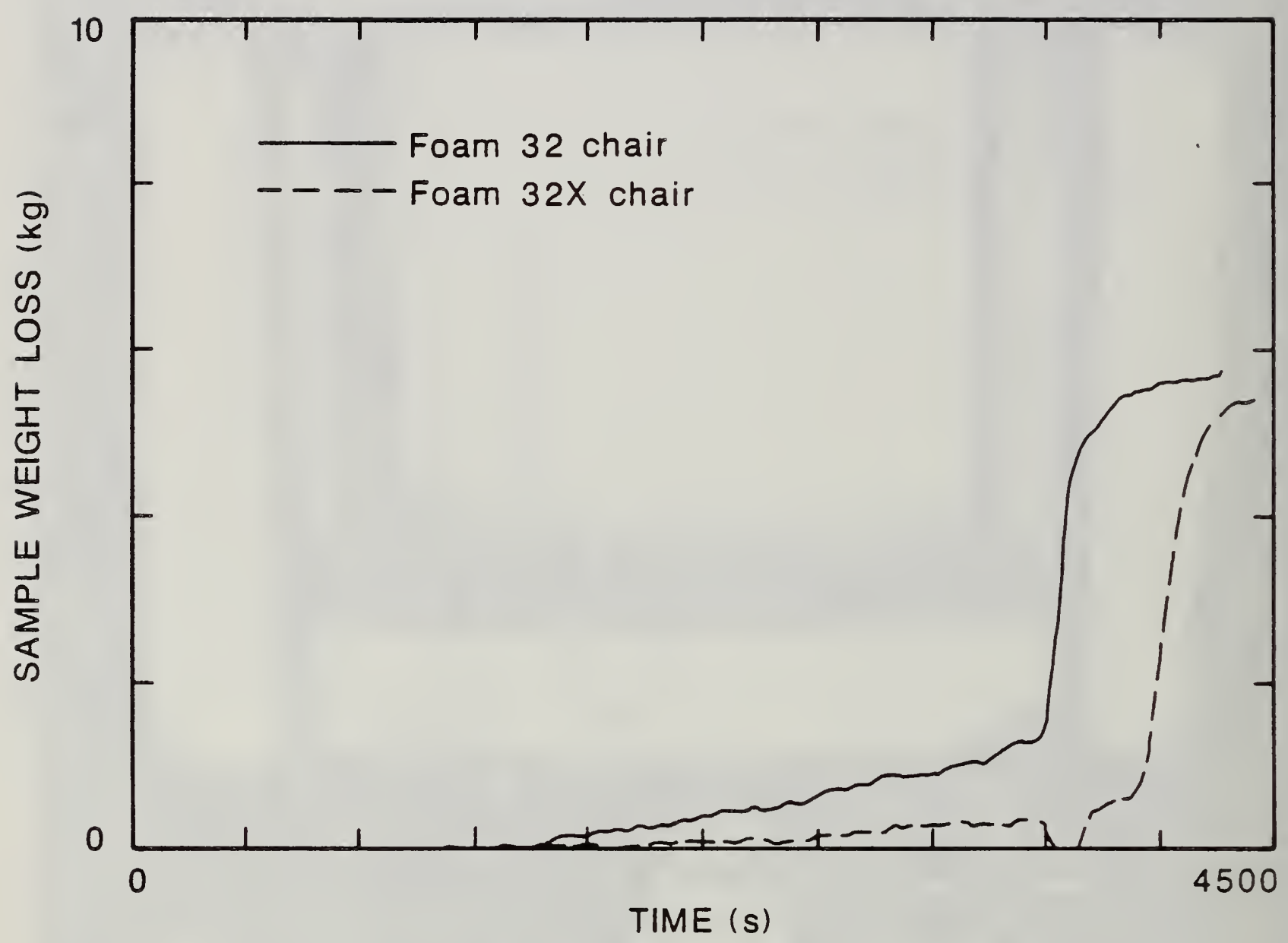

Figure 30. Comparison of Sample weight Loss During Smoldering-to-Flaming Ignitior of Mock-up Upholstery Chairs Made from Foams 32 and $32 \mathrm{X}$ Tested in the Furniture Calorimeter. 


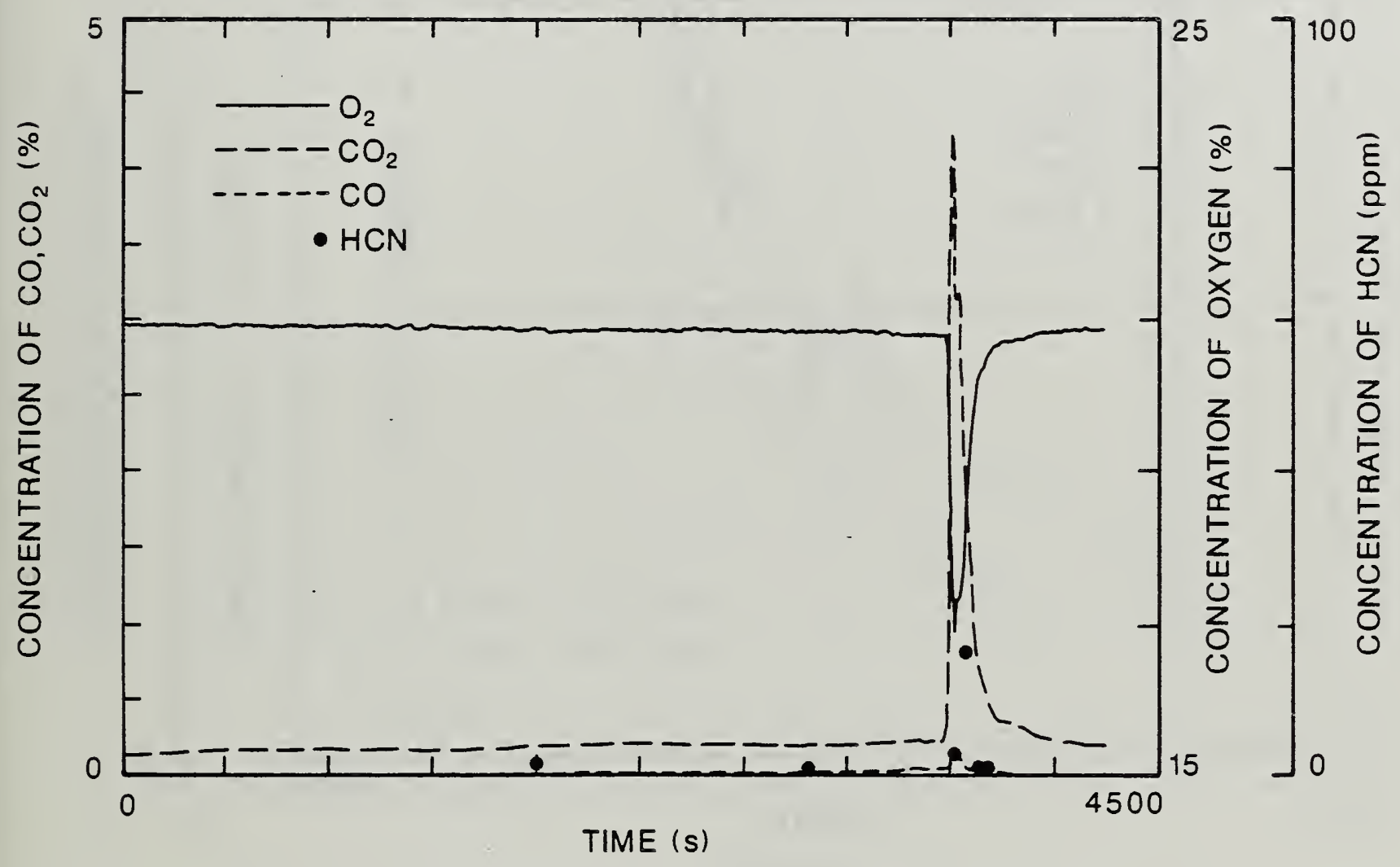

Figure 31. Concentration of $\mathrm{CO}_{2}, \mathrm{CO}, \mathrm{HCN}$, and Oxygen during the Smoldering-to-Flaming Ignition of Foam 32 Mock-up Upholstery Chairs Tested in the Furniture Calorimeter. 


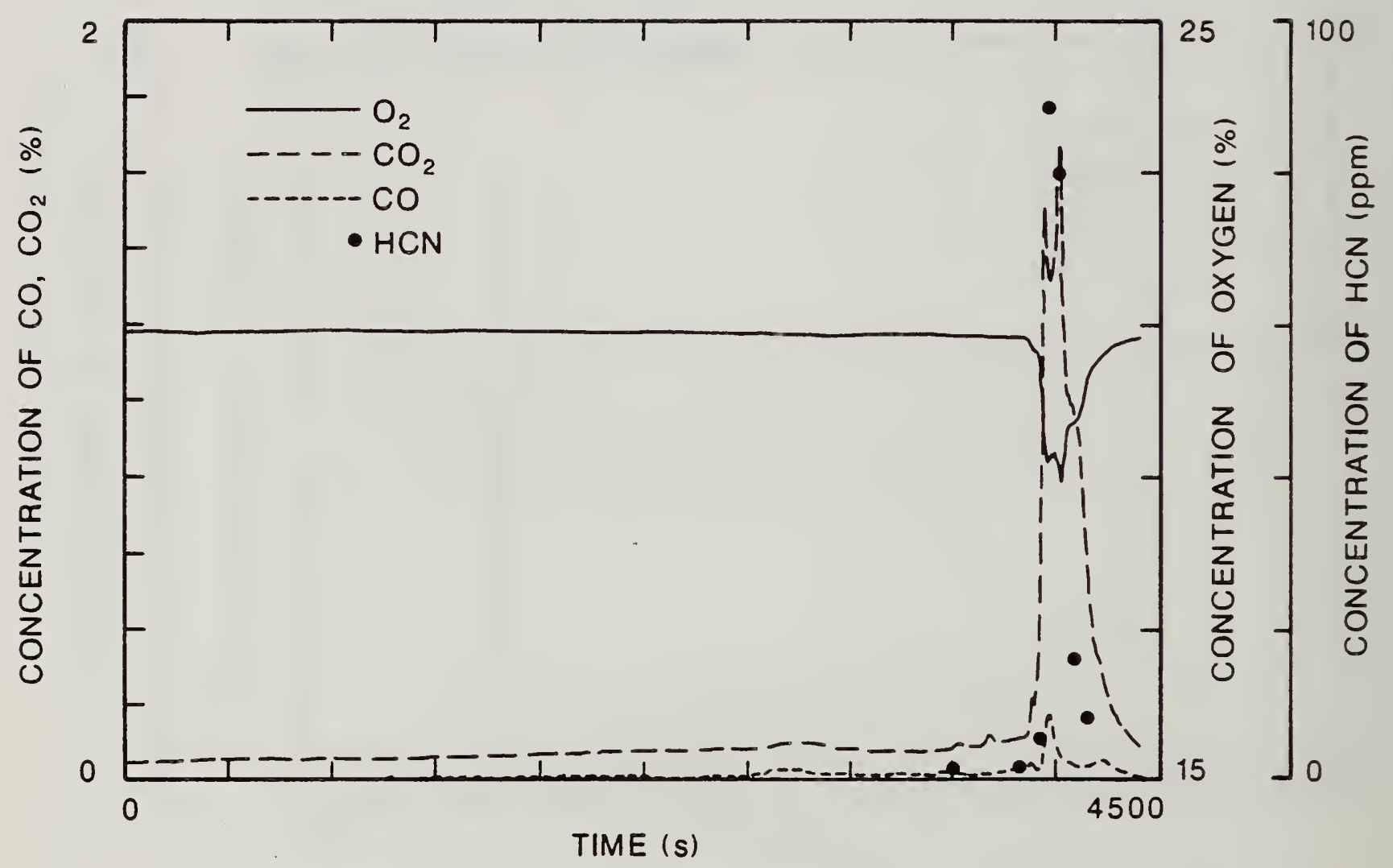

Figure 32. Concentration of $\mathrm{CO}_{2}, \mathrm{CO}, \mathrm{HCN}$, and Oxygen During the Smoldering-to-Flaming Ignition of Foam 32X Mock-up Upholstery Chairs Iested in the Furniture Calorimeter. 


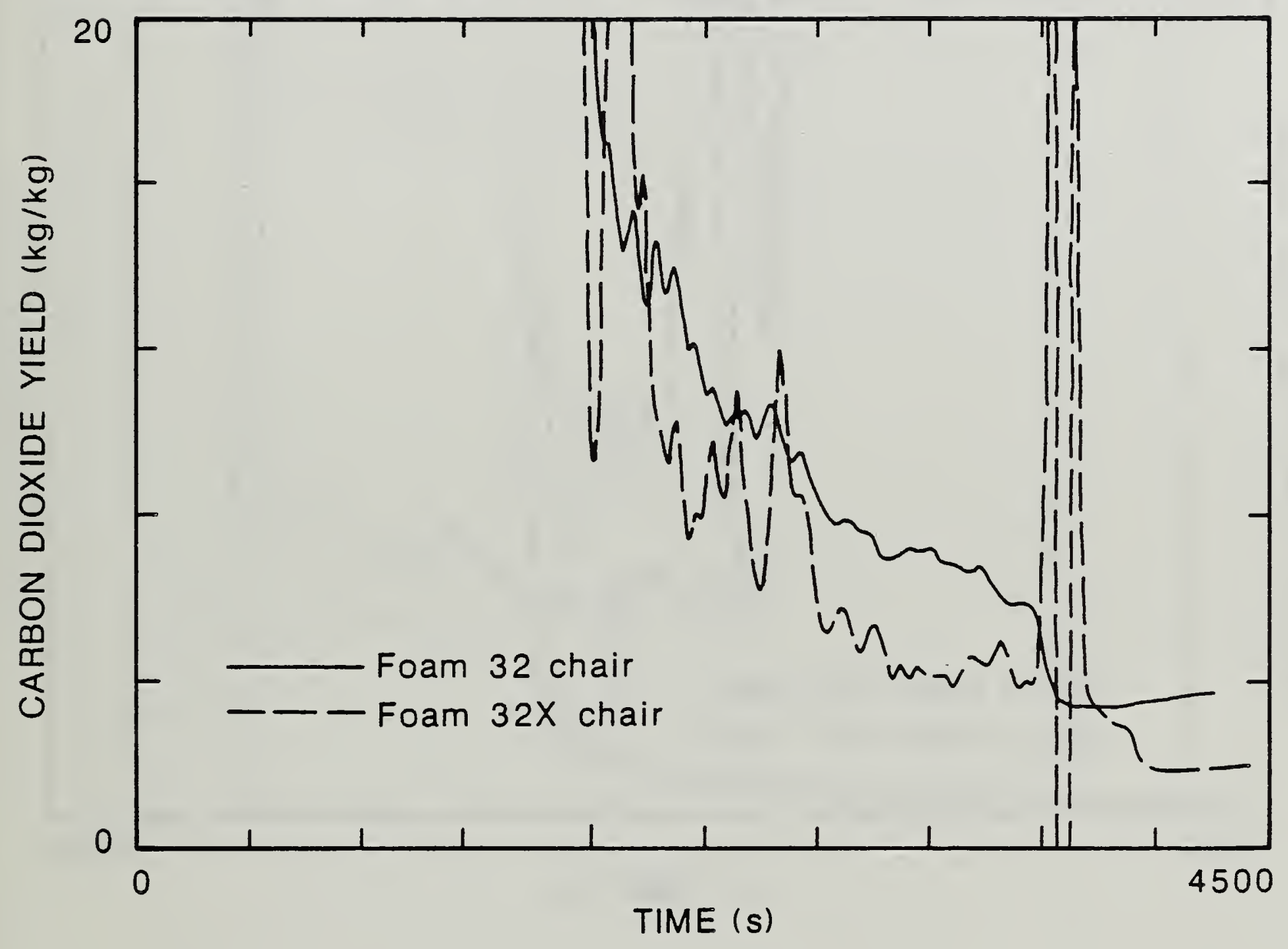

Figure 33. Comparison of Carbon Dioxide Yields for Smoldering-to-Flaming Ignitions of Foams 32 and $32 \mathrm{X}$ Mock-up Upholstery Chairs Tested in the Furniture Calorimeter. 


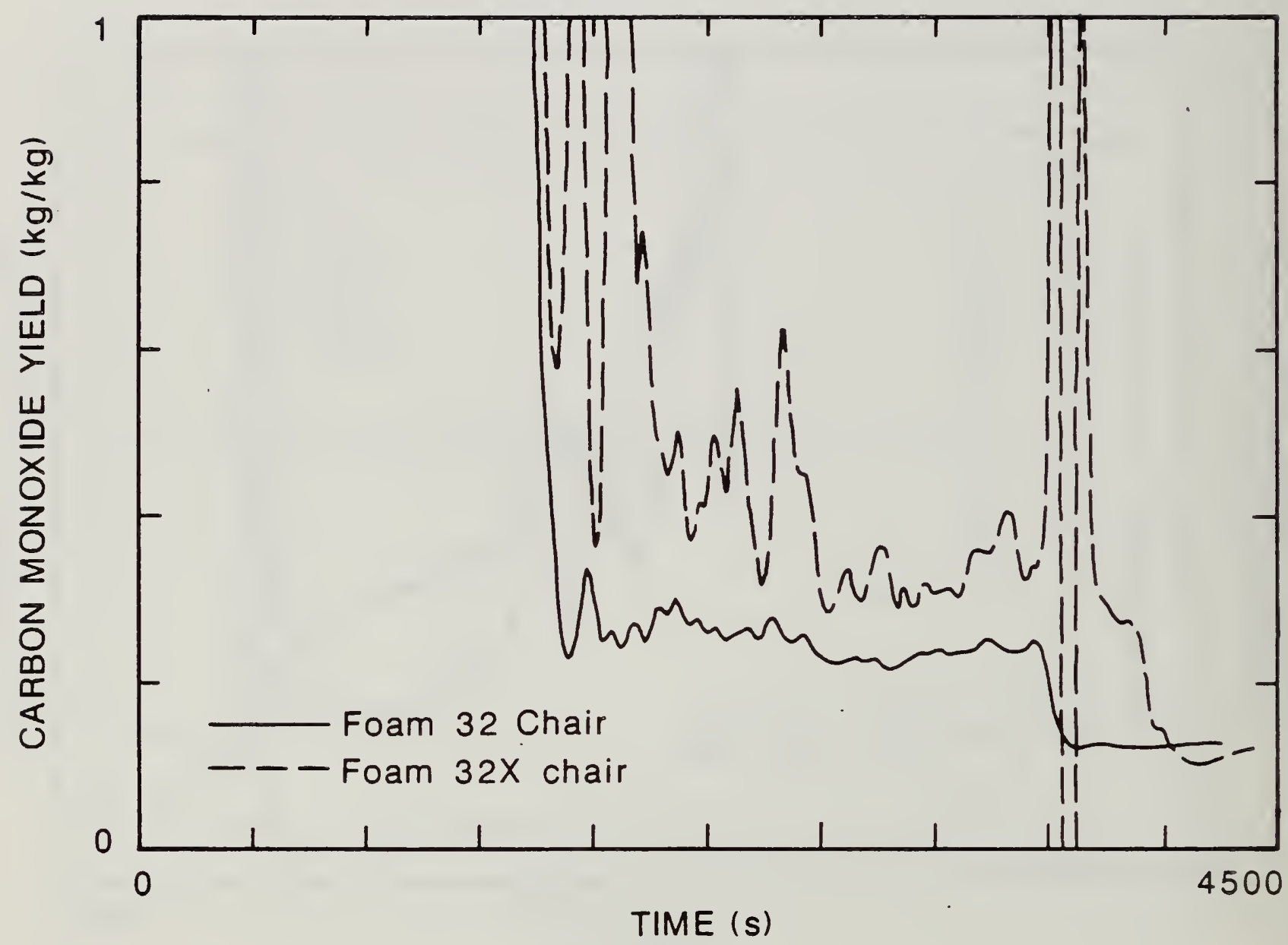

Figure 34. Comparison of Carbon Monoxide Yields for Smoldering-to-Flaming Ignitions of Foams 32 and $32 \mathrm{X}$ Upholstery Chair Mock-ups Tested in the Furniture Calorimeter (excluding early smoldering because of erratic response). 


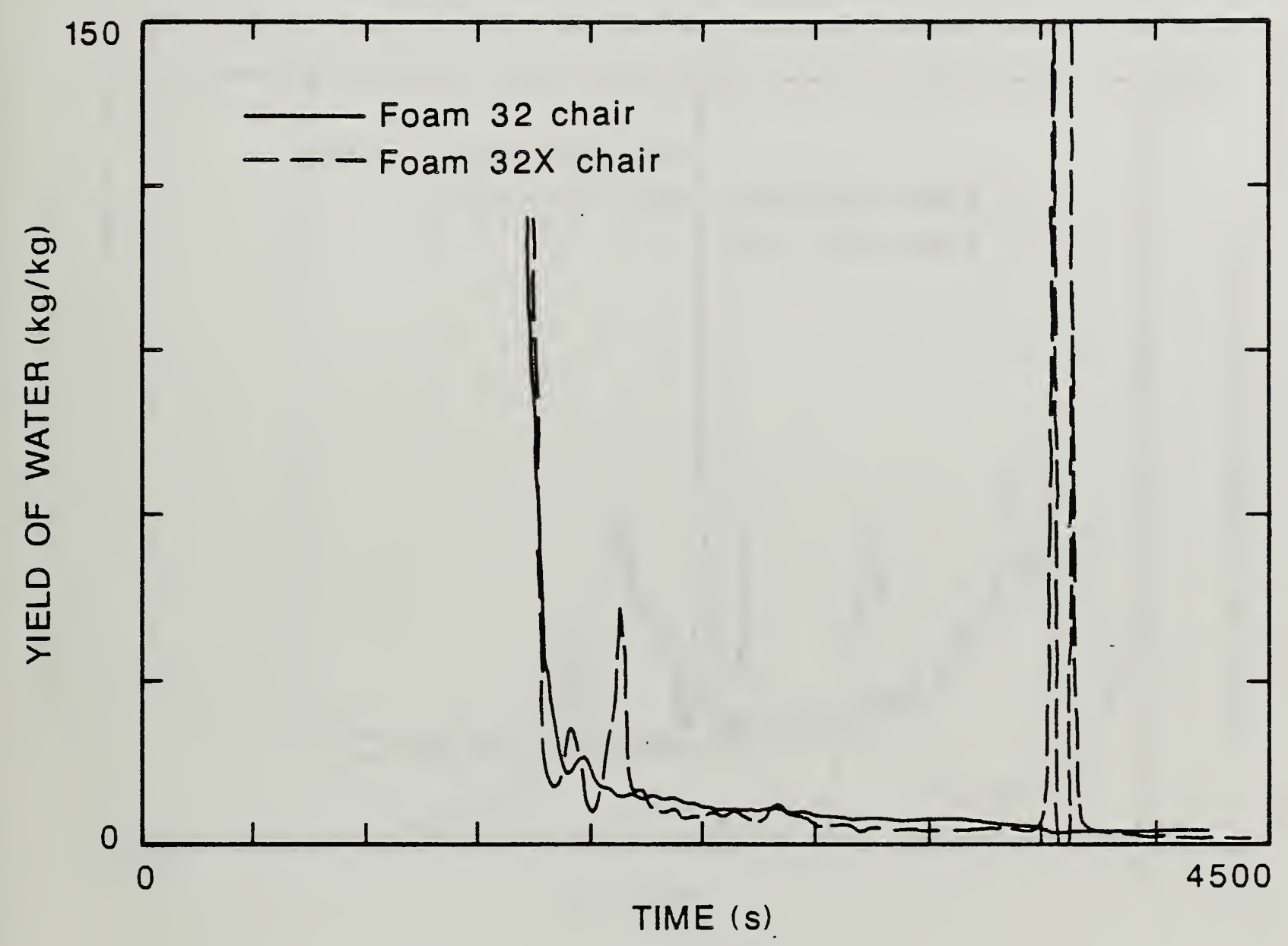

Figure 35. Comparison of the Yield of Water from Smoldering-to-Flaming Ignitions of Foams 32 and $32 \mathrm{X}$ Upholstery Chair Mock-ups Tested in the Furniture Calorimeter (excluding early smoldering because of erratic response). 


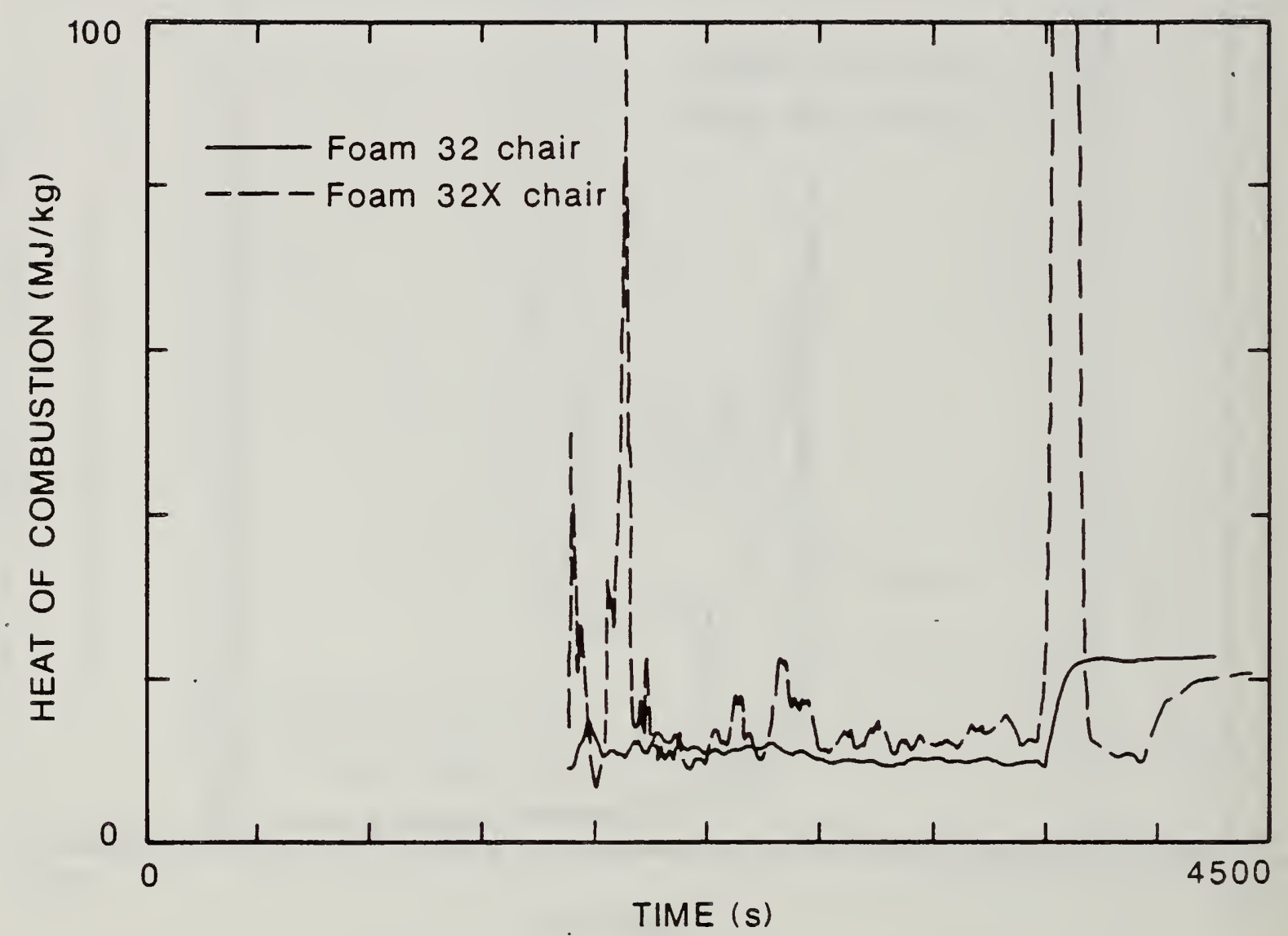

Figure 36. Comparison of The Heat of Combustion from the Smoldering-toFlaming Ignitions of Foams 32 and $32 \mathrm{X}$ Upholstery Chair Mock-ups Tested in the Furniture Calorimeter (excluding early smoldering because of erratic response). 


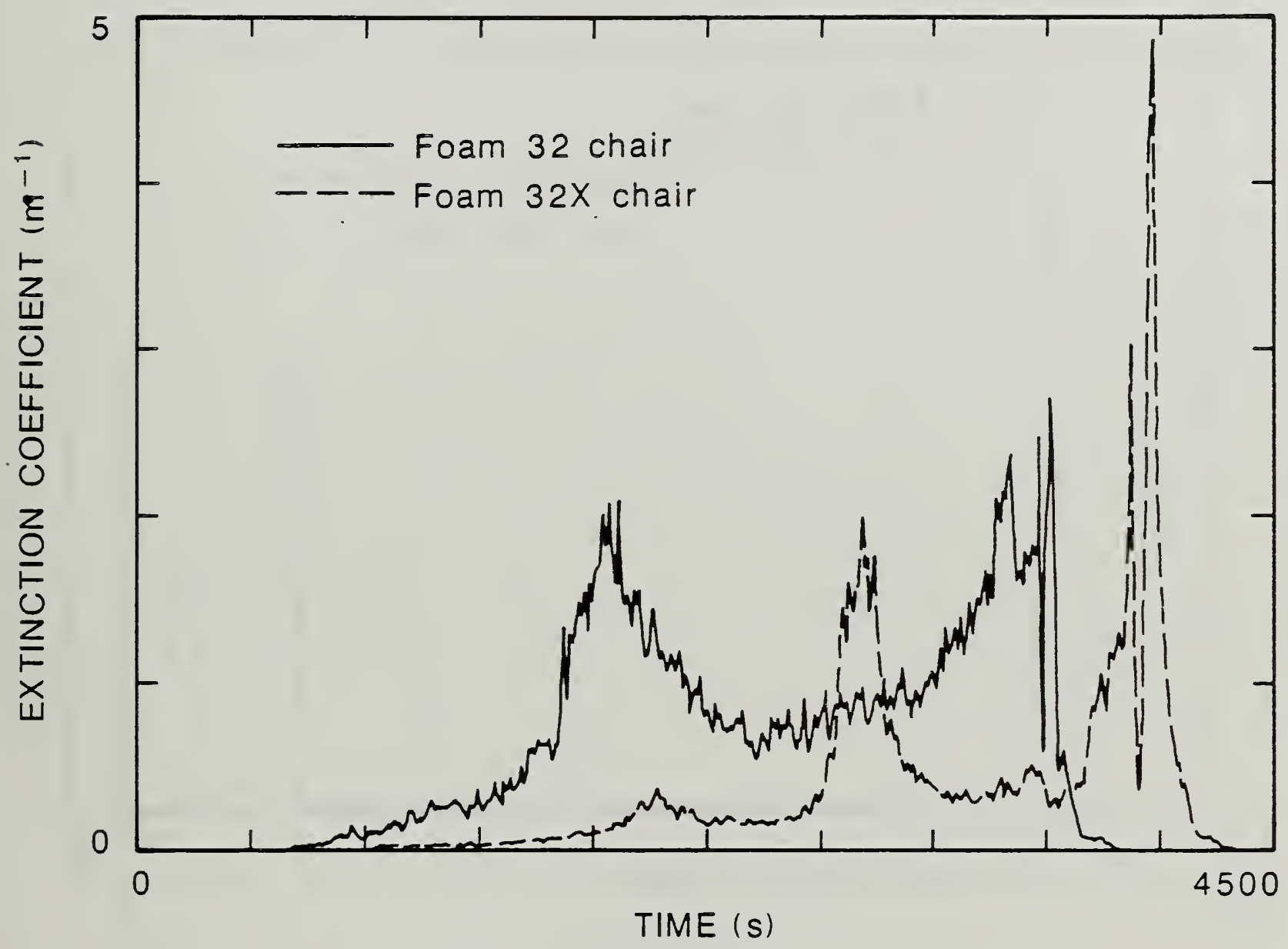

Figure 37. Comparison of the Smoke Extinction Coefficient for the Smoldering-to-Flaming Ignitions of Foams 32 and $32 \mathrm{X}$ Upholstery Chair Mock-ups Tested in the Furniture Calorimeter (excluding early smoldering because of erratic response). 


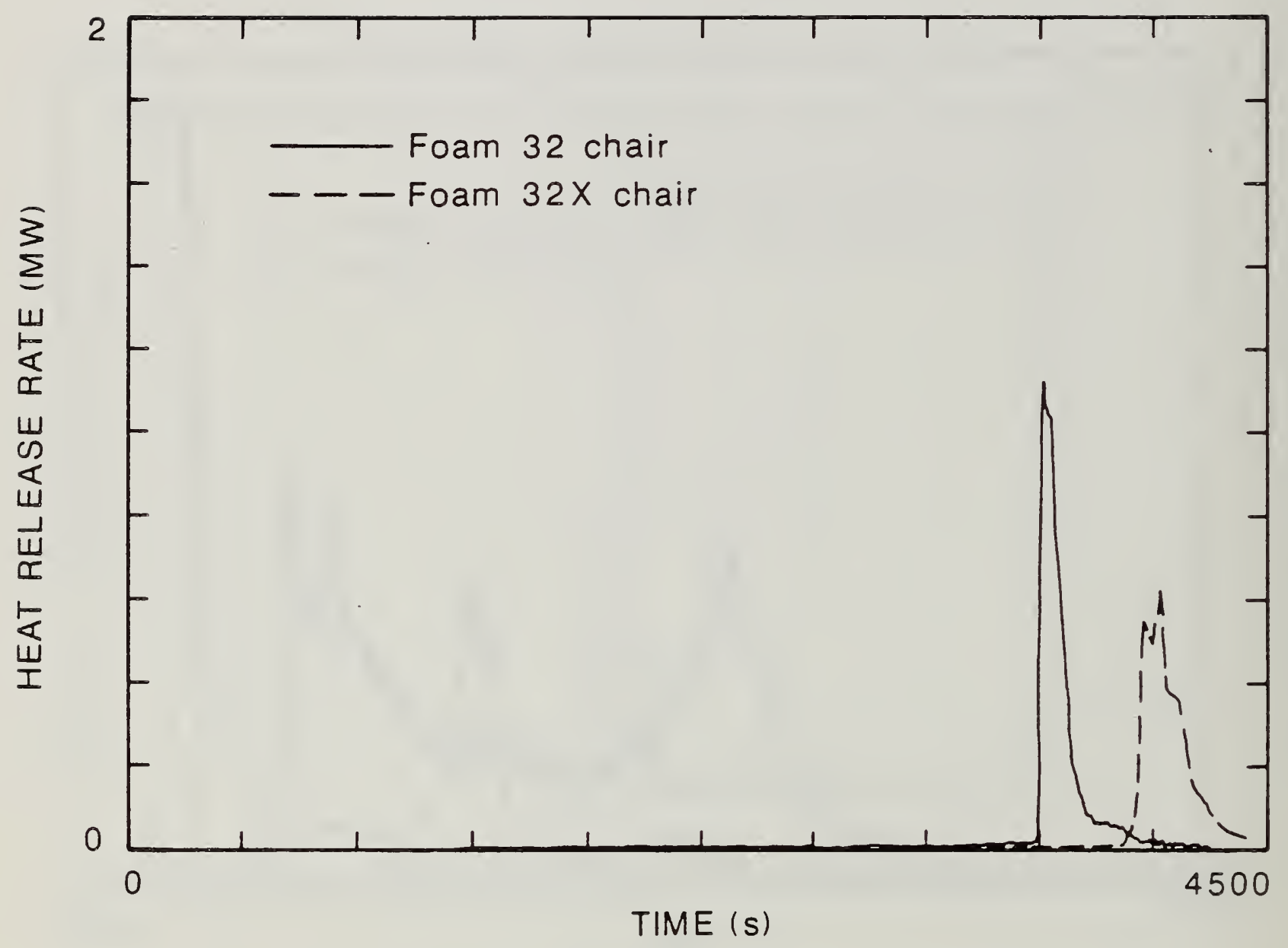

Figure 38. Comparison of the Rate of Heat Release for the Smoldering-toFlaming Ignitions of Foams 32 and $32 \mathrm{X}$ Upholstery Chair Mock-ups Tested in the Furniture Calorimeter (excluding early smoldering because of erratic response).' 


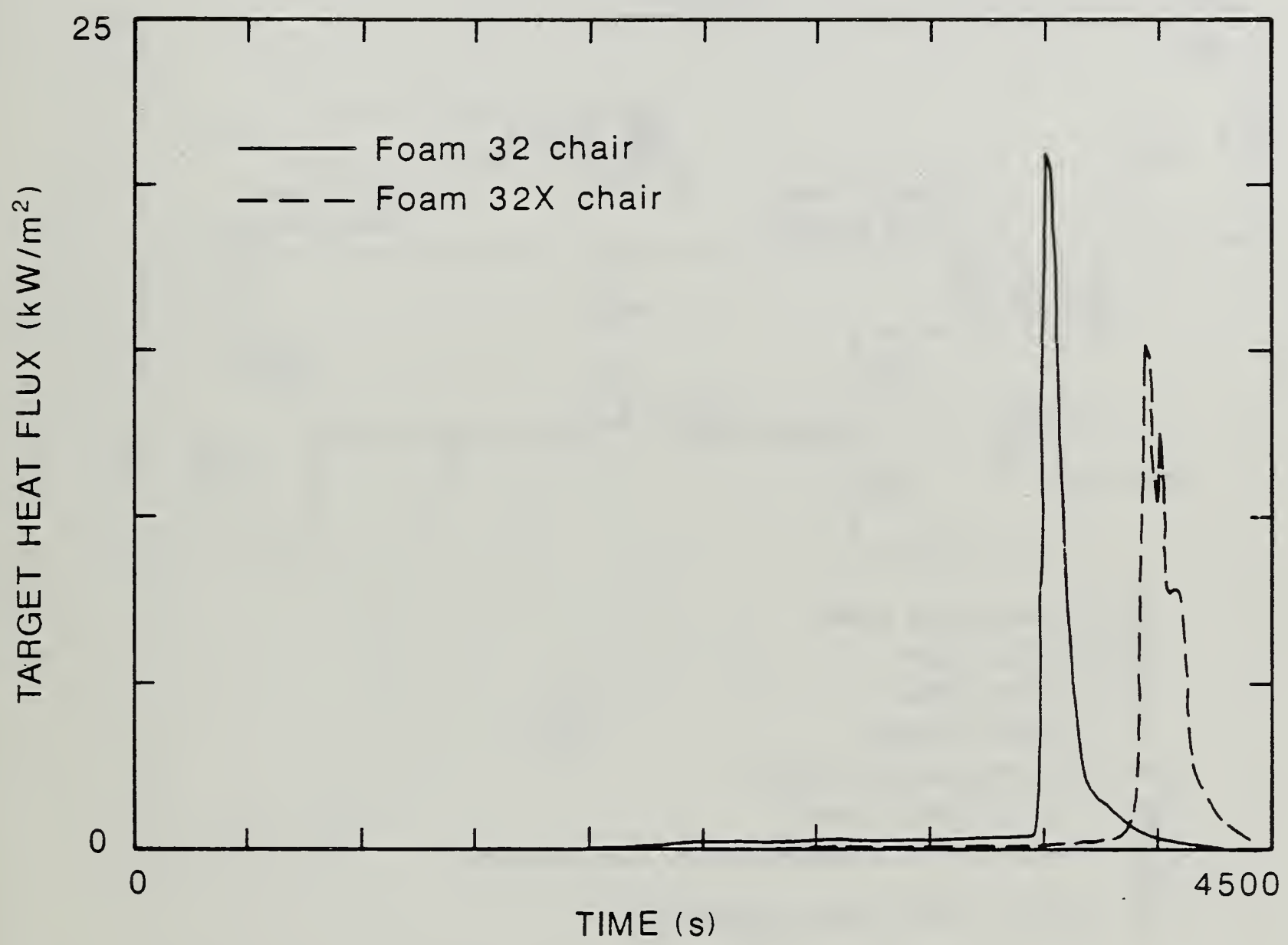

Figure 39. Comparison of the Heat Flux Received by a Target Material from the Smoldering-to-Flaming Ignitions of Foams 32 and $32 \mathrm{X}$

Upholstery Chair Mock-ups Tested in the Furniture Calorimeter.. 


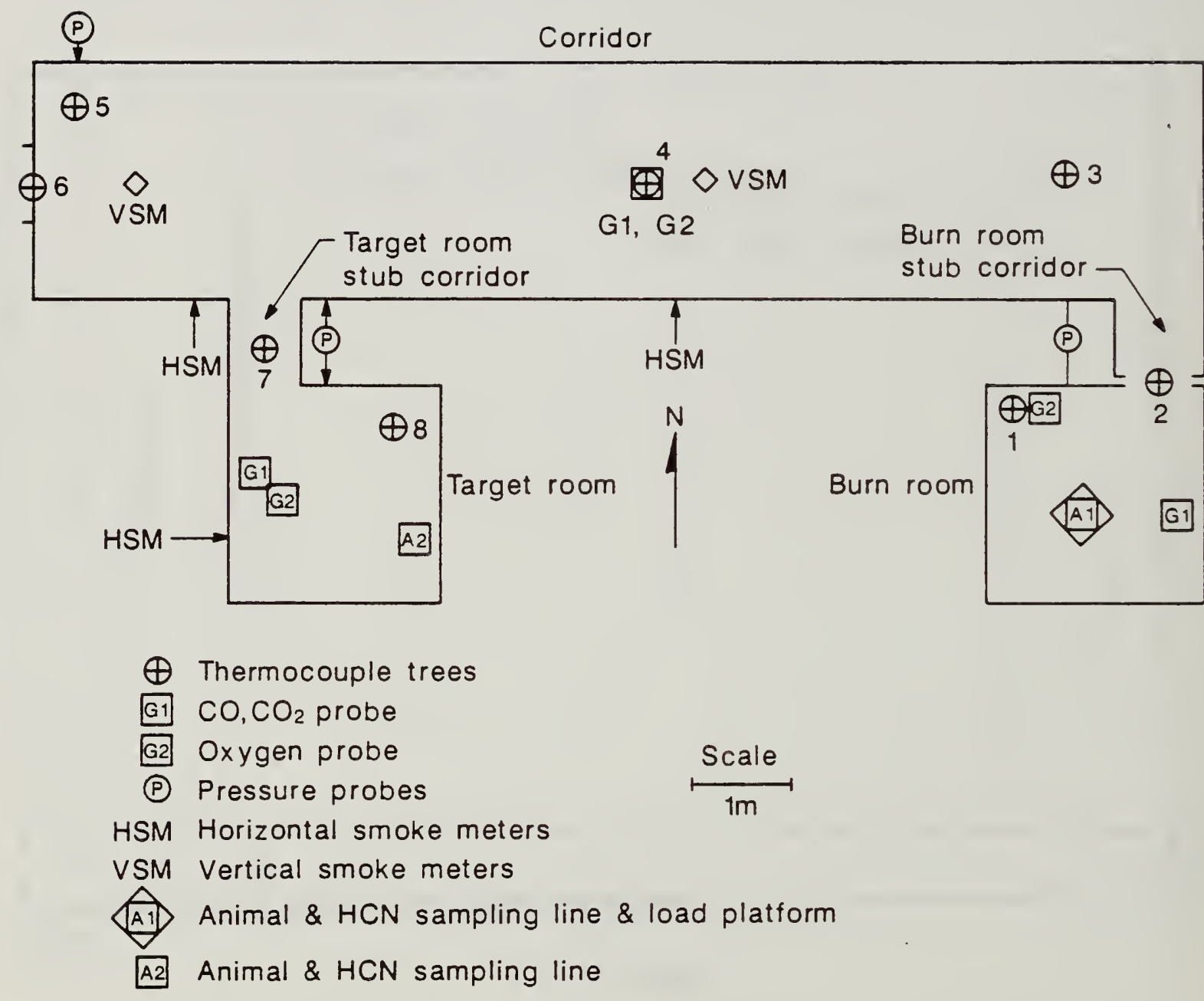

Figure 40. Schematic Floor Plan of The Large-Scale Three Compartment Test Facility. 


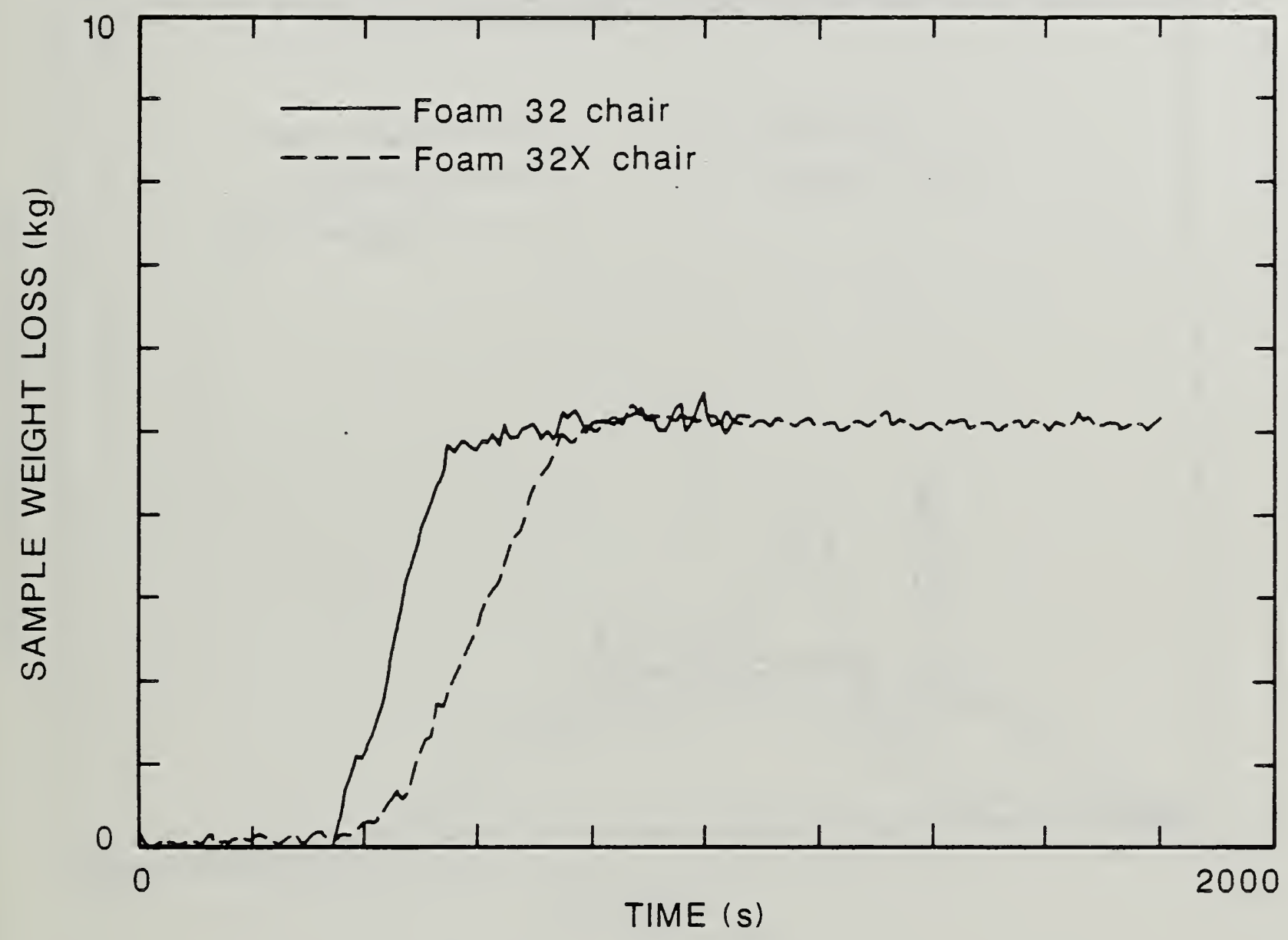

Figure 41. Comparison of Sample Weight loss for Flaming Ignition of Mock-up Upholstery Chairs made from foams 32 and $32 \mathrm{X}$ in the Large-Scale Three Compartment Tests. 


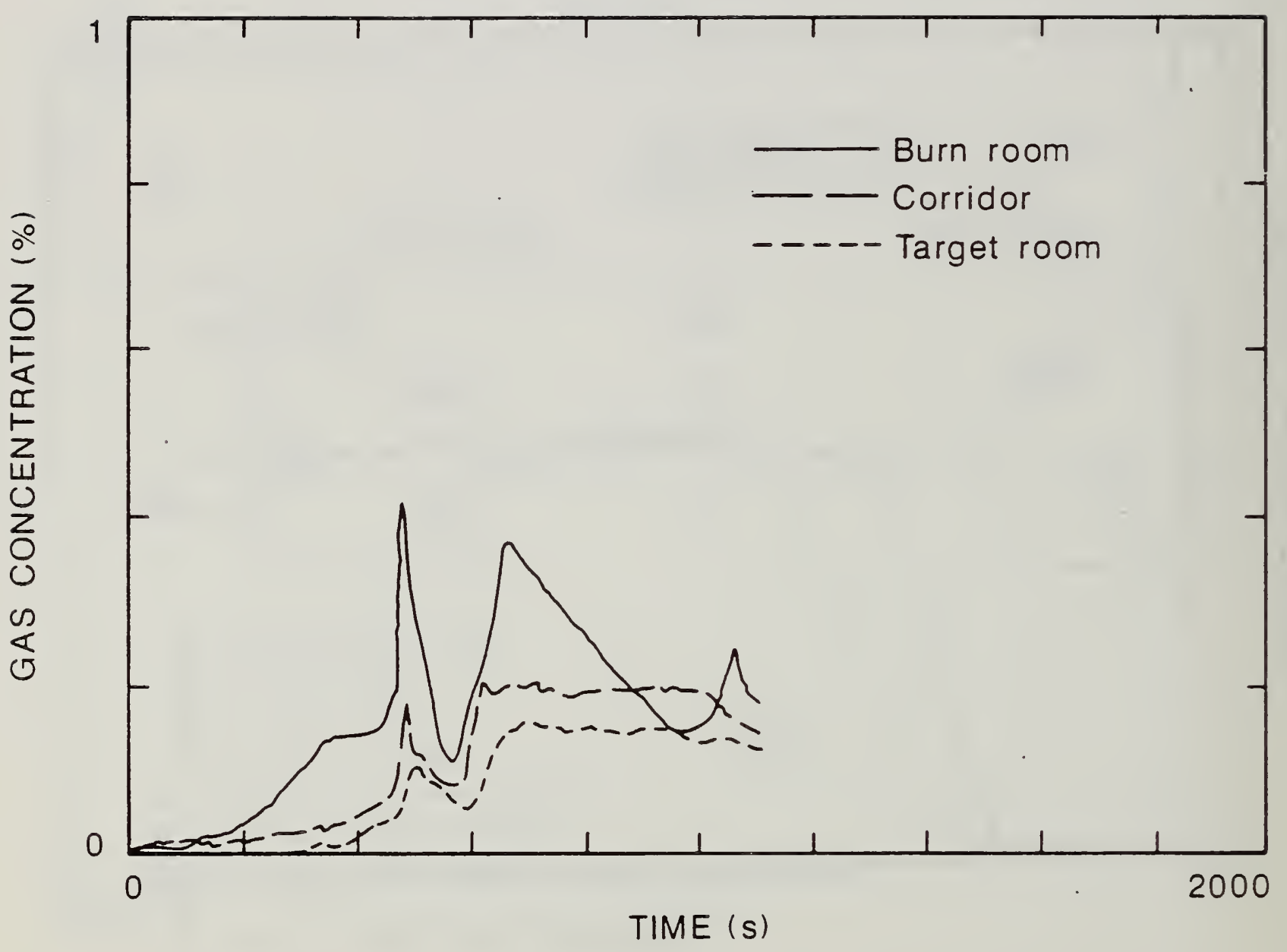

Figure 42. Carbon Monoxide Concentration in Each Compartment of the Large-Scale Facility During Flaming Ignition Test of Foam 32 Mock-up Upholstery Chair Assembly. 


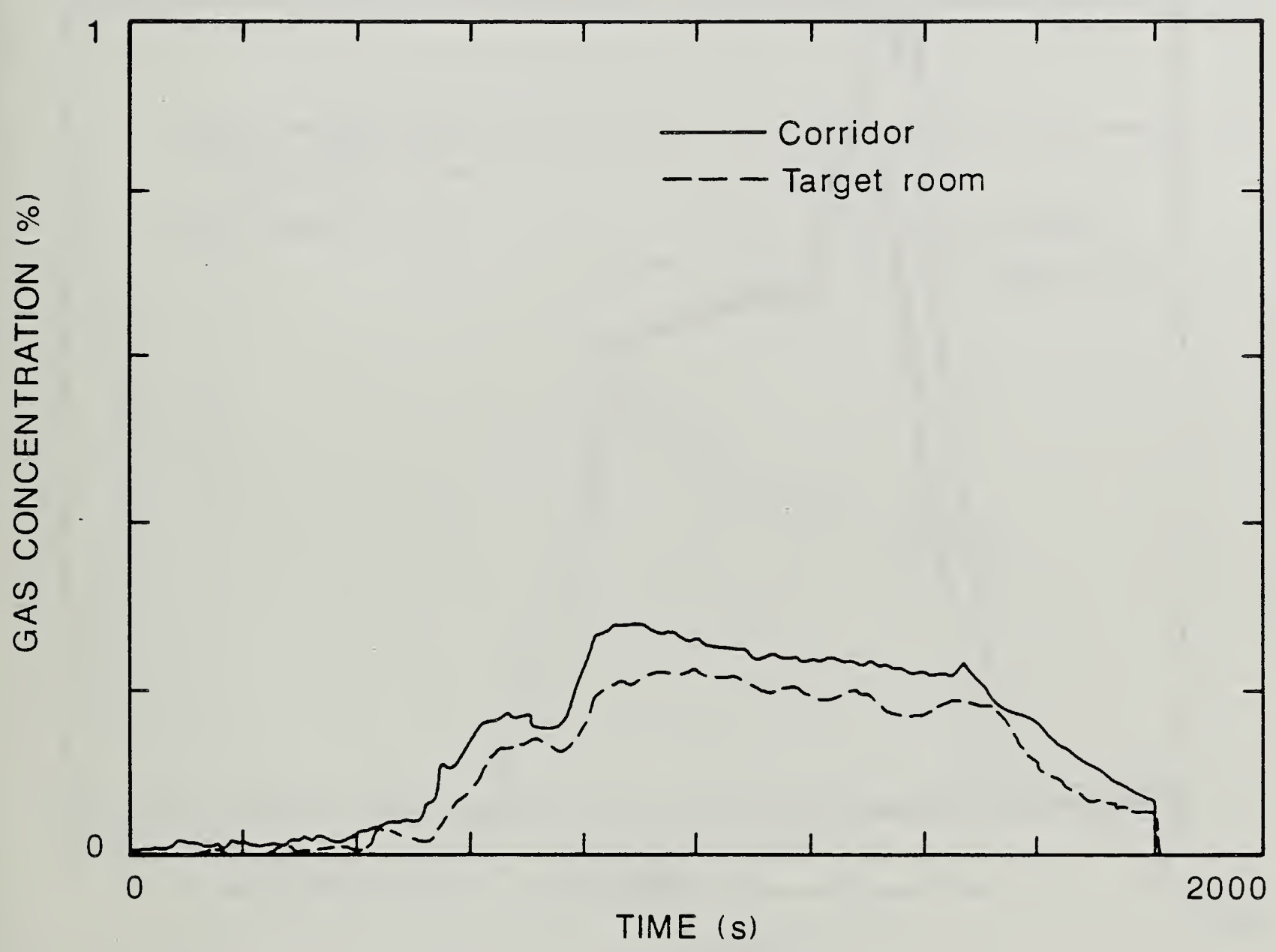

Figure 43. Carbon Monoxide Concentration in Each Compartment of the Large-Scale Facility During Flaming Ignition Test of Foam 32X Mock-up Upholstery Chair Assembly... 


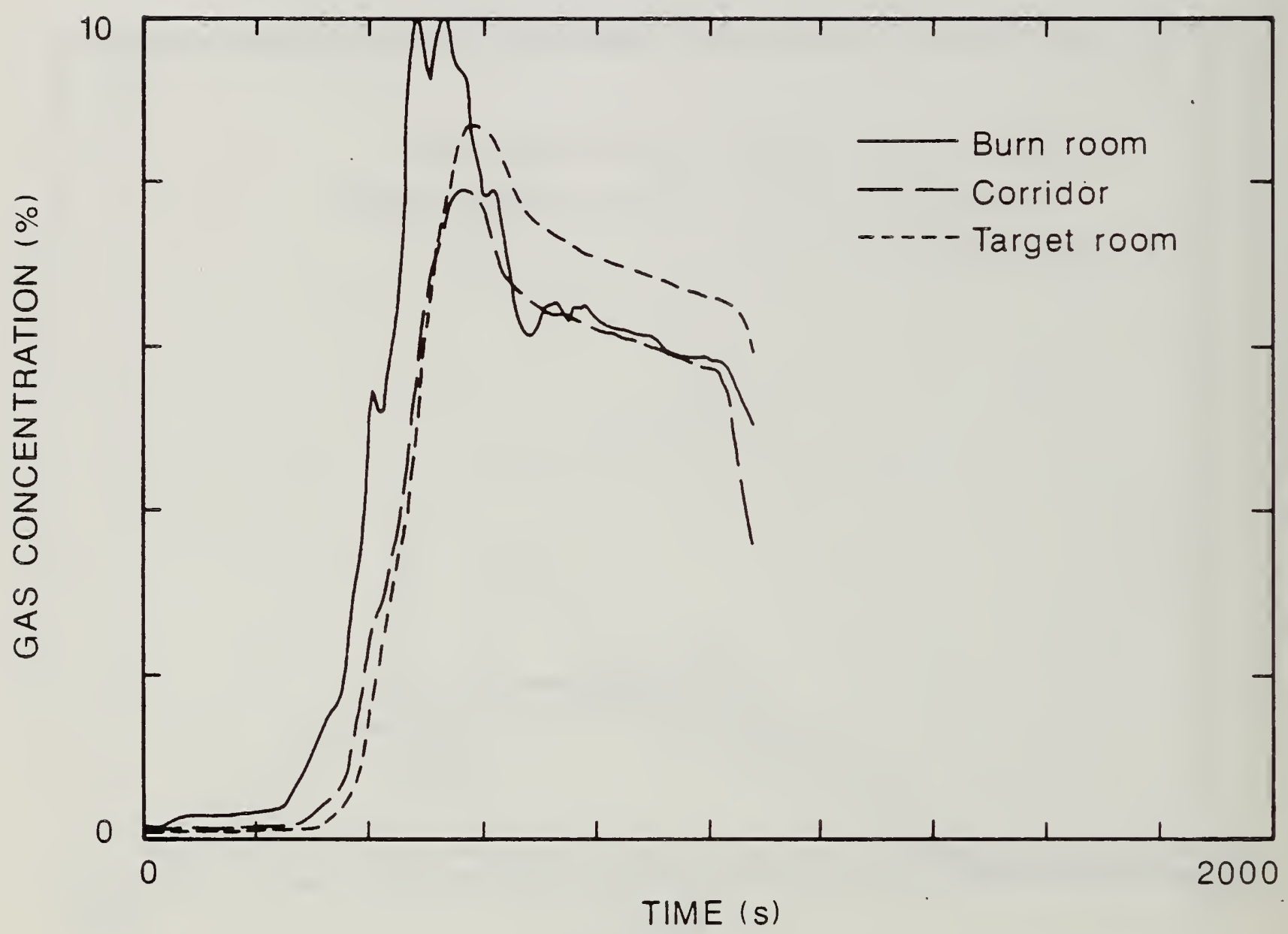

Figure 44. Carbon Dioxide Concentration in Each Compartment of The Large-Scale Facility During Flaming Ignition Test of Foam 32 Mock-up Upholstery Chair Assembly. 


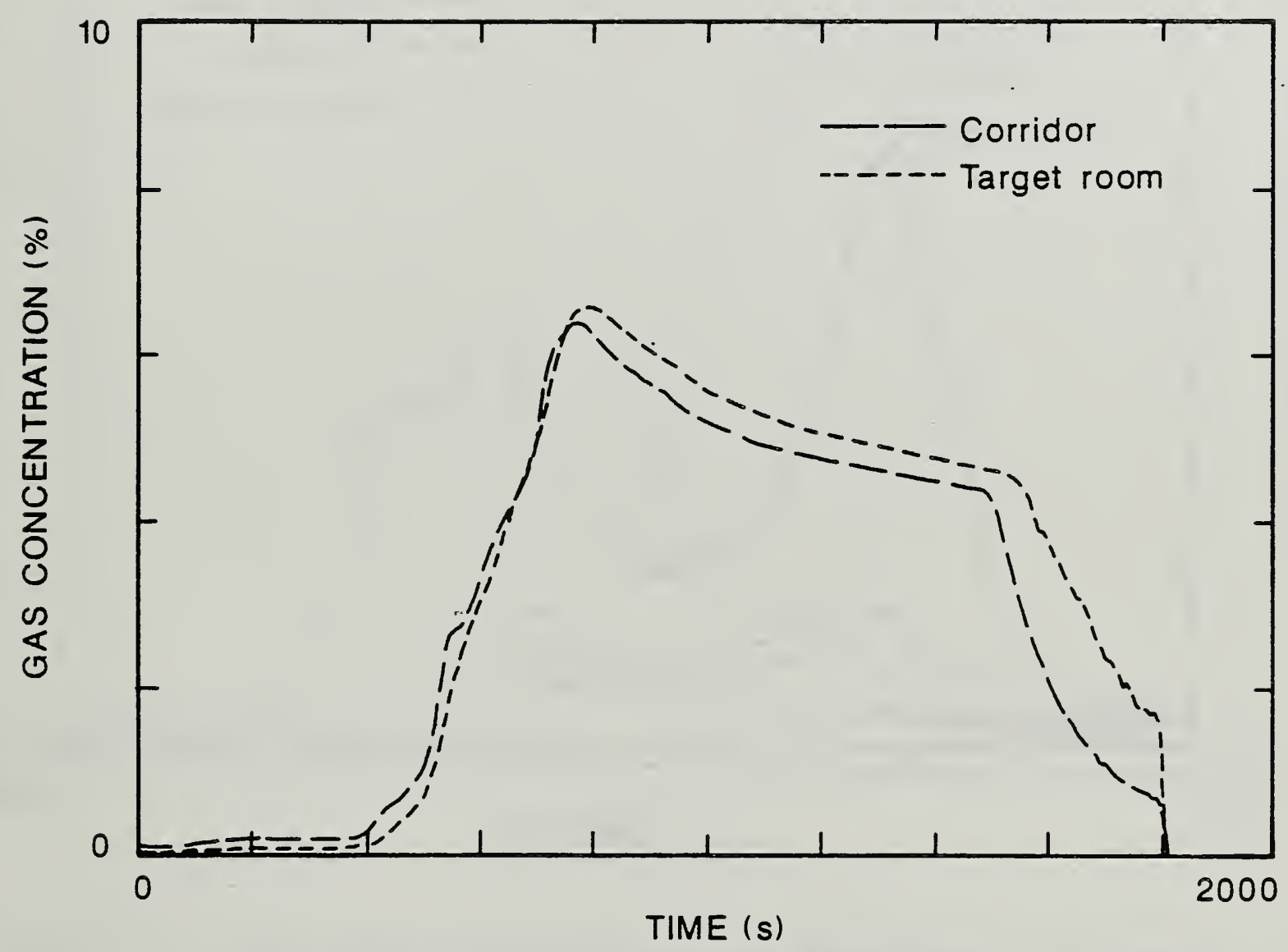

Figure 45. Carbon Dioxide Concentration in Each Compartment of the Large-Scale Facility During Flaming Ignition Test of Foam $32 \mathrm{X}$ Mock-up Upholstery Chair Assembly. 


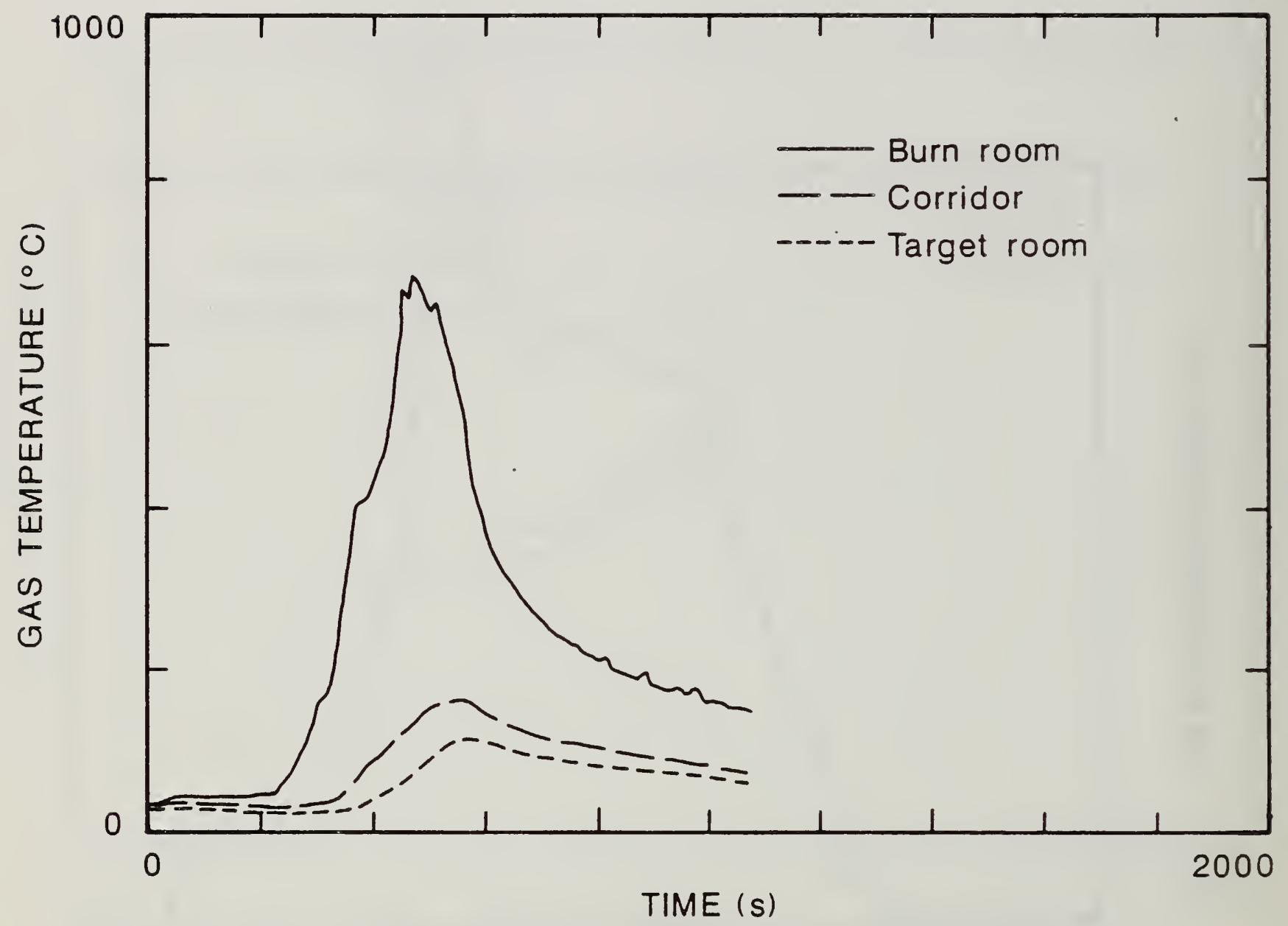

Figure 46. Upper Layer Gas Temperatures in Each Compartment of the Large-Scale Facility During Flaming Ignition test of Foam 32 Mock-up Upholstery Chair Assembly. 


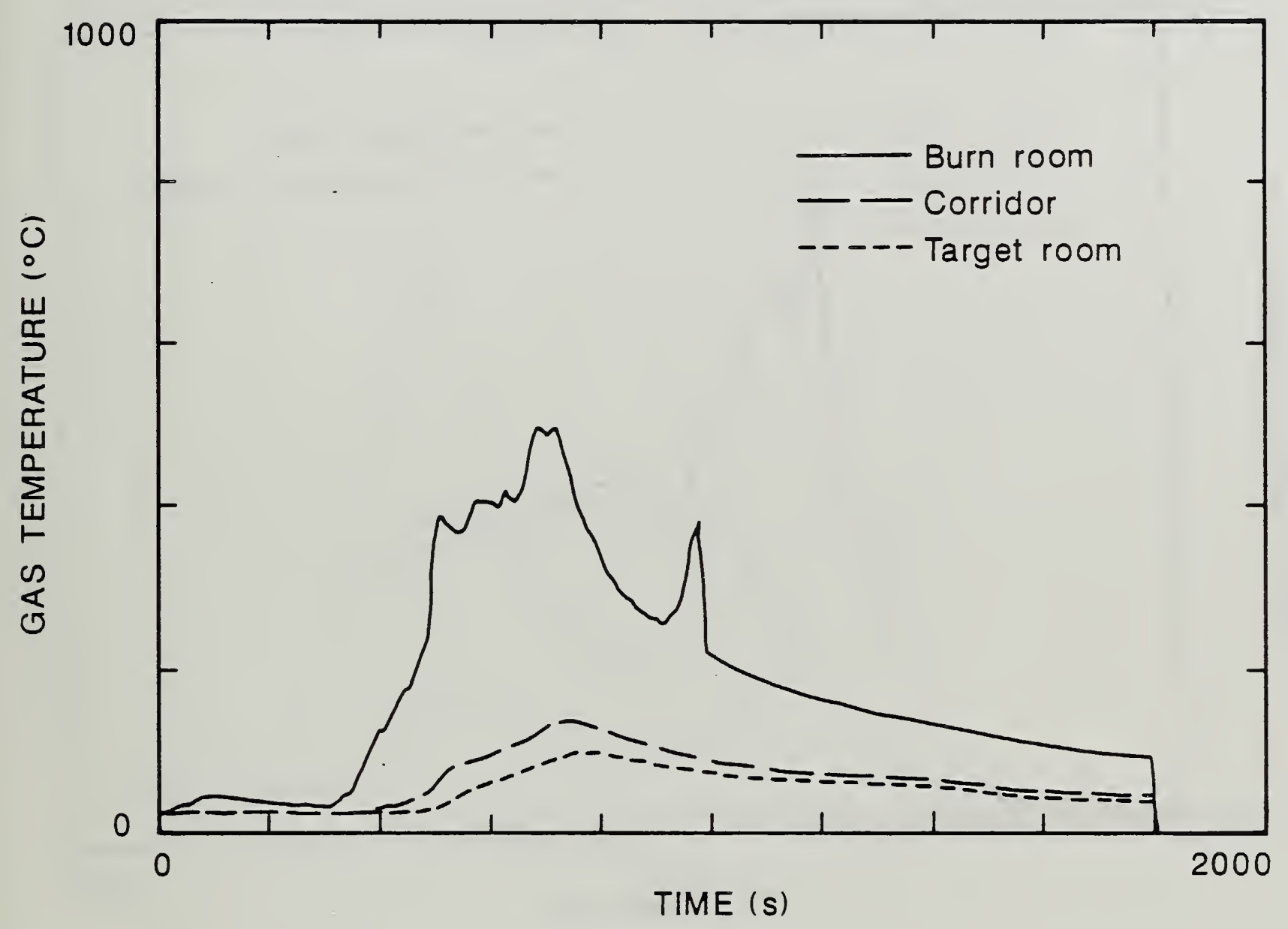

Figure 47. Upper Layer Gas Temperatures in Each Compartment of the Large-Scale Facility During Flaming Ignition test of Foam 32 Mock-up Upholstery Chair Assembly. 


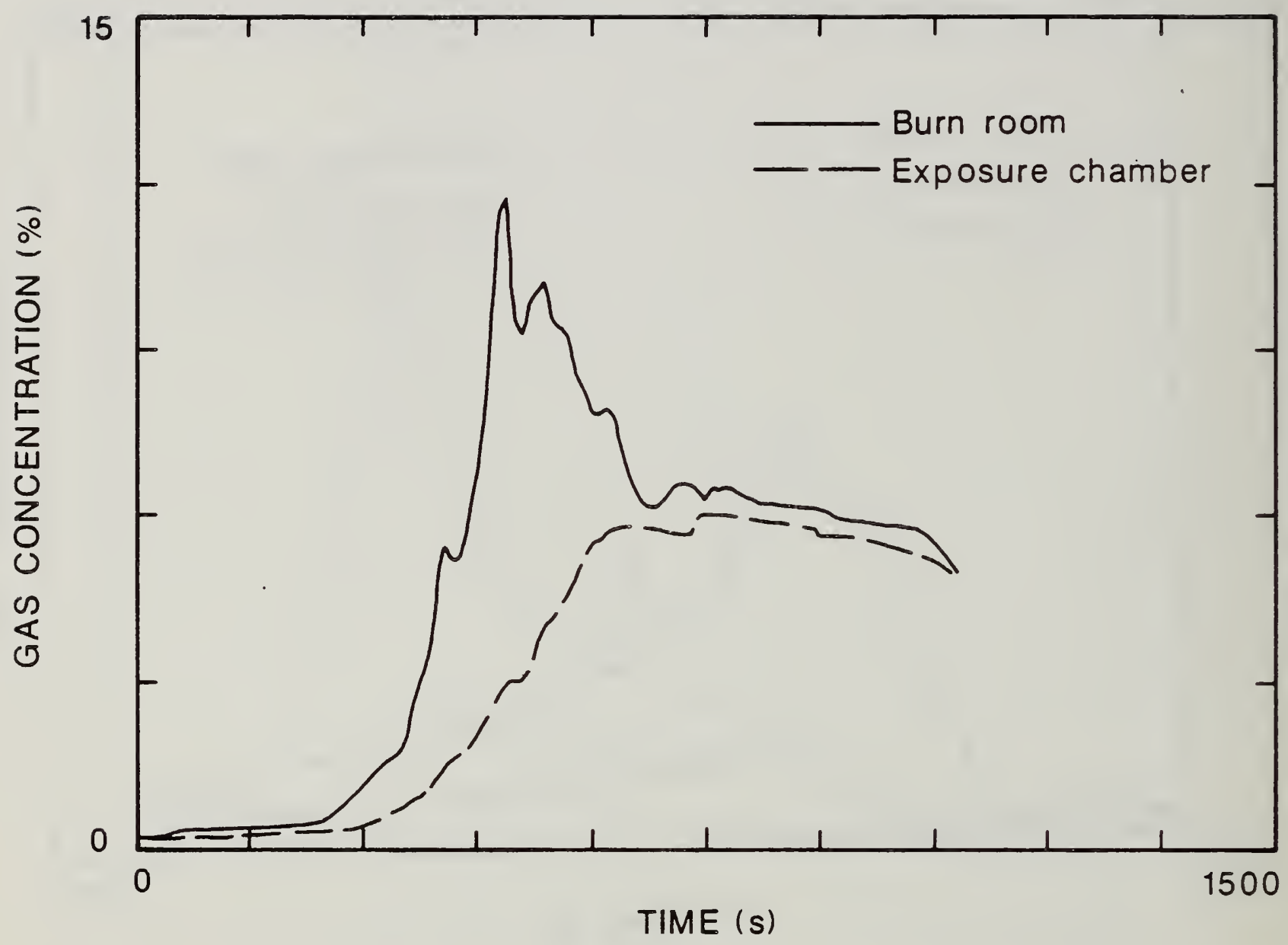

Figure 48. Comparison of Carbon Dioxide Concentration in the Burn Room and the Animal Exposure Chamber for Flaming Ignition of Foam Mock-up Upholstery Chair Assembly. 


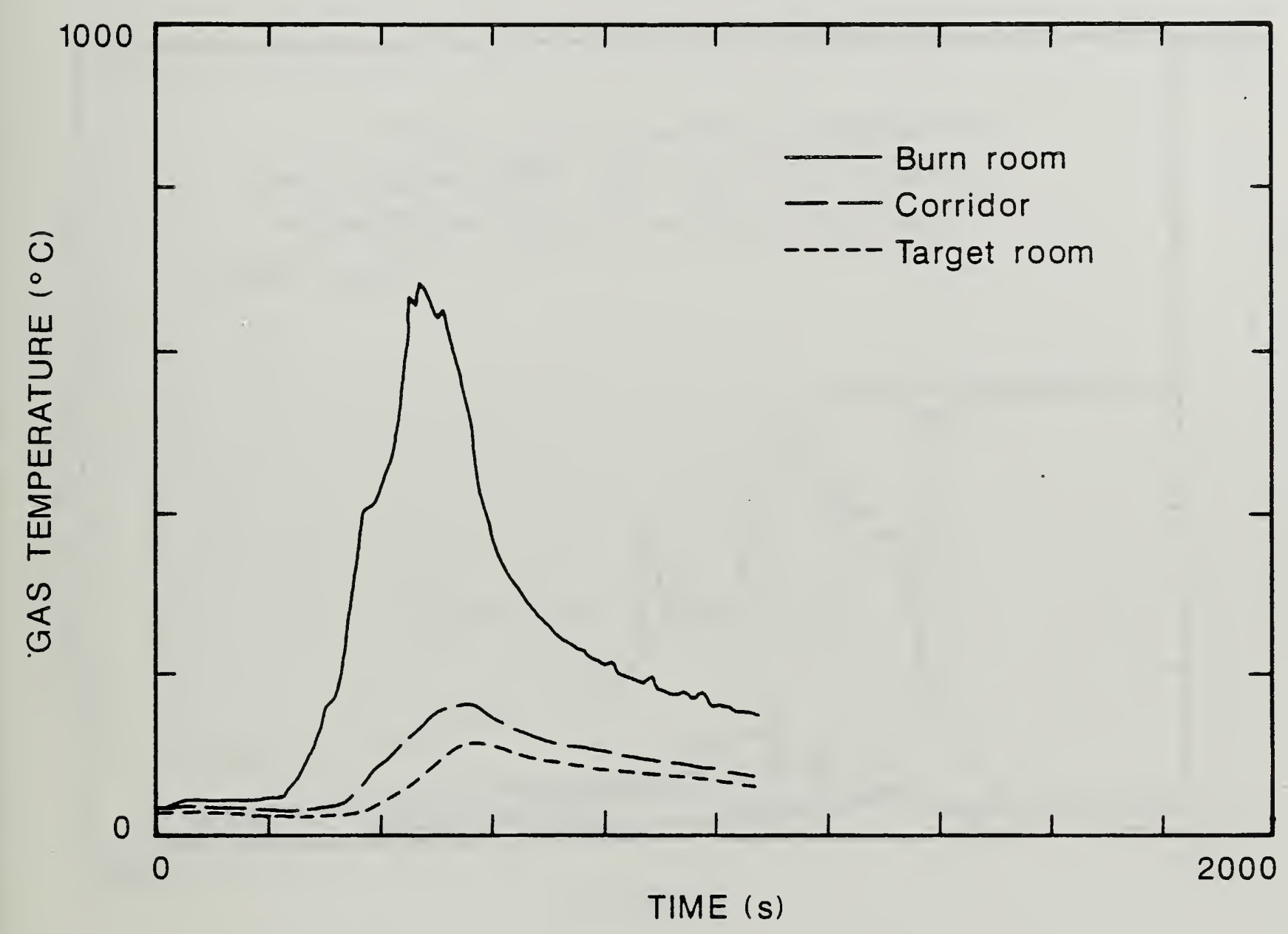

Figure 49. Upper Layer Gas Temperatures in Each Compartment of the Large-Scale Facility During Flaming Ignition Test of Foam 32 Mock-up Upholstery Chair Assembly. 


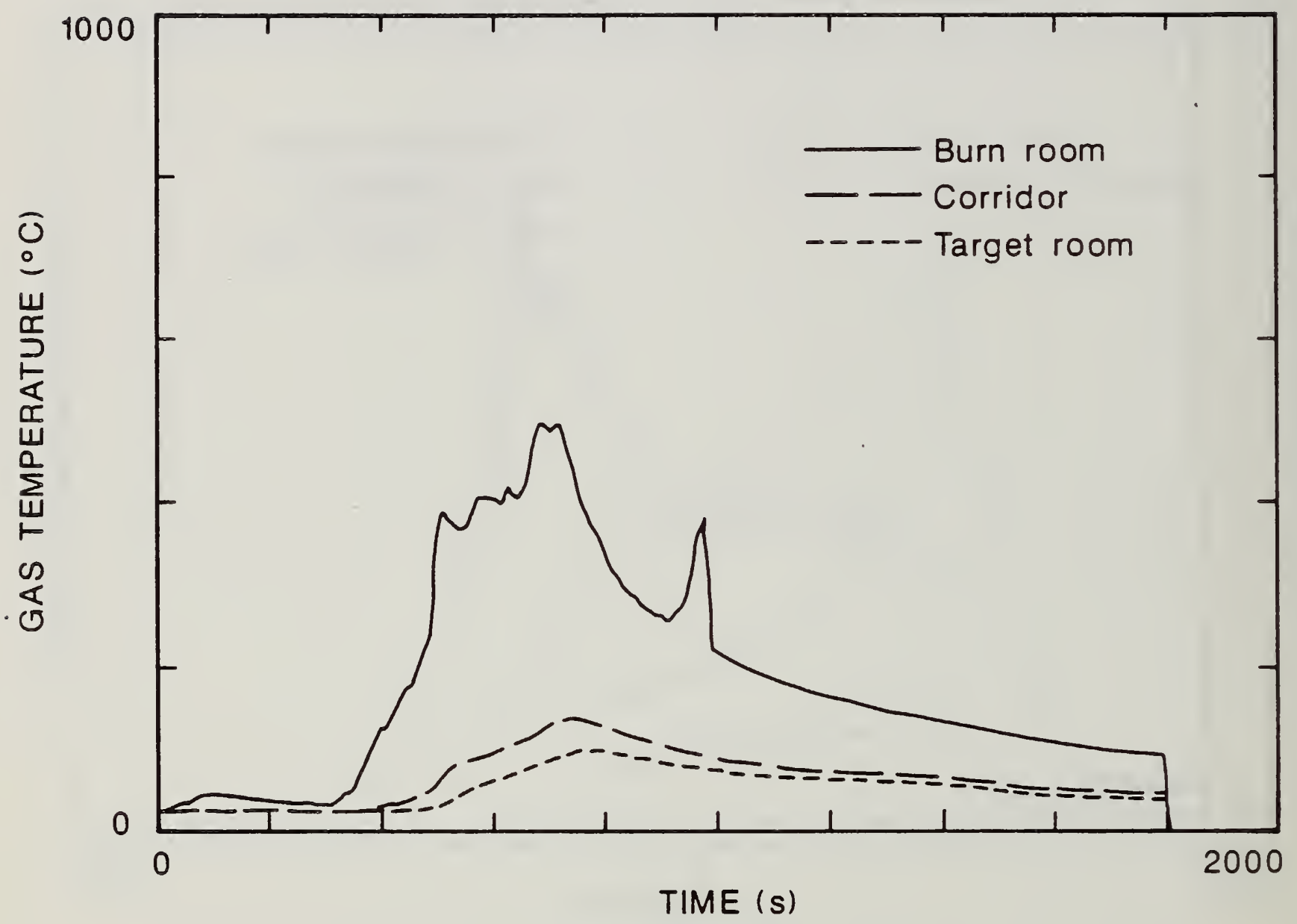

Figure 50. Upper Layer Gas Temperatures in Each Compartment of the Large-Scale Facility During Flaming Ignition Test of Foam $32 \mathrm{X}$ Mock-up Upholstery Chair Assembly. 


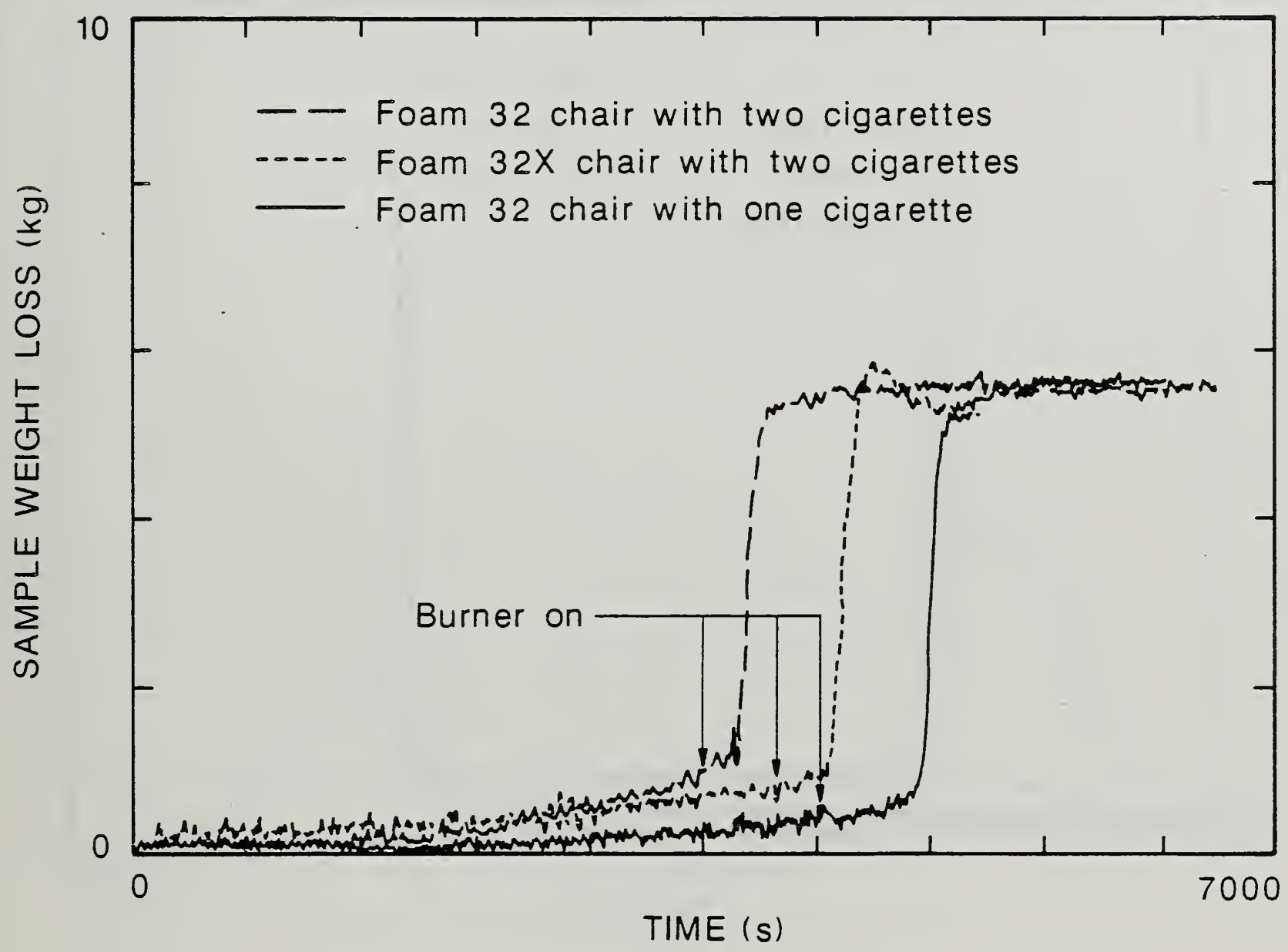

Figure 51. Comparison of Weight Loss for Preliminary Smoldering-to-Flaming Experiments of Foams 32 and $32 \mathrm{X}$ Mock-up Upholstery Chair Assemblies. 


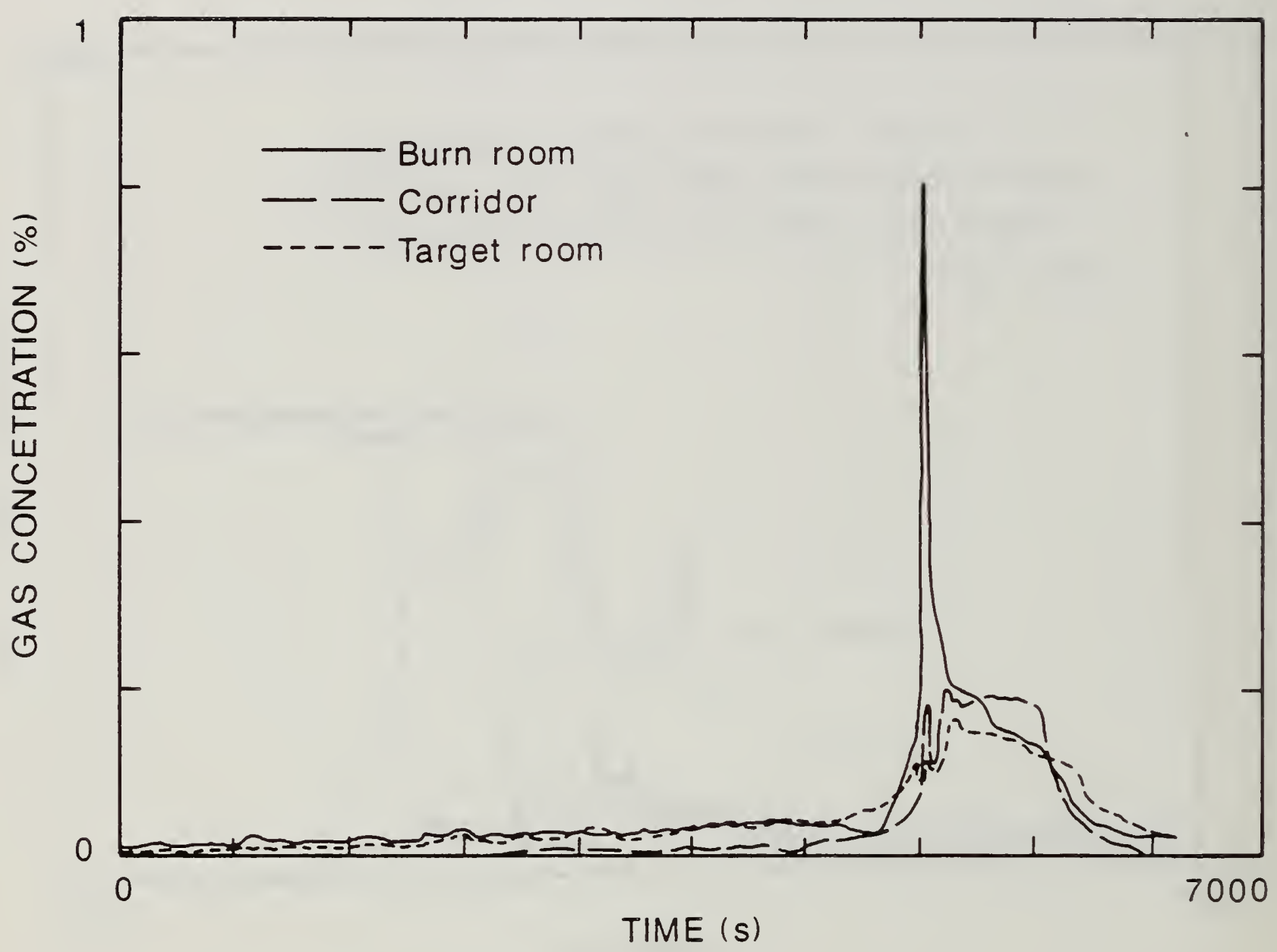

Figure 52. Comparison of Carbon Monoxide Concentrations in Each Compartment of the Large-Scale Test Facility for the One Cigarette Test of Foam 32 Mock-up Upholstery Chair Assembly. 


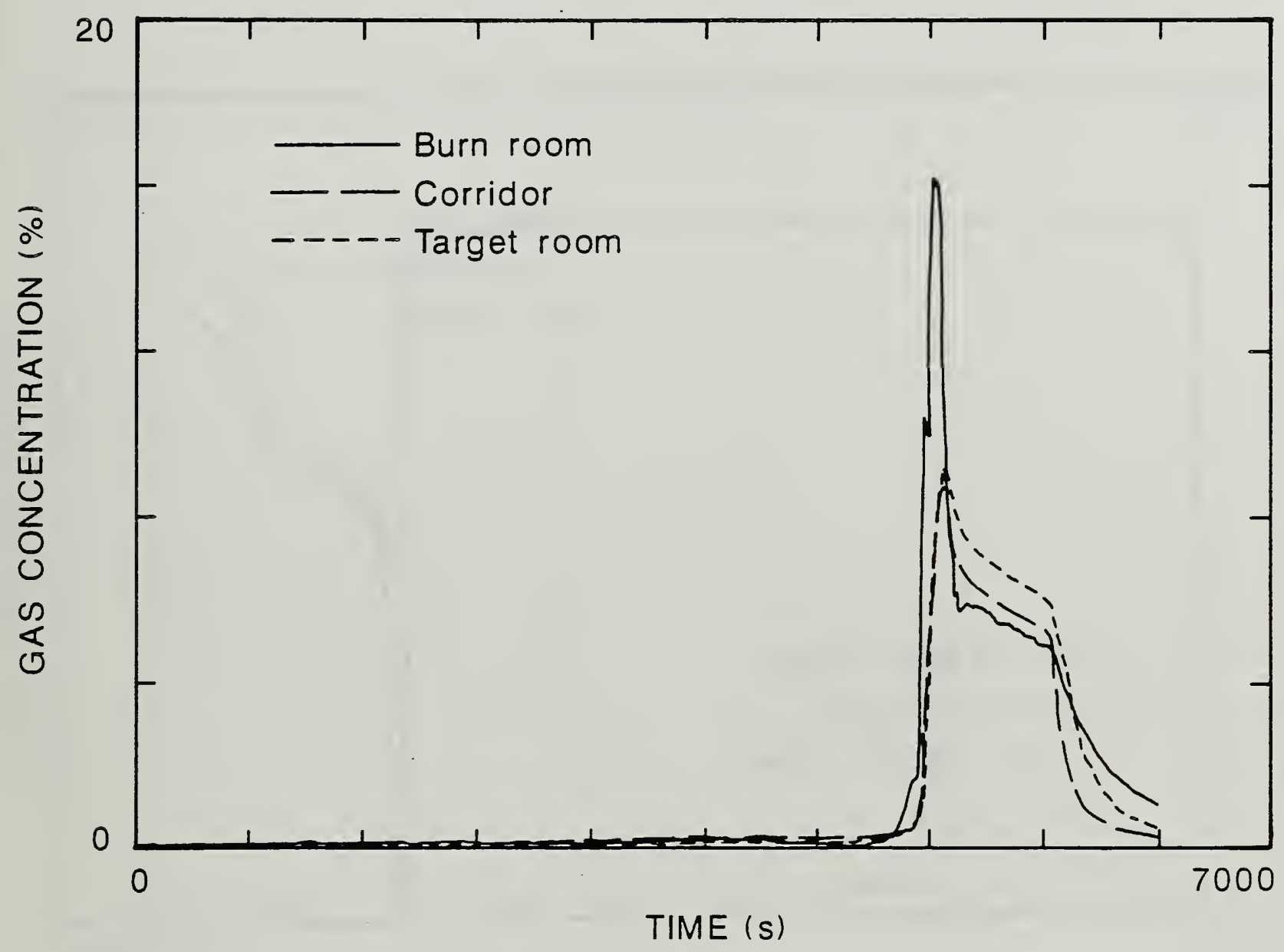

Figure 53. Comparison of Carbon Dioxide Concentrations in Each Compartment of the Large-Scale Test Facility for the One Cigarette Test of Foam 32 Mock-up Upholstery Chair Assembly. 


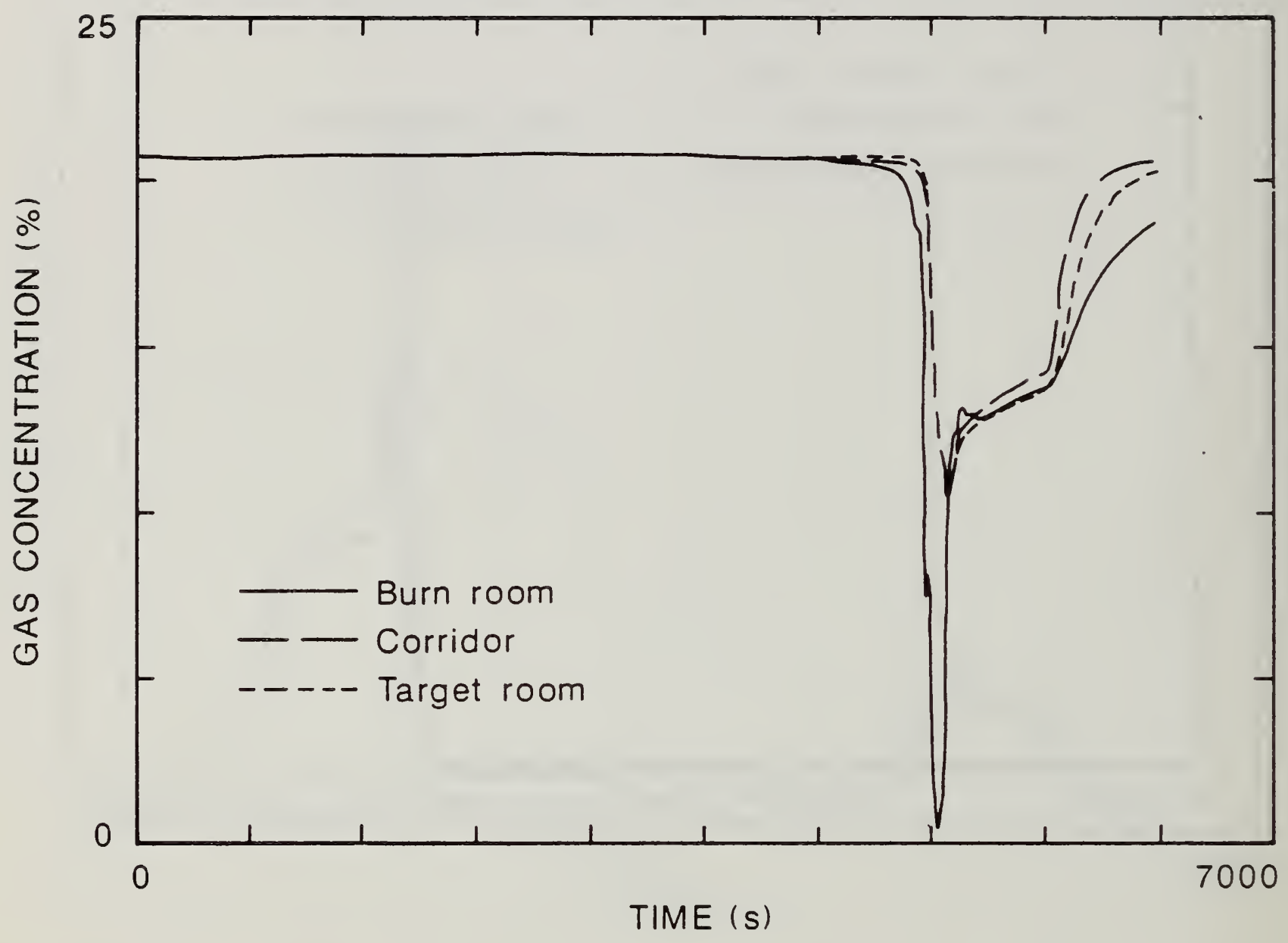

Figure 54. Comparison of Oxygen Concentrations in Each Compartment of the Large-Scale Test Facility for the One-Cigarette Test of Foam 32 Mock-up Upholstery Chair Assembly. 


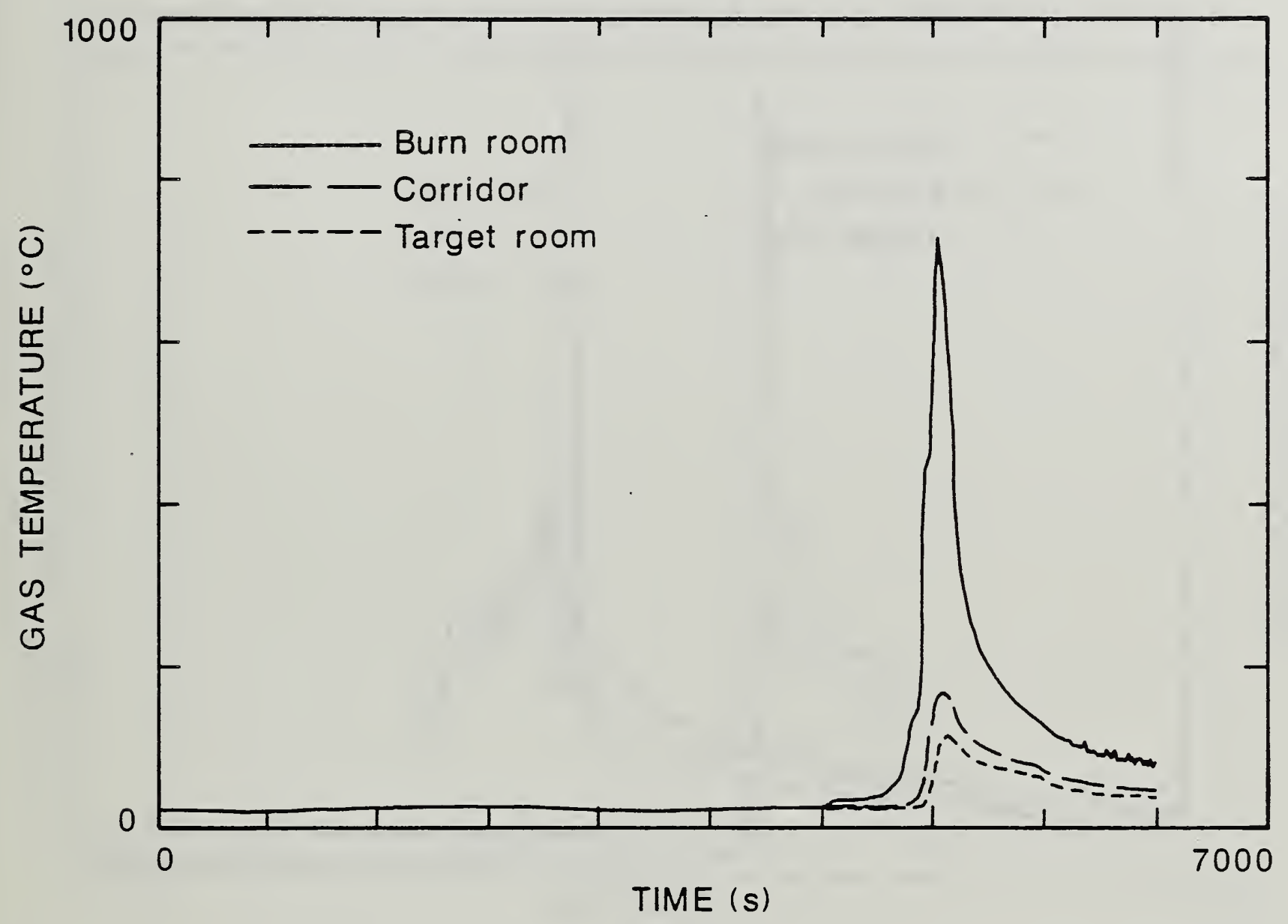

Figure 55. Comparison of lipper Compartment Gas Temperature in Each Compartment of the Large-Scale Test Facility for the OneCigarette Test of Foam 32 Mock-up Upholstery Chair Assembly. 


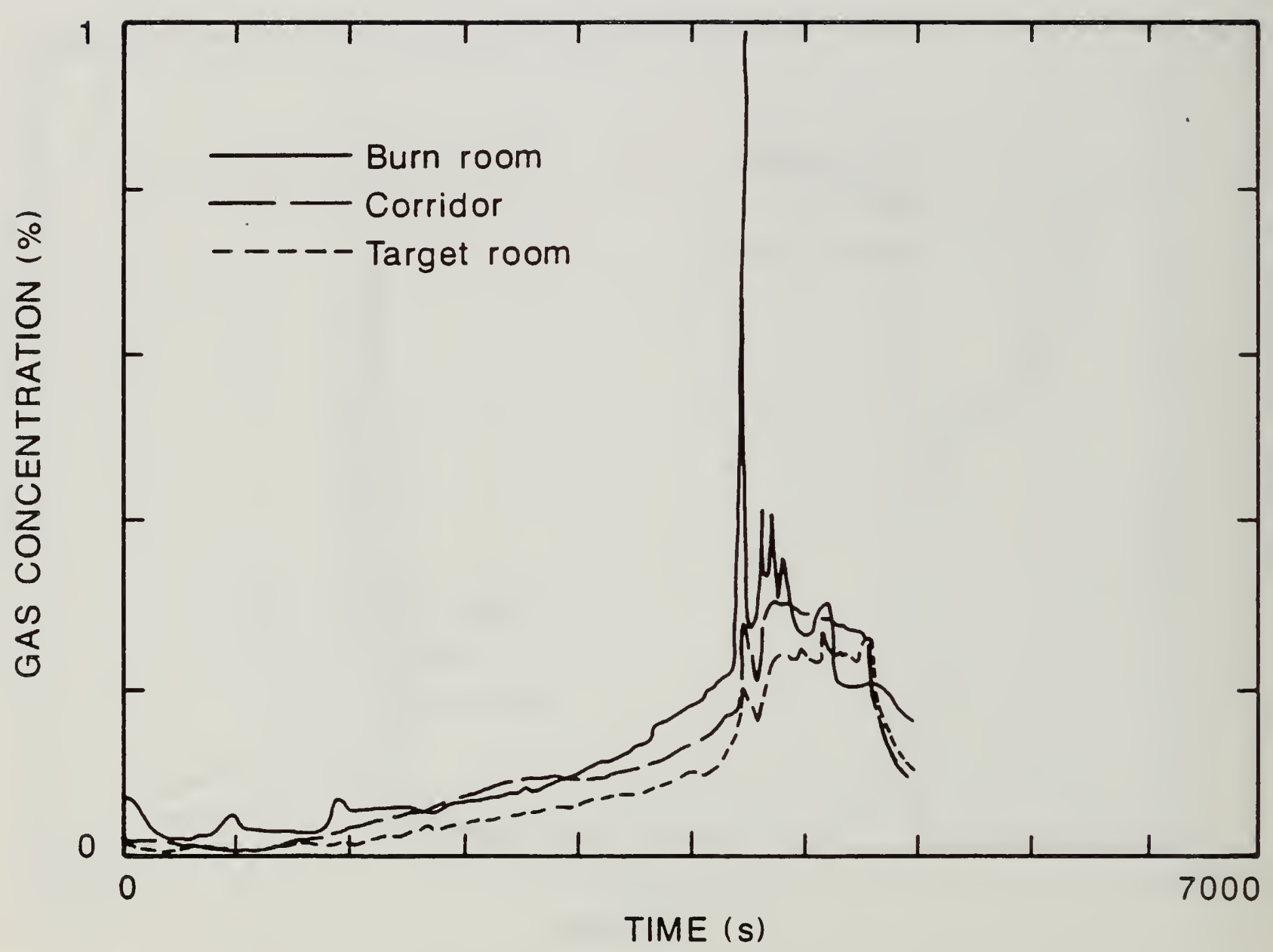

Figure 56. Comparison of Carbon Monoxide Concentrations in Each Compartment of the Large-Scale Test Facility for the Two-Cigarette Test of Foam 32 Mock-up Upholstery Chair Assembly. 


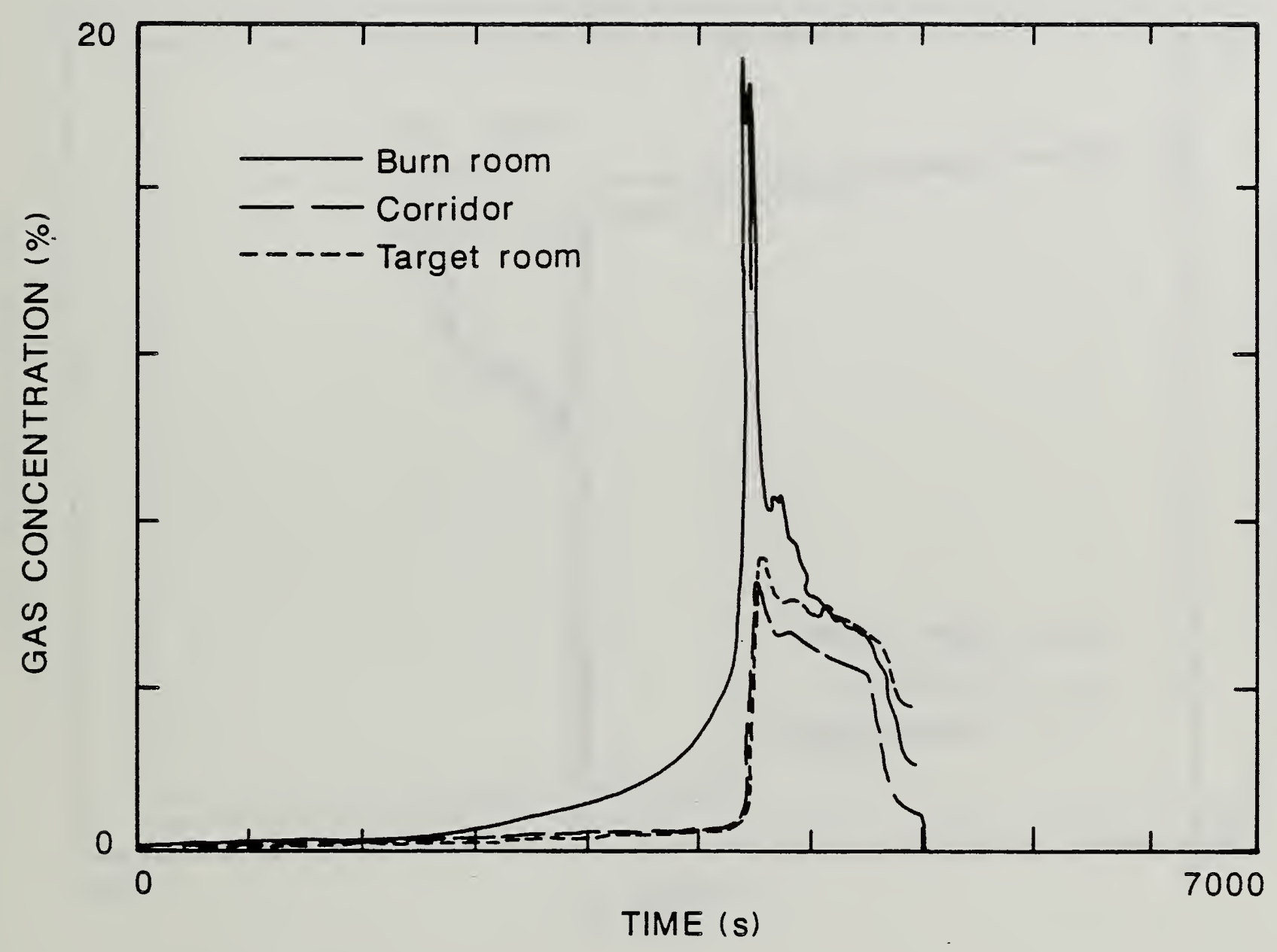

Figure 57. Comparison of Carbon Dioxide Concentration in Each Compartment of the Large-Scale Test Facility for the Two-Cigarette Test of Foam 32 Mock-up Upholstery Chair Assembly. 


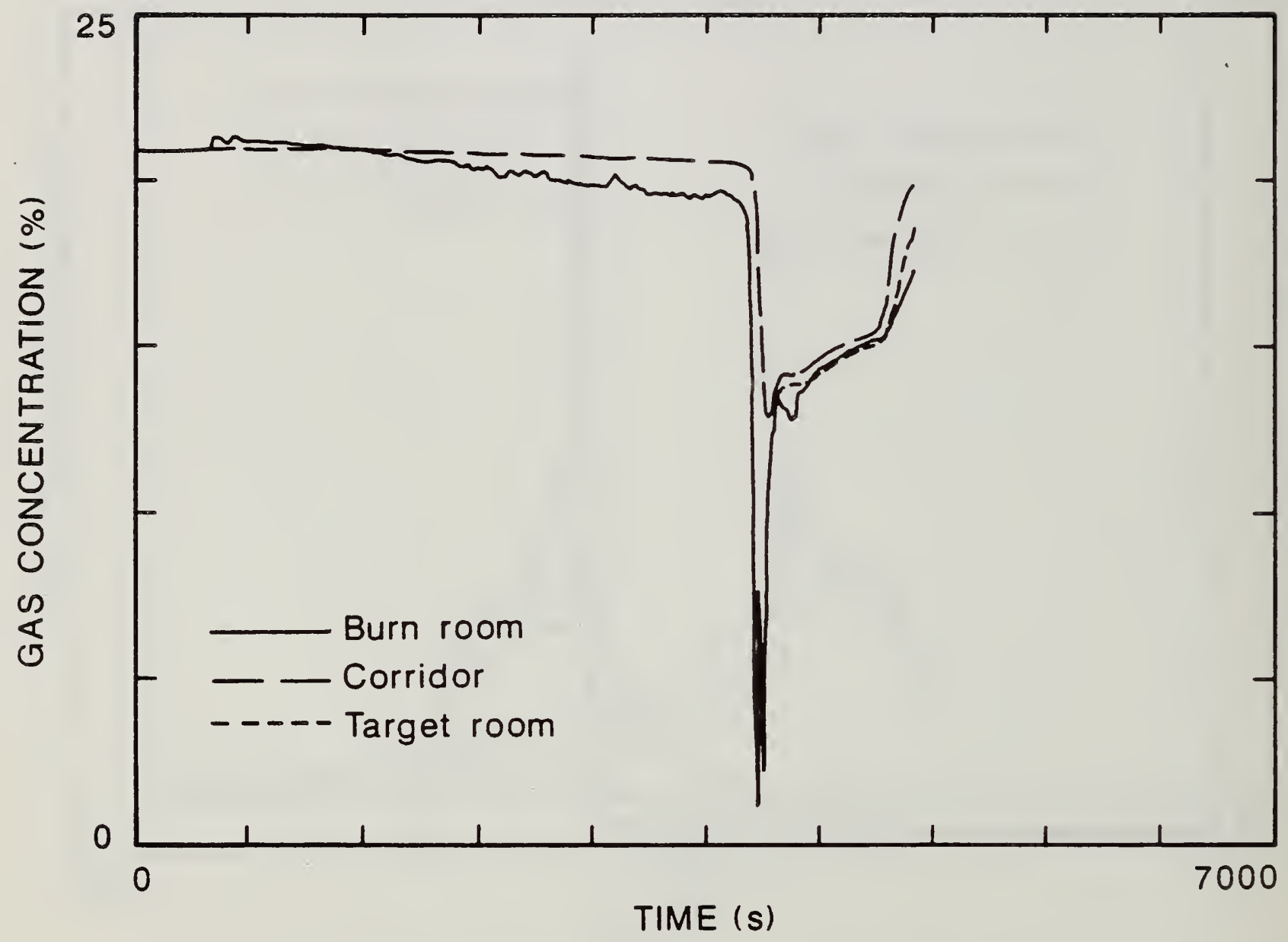

Figure 58. Comparison of Oxygen Concentrations in Each Compartment of the Large-Scale Test Facility for the Two-Cigarette Test of Foan 32 Mock-up Upholstery Chair Assembly. 


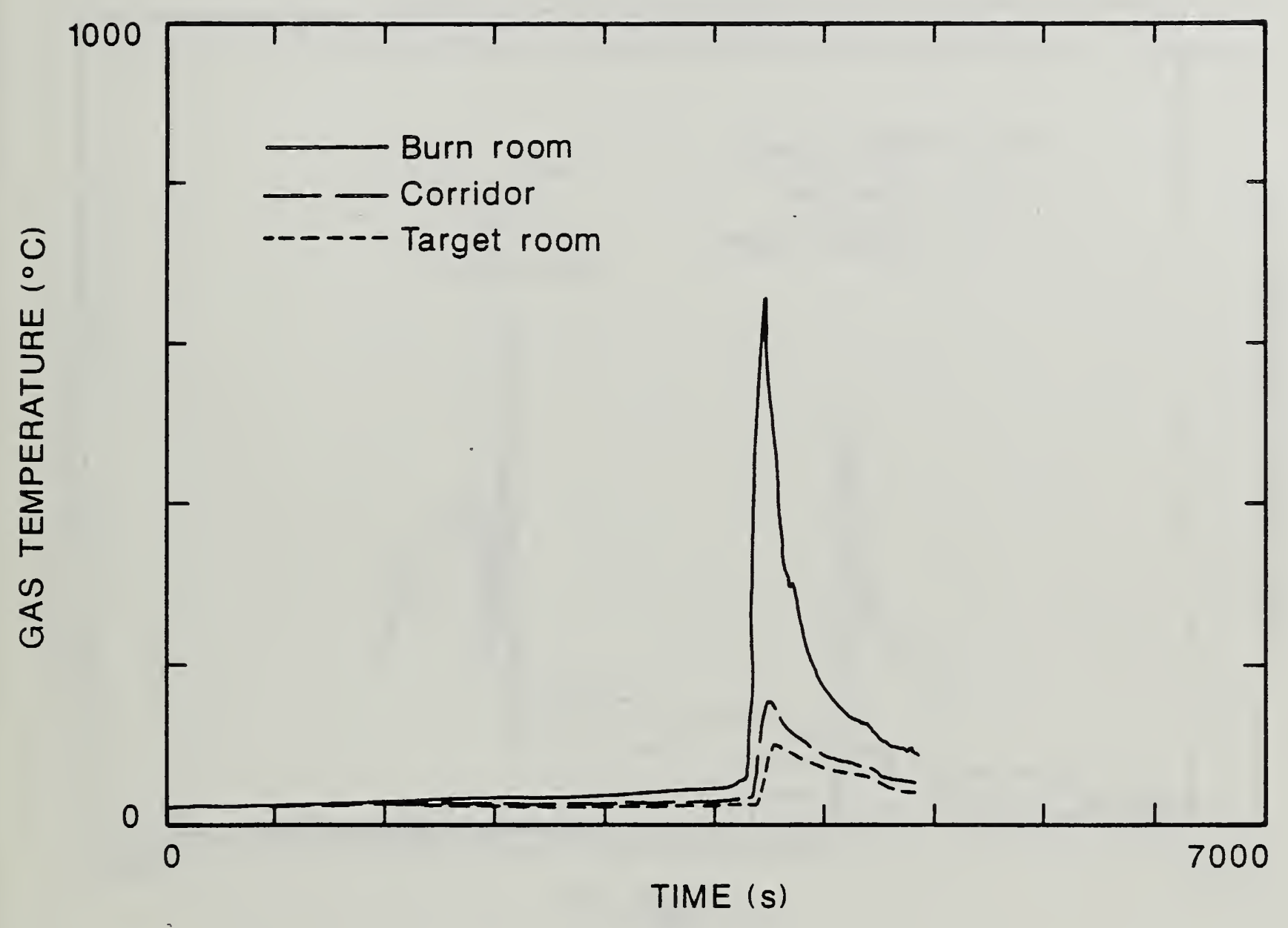

Figure 59. Comparison of Upper Compartment Gas Temperatures in Each Compartment of the Large-Scale Test Facility for the TwoCigarette Test of Foam 32 Mock-up Upholstery Chair Assembly. 


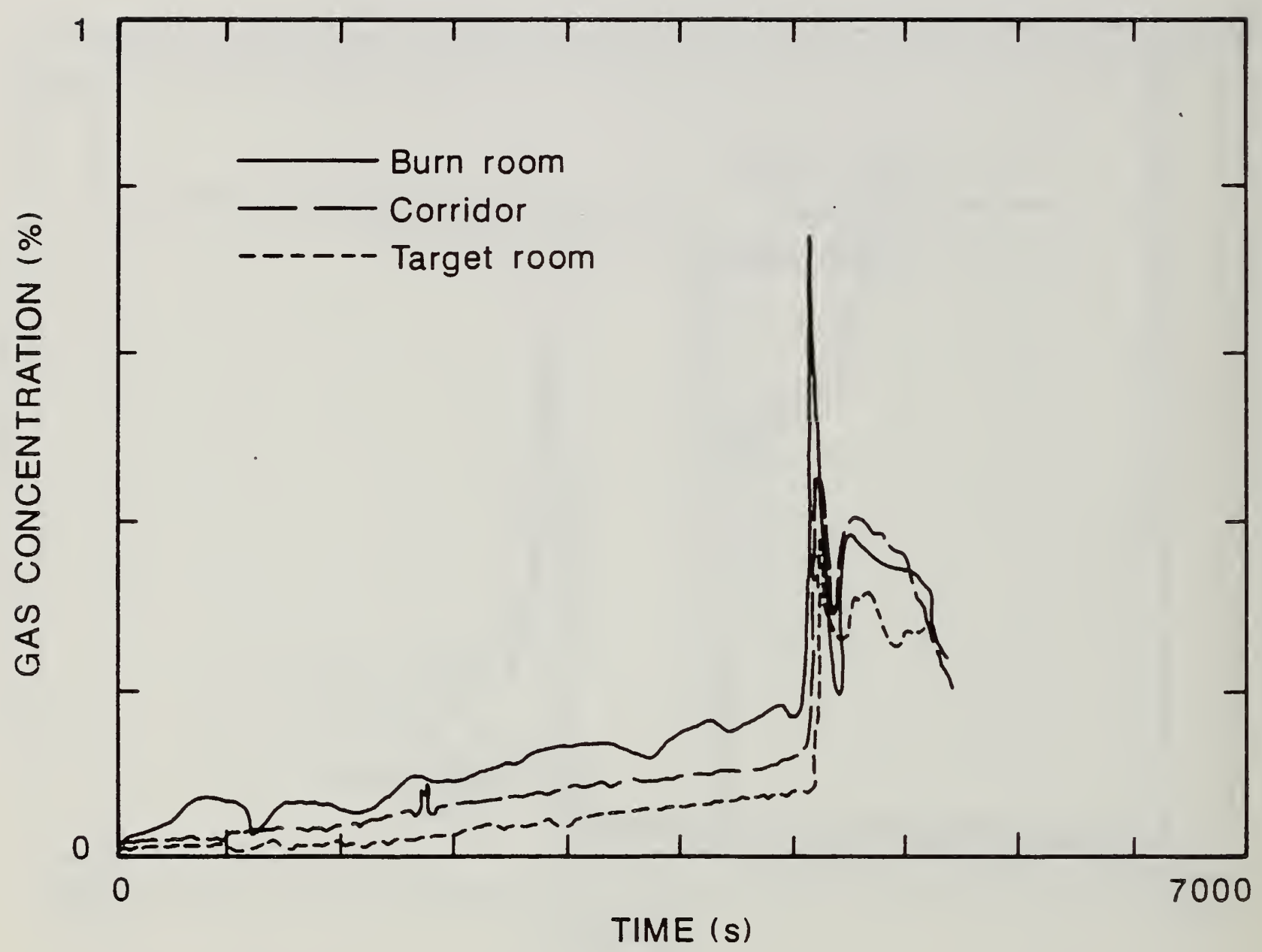

Figure 60. Comparison of Carbon Monoxide Concentrations in Each Compartment of the Large-Scale Test Facility for the TwoCigarette Test of Foam $32 \mathrm{X}$ Mock-up Upholstery Chair Assembly. 


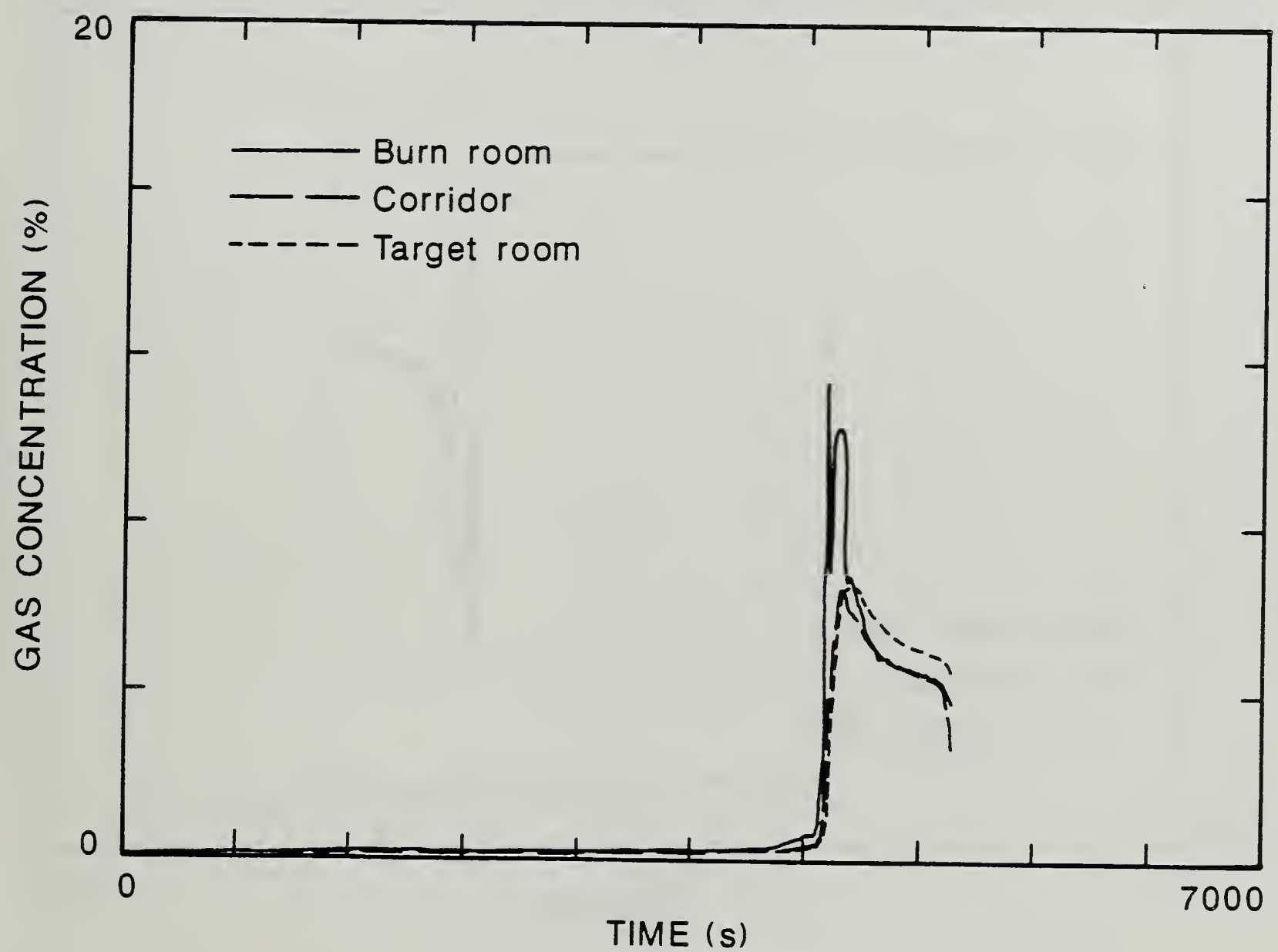

Figure 61. Comparison of Carbon Dioxide Concentrations in Each Compartment of the Large-Scale Test Facility for the Two-Cigarette Test of Foam 32X Mock-up Upholstery Chair Assembly. 


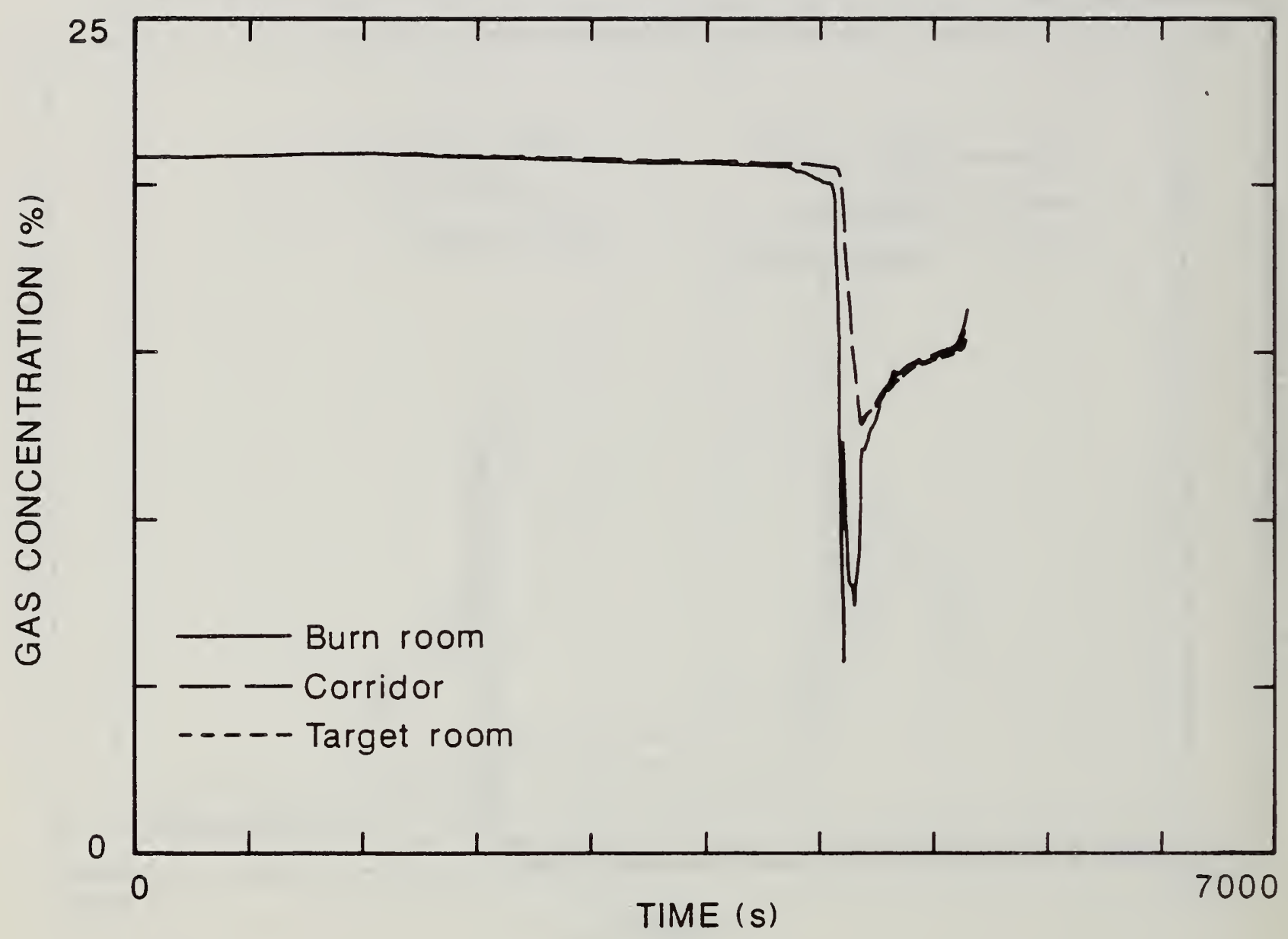

Figure 62. Comparison of Oxygen Concentrations in Each Compartment of the Large-Scale Test Facility for the Two-Cigarette Test of Foam 32X Mock-up Upholstery Chair Assembly. 


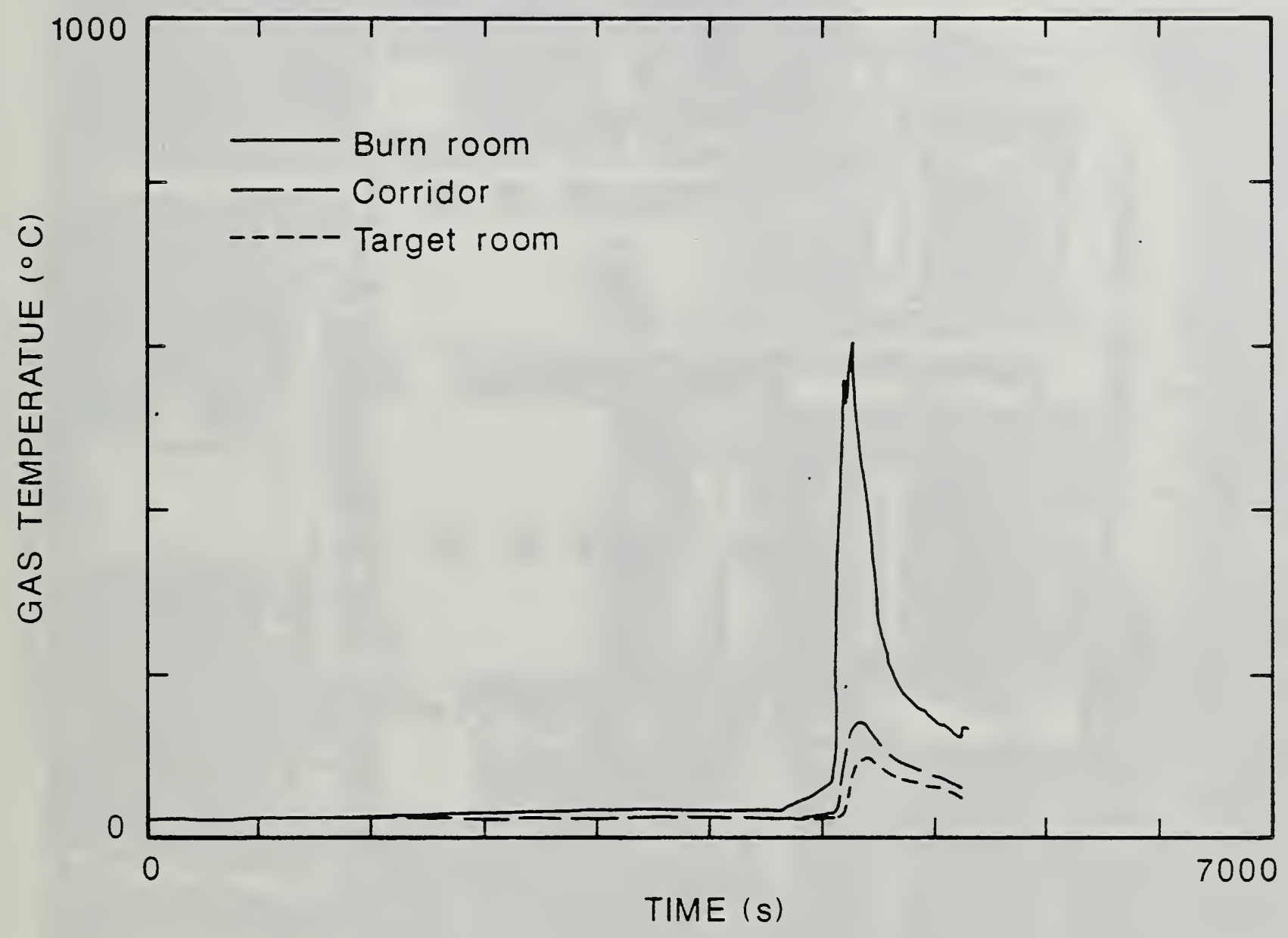

Figure 63. Comparison of the Upper Compartment Gas Iemperatures in Each Compartment of the Large-Scale Test Facility for the Two-

Cigarette Test of Foam $32 \mathrm{X}$ Mock-up Upholstery Chair Assembly. 


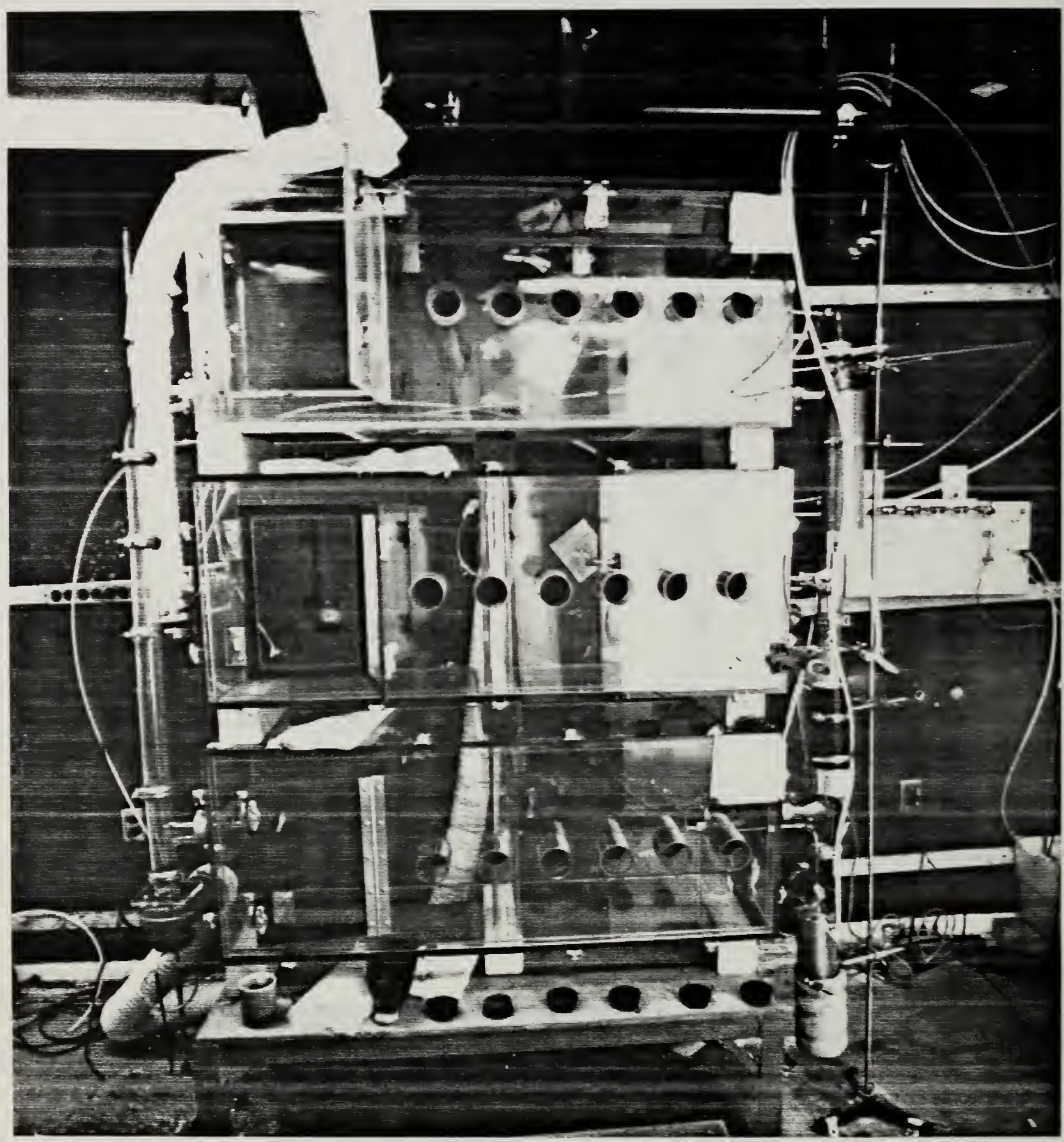

Figure 64. Large-Scale Three Compartment Animal Exposure System - Three Animal Exposure Chambers. 


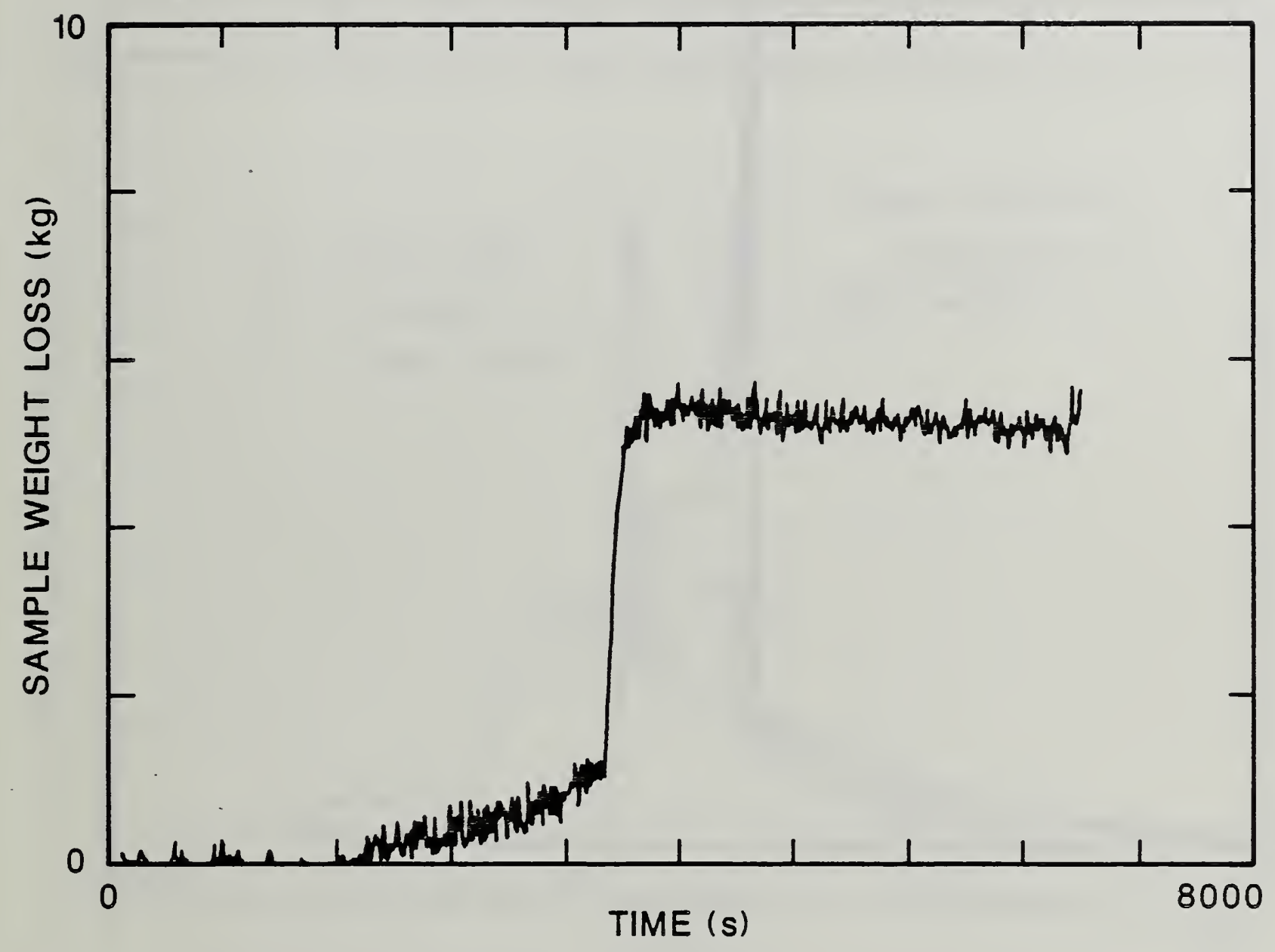

Figure 65. Mass Loss of Upholstery Chair Assembly Made from Foam 32 and Exposed to Two-Cigarettes in the Large-Scale Test Facility With the Animal Exposure Chambers Connected to the Burn Room. 


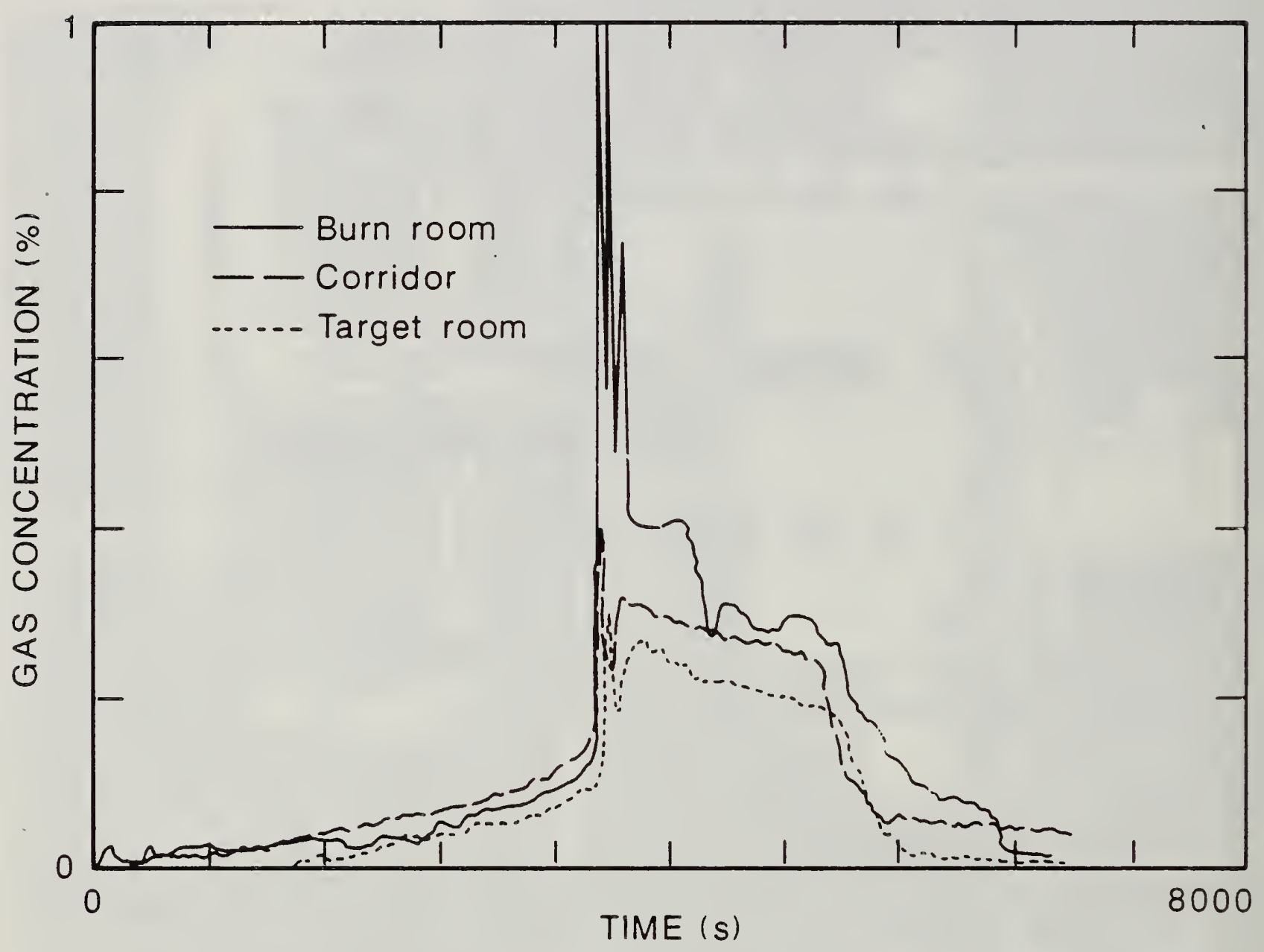

Figure 66. Comparison of Carbon Monoxide Concentrations in Each Compartment of the Large-Scale Test Facility for the Two-Cigarette Test of Foam 32 Mock-up Upholstery Chair Assembly With the Animal Exposure Chambers Connected to the Burn Room. 


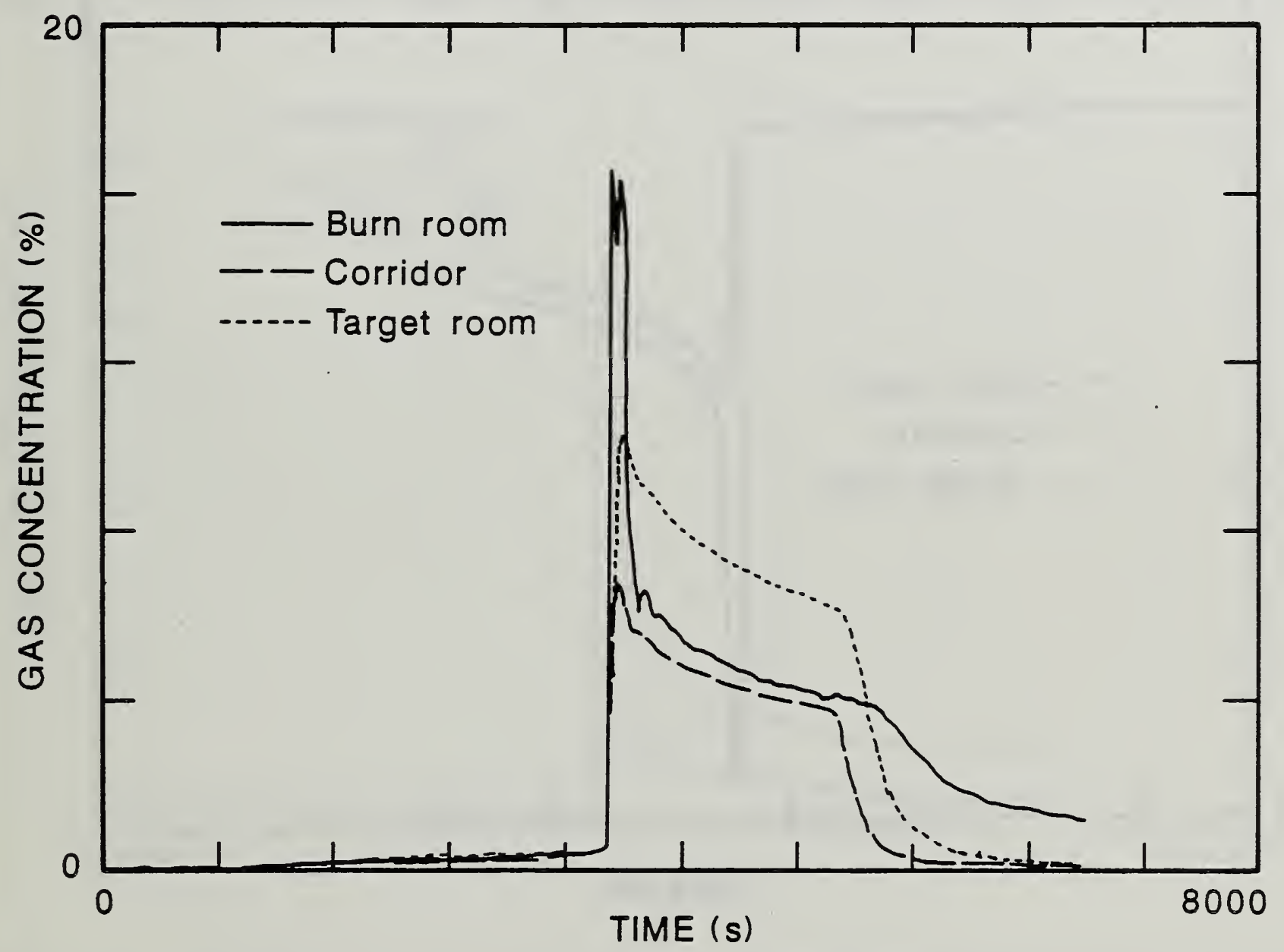

Figure 67. Comparison of Carbon Dioxide Concentrations in Each Compartment of the Large-Scale Test Facility for the Two-Cigarette Test of Foam 32 Mock-up Upholstery Chair Assembly With the Animal Exposure Chambers Connected to the Burn Room. 


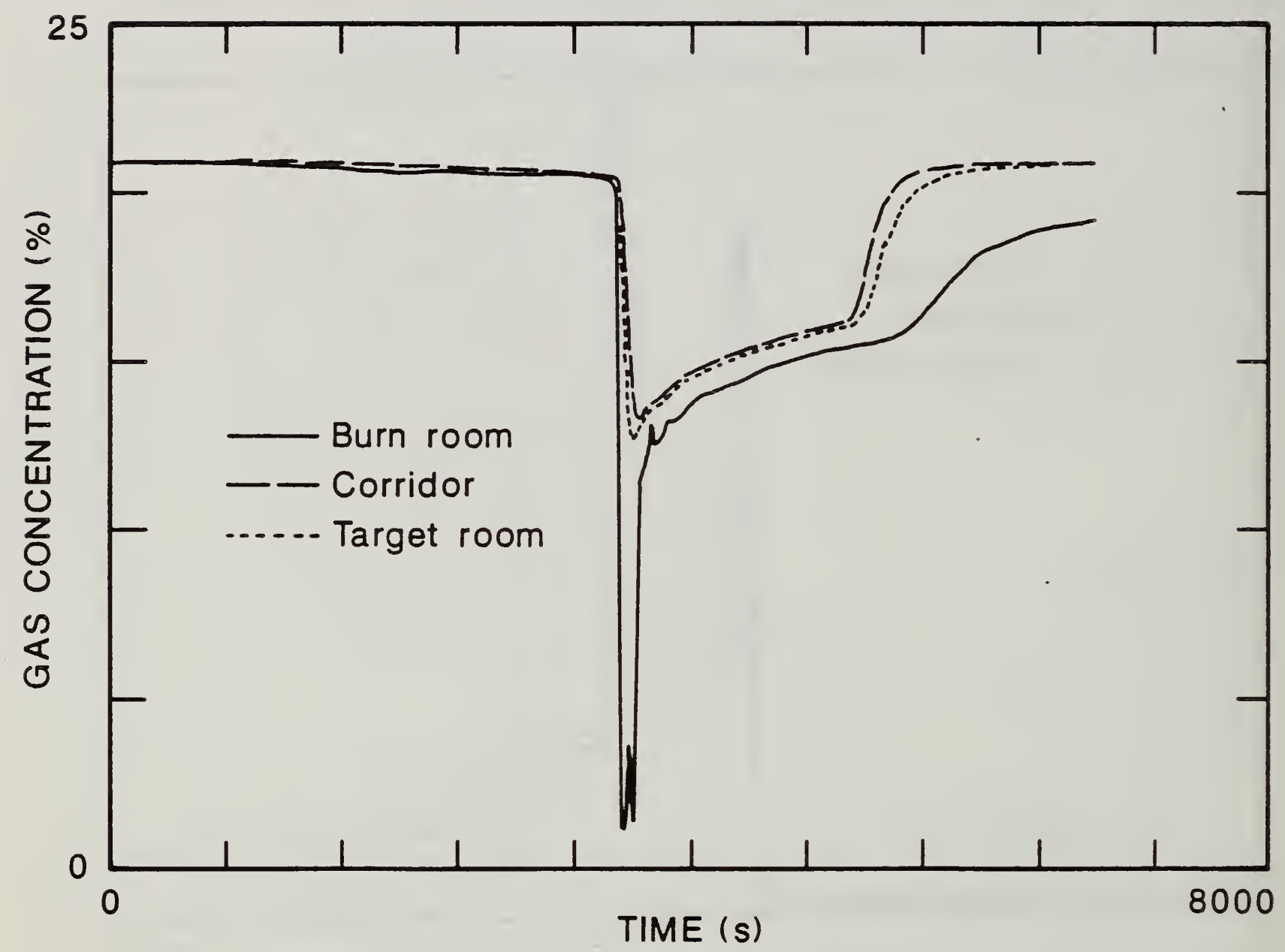

Figure 68. Comparison of Oxygen Concentrations in Each Compartment of the Large-Scale Test Facility for the Two-Cigarette Test of Foam 32 Mock-up Upholstery Chair Assembly With the Animal Exposure Chambers Connected to the Burn Room. 


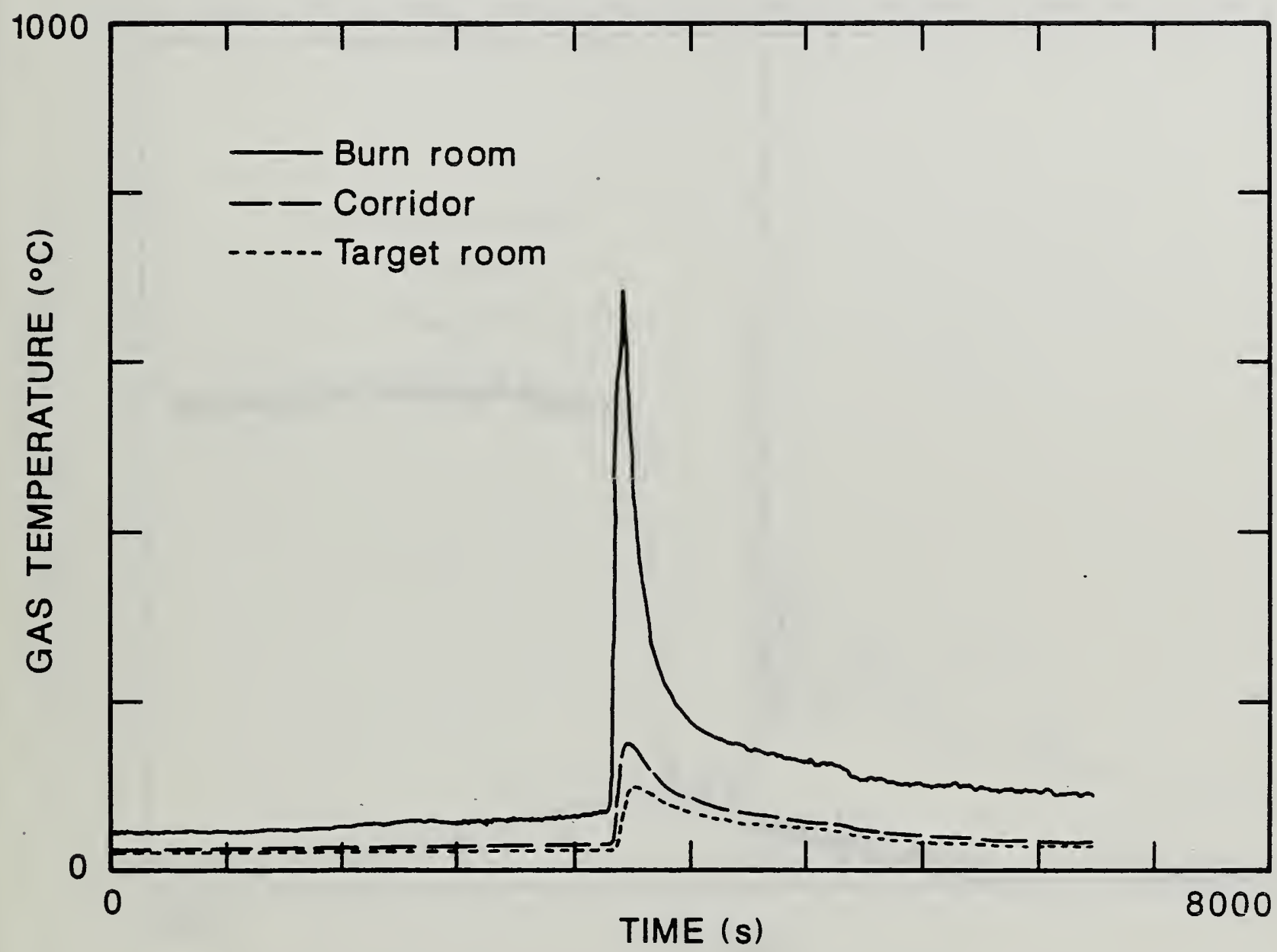

Figure 69. Comparison of the Upper Compartment Gas Temperature in Each Compartment of the Large-Scale Test Facility for the Two Cigarette Test of Foam 32 Mock-up Upholstery Chair Assembly With the Animal Exposure Chambers Connected to the Burn Room. 


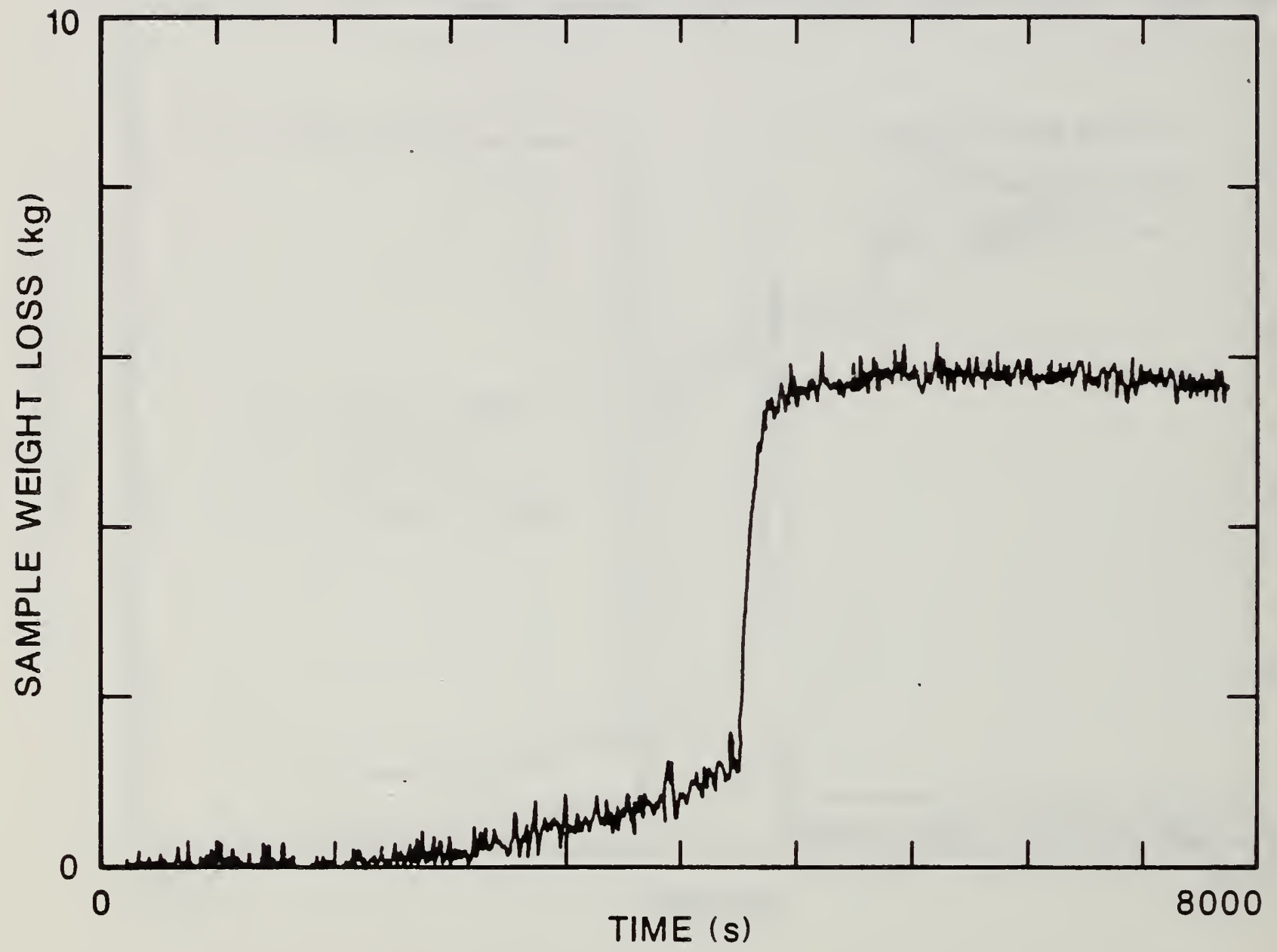

Figure 70. Mass Loss of Upholstery Chair Assembly Made from Foam 32 and Exposed to Two-Cigarettes in the Large-Scale Test Facility With the Animal Exposure Chambers Connected to the Target Room. 


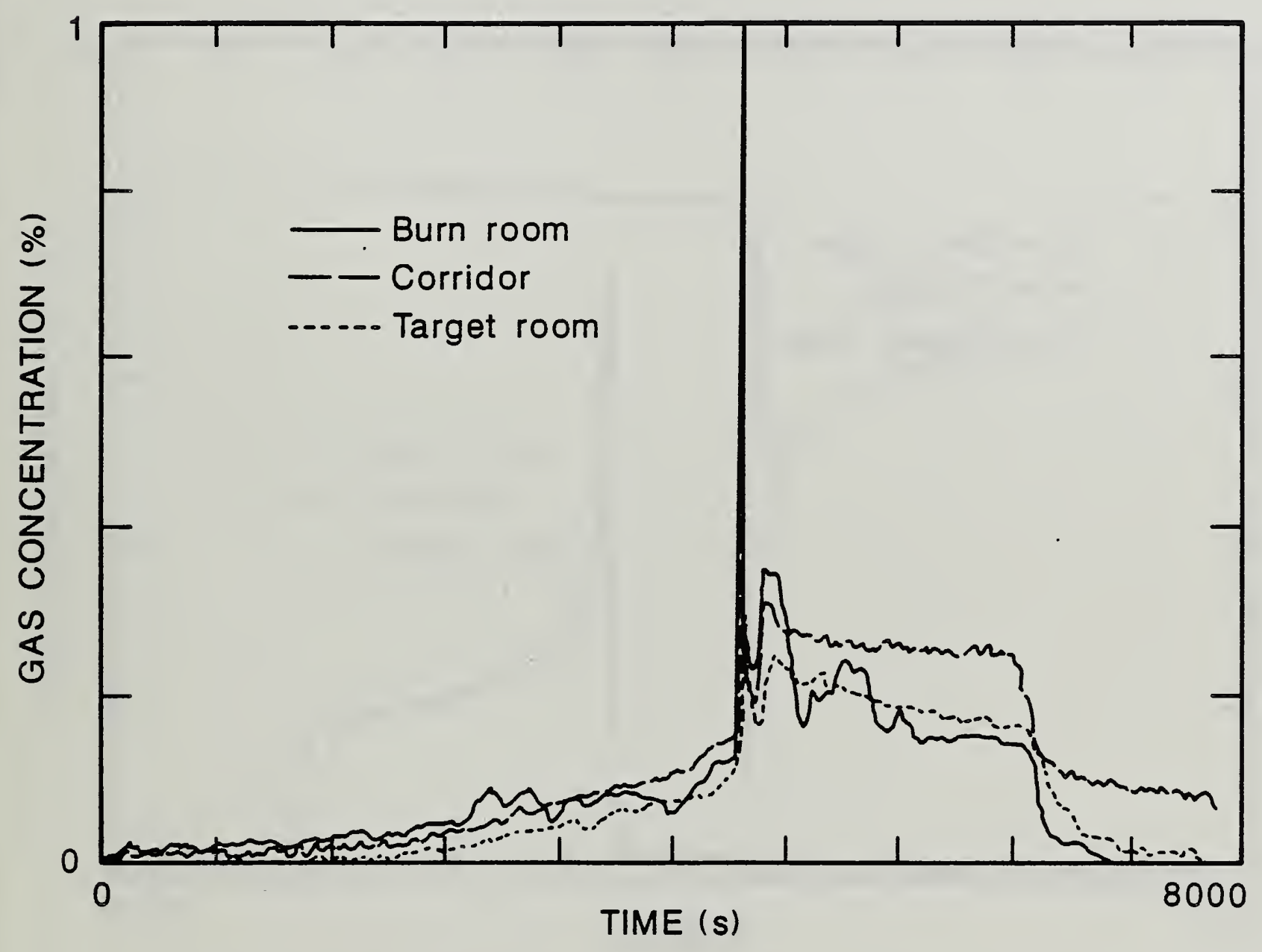

Figure 71. Comparison of Carbon Monoxide Concentrations in Each Compartment of the Large-Scale Test Facility for the Two-Cigarette Test of Foam 32 Mock-up Upholstery Chair Assembly With the Animal Exposure Chamber Connected to the Target Room. 


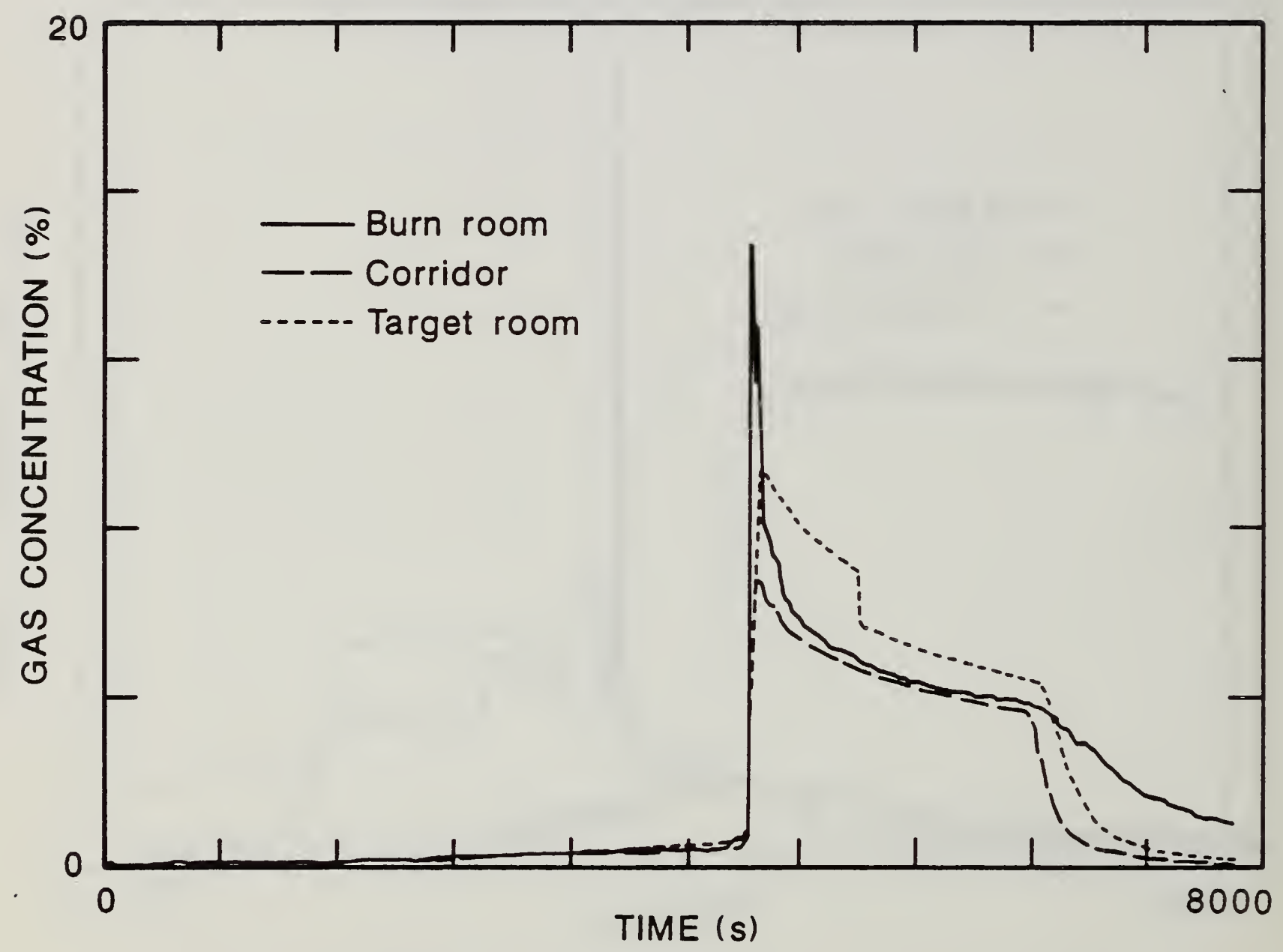

Figure 72. Comparison of Carbon Dioxide Concentration in Each Compartment of the Large-Scale Test Facility for the Two-Cigarette Test of Foam 32 Mock-up Upholstery Chair Assembly With the Animal Exposure Chamber Connected to the Target Room. 


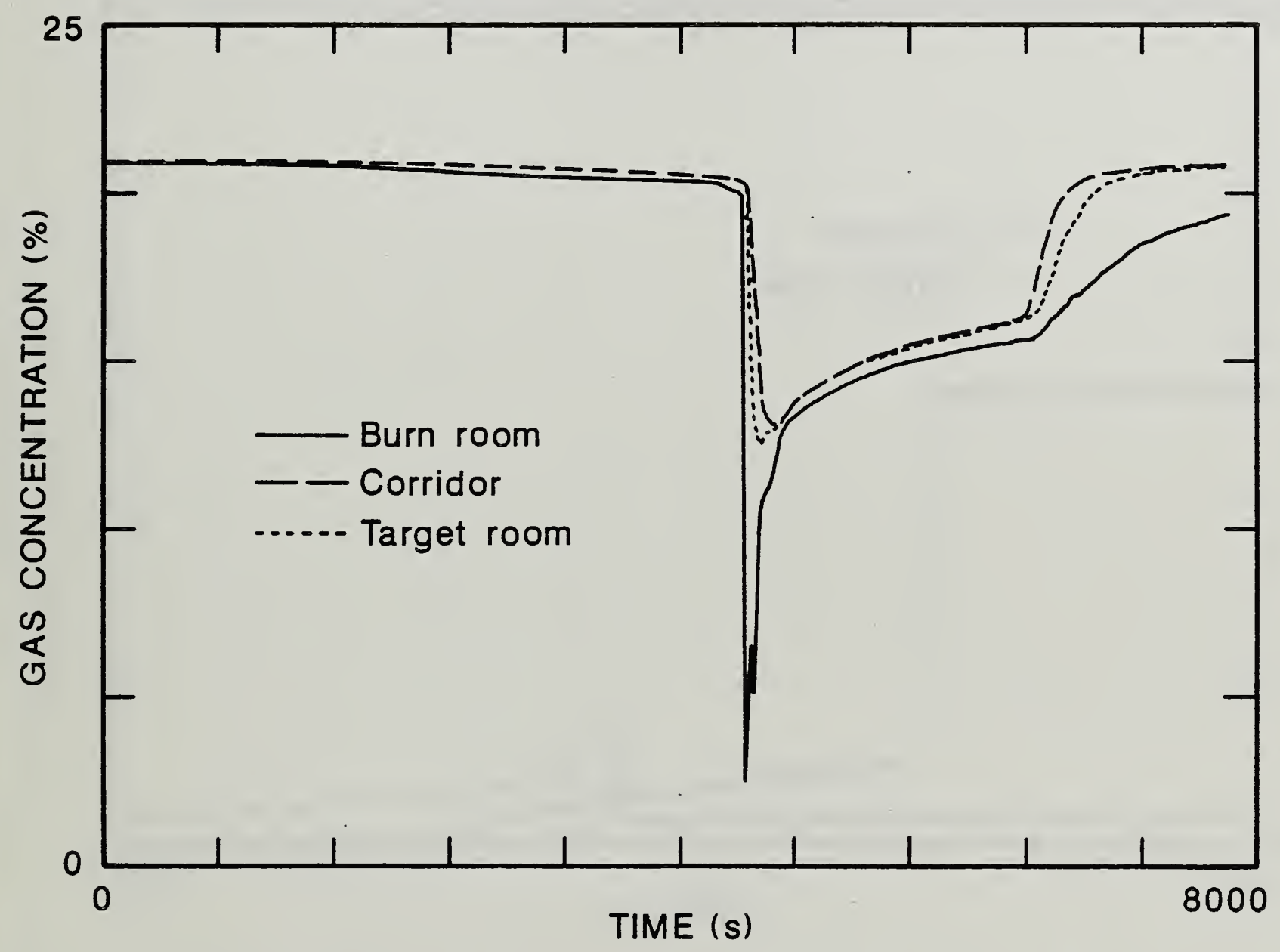

Figure 73. Comparison of Oxygen Concentration in Each Compartment of the Large-Scale Test Facility for the Two-Cigarette Test of Foam 32 Mock-up Upholstery Chair Assembly With the Animal Exposure Chamber Connected to the Target Room. 


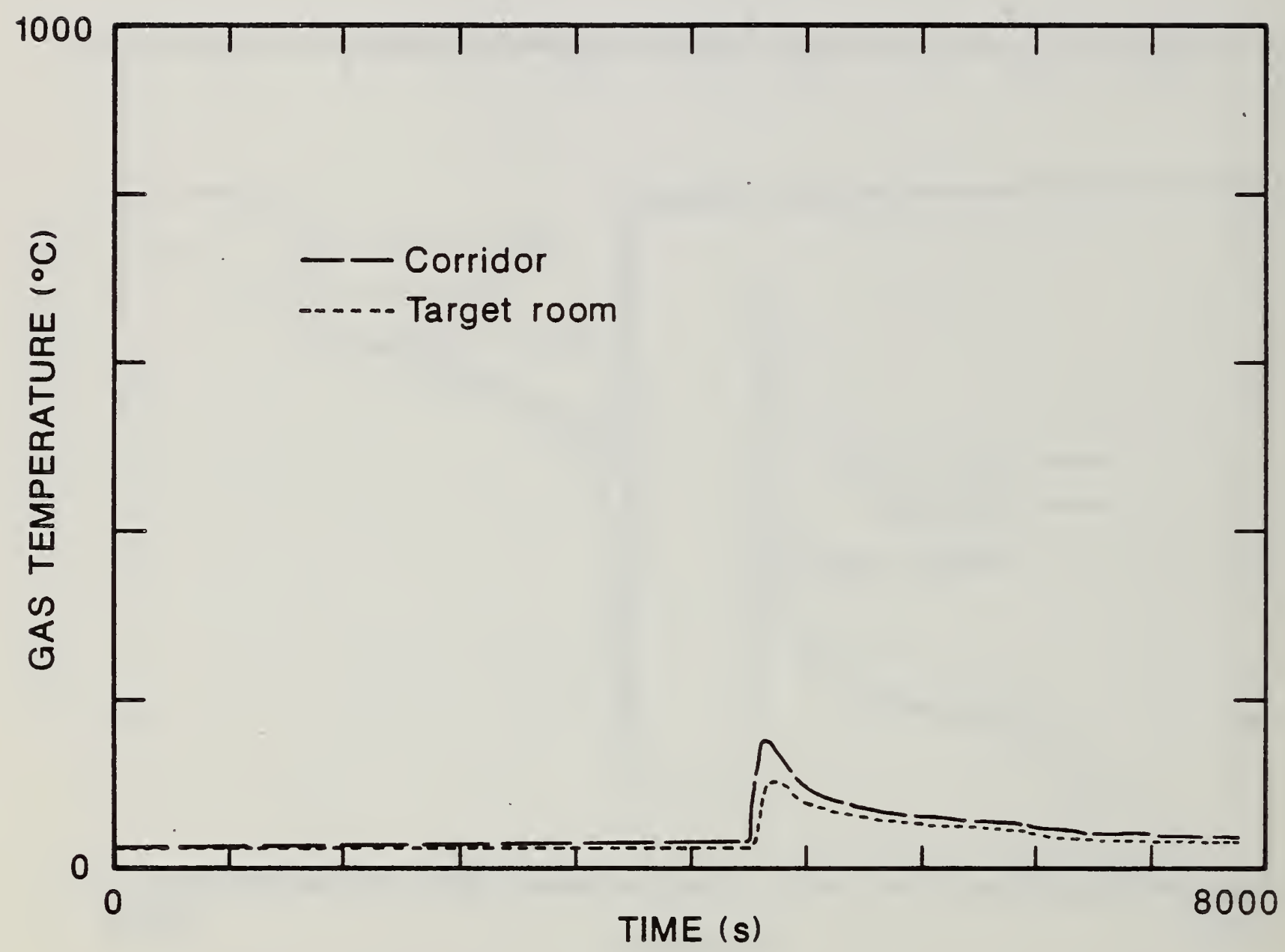

Figure 74. Comparison of the Upper Compartment Gas Temperatures in Each Compartment of the Large-Scale Test Facility for the TwoCigarette Test of Foam 32 Mock-up Upholstery Chair Assembly With the Animal Exposure Chamber Connected to the Target Room. 


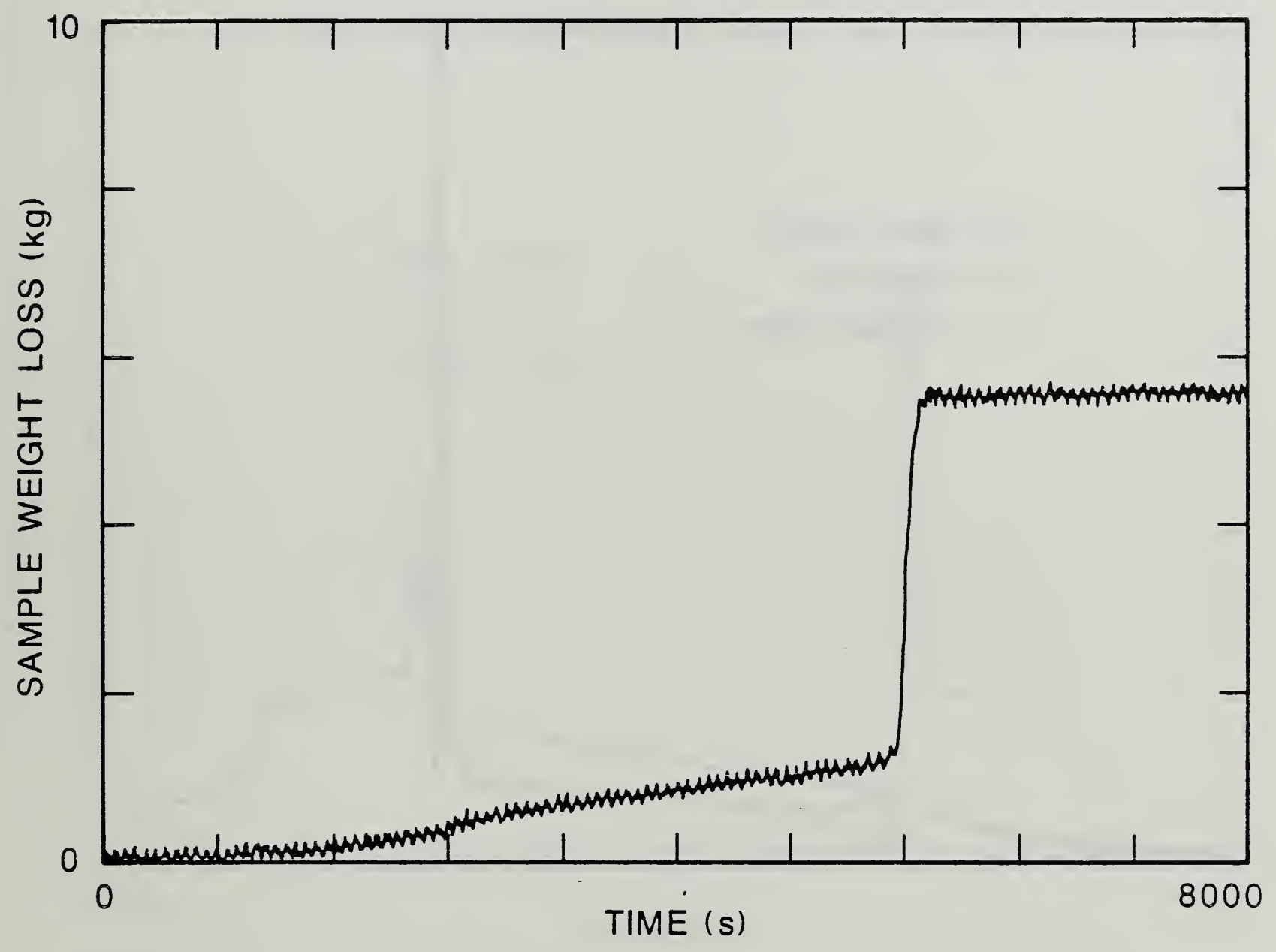

Figure 75. Mass Loss of Upholstery Chair Assembly Made from Foam $32 \mathrm{X}$ and Exposed to Two-Cigarettes in the Large-Scale Test Facility With the Animal Exposure Chambers Connected to the Burn Room. 


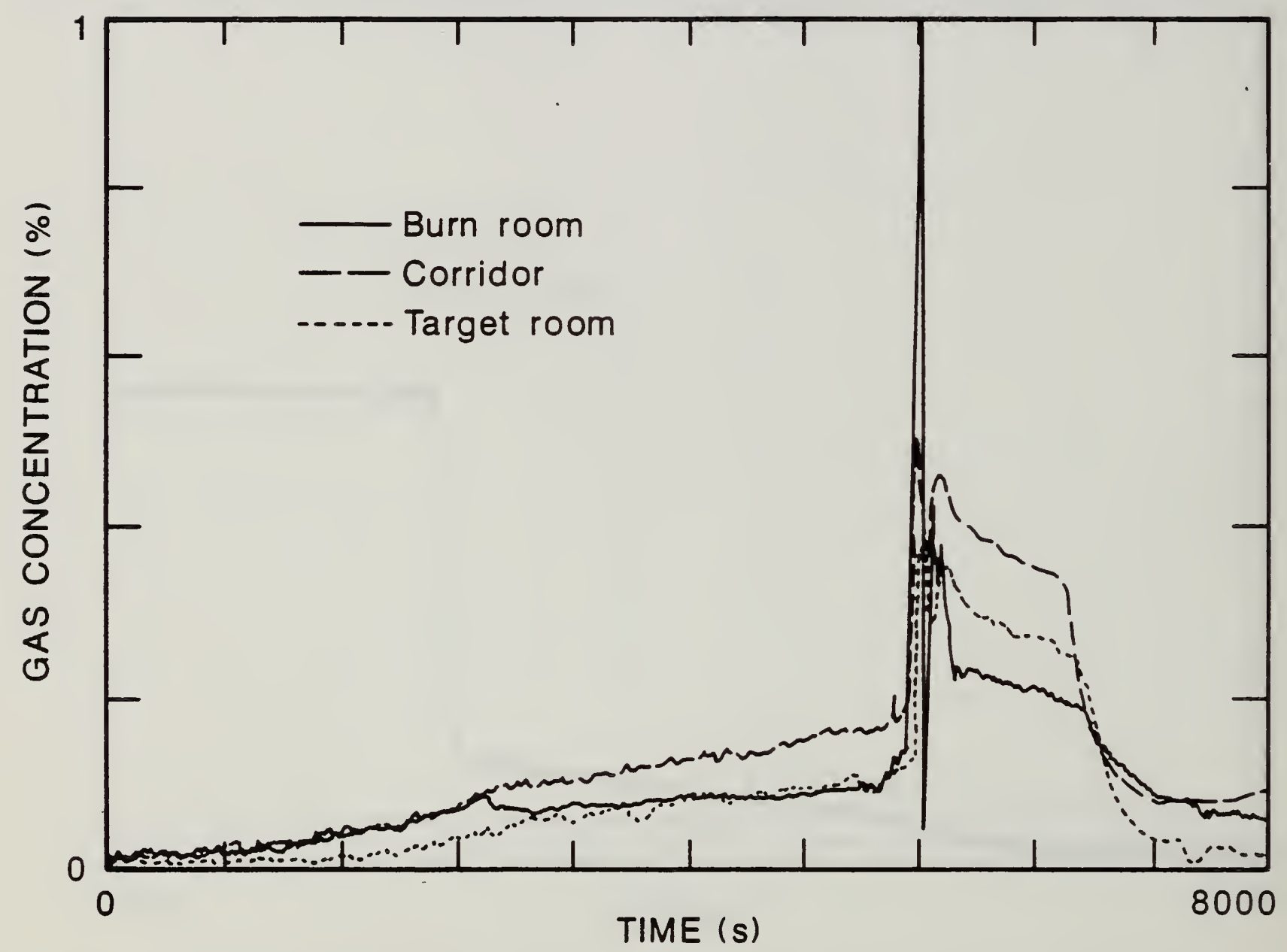

Figure 76. Comparison of Carbon Monoxide Concentrations in Each Compartment of the Large-Scale Test Facility for the Two-Cigarette Test of Foam 32X Mock-up Upholstery Chair Assembly With the Animal Exposure Chambers Connected to the Burn Room. 


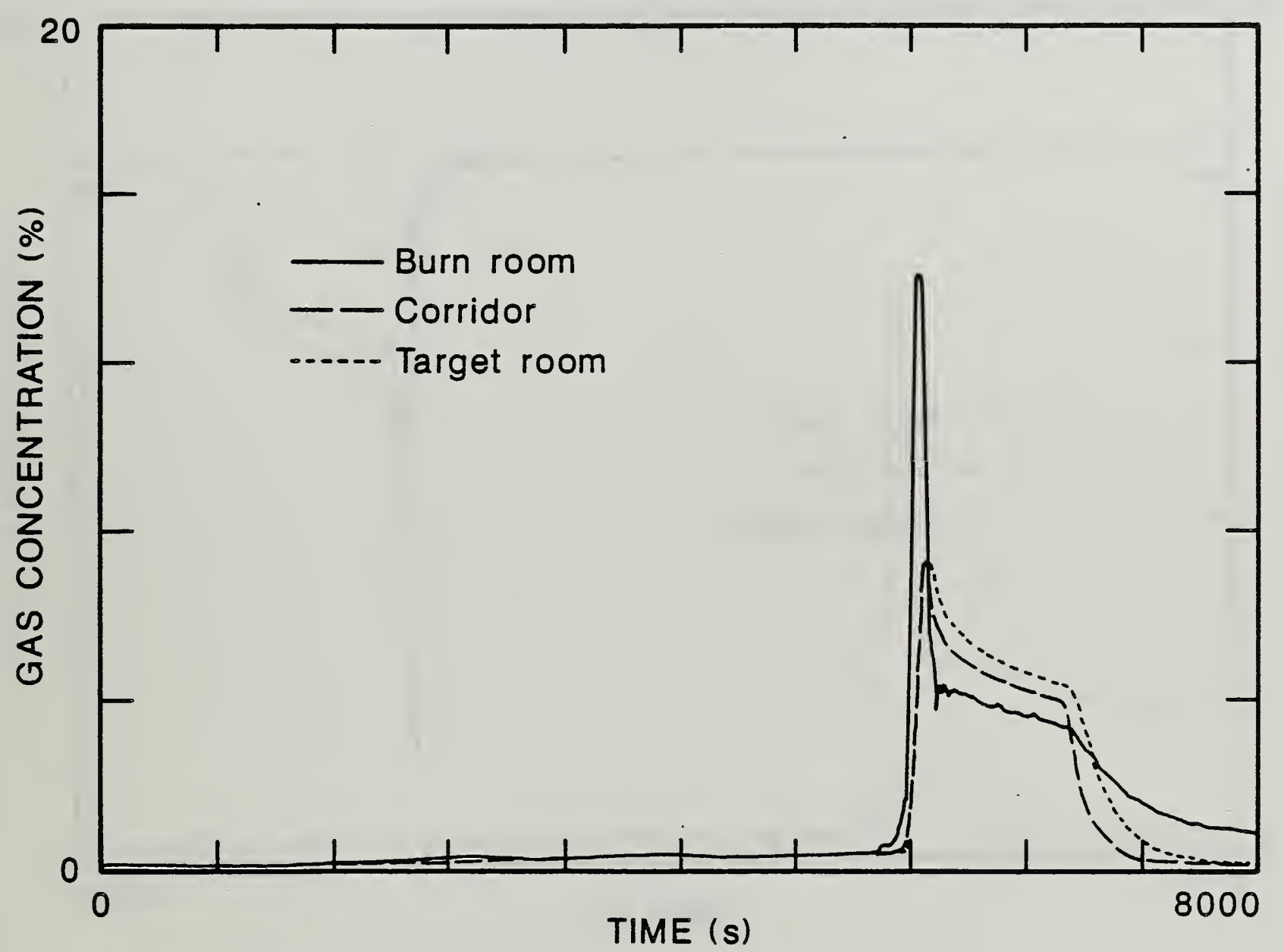

Figure 77. Comparison of Carbon Dioxide Concentrations in Each Compartment of the Large-Scale Test Facility for the Two-Cigarette Test of Foam 32X Mock-up Upholstery Chair Assembly With the Animal Exposure Chambers Connected to the Burn Room. 


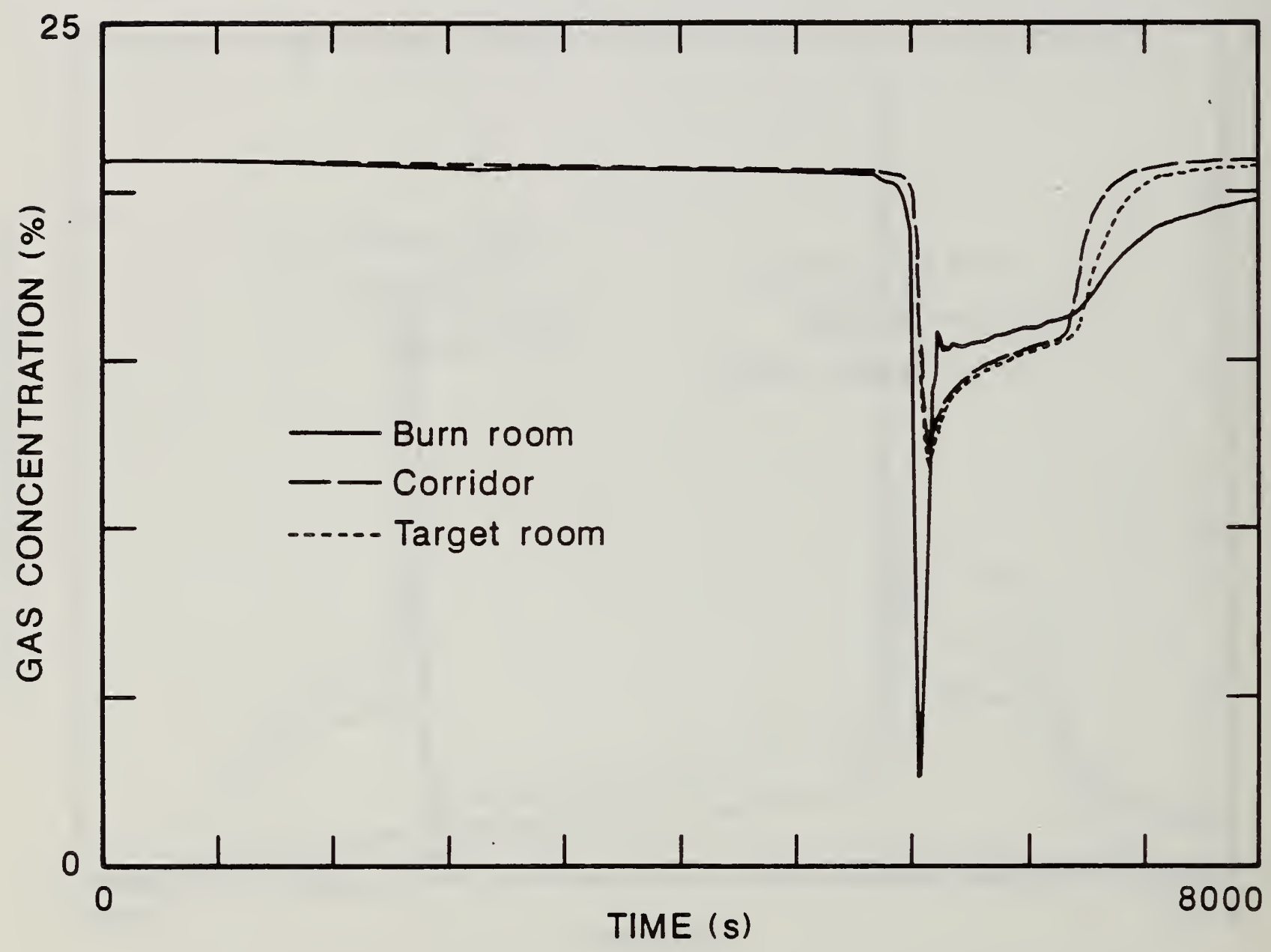

Figure 78. Comparison of Oxygen Concentrations in Each Compartment of the Large-Scale Test Facility for the Two-Cigarette Test of Foam 32X Mock-up Upholstery Chair Assembly With the Animal Exposure Chambers Connected to the Burn Room. 


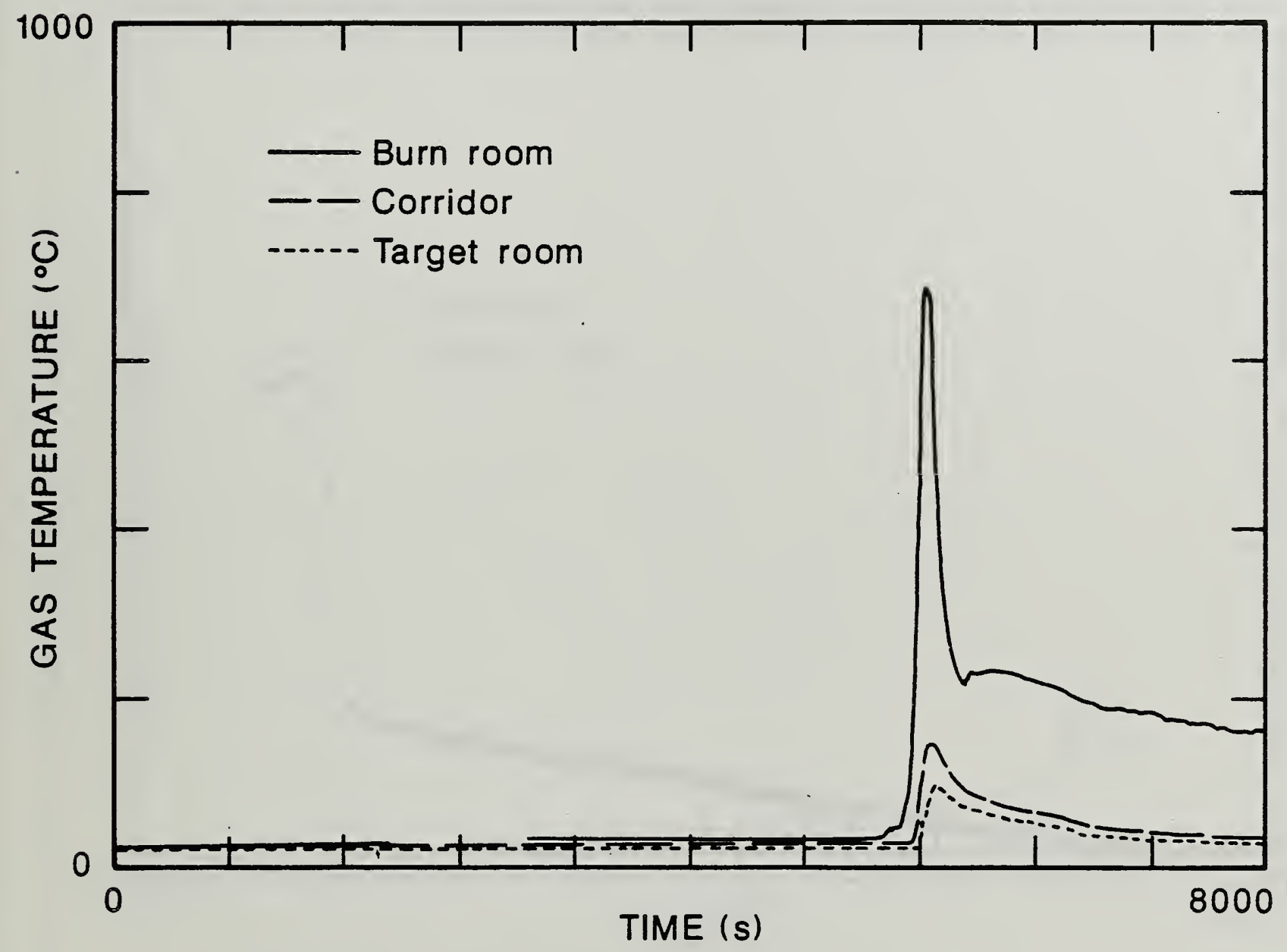

Figure 79. Comparison of Upper Compartment Gas Temperatures in Each Compartment of the Large-Scale Test Facility for the Two Cigarette Test of Foam 32X Mock-up Upholstery Chair Assembly With the Animal Exposure Chambers Connected to the Burn Room. 


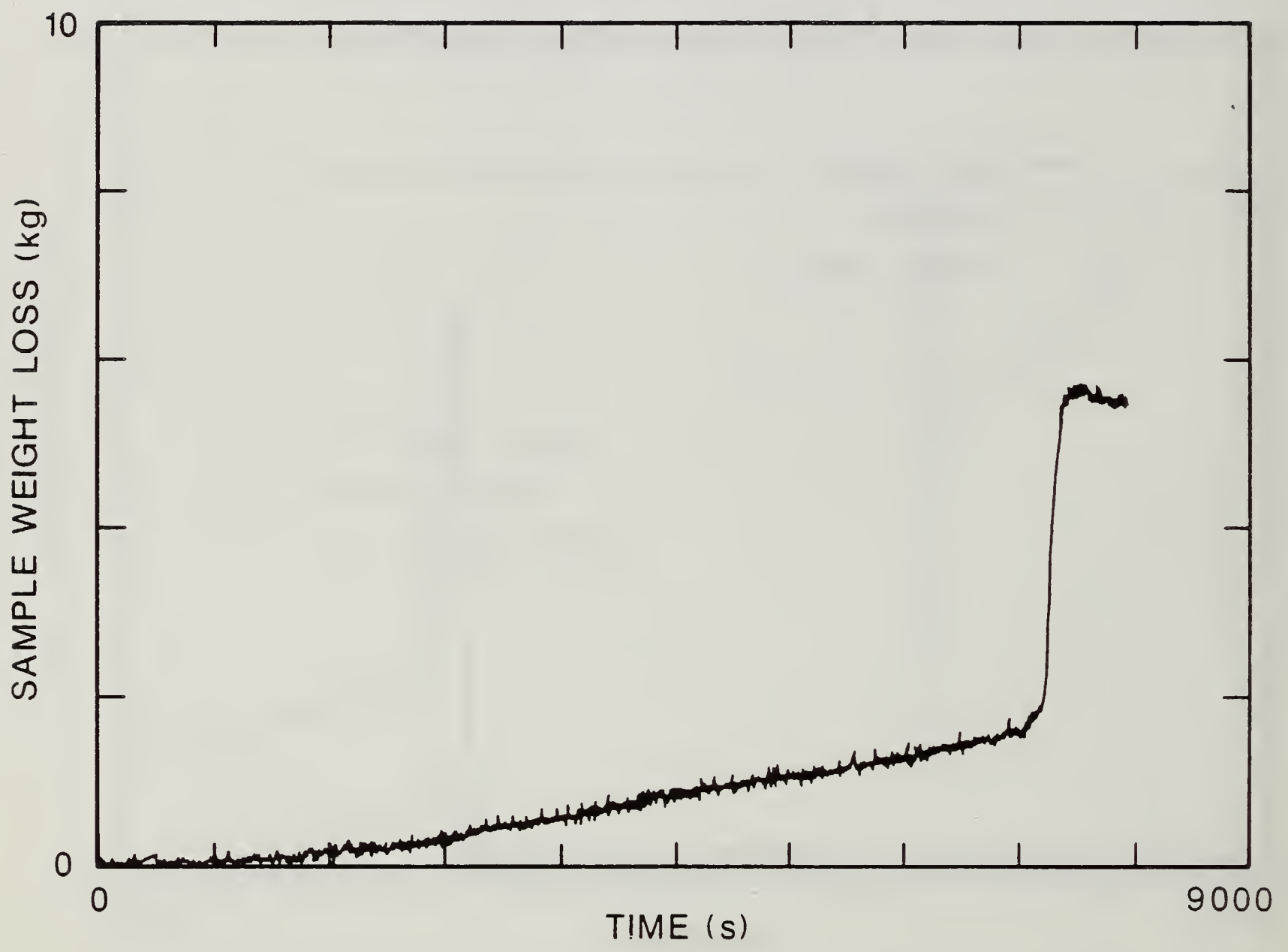

Figure 80. Mass Loss of Upholstery Chair Assembly Made from Foam $32 \mathrm{X}$ and Exposed to Two-Cigarettes in the Large-Scale Test Facility With the Animal Exposure Chambers Connected to the Target Room. 


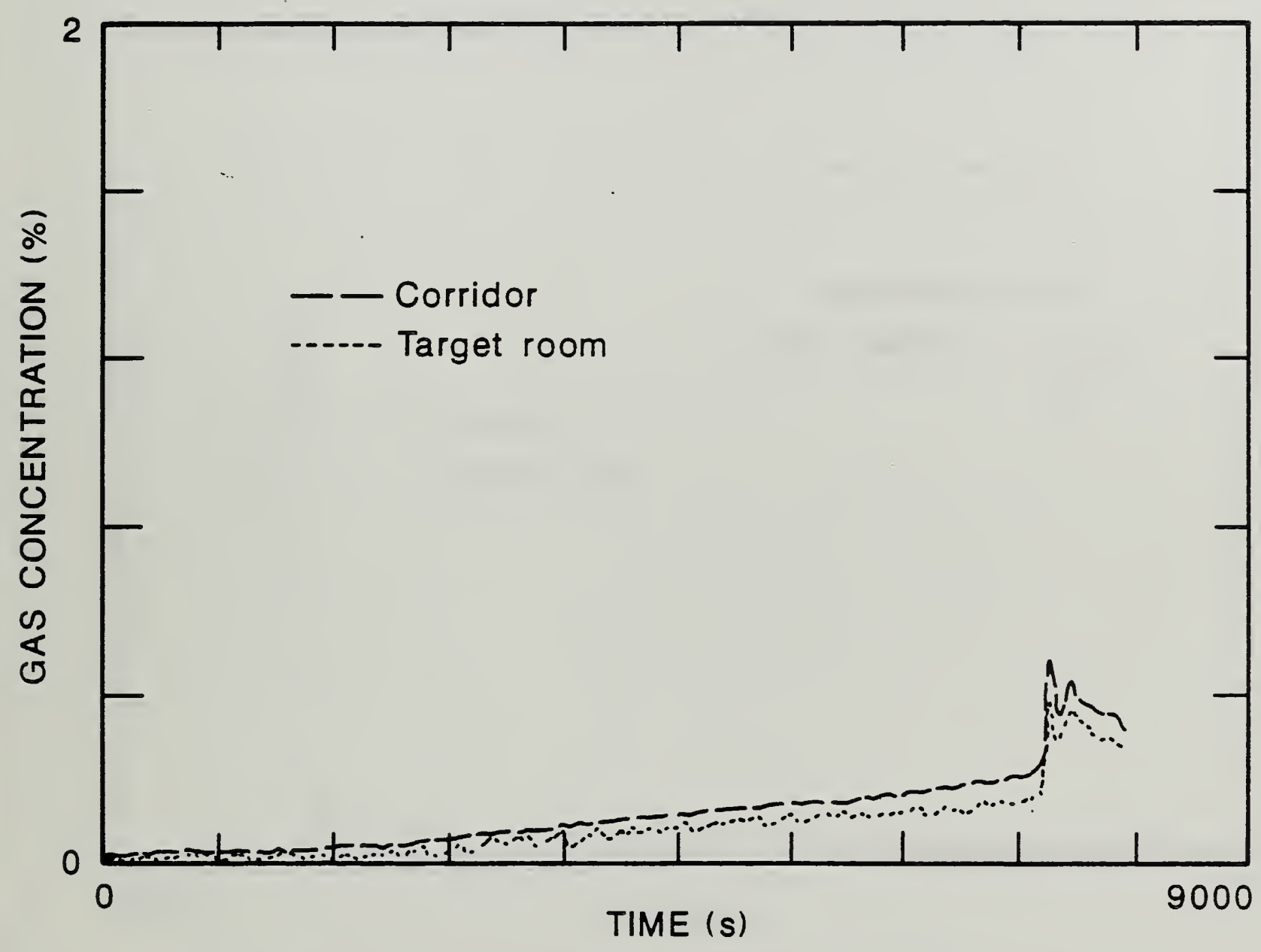

Figure 81. Comparison of Carbon Monoxide Concentrations in Each Compartment of the Large-Scale Test Facility for the Two-Cigarette Test of Foam 32X Mock-up Upholstery Chair Assembly With the Animal Exposure Chambers Connected to the Target Room. 


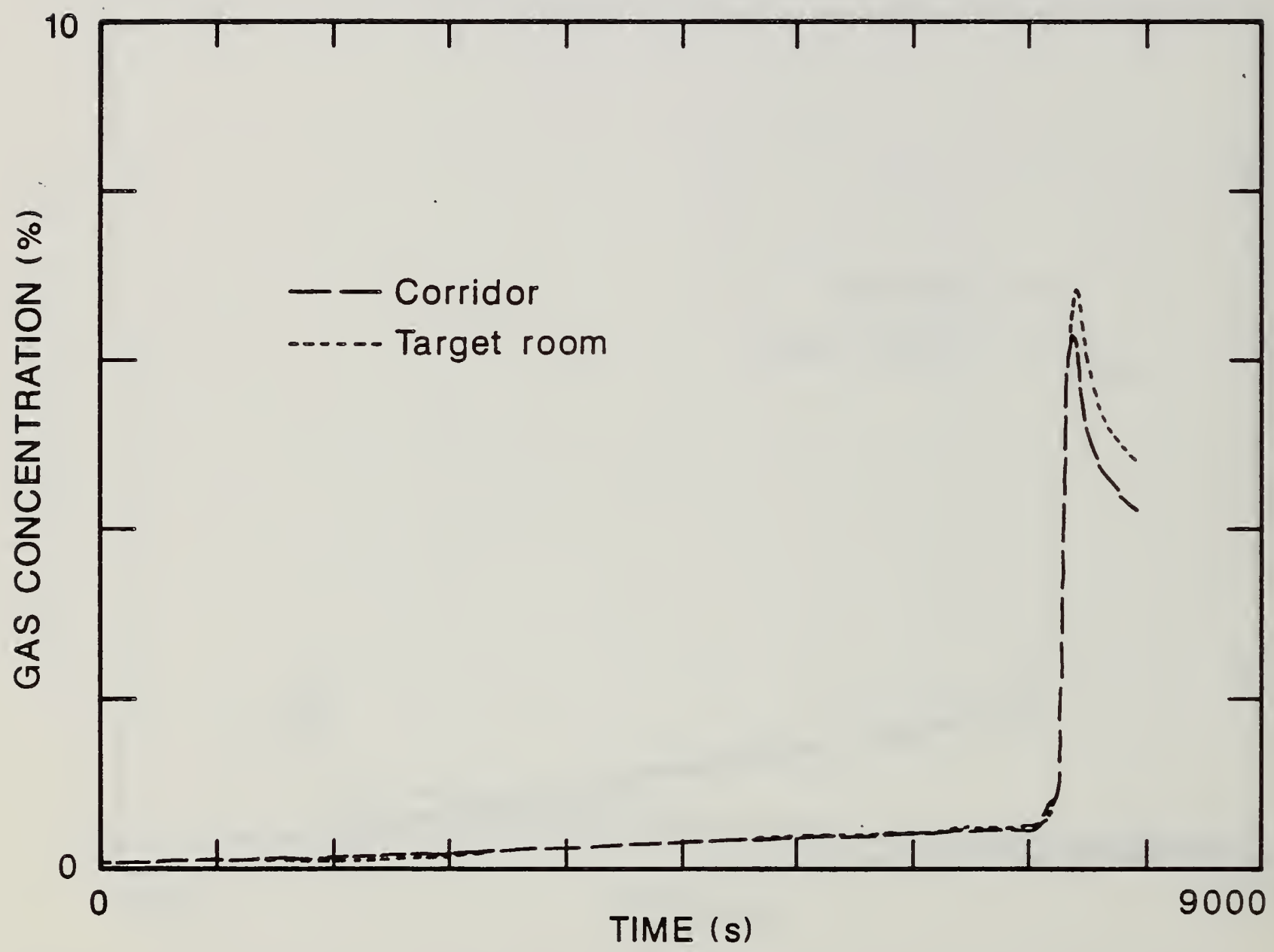

Figure 82. Comparison of Carbon Dioxide Concentrations in Each Compartment of the Large-Scale Test Facility for the Two-Cigarette Test of Foam 32X Mock-up Upholstery Chair Assembly With the Animal Exposure Chambers Connected to the Target Room. 


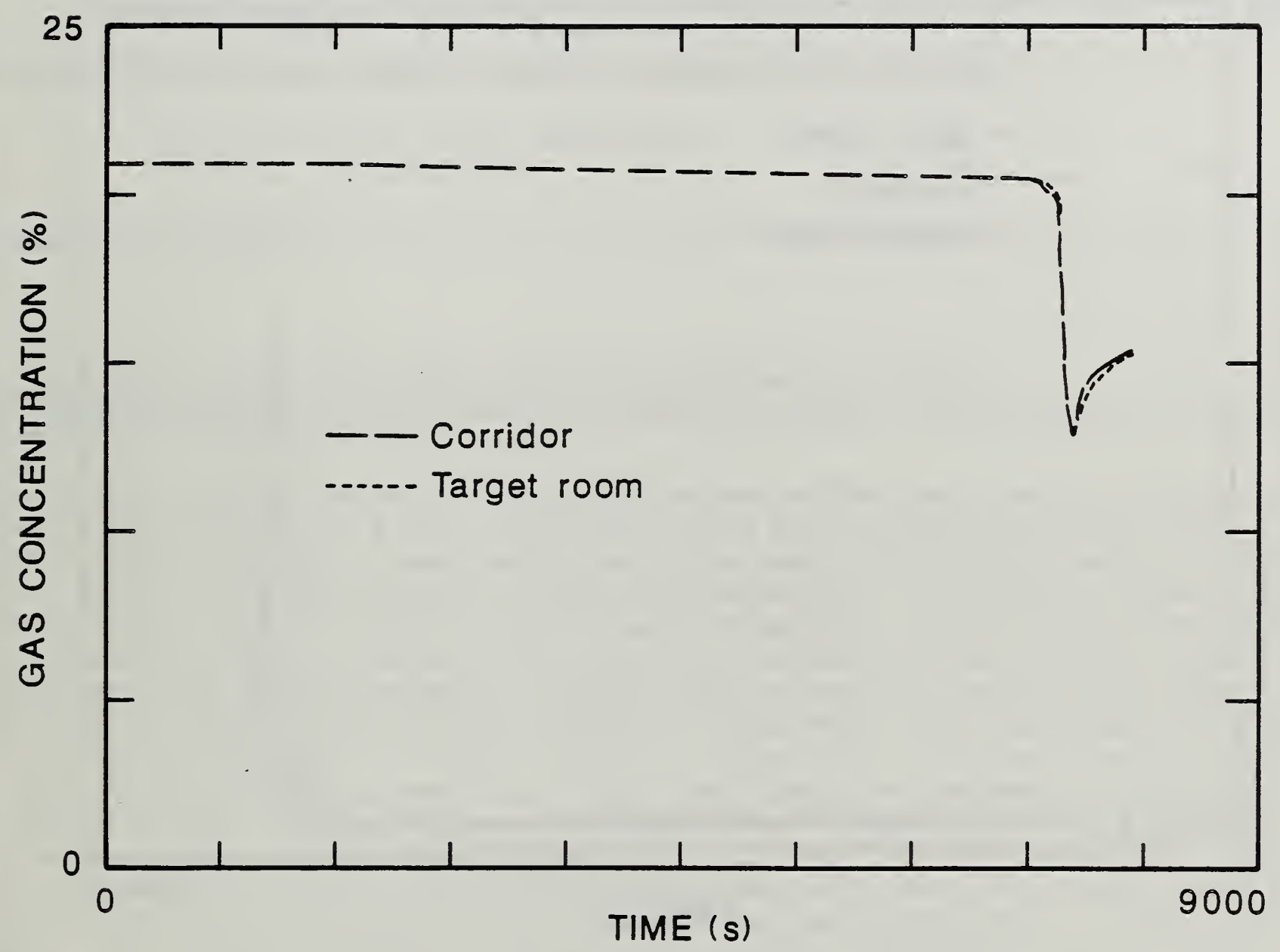

Figure 83. Comparison of Oxygen Concentrations in Each Compartment of the Large-Scale Test Facility for the Two-Cigarette Test of Foam $32 \mathrm{X}$ Mock-up Upholstery Chair Assembly With the Animal Exposure Chambers Connected to the Target Room. 


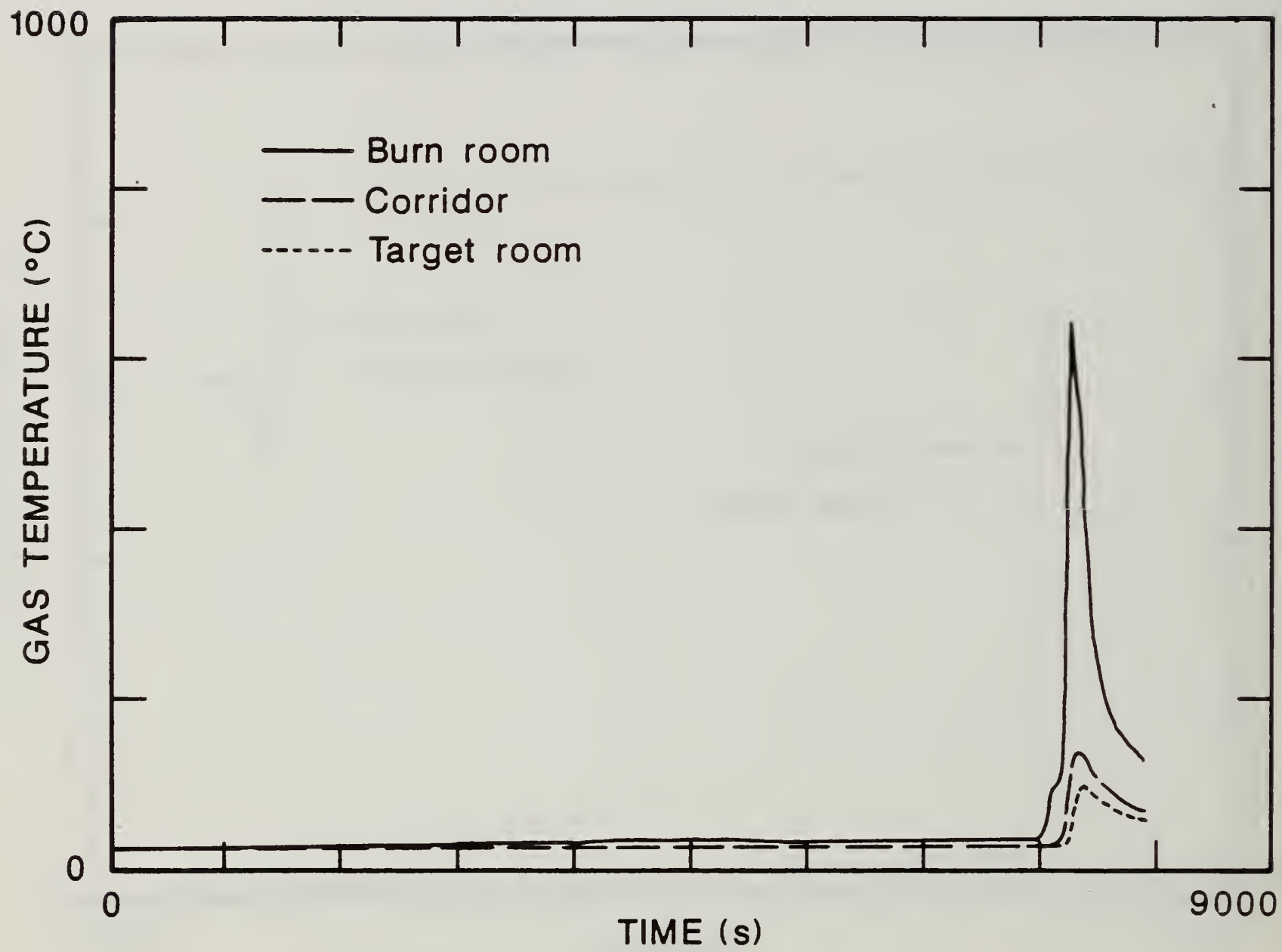

Figure 84. Comparison of Upper Compartment Gas Temperatures in Each Compartment of the Large-Scale Test Facility for the TwoCigarette Test of Foam 32X Mock-up Upholstery Chair Assembly With the Animal Exposure Chambers Connected to the Target Room. 
U.S. DEPT. OF COMM.

BIBLIOGRAPHIC DATA

SHEET (See in struction S)

4. TITLE AND SUBTITLE

1. PUBLICATION OR
REPORT NO.
NBSIR $87-3510$

2. Performing Organ. Report No.

3. Publication Date

FEBRUARY 1987

\section{FIRE TOXICITY SCALING}

\section{AUTHOR(S)}

Emil Braun, Barbara C. Levin, Maya Paabo, Joshua Gurman, Trudi Holt, $J$. Samuel Stee]

6. PERFORMING ORGANIZATION (If joint or other than NBS, see instructions)

\section{NATIONAL BUREAU OF STANDARDS \\ U.S. DEPARTMENT OF COMMERCE \\ GAITHERSBURG, MD 20899}

9. SPONSORING ORGANIZATION NAME AND COMPLETE ADDRESS (Street, City, Stote, ZIP)

7. Contract/Grant No.

8. Type of Report \& Period Covered

Consumer Product Safety Commission

Bethesda, Maryland 20207

10. SUPPLEMENTARY NOTES

Document describes a computer program; SF-185, FIPS Software Summary, is attached.

11. ABSTRACT (A 200-word or less factual summary of most significant information. If document includes a significant bibliography or literature survey. mention it here)

The toxicity of the thermal decomposition products from two flexible polyurethane foams (with and without a fire retardant) and a cotton upholstery fabric was evaluated by a series of small-scale and large-scale tests single mock-up upholstery chair tests during smoldering or flaming decomposition. In addition other fire property data such as rates of heat release, effective heats of combustion, specific gas species yields, and smoke obscuration were measured. The degree of toxicity observed during and following the flaming tests (both large-scale room burns and the NBS Toxicity Tests) could be explained by a 3-Gas Model which includes the combined toxicological effects of $\mathrm{CO}, \mathrm{CO}_{2}$, and $\mathrm{HCN}$. Essentially no animal deaths were noted during the thirty minute exposures to the non-flaming or smoldering combustion products produced in the NBS Toxicity Test Method or the large-scale room test. In these experiments, the concentrations of $\mathrm{CO}, \mathrm{CO}_{2}$, and $\mathrm{HCN}$ were comparable. Postexposure deaths, however, occurred following the small-scale non-flaming foam or cotton tests, but not following exposures to the smoldering phase of the large-scale tests. The ratio of yields of $\mathrm{CO}_{2}$ to $\mathrm{CO}$ were mostly comparable in all four sets of experiments. In the large-scale room tests, little toxicological difference was noted between decomposition products from the burn room and a second room 12 meters away.

12. KEY WORDS (Six to twelve entries; alphabetical order: copitalize only proper names; and seporate key words by semicolons) Cotton; fire tests; large scale fire tests; polyurethane; small scale fire tests; toxicity; upholstery.

13. AVAILABILITY

Unlimited

For Official Distribution. Do Not Release to NTIS

$\square$ Order From Superintendent of Documents, U.S. Government Printing Office, Washington, DC 20402.

\&. Order From National Technical Information Service (NTIS), Springfield, VA 22161
14. NO. OF

PRINTED PAGES

196

15. Price

$\$ 18.95$ 


